\title{
MATHEMATICAL MODEL OF THE SL/RN DIRECT REDUCTION PROCESS
}

\author{
by \\ V. VENKATESWARAN \\ B.E., Indian Institute of Science, 1972
}

A THESIS SUBMITTED IN PARTIAL FULFILMENT OF THE REQUIREMENTS FOR THE DEGREE OF MASTER OF APPLIED SCIENCE

In the Department

of

METALLURGY

We accept this thesis as conforming to the required standard

THE UNIVERSITY OF BRITISH COLUMBIA

April 1976

(C) V. Venkateswaran, 1976 
In presenting this thesis in partial fulfilment of the requirements for an advanced degree at the University of British Columbia, I agree that the Library shall make it freely available for reference and study. I further agree that permission for extensive copying of this thesis for scholarly purposes may be granted by the Head of my Department or by his representatives. It is understood that copying or publication of this thesis for financial gain shall not be allowed without my written pemission.

Department of METALLURGY

The University of British Columbia 2075 Wesbrook Place Vancouver, Canada V6T IW5

Date $23 \div$ April 1976 


\section{ABSTRACT}

A mathematical model has been developed to predict the operating behaviour of an $S L / R N$ direct reduction kiln from a knowledge of the main process variables. The model is based on steady state principles and is capable of quantitatively describing the complex chemical reactions in the kiln such as reduction, Boudouard reaction, coal volatilization and combustion in the freeboard together with the mass and heat flows. Output from the model is in the form of axial profiles of gas, solids and wall temperatures, and concentrations in both the gas and the solid phases. Results from the model are in good agreement with measurements made on the 100 ton per day pilot kiln at the Steel Company of Canada. The influence of important process variables such as the type of coal, ore, degree of reduction, throughput etc. has been examined and predictions made regarding the operation of large commercial $S L / R N$ kilns for sponge iron production. 


\section{TABLE OF CONTENTS}

\section{Page}

ABSTRACT. . . . . . . . . . . . . . $i \mathrm{i}$

LIST OF FIGURES . . . . . . . . . . . . . . vi

LIST OF TABLES. . . . . . . . . . . . . . . $x i$ ACKNOWLEDGMENTS ............................. . . .

Chápter

1 INTRODUCTION. . . . . . . . . . . . . 1

$1.1 \mathrm{SL} / \mathrm{RN}$ Process........ . 5

1.2 0ther Direct Reduction Processes. . . . 11

1.3 Review of the Previous Work ...... 15

1.4 Scope of the Present Work . . . . 17

2 Development OF the MAThematical MOdel . . . . . 19

2.1 Assumptions Made in the Mode1 . . . . 19

2.2 Mass and Heat Balance Equations.... 21

2.2.1 Mass Balance on Solids. . . 23

2.2.2 Mass Balance for Gases. . . 25

2.2.3 Heat Balance on Solids.... 30

2.2.4 Heat Balance on Gases.... 32

2.2.5 Heat Balance on Wall.... 33 
2.3 Rate Expressions. . . . . . . . 34

2.3.1 Boudouard and Reduction Reaction Rates....... 34

2.3.2 Air Profile in the Kiln... 41

2.3.3 Evolution of Volatiles from Coal......... 44

2.3.4 Drying of Solids. . . . . . 44

2.3.5 Combustion in the Freeboard. . 46

2.3.6 Calcination of Dolomite... 48

2.42 .4 .1 Specific Heats of Solids and Gases....... . 49

2.4.2 Partial Pressures in the Freeboard Gas Phase... . . 50

2.5 Heat Transfer in Rotary Kilns..... . 50

2.5.1 Heat Transfer Coefficients Used in the Present Model. . 54

2.5.2 Area Terms for Heat Transfer. . 63

2.6 Numerical Procedure Used in the Model. . 54

2.7 Internal Consistency of the Mode1... . 69

2.8 Starting and Instability Problems . . . 71

2.9: Adjustable Parameters in the Model. . . 74

3 MODEL CALCULATIONS AND DISCUSSION . . . . . . . 75

3.1 Evaluation of the Model . . . . . . 75

3.1.1 Evaluation Runs...... . 76

3.2 Predicted Influence of Operating

Variables on Kiln Performance..... 98 
3.2.1 Effect of Degree of

Reduction Achieved. . . . . . 99

3.2.2 Effect of Throughput. . . . . 104

3.2.3 Effect of Lower Coal

Reactivity.......... 104

3.2.4 Effect of Pellet Type.... . 114

3.2.5 Effect of Natural Gas..... 114

3.2.6 Effect of Dust in the

Freeboard Gas....... 124

3.2.7 Predictions for the

Griffith Kiln........ 127

3.3 General Comments on the SL/RN Process. . 136

4 SUMMARY AND CONCLUSIONS.............. . . 149

4.1 Suggestions for Future Work . . . . . 152

REFERENCES. . . . . . . . . . . . . . . . . 153

APPENDICES

I Source Listing of Computer Programme . . . . . 156

I I Important Data Used in the Mode1. . . . . . 187 


\section{LIST OF FIGURES}

Figure

$\underline{\text { Page }}$

1 Schematic diagram of the SL/RN process..... 6

2 Schematic diagram of the solids temperature profile in the SL/RN kiln............. 9

3 Sectional view of the SL/RN kiln showing the control volume.............. . 22

4 Air profile for a typical run........... 43

5 Rates of evolution of volatiles from Forestburg coal............... 45

6 Rate of moisture evolution from Forestburg coal....................

7 (a) Cross-section of the kiln showing the heat transfer modes. . . . . . . . . . . . 52

7 (b) Cross-section of the kiln showing the area terms involved in the different heat transfer equations.................. . 52

8 Gas emissivity for carbon dioxide (from Perry (30))............... 56

9 Gas emissivity for water vapour (from Perry $(30))$................ . . 57

10 Cross-section of the rotary kiln showing the different radius terms used for calculating heat loss to surroundings........ 
11 Flow sheet of the computer program . . . . . . 66

12 Effect of starting solids temperature on the solids temperature profile........ 73

13 Air profile for the kiln run using Forestburg coal and Griffith pellets........... 78

14 Solids temperature profile for the kiln run using Forestburg coal and Griffith pellets... . 79

15 Gas temperature profile for the run using Forestburg coal and Griffith pellets...... 81

16 Inner wall and outer shell temperature for the kiln run using Forestburg coal and Griffith pellets.

17 Reduction profile for the kiln run using Forestburg coal and Griffith pellets... . . . 84

18 Boudouard reaction rate for the kiln run using Forestburg coal and Griffith pellets... . 86

19 Freeboard gas composition for the kiln run using Forestburg coal and Griffith pellets...

20 Interior view of the pilot SL/RN kiln taken from the discharge end . . . . . . . . . 89

21 Air profile for the kiln run using lignite coal and Griffith pellets. . . . . . . . . 92

22 Solids temperature profile for the kiln run using lignite coal and Griffith pellets.....

23 Gas temperature profile for the kiln run using lignite coal and Griffith pellets..... . 94

24 Inner wall and outer shell temperature profiles for the kiln run using lignite coal and Griffith pellets. 
25 Reduction profile for the kiln run using lignite coal and Griffith pellets. . . . . . . 96

26 Freeboard gas composition for the kiln run using lignite coal and Griffith pellets. . . . . 97

27 Air profile for the kiln run using Forestburg coal and Griffith pellets with a degree of reduction of $95 \%$............... 101

28 Solids, gas, inner wall and outer shell temperature profiles for the kiln run using Forestburg coal and Griffith pellets with a degree of reduction of $95 \%$. . . . . . . . . 102

29 Reduction and freeboard gas composition profiles for the run using Forestburg coal and Griffith pellets with a degree of reduction of $95 \%$.............. 103

30 Air profile for the kiln run using Forestburg coal and Griffith pellets with a $30 \%$ higher throughput.

31 Solids, gas, inner wall and outer shell temperature profiles for the kiln run using Forestburg coal and Griffith pellets with a $30 \%$ higher throughput . . . . . . . . 107

32 Reduction and freeboard gas composition profiles for the kiln run using Forestburg coal and Griffith pellets with a $30 \%$ higher throughput. . . . . . . . . . . . 108

33 Air profile for the kiln run using anthracite coal and Griffith pellets...... . 111

34 Solids, gas, inner wall and outer temperature profiles for the kiln run using anthracite coal and Griffith pellets........... 112 
35 Reduction and freeboard gas composition profiles for the kiln run using anthracite coal and Griffith pellets........... 113

36 Air profile for the kiln run using Forestburg coal and Falconbridge pellets......... 116

37 Solids, gas, inner wall and outer shell temperatures for the run using Forestburg coal and Falconbridge pellets.

38 Reduction and freeboard composition profiles for the kiln run using Forestburg coal and Falconbridge pellets

39 Air profile for the kiln run using Forestburg coal and Griffith pellets without any natural gas.

40 Solids, gas, inner wall and outer shell temperature profiles for the kiln run using Forestburg coal and Griffith pellets without any natural gas..............

41 Reduction and freeboard gas composition profile for the kiln run using Forestburg coal and Griffith pellets without any natural gas.

42 Effect of the emissivity of gas on the gas temperature.

43 Air profile for the Griffith kiln run using the Forestburg coal and Griffith pellets for the designed throughput.

44 Solids temperature profile for the Griffith kiln run using the Forestburg coal and Griffith pellets for the designed throughput.

45 Gas temperature profile for the Griffith kiln run using the Forestburg coal and Griffith pellets for designed throughput. 
46 Inner wall temperature profile for the Griffith kiln run using Forestburg coal and Griffith pellets for designed

throughput

47 Reduction profile for the Griffith

kiln run using Forestburg

coal and Griffith pellets for designed

throughput . . . . . . . . . . . . . . . . 134

48 Freeboard gas composition profiles for the Griffith kiln run using Forestburg coal and Griffith pellets for designed throughput . . . . . . . . . . . . . . 135

49 Air profile for the Griffith kiln run using Forestburg coal and Griffith pellets with a $30 \%$ higher throughput . . . . . . . . . 138

50 Solid temperature profile for the Griffith kiln run using Forestburg coal and Griffith pellets with a $30 \%$ higher throughput..

51 Gas temperature profile for the Griffith kiln run using Forestburg coal and Griffith pellets with a $30 \%$ higher throughput... . . 140

52 Inner wall and outer shell temperature profiles for the Griffith kiln run using Forestburg coal and Griffith pellets with a $30 \%$ higher throughput. ............ 141

53 Reduction profile for the Griffith kiln run using Forestburg coal and Griffith pellets with a $30 \%$ higher throughput.

54 Freeboard gas composition profiles for the Griffith kiln run using Forestburg coal and Griffith pellets with a $30 \%$ higher throughput. .............. 143

55 Effect of kiln diameter on the A/V ratio for different degrees of fill......... 146

56 Effect of the degree of fill on the A/V ratio and mean retention time for a kiln

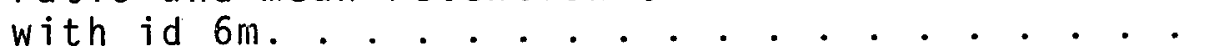




\section{LIST OF TABLES}

$\underline{\text { Table }}$

Page

1 Reactivity Parameter for Different

Chars.................. . 37

2 Typical Data for the Air Blown into a

$35 \mathrm{~m}$ Long SL/RN Kiln............. 42

3 Heat Transfer Coefficients in the Literature. . . 53

4 Input Data for the Kiln Run Using

Forestburg Coal and Griffith Pellets. . . . . . 77

5 Input Data for the Kiln Run using Lignite

Coal and Griffith Pellets............ . 91

6 Input Data for the Kiln Run Using Forestburg

Coal and Griffith Pellets with a Degree of

Reduction of $95 \%$. . . . . . . . . . . . 100

7 Input Data for the Kiln Run Using Forestburg

Coal and Griffith Pellets with a $30 \%$ Higher

Throughput. . . . . . . . . . . . . . 105

8 Input Data for the Kiln Run Using

Anthracite Coal and Griffith Pellets. . . . . . 110

9 Input Data for the Kiln Run Using

Forestburg Coal and Falconbridge Pellets. . . . 115

10 Input Data for the Kiln Run Using

Forestburg Coal and Griffith Pellets

Without any Natural Gas............ 120 
11 Input Data for the Griffith Kiln Run Using Forestburg Coal and Griffith Pellets for the Designed Throughput. . . . . . 128

12 Input Data for the Griffith Kiln Run Using Forestburg Coal and Griffith Pellets for a 30\% Higher Throughput. . . . . . 137 


\section{ACKNOWLEDGMENTS}

I would like to sincerely thank my research supervisor Dr. Keith Brimacombe, for his assistance and guidance throughout the course of this research project. Thanks are also extended to the other faculty members of the department and fellow graduate students for the helpful discussions, with special appreciation to Mr. B. Prabhakar. The help received from the technical staff of the department is very much appreciated.

In addition gratitute is expressed to the Steel Company of Canada for the financial support, and to Dr. T.R. Meadowcroft, Mr. K. Wilson, Dr. P.C. Rhee, Mr. Nick Daneliak and Mr. C.W.E. Johnson of the Research Centre, Stelco for the invaluable help provided during the course of this research. 


\section{Chapter 1}

\section{INTRODUCTION}

The SL/RN process is one of a number of direct reduction processes that have been designed to produce sponge iron from iron oxide on a commercial scale. The process has been developed over a period of many years, initially by Republic Steel and the National Lead Company [1] (RN) and more recently by the Steel Company of Canada Ltd. and Lurgi [2-4] $(S L)$. As will be seen in the next section it is distinguished from the other commercial direct reduction processes by its use of solid coal as the reducing agent, rather than a gaseous reductant, and by its use of a rotary kiln as the reactor, rather than a vertical shaft.

When viewed together, the $S L / R N$ and other commercial direct reduction processes are seen to occupy an increasingly important position in the future of steelmaking. This is because the sponge iron product can be fed directiy into an electric arc furnace for conversion to steel. This combination of direct reduction with electric arc furnace steelmaking 
is attracting considerable attention as an alternative to the conventional blast furnace and basic oxygen furnace. The heightened interest in the direct reduction-electric arc furnace route to steelmaking in recent years can be attributed to the following factors [5].

\section{(i) Technological feasibizity: Several direct}

reduction processes have overcome the technological uncertainty associated with commercial-size operations and are now in full production. At the end of 1974 direct reduction plants were producing 5.2 million metric tons of sponge iron [6]. An additional 12.7 million tons of production capacity is due to be brought on stream in the next three to four years.

\section{(ii) Decreasing supply of coking coal: It is pre-} dicted that the rapid growth in steel production if tied to blast furnaces, will lead to double the present demand on world supplies of coking coal by the end of the century. Since the assured supply of coking coal is already a major problem with existing steel-making capacity it is likely to present an even greater difficulty with higher future capacity. Although the development of formed coke processes might alter this picture, the present uncertainty with regard to coke has enhanced the position of direct reduction processes which are not based on coking coal. It is important to note in this 
respect that partially reduced iron oxide from a direct reduction plant can also be employed as burden in a blast furnace operation [8]. This has the beneficial effect of increasing production without requiring investment in new furnaces and coke ovens.

\section{(iii) Advantage of scaze: It is well known that} the blast furnace - BOF route is only economical on a large scale, of the order of two million metric tons per year [6]. Thus if new steelmaking facilities are planned based on this technology, large capacity and high capital cost are required. In the case of countries with a relatively low demand for steel the large increase in production often cannot be justified owing to market conditions. The direct reduction-electric arc furnace route on the other hand requires a lower capital investment per ton of steel in the lower production range making it more attractive for smaller markets.

Although the direct reduction-electric arc furnace route has advantages of scale at the lower end of the capacity range, economy of large scale operation is also being realised. The maximum capacity of a single direct reduction unit which up until now has been 400,000 metric tons per year is increasing steadily.

(iv) Improvement in electric are furnace operation: Industrial tests have shown that the feeding of sponge iron 
into an electric arc furnace has advantages over scrap iron feeding $[6,9]$. In the first place, the tap-to-tap time is decreased, thereby increasing.productivity. Furthermore, owing to its low tramp element content, sponge iron can be used to produce higher quality steel. It also appears that sponge iron feed reduces the gas and noise emission from an electric arc furnace although the dust emission increases. A final advantage of sponge iron lies in its ability to be fed continuously. Continuous feeding, which has been achieved in practice, provides a basis for automation of the electric arc furnace.

The important role that direct reduction is expected to play in the future of steelmaking is reflected in a recent projection of world steelmaking capacity [10]. In 1973, the world steel production totalled about 700 million metric tons per year. Of this $85 \%$ resulted from the conventional blast furnace. In the 1980's the world production is expected to be close to 1 billion metric tons per year with $25 \%$ coming from the electric furnace. If this projected figure proves correct it means that $25 \%$ more steel will be made via the coke oven-blast furnace route while $150 \%$ more steel will be produced by the electric arc furnace. Since sufficient scrap may not be avairable at reasonable cost to meet this expected demand an increasing amount of sponge iron will undoubtedly be required by the electric arc furnace.

The SL/RN process is emerging as one of the strong contenders in the field of the direct reduction of iron ore 
because of its ability to use solid reductant such as low grade coal. Naturally there is considerable interest in obtaining a clearer understanding of the physical and chemical nature of the process from the standpoint of design and optimisation. For this reason the present study has been undertaken to mathematically model the SL/RN process and so relate in quantitative terms, kiln performance to process variables.

\subsection{SL/RN Process}

In this section the SL/RN process is described in detail to provide a clear picture of the chemical and physical phenomena vital to its operation. This material is essential to understanding not only the process itself but also its mathematical simulation with which this study is concerned.

The SL/RN process produces sponge iron by reduction of iron ore with coal in a rotary kiln. The importance of this process rests in the fact that the coal used can be noncoking and therefore inexpensive compared to natural gas used by most other direct reduction processes. In most parts of the world natural gas is a less attractive reducing agent owing to its relatively high cost and scarcity.

A schematic diagram of the SL/RN process is given in Fig. 1. The charge to the SL/RN kiln consists of iron oxide pellets, coal, recycled char and sometimes dolomite, which is added if the sulphur level in the coal is high. 


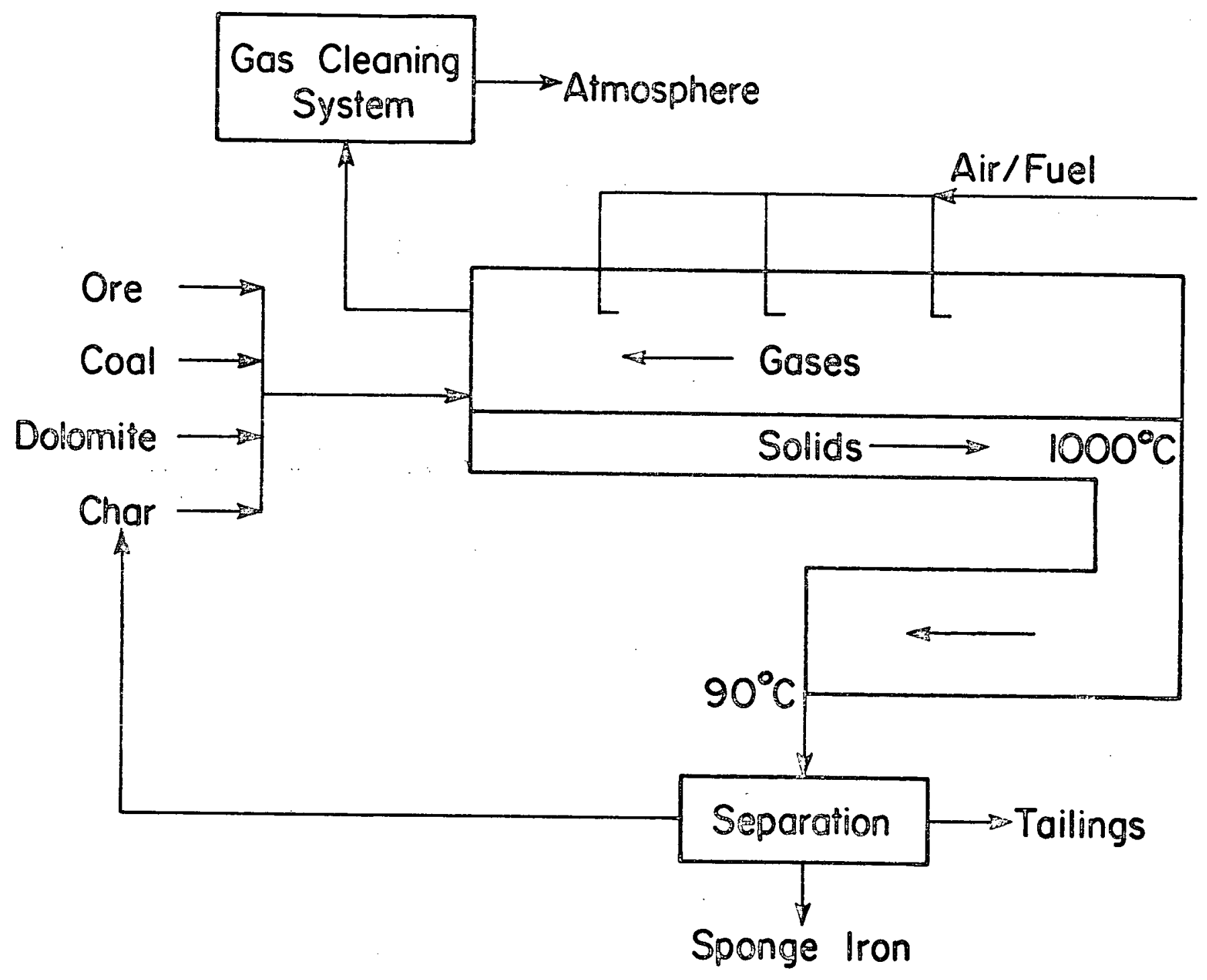


Shell burners are positioned along the length of the kiln and are supplied with air by shell fans. Provision is also made for the supply of natural gas if required as auxiliary fuel. In the process the solids and gases flow in a countercurrent fashion. The rotary kiln is operated usually with a slightly positive pressure to prevent the intrusion of unregulated air. Dams are provided at both ends of the kiln to control the flow of solids in the moving bed. The kiln is normally operated with $25 \%$ filling, a slope of about $3 \%$ and a rotational speed of 0.3 to $0.6 \mathrm{rpm}$. The hot products consisting of $91-95 \%$ reduced iron, unreacted coal char and gangue exit the kiln at about $1000^{\circ} \mathrm{C}$ via a transfer chute into a rotary cooler. There the products are cooled to roughiy $90^{\circ} \mathrm{C}$ and upon discharge from the cooler are magnetically separated into sponge iron and a non-magnetic tailing. The amount of coal fed into the kiln is adjusted such that there is always a slight excess of unreacted carbon in the product. This procedure minimises the possibility that the reduced iron could become reoxidised before exiting the kiln. The unreacted coal char is recycled as feed back into the kiln. The waste gases exiting the kiln pass through an afterburner before discharging into the atmosphere.

Looking at the process in more detail the kiln conveniently can be divided into two sections:

$$
\begin{aligned}
& \text { 1. Preheat Zone } \\
& \text { 2. Reduction Zone }
\end{aligned}
$$


This division is more obvious from Fig. 2 where a schematic diagram is provided to show the solid temperature profile in the kiln. In the preheat zone the solids are heated from their feed temperature to the temperature where co reduction can proceed. Heating is achieved by heat transfer from the hot freeboard gases leaving the reduction zone. Extra heat can be transferred into the solids by combusting natural gas in the preheat zone. In addition to heat transfer the following reactions occur in the preheat zone:

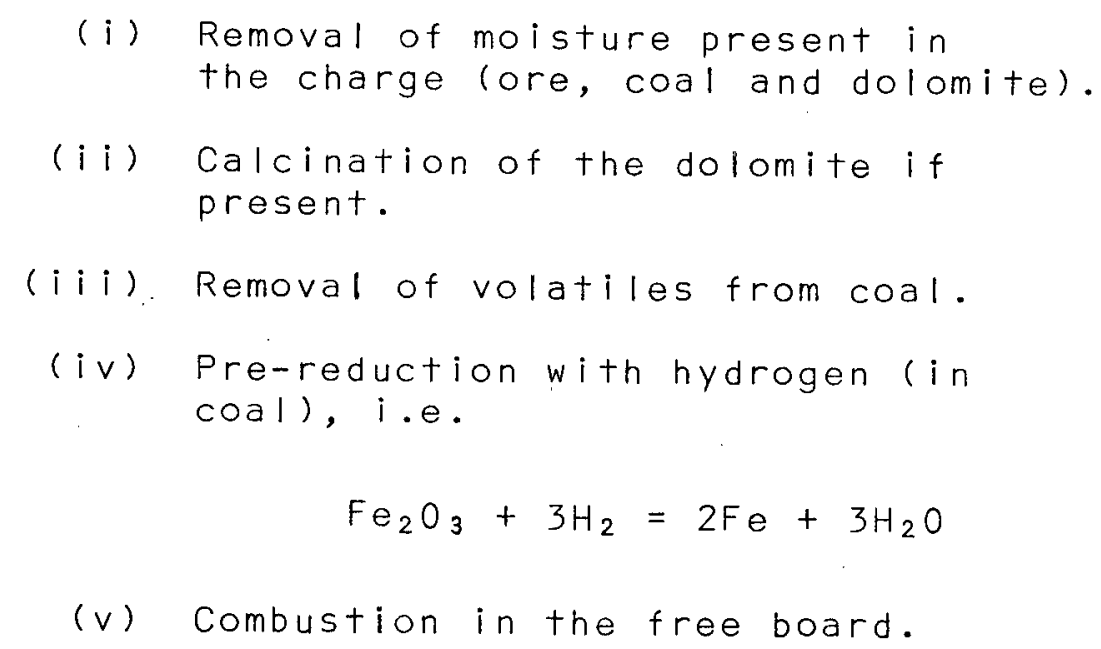

The length of the preheat zone is usually about 40 to $50 \%$ of the total length of the kiln. For efficient use of the rotary kiln this zone should be made as small as possible.

As the solids reach a temperature in excess of $900^{\circ} \mathrm{C}$ the carbon gasification reaction, more commonly known as the Boudouard reaction, sets in. Owing to the endothermic nature of this reaction the temperature of the solids ceases to rise any further. The temperature at which the solid bed 


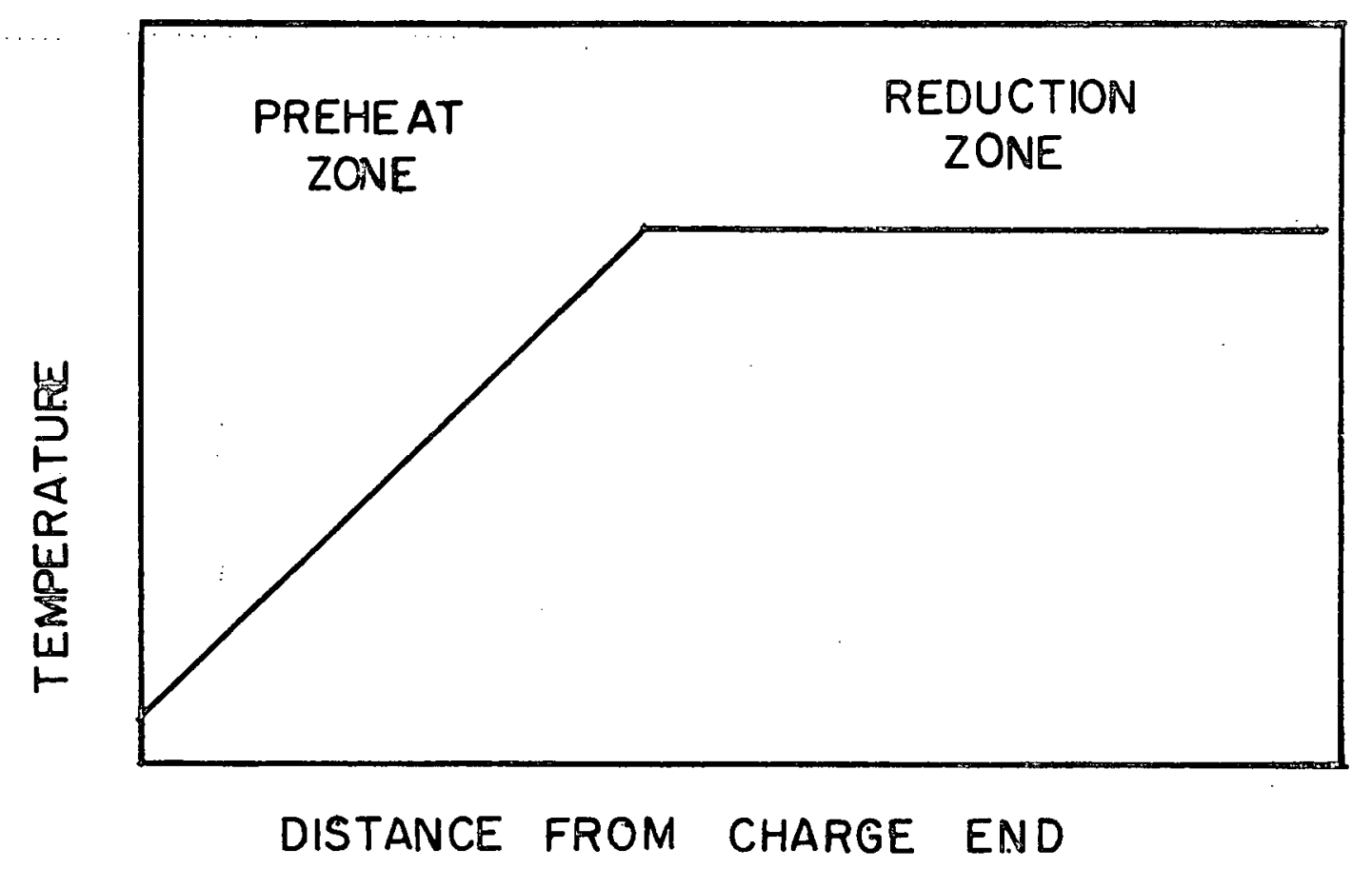

Fig. 2. Schematic diagram of the solids temperature profile in the SL/RN kiln. 
stabilises depends on a number of factors, the most important being the reactive nature of the coal and ore, and the heat transfer rate from gases and wall to the solids. The co generated through the Boudouard reaction is used in the reduction of iron oxide. The specific reactions are:

$$
\begin{gathered}
\mathrm{CO}_{2}+\mathrm{C}=2 \mathrm{CO} \\
\mathrm{Fe}_{2} \mathrm{O}_{3}+\mathrm{CO}=2 \mathrm{Fe}+3 \mathrm{CO}_{2}
\end{gathered}
$$

An important point to note is that

the gaseous atmosphere inside the solids bed is reducing in nature as opposed to the oxidising character of the free board gas. A part of the Co generated through the Boudouard reaction in the solids bed also enters the freeboard gas phase. Depending on the availability of oxygen this is burnt on the surface of the solids bed or at the mouth of the air tubes. Visual observation into the discharge end of the kiln has indicated that over much of the reduction zone the flame is localised on the surface of the bed. The coal used in the SL/RN kiln can be of inferior rank but at the same time should have the following properties:

1. High reactivity

2. Low free swelling index

3. Low caking teridency

4. High fixed carbon

5. High ash fusion temperature 
The maximum temperature at which the kiln can be operated is dependent on the ash fusion temperature of the coal. If the kiln is operated beyond this point, ringing (accretion) problems can develop. With the low rank, highly reactive coals the bed is maintained at roughly 950 to $970^{\circ} \mathrm{C}$ while, using high rank coal with a low reactivity such as anthracite, the bed temperature is higher, roughly around $1100^{\circ} \mathrm{C}$, if proper metallisation is to be achieved.

The sponge iron product from this process has been successfully used as feed to the electric arc furnace. In addition it is being employed in place of scrap iron for the cementation of copper and has also found use as coolant in the BOF, and as charge to the blast furnace.

\subsection{0ther Direct Reduction Processes}

Although a relatively large number of direct reduction processes have been investigated, only a handful have been proven on the scale of a commercial operation. In order to view the SL/RN process in the proper perspective this section provides a brief description of the other important reduction processes $[5,12-14]$.

HyL Process: This process has been in operation since 1957. The reductant used here is a mixture of hydrogen and carbon monoxide which is generated by reforming natural 
gas in the presence of a catalyst. The reduction is carried out in a static bed through which the hot reducing gases are circulated. The reduction section consists of four reactors with each reactor being operated in the following staged sequence:

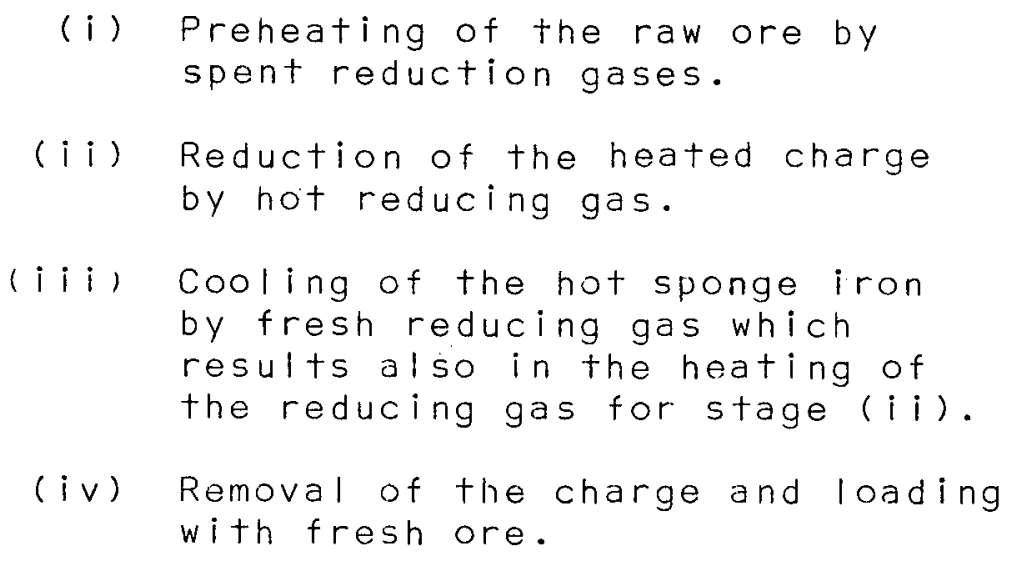

Each sequence of operation takes roughly three hours, giving a total solids residence time of about 12 hours. The reduction is carried out in a temperature range of approximately 870 to $1050^{\circ} \mathrm{C}$. There are six HyL plants in operation presently with a total installed capacity of 1.35 million tons per year.

Midrex Process: This process has been in operation since 1967. Unlike the other reduction processes it has achieved an impressive degree of popularity in a relatively short time. In contrast to the HyL process which is based on batch operation, the Midrex process is continuous. The reduction plant consists of two main components: a gas 
reforming unit for the production of reducing gas and a shaft furnace in which iron ore pellets are reduced to sponge iron. The shaft furnace is equipped with separate zones for reduction and cooling, and the solids flow counter-current to the rising hot reducing gases. In the upper reduction zone the incoming material is first heated to a reaction temperature of about $800^{\circ} \mathrm{C}$ by the exiting reducing gases. The normal metallisation achieved in this zone is around 92 to $96 \%$ and the sponge iron is carburised to 1 to $1.5 \%$. The sponge iron then descends into the lower zone where it is cooled to $50^{\circ} \mathrm{C}$ by gases in a closed loop system. The spent reducing gas from the top zone contains $60 \%$ of the original carbon monoxide and hydrogen, and two-thirds is returned to the reformer for generation of fresh $95 \% \mathrm{CO}_{-} \mathrm{H}_{2}$ reducing gas. The rest is used as reformer fuel. Four plants are in operation and several more are scheduled for completion in 1976.

Aumco Process: This process has been developed by Armco over a ten-year period and has many similar features to the Midrex process. The Armco process employs a vertical shaft furnace with solids descending against rising gases. However, unlike the Midrex process which uses a closed loop system for its cooling gases, the cooling gases in the Armco process are not: withdrawn separately from the reducing gases but instead rise to the top and exit along with the spent reducing gas. The top gas is scrubbed, cooled and split into 
two portions. About $60 \%$ becomes reformer fuel while the remainder is further cooled, compressed for re-use as cooling gas, and also for blending with fresh reducing gas. The Armco plant at Houston uses a steam-methane catalytic reformer to produce the reductant from the natural gas. Originally pebble stove reforming was attempted in their pilot plant, but later it was dropped in preference to a steam-natural gas catalytic reformer owing to the simplicity of operation of the latter.

Purofer Process: The process was developed in Germany and employs a shaft furnace and two alternately operating gas reformers. One of the reformers cracks natural gas to reducing gas of carbon monoxide and hydrogen while the other is being heated. After a 40 minute period the operation is reversed. The reforming occurs at a temperature of $1400^{\circ} \mathrm{C}$ and produces a gas that is free of soot and contains less than $2 \% \mathrm{CO}_{2}+\mathrm{H}_{2} \mathrm{O}$. This process can tolerate sulphur up to a level of $30 \mathrm{ppm}$ in the natural gas. The raw materials are mostly indurated pellets or sized lumps of ore, and work is in progress to investigate the charging of green pellets.

FIOR Process: In this process high grade iron ore fines are reduced to sponge iron in a fluidised bed reactor. The reduced iron particles then are normally compacted into a uniform high density briquette. Ore preparation forms an 
integral part of this process. The reactor system contains multiple fluidized bed stages in series. Reducing gas is prepared by one of a number of processes, e.g. catalytic steam reforming, or partial oxidation from a variety of hydrocarbon feedstocks (natural gas, LPG, naphtha, heavy oils etc.). The product metallisation ranges from 90 to $95 \%$ and the final carbon content of the iron product ranges from near zero to as much as $2 \%$. A plant is under construction in the Guayana region of Venezuela having a capacity of 500,000 tons per year.

A number of other direct reduction processes are under various stages of development, but due to limitation of space cannot be discussed here.

\subsection{Review of the Previous Work}

The rotary kiln is a widely used reactor in chemical and metallurgical industries. Some of its most important uses are in cement production and calcination. Although the reactor has been in use for a long time, very little work has been done on important aspects of its operation, particularly heat transfer. For this reason the design and scale-up of rotary kilns is based neavily on experience rather than on fundamental principles. Nevertheless, the fundamental approach has been attempted in the past through the formulation of mathematical models of rotary kilns for different applications but not for the specific case of the SL/RN process. 
All the mathematical models developed so far for the rotary kilns are based on principles of mass and heat balances. The differences between the models are found in the type of application for which the rotary kiln is used, e.g.: drying, calcination, cement production etc. Imber and Paschkis [15] were the first to develop a mathematical model of the rotary kiln, based on heat transfer alone, for the purpose of calculating the length of kiln required to heat solids by a desired amount. Their model did not take into account any chemical reactions. Saas [16-17] has described a mathematical model for rotary kilns used in drying. As in the previous case it deals mainly with heat transfer but takes into account the removal of moisture from the solids.

Riffaud et al. [18] modelled a rotary kiln for alumina production. Using both analog and digital computers they were able to simulate steady state and dynamic conditions of the rotary kiln. Sprang [19] describes a dynamic model for a cement kiln. Though no data was available to check his predicted values, he claims qualitative agreement between his model and that of an actual cement kiln. Recently Manitius et az. [20] have formulated a steady state model for the calcination of basic ammonium aluminium sulphate in a rotary kiln. Their model does not involve burning in the free board gas phase of the kiln but takes into account the carryover of dust in the gas phase. The results obtained from their model were shown to be in reasonable agreement with measured data. 
The only published work on the mathematical modelling of rotary kilns for iron oxide reduction has been the work of Wingfield et al. [21]. It is essentially a mathematical model for the gaseous reduction of iron oxide by hydrogen in a rotary kiln. Since they did not have any actual data with which to compare their results, their model was of limited use. It should be noted also that the model they developed was prone to instability problems and the results they obtained from the model, e.g. solids temperature, retention time, were quite unrealistic from an operating viewpoint.

No work has so far been reported in the literature on the mathematical modelling of the SL/RN process.

\subsection{Scope of the Present Work}

The present project was established in co-operation with the Steel Company of Canada with the specific aim of developing a mathematical model of the SL/RN process. The model was to embody the rate expressions for all the important chemical and physical processes occurring inside an SL/RN kiln, including the Boudouard reaction, iron oxide reduction, coal volatilization, combustion, drying and heat transfer; and to calculate kiln performance expressed in terms of axial profiles of temperature and concentration, as a function of important kiln operating variables. An important part of the project was to evaluate the model by comparison of predictions to data obtained in the 100 ton/day pilot plant at the Hilton 
works, Hamilton. Finally the model was to be used to predict the effect of operating variables including type of coal and ore, throughput and degree of reduction on the performance of the kiln. In addition particular attention was to be paid to the problem of scale-up of the SL/RN kiln. 
Chapter 2

\section{DEVELOPMENT OF THE MATHEMATICAL MODEL}

The mathematical model of the SL/RN process, that is developed in this section, is based on fundamental principles of mass and heat flow. The different physical and chemical reactions occurring in the $S L / R N$ process are quartitatively described through mathematical equations. The solution of these mass and heat balance equations result in temperature profiles for the solids, gas and wall, and concentration profiles for the different species along the entire length of the kiln. This section gives the general assumptions made in the model, the development of mass and heat balance equations, description of the various rate terms followed by the numerical procedure used for solving the equations.

\subsection{Assumptions Made in the Mode1}

In order to simplify the complex mathematical problem of describing the SL/RN process a number of assumptions have been made and these are 1 isted below. 
1. The mathematical model is developed for quasisteady state conditions, that is, the derivative of the dependent variables with time are zero at all points in the kiln.

2. The solids and gases move in plug flow, which means there is no axial mixing. Since the SL/RN process employs kilns that have a large L/D ratio this is a valid assumption.

3. Heat transfer by conduction and radiation in the axial direction is negligible relative to radially directed heat transfer. This assumption is thought to be reasonable since axial heat transfer by bulk motion of gases and solids is considerably larger than axial conduction and radiation.

4. There are no radial temperature gradients in the solids bed and in the freeboard gas phase. This implies that the solids and gases are well mixed radially. As a result the freeboard gases and the bed each can be characterised by a single temperature at a given point in the kiln.

5. The degree of fill of solids is constant throughout the kiln. If deemed necessary it is possible to incorporate a position-dependent degree of fill into the model without any difficulty.

6. Combustion in the freeboard is instantaneous. Here again it is possible to take into account the case of incomplete combustion if data is avalable on burning rates. 
7. Air and natural gas introduced into the kiln burner nozzles are considered to be line sources. This approximation is close to the real situation.

8. Within the solids bed the sum of partial pressures of $\mathrm{CO}$ and $\mathrm{CO}_{2}$ are equal to one atmosphere in the reduction zone. This is used in the calculation of the volumetric rate of the Boudouard reaction.

The above-mentioned are the major assumptions made in the model. A few other minor assumptions that were necessary will be indicated in the appropriate sections in this chapter.

\subsection{Mass and Heat Balance Equations}

Having made the general assumptions presented in the previous section, the kiln was broken down into thin slices. One such slice, known as the control volume, is given in Fig. 3. Heat and mass balances were performed on this control volume and the resulting equations were integrated over the entire length of the kiln to yield concentration profiles for the different species (from the mass balance equations) and temperature profiles (from the heat balance equations). Here the solids and gases flow in a counter-current fashion and the direction in which gas flows is considered positive. 

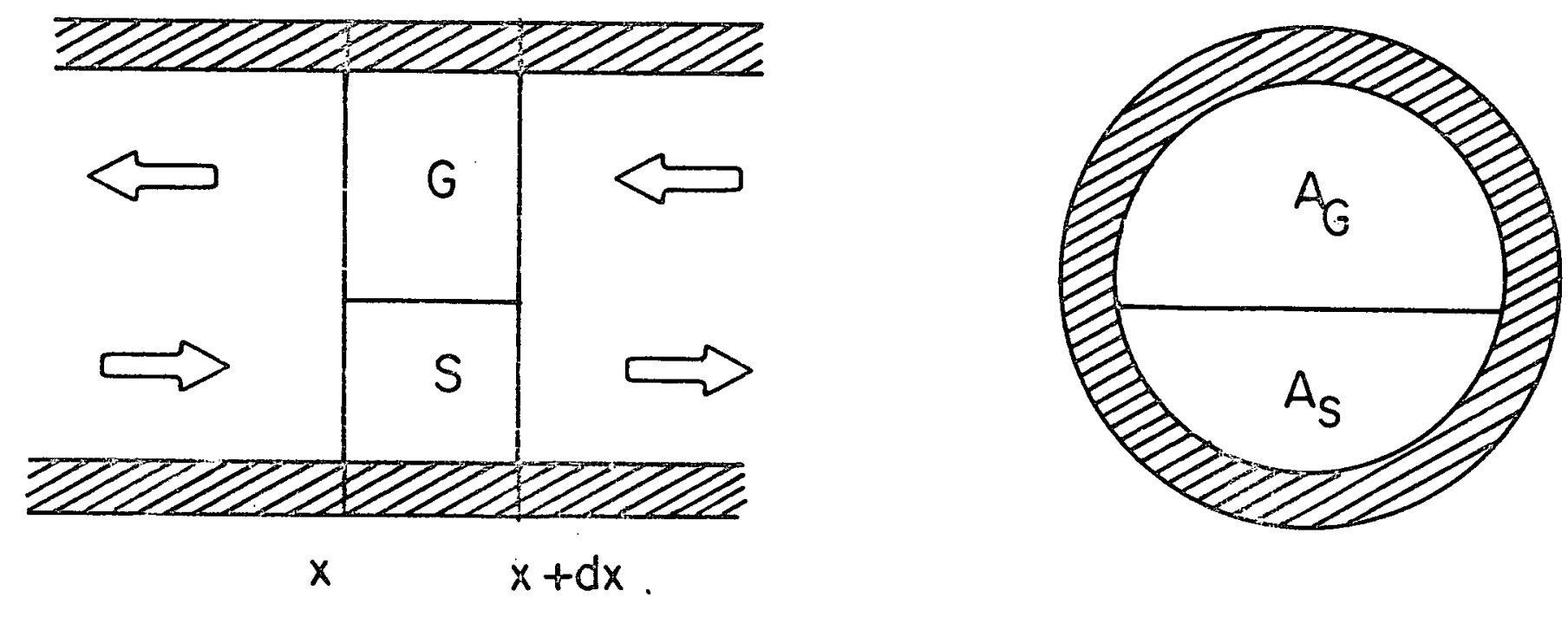

Fig. 3. Sectional view of the SL/RN kiln showing the control volume. 


\subsubsection{Mass Balance on Solids}

The general equation used to describe the mass balance of any species is the following:

$\left[\begin{array}{l}\text { Rate of mass } \\ \text { flow into the } \\ \text { control volume }\end{array}\right]-\left[\begin{array}{l}\text { Rate of mass } \\ \text { flow out of the } \\ \text { control volume }\end{array}\right]+\left[\begin{array}{l}\text { Rate of mass } \\ \text { generation in } \\ \text { the control volume }\end{array}\right]-\left[\begin{array}{l}\text { Rate of mass } \\ \text { consumption in } \\ \text { the control volume }\end{array}\right]=0$

Since the moving bed of solids is comprised of three components (ore, coal and dolomite) one ends up with three equations describing the mass balance for solids.

(a) Ore:

Following on from Eq. (4) we obtain for the ore,

Rate of ore in $=-\left(G_{0} A_{s}\right), \frac{g}{\mathrm{~cm}^{2} \cdot s} \mathrm{~cm}^{2}$

Rate of ore out $=-\left[G_{0} A_{S}+\left(\frac{d G_{0}}{d x}\right) d x \cdot A_{S}\right] \frac{\mathrm{g}}{\mathrm{cm}^{2} \cdot s} \mathrm{~cm}^{2}$

Rate of generation $=0$

Rate of consumption $=r_{\text {red }} A_{s} d x+r_{d r y} A_{s} d x \frac{g}{\mathrm{~cm}^{3} \cdot s} \mathrm{~cm}^{3}$

Substituting back into Eq. (4) the result is 


$$
-G_{0} A_{S}+\left[G_{0} A_{S}+\left(\frac{d G_{0}}{d x}\right) d x A_{s}\right]-r_{r e d} A_{S} d x-r_{d r y} A_{s} d x=0
$$

Then dividing throughout by $A_{S} d x$ the final equation is obtained

$$
\frac{d G_{0}}{d x}=r_{r e d}+r_{d r y}
$$

where $\quad G_{0}$ is the $f l u x$ of ore, $\mathrm{g} / \mathrm{cm}^{2} \cdot \mathrm{s}$

$A_{s}$ is the cross sectional area of solids, $\mathrm{cm}^{2}$

$r_{\text {red }}$ is the volumetric rate of reduction, $\mathrm{g} / \mathrm{cm}^{3} \cdot \mathrm{s}$

$r_{d r y}$ is the volumetric rate of drying, $\mathrm{g} / \mathrm{cm}^{3} \cdot \mathrm{s}$

Here the volumetric generation term is zero since nothing is added on to the ore. The volumetric rate term used in Eq. (5) and in the other equations derived here will be described in detail in a later section in this chapter.

\section{(b) $\underline{\text { Coa } 1}$}

The derivation of the mass balance equations for codl and dolomite are the same as for ore. The equation for coat is

$$
\frac{d G}{d x}=r_{\text {boud }}+r_{d r y c}+r_{\text {volt }}
$$

where $G_{c}$ is the flux of coal

$r_{\text {boud }}$ is the volumetric rate of Boudouard reaction 


\section{$r_{\text {dryc }}$ is the volumetric rate of drying $r_{\text {volt }}$ is the volumetric rate of removal of
volatiles from coal}

(c) Dolomite

$$
\frac{d G d}{d x}=r_{c a l}+r_{d r y d}
$$

where $G_{d}$ is the flux of dolomite

$r_{c a l}$ is the volumetric rate of calcination of dolomite $r_{\text {dryd }}$ is the volumetric rate of drying

In equations (5) to (7) the rate expressions have to be evaluated per unit volume of solids bed.

\subsubsection{Mass Balance for Gases}

The mass balance equations for the gases are obtained again from Eq. (5) with the gases having a positive flux.

$$
\begin{aligned}
& \text { (a) Nitrogen } \\
& \text { Rate of nitrogen in }=G_{n} A_{g} \cdot \\
& \text { Rate of nitrogen out }=G_{n} A_{g}+\frac{d G_{n}}{d x} \cdot d x \cdot A_{g} . \\
& \text { Rate of generation }=r_{n a} \cdot A_{g} d x+r_{n v} A_{g} d x . \\
& \text { Rate of consumption }=0 .
\end{aligned}
$$


Substituting these values into Eq. (5) and dividing by $A_{g} d x$ the final equation is

$$
\frac{d G_{n}}{d x}=r_{n a}+r_{n v}
$$

where $G_{n}$ is the flux of nitrogen

$A_{g}$ is the area of freeboard gas

$r_{n a}$ is the volumetric rate of generation of
nitrogen from air supply

$r_{n v}$ is the volumetric rate of generation of

(g) oxygen

As in the case of nitrogen

$$
\frac{d G_{o x}}{d x}=r_{o a}-r_{o b}
$$

where $\quad G_{o x}$ is the fluy of oxygen

$r_{\text {oa }}$ is the volumetric rate of oxygen supply
from air

rob is the volumetric rate of oxygen used up
in burning combustibles 
27

(c) Carbon dioxide

$$
\frac{{ }^{d G_{C O_{2}}}}{d x}=r_{\mathrm{CO}_{2} b}+r_{\mathrm{CO}_{2} v}+r_{\mathrm{CO}_{2} \mathrm{C}}
$$

where $\quad \mathrm{G}_{\mathrm{CO}_{2}}$ is the flux of $\mathrm{CO}_{2}$

$$
\begin{aligned}
& r_{\mathrm{CO}_{2} b} \text { is the volumetric rate of } \mathrm{CO}_{2} \text { generation } \\
& \text { from combustion products } \\
& \mathrm{r}_{\mathrm{CO}_{2} v} \begin{array}{l}
\text { is the volumetric rate of } \mathrm{CO}_{2} \text { generation } \\
\text { from volatiles in coal }
\end{array} \\
& \mathrm{r}_{\mathrm{CO}_{2} \mathrm{C} \text { is the volumetric rate of } \mathrm{CO} \text { generation }} \\
& \text { from dolomite calcination }
\end{aligned}
$$

(d) Carbon monoxide

$$
\frac{{ }^{d G} C_{0}}{d x}=r_{\text {Coped }}+r_{C O v}-r_{C O b}
$$

where $G_{\mathrm{CO}}$ is the flux of $\mathrm{co}$

robed is the volumetric rate of co generation through Boudouard reaction in the bed

$r_{\text {cor }}$ is the volumetric rate of co generation through volatiles in coal

${ }^{r}$ cob is the volumetric rate of co consumption through burning with oxygen 
28

(e) Methane

$$
\frac{d G_{m}}{d x}=r_{m v}+r_{m n}-r_{m b}
$$

where $\quad G_{m}$ is the flux of methane

$r_{m v}$ is the volumetric rate of generation of methane from volatiles in coal

$r_{m n}$ is the volumetric rate of generation of methane from volatiles in natural gas supply

$r_{m b}$ is the volumetric rate of consumption through burning with oxygen

(f) Water vapour

$$
\frac{d G_{w}}{d x}=r_{w S}+r_{w b}
$$

where $\quad G_{w}$ is the flux of water vapour

$r_{w s}$ is the volumetric rate of generation of water vapour from drying solids

$r_{w b}$ is the volumetric rate of generation of water vapour from combustion products

(g) Propane

$$
\frac{d G_{p}}{d x}=r_{p v}+r_{p n}-r_{p b}
$$


where

$G_{p}$ is the flux of propane

$r_{p v}$ is the volumetric rate of generation of propane from volatiles in coal

$r_{p n}$ is the volumetric rate of generation of propane from natural gas supply

$r_{p b}$ is the volumetric rate of consumption of propane through burning with oxygen

(h) Hydrogen

$$
\frac{d G_{h}}{d x}=r_{h v}-r_{h b}
$$

where $\quad G_{h}$ is the flux of hydrogen

$r_{h v}$ is the volumetric rate of generation of hydrogen from volatiles in coal

$r_{h b}$ is the volumetric rate of consumption of hydrogen through burning with oxygen

\section{(i) Ethane}

$$
\frac{d G}{d x}=r_{e v}+r_{e n}-r_{e b}
$$

where $G_{e}$ is the flux of ethane

$r_{\text {ev }}$ is the volumetric rate of generation of ethane from volatiles in coal

$r$ is the volumetric rate of generation of ethane from natural gas supply 
$r$ is the volumetric rate of consumption of
ethane through burning with oxygen

In Eqs. (8) to (16) a 11 the rate expressions are calcaulted per unit volume of the freeboard gas.

\subsubsection{Heat Balance on Solids}

Referring again to the control volume in Fig. 3 , heat balances are performed on the solids in the following way.

Rate of heat into the control volume $=-H_{S} A_{S}$.

Rate of heat out of the control volume $=$ $-\left[H_{s} A_{s}+\frac{d H_{s}}{d x} \cdot d x \cdot A_{s}\right]$.

Rate of heat generation $=\sum r_{s g} A_{s} d x$.

Rate of heat consumption $=\sum r_{S C} A_{S} d x$. under steady state conditions

$-H_{s} A_{s}+\left[H_{s} A_{s}+\frac{d H_{s}}{d x} \cdot A_{s} \cdot d x\right]+\sum r_{s g} A_{s} d x-\sum r_{s c} A_{s} d x=0$

$$
\frac{d H_{s}}{d x}+\sum r_{s g}-\sum r_{s c}=0
$$

where $\quad H_{S}$ is the enthalpy content of solids, cal $/ \mathrm{cm}^{2} \mathrm{~s}$

¿rsg is the summation of all heat generation terms per unit volume in the solids bed, cal/ $\mathrm{cm}^{3} \mathrm{~s}$ 
31

$\sum r_{s c}$ is the summation of all heat consumption terms per unit volume of solids bed, cal $/ \mathrm{cm}^{3} \mathrm{~s}$

For the three components in the bed of solids

$$
H_{s}=\left(G_{0} C_{p o}+G_{c} C_{p c}+G_{d} C_{p d}\right)\left(T_{s}-T_{r}\right)
$$

and

$$
\begin{gathered}
\frac{d H_{s}}{d x}=\left[T_{s}-T_{r}\right]\left[C_{p o} \frac{d G_{0}}{d x}+C_{p c} \frac{d G_{C}}{d x}+C_{p d} \frac{d G}{d x}\right]+ \\
{\left[T_{s}-T_{r}\right]\left[G_{0} \frac{d C_{p o}}{d T_{s}}+G_{c} \frac{d C_{p c}}{d T_{s}}+G_{d} \frac{d C_{p d}}{d T}\right] \frac{d T_{s}}{d x}+} \\
{\left[G_{0} C_{p o}+G_{C} C_{p c}+G_{d} C_{p d}\right] \frac{d T_{s}}{d x}}
\end{gathered}
$$

substituting this in Eq. (17)

$$
\frac{d T_{s}}{d x}=\frac{\sum r_{s c}-\sum r_{s g}-\left(T_{s}-T_{r}\right)\left[C_{p o} \frac{d G_{0}}{d x}+C_{p c} \frac{d G_{C}}{d x}+C_{p d} \frac{d G_{d}}{d x}\right]}{\left[G_{0} C_{p o}+G_{c} C_{p c}+G_{d} C_{p d}\right]+\left(T_{s}-T_{r}\right)\left[G_{0} \frac{d C_{p o}}{d T_{s}}+G_{C} \frac{d C_{p C}}{d T_{s}}+G_{d} \frac{d C_{p d}}{d T_{s}}\right]}
$$

where $\quad C_{p o}, C_{p c}, C_{p d}$ are the specific heats of ore, coal and dolomite respectively 
32

$$
\begin{aligned}
& T_{s} \text { is the solids temperature, }{ }^{\circ} \mathrm{C} \\
& T_{r} \text { is the reference temperature, }{ }^{\circ} \mathrm{C}
\end{aligned}
$$

2.2.4 Heat Balance on Gases

In the same manner a heat balance on the freeboard gases gives,

$$
\begin{gathered}
H_{g} A_{g}-\left[H_{g} A_{g}+\frac{d H_{g}}{d x} \cdot d x \cdot A_{g}\right]+\sum r_{g g} A_{g} d x-\sum r_{g c} A_{g} d_{x}=0 \\
\frac{d H_{g}}{d x}=\sum r_{g g}-\sum r_{g c}
\end{gathered}
$$

where $\mathrm{H}_{g}$ is the heat flux of gases

arg is the summation of heat generation terms per unit volume of gas phase Ergo is the summation of heat consumption terms
per unit volume of gas phase

$H_{g}$ in turn is given by

$$
\begin{gathered}
H_{g}=\left(T_{g}-T_{r}\right) \sum C_{p g_{i}} G_{g_{i}} \\
\frac{d H_{g}}{d x}=\left(T_{g}-T_{r}\right) \sum_{i} C_{p g} \frac{d G_{i}}{d x}+\left(T_{g}-T_{r}\right) \frac{d T_{g}}{d x} \sum_{i} G_{g_{i}}-\frac{d C_{p g}}{d T_{g}} \\
+\frac{d T_{g}}{d x} \sum_{i} p C_{p g_{i}} G_{g_{i}}
\end{gathered}
$$


where $\mathrm{T}_{\mathrm{g}}$ is the gas temperature, ${ }^{\circ} \mathrm{C}$

and

$C_{p g}$ is the specific heat of a particular gas

The summation represents all the gas species described in Eqs. (8) to (16). Substituting Eq. (2.1) in Eq. (20) results in,

$$
\frac{d T_{g}}{d x}=\frac{\sum r_{g g}-\sum r_{g c}-\left(T_{g}-T_{r}\right) \sum C_{p g_{i}} \frac{d G_{g_{i}}}{d x}}{\left(T_{g}-T_{r}\right) \sum G_{g_{i}} \frac{d C_{p g}}{d T_{g}}+\sum C_{p g_{i}} G_{g i}}
$$

\subsubsection{Heat Balance on the Wall}

In addition to the twelve mass balance equations and two heat balance equations derived above an additional equation is obtained by performing a heat balance on the wall under steady state conditions.

$\left[\begin{array}{c}\text { Heat } \\ \text { by the waived } \\ \text { from the gas }\end{array}\right]-\left[\begin{array}{c}\text { Heat transferred } \\ \text { to } \\ \text { solids }\end{array}\right]-\left[\begin{array}{c}\text { Heat loss from } \\ \text { outside wall } \\ \text { to atmosphere }\end{array}\right]=0$

The wall temperature is not known a priori in these calculations but can be calculated on an iterative scheme. A value for the wall temperature is first assumed and all heat transfer rates are calculated. Then the wall temperature is checked to determine whether Eq. (23) is obeyed. If not a 
new wall temperature is assumed and the entire procedure repeated until a satisfactory balance is obtained. In the mathematical model the error allowed between the assumed and calculated temperatures is $2^{\circ} \mathrm{C}$.

\subsection{Rate Expressions}

The different volumetric terms used in the mass and heat balance equations are described in this section.

\subsubsection{Boudouard and Reduction Reaction Rates}

The reduction of iron oxide is one of the most extensively studied subjects in the literature. A large number of models (topochemical, non-topochemical, etc.) have been proposed to describe the rate of reduction. Since these models are very complex and require many parameter values like porosity, diffusion coefficients, tortuosity etc., they are awkward to use in the present mathematical model. Moreover, when it comes to industrial process like the $S L / R N$, these models are of little value since the pellets undergo spalling, swelling and sometimes cracking. For these reasons the reduction rate employed in the present mathematical model is a simple first order equations based on experimental work carried out by P.C. Rhee [22] at the Stelco Research Centre with the raw materials used in the SL/RN kiln. This essentially follows the approach of Bogdandy [23]. The 
justification for using this method lies in the fact that it is able to give meaningful results.

Although the reducing agent used in the SL/RN process is carbon in the form of coal, the reduction involves a gaseous intermediate, carbon monoxide, according to the familiar reactions:

$$
\begin{gathered}
\mathrm{Fe}_{2} \mathrm{O}_{3}(\mathrm{~s})+3 \mathrm{CO}(\mathrm{g})=2 \mathrm{Fe}(\mathrm{s})+3 \mathrm{CO}_{2}(\mathrm{~g}) \\
\mathrm{CO}_{2}(\mathrm{~g})+\mathrm{C}(\mathrm{s})=2 \mathrm{CO}(\mathrm{g})
\end{gathered}
$$

In this way, the carbon monoxide used for reduction is replenished by the Boudouard reaction. Since the carbon gasification reaction is highly endothermic in nature the overall rate of reduction strongly depends on the rate of heat transfer from the freeboard gas to the solids bed.

The volumetric rate of carbon consumption by the Boudouard reaction is described by,

$$
v_{c}=k_{e f f}\left(c_{\mathrm{CO}_{2}}-c_{\mathrm{CO}_{2}(b)}\right)
$$

where $\quad v_{c} \quad$ is the volumetric rate of carbon gasification,

$\mathrm{C}_{\mathrm{CO}_{2}}$ is the concentration of $\mathrm{CO}_{2}$ in the bed, 


$$
\begin{aligned}
& \mathrm{C}_{\mathrm{CO}_{2}(b)} \text { is the equilibrium } \mathrm{CO}_{2} \text { concentration } \\
& \text { solids temperature }
\end{aligned}
$$

and

$$
K_{\text {eff }}=M_{C} H_{c} \exp \left(-\frac{E_{B}}{R T_{s k}}\right)
$$

where

$$
\begin{aligned}
& M_{C} \text { is the carbon density, } \mathrm{gC} / \mathrm{cm}^{3} \\
& H_{C} \text { is the reactivity of the char, } \mathrm{cm}^{3} / \mathrm{gs} \\
& \mathrm{E}_{B} \text { is the activation energy for this } \\
& \text { reaction, } \frac{\mathrm{cal}}{\mathrm{mol}} \\
& \mathrm{T}_{\mathrm{sk}} \text { is the temperature of solids, }{ }^{\circ} \mathrm{K}
\end{aligned}
$$

The reactivity parameter $H_{C}$, in Eq. (27) is characteristic of a particular type of coal char. This is a measure of the readiness with which the char reacts with carbon dioxide to produce the carbon monoxide required for reduction. Table 1 gives the reactivity values for different types of chars that have been evaluated for the $S L / R N$ process [22]. The activation energy $E_{B}$ used in Eq. (27) is $86 \mathrm{Kcal} / \mathrm{mol}$.

The equation used to describe the rate of reduction is a slight modification of the equation proposed by Bogdandy [23]. In the present work the temperature effect of the reaction rate is represented by an Arrehenius type of equation as follows. 
Table 1

Reactivity Parameters for Different Chars

\begin{tabular}{lcc}
\hline Char Type & $\begin{array}{l}\text { Reactivity } \\
H_{C}\left(10^{-16}\right)\end{array}$ & $\begin{array}{r}\text { Relative Reactivity } \\
\text { to Anthracite }\end{array}$ \\
\hline Anthracite & .0269 & 1 \\
Elkhorn $^{*}$ & 0.332 & 22.4 \\
Forestburg & \\
Lignite & 51.9 & 1930 \\
& 58.3 & 2165 \\
\hline
\end{tabular}

\footnotetext{
* Bituminous rank

** Sub-bituminous rank
} 
38

$$
v_{0}=4.48\left(10^{-2}\right) A_{p} \exp \left(-\frac{E_{R}}{R T S k}\right)(1-R) M_{F e} \frac{\left(C_{C_{C O}(R)}-C_{C_{C O}}\right)}{C_{\mathrm{CO}_{2}}(R)}
$$

(28)

where $v_{0}$ is the rate of oxygen removal per $\mathrm{cm}^{3}$ per second

$A_{p} \quad$ is the pre-exponential constant characeristic of the type of pellet

$E_{R}$ is the activation energy for the reduction reaction

$M_{F e}$ is the iron concentration in the bed

$\mathrm{R}$ is the fractional reduction

$\mathrm{C}_{\mathrm{CO}_{2}}(\mathrm{R})$ is the equilibrium $\mathrm{CO}_{2}$ concentration for the reduction reaction

$$
\mathrm{C}_{\mathrm{CO}_{2}} \text { is the actual concentration of } \mathrm{CO}_{2} \text { in the }
$$

The fractional degree of reduction is calculated on the basis of the amount of oxygen present in the ore ( $A$ value of 1.0 corresponds to hematite composition). Replacing the concentreLion terms with partial pressures the following equations are obtained.

$$
v_{C}=M_{C} H_{C} \exp \left(-\frac{E_{B}}{R T}\right) \frac{P_{C_{2} O_{2}}-P_{C O}(B)}{R T s k}
$$




$$
V_{0}=4.48\left(10^{-2}\right) A_{p} \exp \left(-\frac{E R}{R T S k}\right)(1-R) M_{F e} \frac{\left[P_{C O_{2}(R)}-P_{C O_{2}}\right]}{\left[P_{C O_{2}(R)}\right]}
$$

The partial pressure of carbon dioxide is determined from the fact that under steady state conditions,

$$
v_{c}=v_{0}
$$

This implies that one carbon atom removes only one oxygen atom from the ore which corresponds to a maximum carbon consumption. In actual practice it is found that the higher the reactivity value; the closer is the carbon consumption to this maximum value. The different steps involved in the calculation of the volumetric rate of Boudouard and reduction reactions are listed below.

(i) From the solids temperature, equilibrium constants for the Boudouard and reduction reactions are calculated from the following equations

$$
\ln K_{b}=\frac{-20360}{T}+20.97
$$

where $\quad k_{b}$ is the equilibrium constant for the Boudouard

$$
\operatorname{lnk} r=\frac{2105}{T_{s k}}-2.525
$$

where

$$
K_{r} \text { is the equilibrium constant for the reduction }
$$


(ii) From the equilibrium constants the equilibrium carbon dioxide partial pressure for the two reactions is computed.

$$
\begin{gathered}
P_{\mathrm{CO}_{2}(B)}=\frac{\left(2+K_{b}\right)-\sqrt{4 K_{b}+K_{b}^{2}}}{2} \\
P_{\mathrm{CO}_{2}(R)}=\frac{K_{r}}{1+K_{r}}
\end{gathered}
$$

Eqs. (34) and (35) are derived assuming $\mathrm{P}_{\mathrm{CO}_{2}}+\mathrm{P}_{\mathrm{CO}}=1$ in the solids bed.

(iii) Using the steady state condition, $v_{c}=v_{0}$, the partial pressure of carbon dioxide in the bed is computed.

(iv) The actual volumetric rates for the Boudouard and reduction reactions are finally calculated.

It should be noted that the equilibrium partial pressure of carbon dioxide, $\mathrm{P}_{\mathrm{CO}_{2}(\mathrm{R})}$, corresponds to the reaction -

$$
\mathrm{FeO}+\mathrm{CO}=\mathrm{Fe}+\mathrm{CO}_{2}
$$

In addition to reduction of iron oxide by carbon monoxide, reduction by hydrogen is also considered in the model. Hydrogen reduction is possible if the coal employed for reduction has a 
high content of volatile matter containing hydrogen. When hydrogen reduction occurs the rate of reduction in the model is coupled to the rate of hydrogen evolution from the coal.

\subsubsection{Air Profile in the Kiln.}

The air profile in the kiln is perhaps the most important operating parameter used for controlling the freeboard gas temperature. In contrast to other operating variables like throughput, the effect on kiln performance of a change in air profile is almost instantaneous. In order to determine the air profile for the model, data pertaining to the air rate through different burners is required, together with the burner position along the length of the kiln. In the mathematical model the air supply is treated as a line source. In addition, since the air is blown counter-current to the gas flow, a certain extent of back flow is allowed. This necessitated a smoothening of the air profile to prevent any abrupt change in the gas temperatures in the freeboard. By way of example, Fig. 4 gives the air profile which results from the air distribution described in Table 2. The area under the curve gives the total air fed into the kiln minus the air blown through the end burner which appears as an initial condition in the mode 1 . 
Table 2

Typical Data for the Air Blown into a $35 \mathrm{~m}$ Long SL/RN KiIn

\begin{tabular}{|c|c|c|}
\hline Burner & $\begin{array}{l}\text { Burner Position } \\
\text { From Charge End }(m)\end{array}$ & $\begin{array}{l}\text { Air Blown } \\
\text { cft/min }\end{array}$ \\
\hline 1 & 5.48 & 700 \\
\hline 2 & 8.23 & 700 \\
\hline 3 & 11.58 & 700 \\
\hline 4 & 14.32 & 700 \\
\hline 5 & 16.15 & 690 \\
\hline 6 & 18.89 & 680 \\
\hline 7 & 21.18 & 690 \\
\hline 8 & 23.77 & 690 \\
\hline 9 & 26.51 & 640 \\
\hline 10 & 27.73 & 550 \\
\hline END & 34.13 & 300 \\
\hline
\end{tabular}




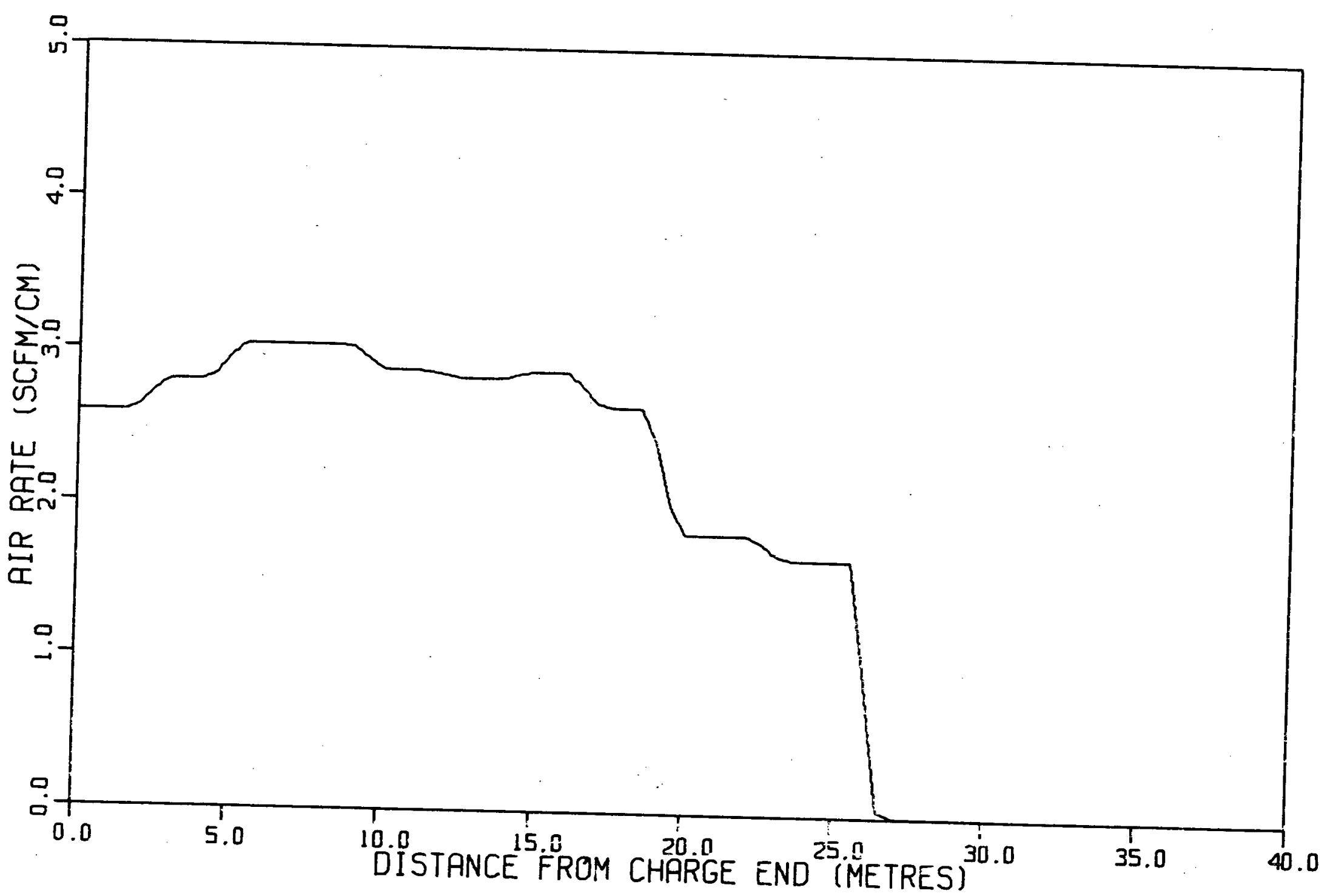

Fig. 4. Air profile for a typical run.

$\stackrel{\oplus}{\omega}$ 


\subsubsection{Evolution of Volatiles from Coal}

Because the coal employed in the SL/RN process contains a considerable quantity of volatiles, the evolution of volatiles from the coal constitutes one of the important reactions in the preheat zone. In order to obtain an accurate picture regarding the different volatile components present and their rates of evolution, a test programme was established at the Fuels Research Institute (Mines Branch) by Stelco. The tests consisted of heating a sample of coal at the same rate as it is heated in an SL/RN kiln, collecting the gases evolved at regular intervals and analysing them by mass spectrometer. Fig. 5 shows the results of one such test involving forestburg coal (sub-bituminous rank), heated at a rate of $9^{\circ} \mathrm{C}$ per minute. It is important to note in Fig. 5 that hydrogen is evolved at a considerable rate from $360^{\circ} \mathrm{C}(40 \mathrm{~min})$ to $1080(120 \mathrm{~min})$. Since hydrogen is capable of reducing iron oxide at temperatures as $10 \mathrm{w}$ as $500^{\circ} \mathrm{C}$, it is reasonable to expect some hydrogen reduction of ore pellets in the preheat zone in advance of co reduction. As mentioned earlier, this has been incorporated in the model. The expressions for the rate at which the different volatile components are released by the coal were arrived at by approximating the curves in Fig. 5 with polynomial equations.

\subsubsection{Drying of Solids}

In addition to the removal of volatile components from coal another important reaction proceeding in the preheat 


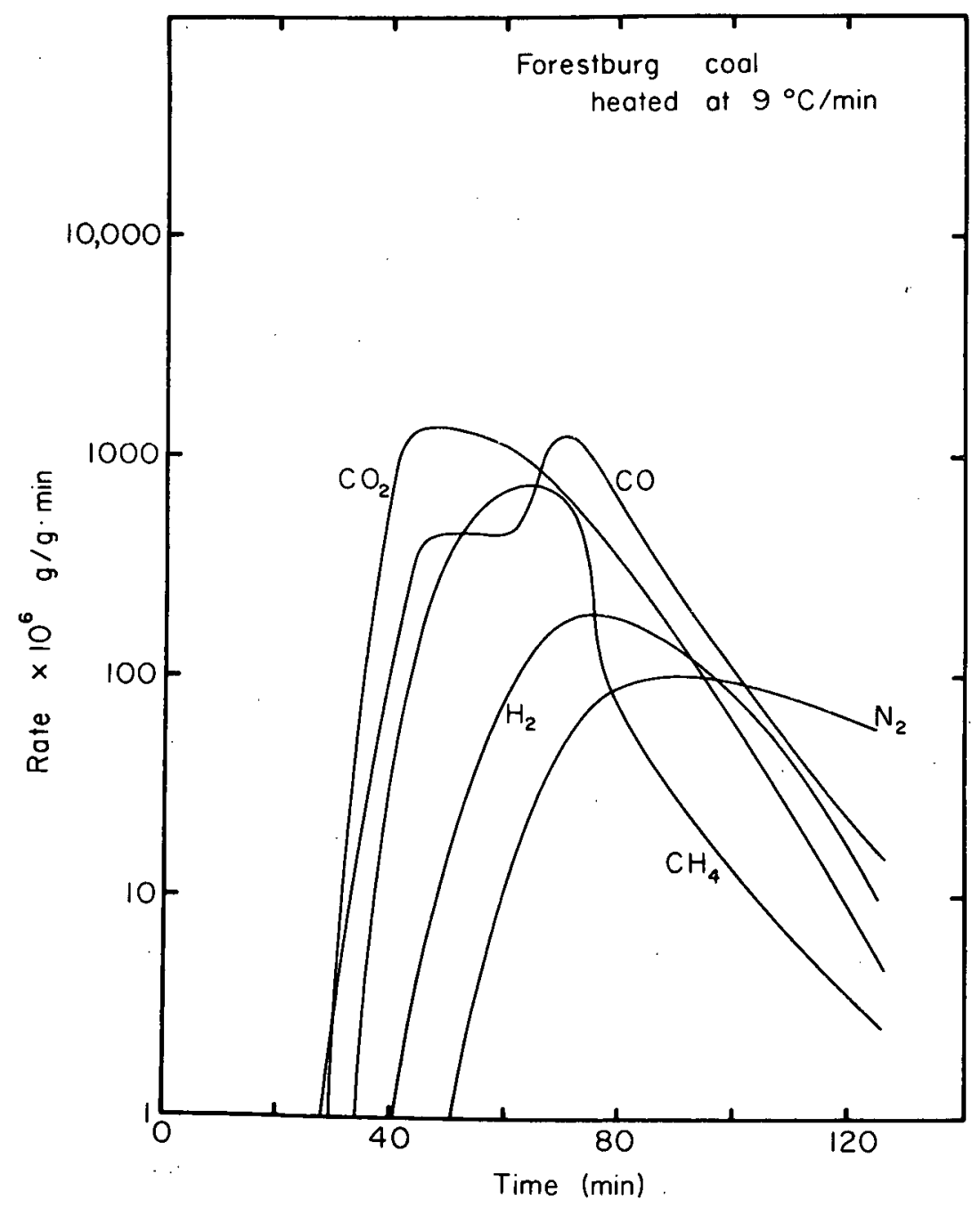

Fig. 5. Rates of evolution of volatiles from Forestburg coal. 
zone is the removal of moisture from all three solid components: ore, coal and dolomite. Since the ore and dolomite contain a relatively smaller amount of moisture and also since the amount of dolomite fed is small, the removal of moisture from ore and dolomite is of minor importance compared to coal. In the case of ore and dolomite the volumetric rate of moisture removal is considered constant over a selected region of the ki ln .

For the case of coal the drying data used in the model was based on the tests conducted at the Fuels Research Institute where moisture was also collected together with the volatiles. Fig. 6 gives the results obtained from the test for Forestburg coal. It is clear from Fig. 6 that a considerable amount of moisture is evolved at temperature higher than $100^{\circ} \mathrm{C}$. This means that a proximate analysis cannot be used to give an accurate value of the total moisture in the coal, since the temperature used is only 104 to $110^{\circ} \mathrm{C}$. The curve in Fig. 6 was again approximated by a polynomial equation for use in the model.

\subsubsection{Combustion in the Freeboard}

In order to maintain the solids bed at the required temperature in the reduction zone, a large quantity of heat has to be transferred continuously from the feeboard gas to the solids. This is necessary to meet the large heat requirements 


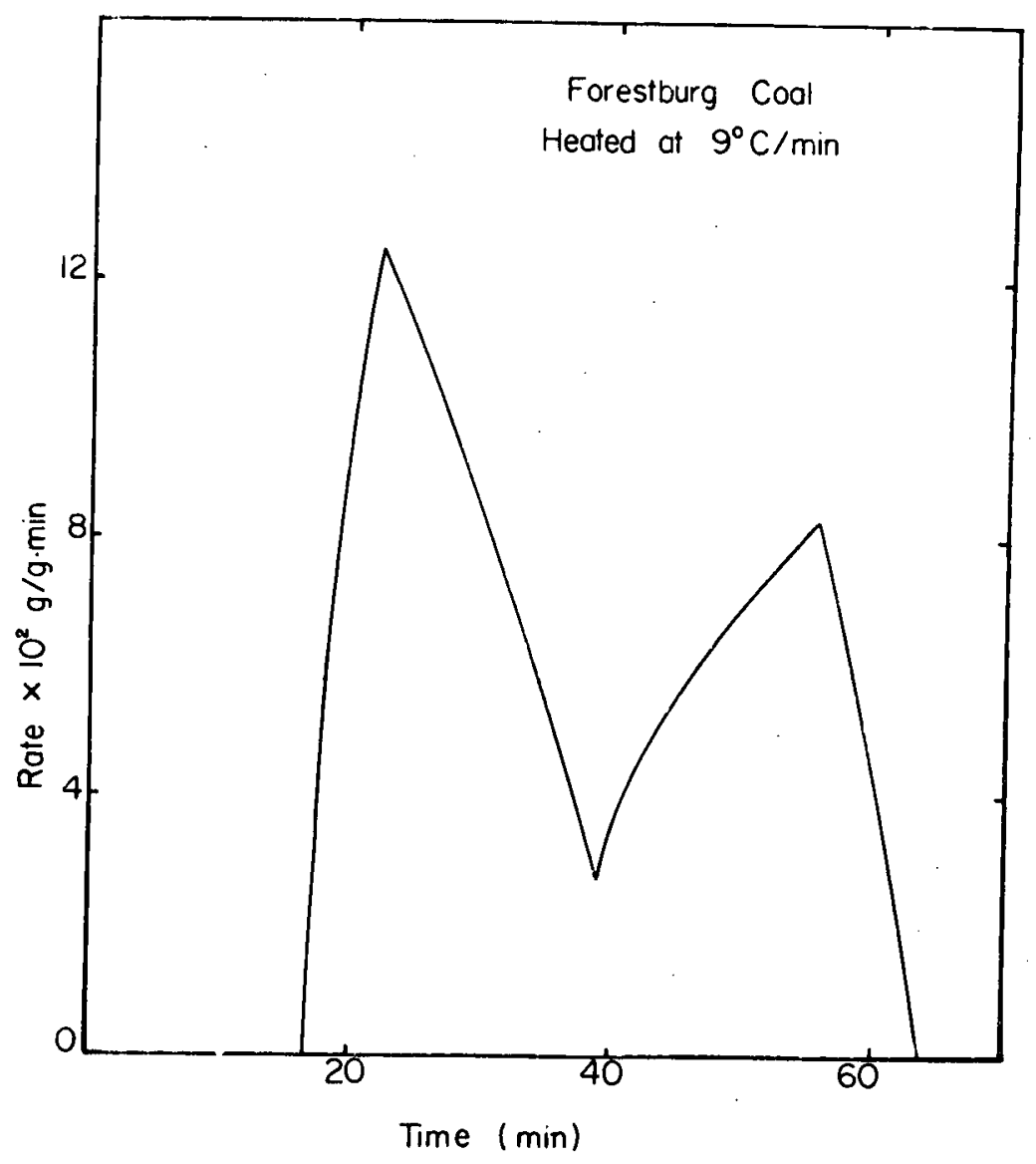

Fig. 6. Rate of moisture evolution from Forestburg coal. 
of the endothermic Boudouard reaction. This heat is generated in the freeboard area by the burning of combustibles.

In the SL/RN process the main combustible constituent is carbon monoxide which is released from the bed as the Boudouard reaction proceeds. Another combustible is natural gas which is often injected in the preheat zone as an auxiliary heat supply. Natural gas injection is practised frequentry in kiln runs involving coal with a high moisture content.

As mentioned at the beginning of this chapter, it is assumed in the model that instantaneous combustion is achieved in the freeboard gases. Before calculating the quantity of the various combustibles burnt, however, a check is made to assess whether sufficient oxygen is available for complete combustion. If not, burning is allowed only to the extent that oxygen is present. The heat generated by combustion is considered to be a volumetric heat source which circumvents the need to treat flame heat transfer separately.

\subsubsection{Calcination of Dolomite}

Dolomite is included in the charge to the SLLRN kiln if the sulphur content of the coal is excessively high. The dolomite essentially acts as a scavenger for sulphur and prevents the sulphur content of the sponge iron from being unacceptably high. During heating, the dolomite calcines by releasing $\mathrm{CO}_{2}$ to the freeboard gas. The influence of this reaction on both 
the heat and mass balances over the kiln is relatively insignificant, however, because of the small quantity charged. Nevertheless, calcination of the dolomite is incorporated into the model being allowed to proceed at a constant rate between set temperature limits.

\subsubsection{Specific Heats of Solids and Gases}

Since the solids are a mixture of ore, coal and dolomite, the average specific heat of the solids at any temperature will depend on the average specific heats of the individual components. In addition, since the composition of these solid components also change with position along the kiln (with temperature) it: is necessary to calculate the composition of individual solid components before venturing into the calculation of the specific heats. It should be mentioned here that the solid components are assumed to be a mechancial mixture in the specific heat calculations. For example, ore is assumed to be a mixture of iron oxide, gangue and moisture. Here again the specific iron oxide used in the above calculations depends on the degree of reduction. Thus at the beginning of reduction the oxide present will be $\mathrm{Fe}_{2} \mathrm{O}_{3}$, then a mixture of $\mathrm{Fe}_{2} \mathrm{O}_{3}$ and $\mathrm{Fe}_{3} \mathrm{O}_{4}$ followed by the sequence, $\mathrm{Fe}_{3} \mathrm{O}_{4}$, a mixture of $\mathrm{Fe}_{3} \mathrm{O}_{4}+$ $\mathrm{Fe} 0$, FeO and finally a mixture of $\mathrm{FeO}+\mathrm{Fe}$. The same procedure is followed for coal and dolomite.

The specific heats of the freeboard gases are less difficult to calculate compared to the solids. The average 
specific heat of the gases is computed from the specific heat of individual components based on the respective weight fractions.

In addition to calculating the specific heat, one should also calculate the derivative of the specific heat with respect to temperature. This is obvious from Eqs. (19) and (22), and arises from the fact that the specific heat is allowed to vary with temperature in the calculations.

\subsubsection{Partial Pressures in the Freeboard Gas Phase}

Knowledge of the partial pressures of the individual components comprising the freeboard gas phase is required for the calculation of radiation heat transfer from the gases to solids and inside wall of the kiln. Since the mass flow rate of the individual gas components is calculated at each point in the kiln from the differential mass balances, the partial pressure is easily computed using the corresponding molecular weights and assuming a total pressure of one atmosphere. This calculation is repeated for each slice of the kiln to yield axial profiles of partial pressures.

\subsection{Heat Transfer in Rotary Kilns}

In spite of the rotary kiln being used in industrial. operations such as drying and the production of cement for several decades, a quantitative understanding of the heat 
transfer mechanisms in rotary kilns is still not clear. The uncertainty arises because there are several different heat transfer modes, all of which are influenced to a different extent by the kiln variables. Referring to Fig. 7(a), these different modes can be characterised as follows:

$\begin{array}{lll}\text { (i) Radiation from gas to wall } & \left(A_{2}\right) \\ \text { (ii) Convection from gas to wall } & \left(A_{2}\right) \\ \text { (iii) Radiation from gas to solids } & \left(A_{1}\right) \\ \text { (iv) Convection from gas to solids } & \left(A_{1}\right) \\ \text { (v) } \text { Radiation from exposed inner } & \left(A_{1}\right) \\ \text { wall to solids } & \\ \text { (vi) Conduction from covered wall } & \left(A_{3}\right) \\ \text { to solids } & \end{array}$

The terms $A_{1}, A_{2}$ and $A_{3}$ listed in parenthesis correspond to the areas affecting the individual heat transfer modes.

In the literature different equations have been used by individual authors to describe the co-efficients which govern the heat transfer rate of the different modes. These are given in Table 3 . From this table it is clear that there is no uniform set of equations that have been employed previously. Also in many instances there is no indication given as to why a particular equation has been selected in preference to another. 


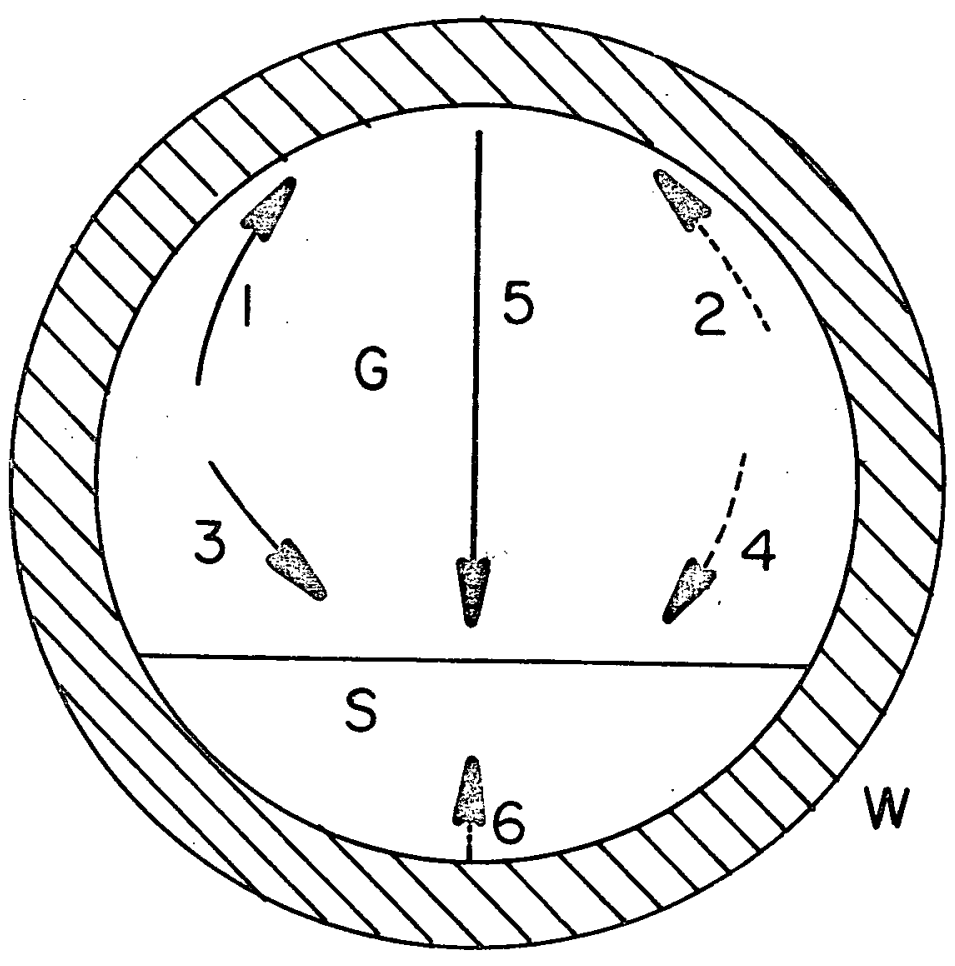

Radiation

\section{Convection}

Conduction

Fig. $7(a)$. Cross-section of the kiln showing the heat transfer modes.

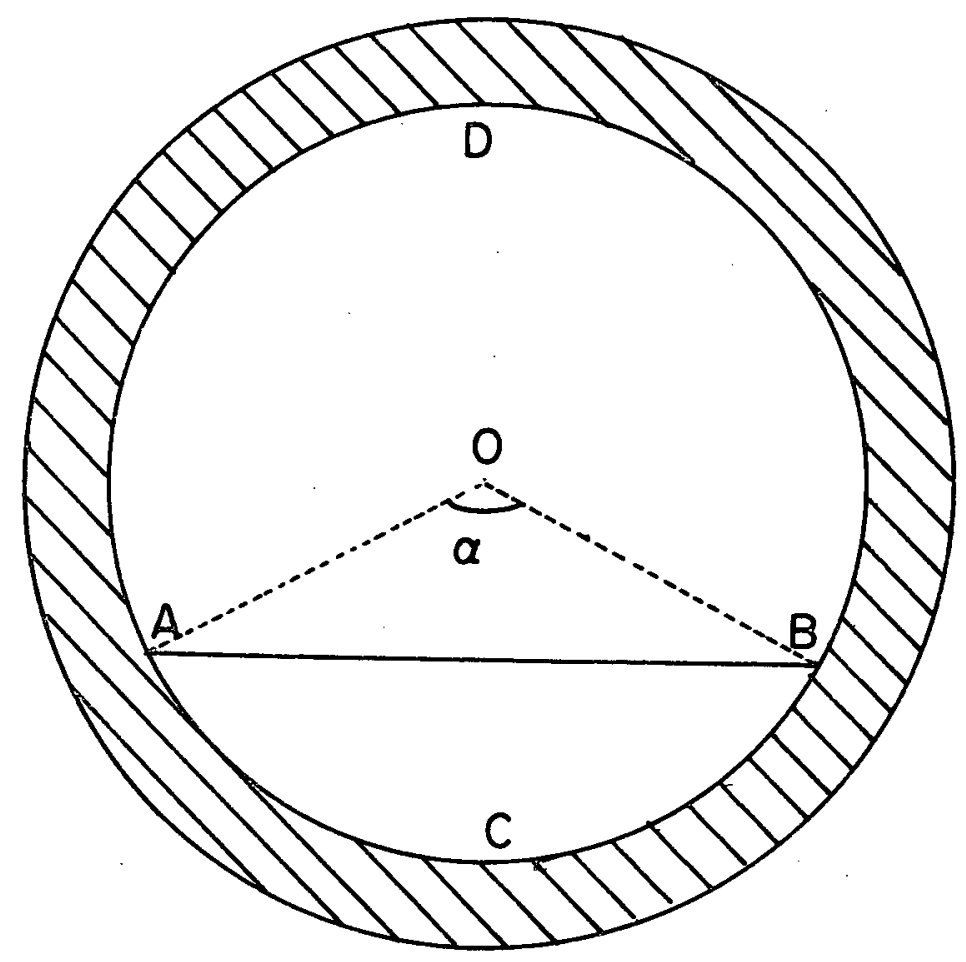

$\begin{array}{ll}\text { Chord } A B & A_{1} \\ \text { Arc } A D B & A_{2} \\ \text { Arc } A C B & A_{3}\end{array}$

Fig. 7(b). Cross-section of the kiln showing the area terms involved in the different $N$ heat transfer equations. 
Table. 3 Heat Transfer Coefficients in the Literature

Riffaud (18) Sass (16) Wingfield (21) Manitius (20) Lyons (31) Sprang (19)

\begin{tabular}{|c|c|c|c|c|c|c|}
\hline $\begin{array}{l}\text { GAS TO SOLIDS } \\
\text { CONVECTION }\end{array}$ & $0.05 c^{0.57}$ & $0.05 \mathrm{G}^{0.67}$ & 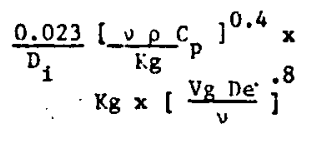 & $17.8\left(\lambda_{g} D 1\right)^{0.2}\left(v_{g} / C_{P}\right)^{0.8}$ & ${ }^{4} \frac{\text { B.T.U }}{h r \cdot f t^{2} \cdot F}$ & $\frac{4 \text { B.T.U. }}{h r \cdot f t^{2} \cdot \mathrm{F}}$ \\
\hline $\begin{array}{l}\text { GAS TO SOLIDS } \\
\text { RADIATION }\end{array}$ & $\sigma \varepsilon_{8} \frac{\left(T_{g}^{4}-T_{s}^{4}\right)}{\left(T_{g}-T_{s}\right)}$ & $\sigma \varepsilon_{g} \frac{\left(T_{g}^{4}-T_{B}^{4}\right)}{\left(T_{g}-T_{g}\right)}$ & $\sigma \varepsilon_{g} \frac{\left(T_{g}^{4}-T_{g}^{4}\right)}{\left(T_{g}-T_{s}\right)}$ & $\sigma \varepsilon_{0}^{\frac{\left(\varepsilon_{g} T^{4}-\alpha_{B}^{1} T^{4}\right)}{\left(T g-T_{B}\right)}}$ & $2 \sigma \varepsilon_{g} \varepsilon_{s}\left(T_{B}^{3}-T_{B}^{3}\right)$ & $\sigma \varepsilon_{B} E_{B} \frac{\left(T_{B}^{4}-T_{B}^{4}\right)}{\left(T_{8}-T_{B}\right)}$ \\
\hline $\begin{array}{l}\text { GAS TO WALI. } \\
\text { CONVECTION }\end{array}$ & $0.05 a^{n .67}$ & $0.05 c^{0.67}$ & $\begin{array}{l}\text { same as in gas } \\
\text { to solids convec- } \\
\text { tion. }\end{array}$ & $\begin{array}{l}\text { same as in gas to solids } \\
\text { convection }\end{array}$ & $5 \frac{\text { B.T.U. }}{h r . f t^{2} \cdot F}$ & $4 \frac{\text { B.T.U. }}{h r \cdot f t^{2} \cdot F}$ \\
\hline $\begin{array}{l}\text { GAS TO WALL } \\
\text { RADIATION }\end{array}$ & $\sigma \varepsilon_{g} \frac{\left(T_{g}^{4}-T_{w}^{4}\right)}{\left(T_{g}-T_{w}\right)}$ & $\sigma \varepsilon g \frac{\left(T_{g}^{4}-T_{w}^{4}\right)}{\left(T_{g}-T_{w}\right)}$ & $\sigma E \frac{\left(T_{B}^{4}-T_{w}^{4}\right)}{\left(T_{g}-T_{w)}\right.}$ & $\sigma \varepsilon_{w} \frac{\left(\varepsilon_{B} T_{B}^{4}-\alpha_{g} T^{T^{4}}\right)}{\left(T_{g}-T_{w}\right)}$ & $2 \sigma \varepsilon_{B} \varepsilon_{w}\left(T_{g}^{3}+T_{w}^{3}\right)$ & $\left(1-h_{g}\right) \sigma \varepsilon_{g} e_{w} \frac{\left(T_{g}^{4}-T_{w}^{4}\right)}{\left(T_{g}-T_{w}\right)}$ \\
\hline $\begin{array}{l}\text { INNFR VALI. TO } \\
\text { SOLINS } \\
\text { RADLATION }\end{array}$ & $\sigma \varepsilon_{8} \frac{\left(T_{w}^{4}-T_{B}^{*}\right)}{\left(T_{w}-T_{B}\right)}$ & $\sigma E_{8} f \frac{\left(T_{w}^{4}-T_{8}^{4}\right)}{\left(T_{w}-T_{8}\right)}$ & $\sigma \in \frac{\left(T_{w}^{4}-T_{B}^{4}\right)}{\left(T_{w}-T_{s}\right)}$ & $\varepsilon_{w} \varepsilon_{s} \frac{\left[{ }_{g}^{\left(1-a_{g}^{\prime \prime}\right) T_{w}^{4}-\left(1-a_{g}\right) T_{8}^{4}}\right.}{\left(T_{w}-T_{8}\right)}$ & $2 \sigma \varepsilon_{B} \varepsilon_{w}{ }_{A_{S}}^{A_{w}}\left(T_{g}^{3}+T_{w}^{3}\right)$ & $h \sigma \varepsilon_{w} \varepsilon_{B} \frac{\left(T_{w}^{4}-T_{s}^{4}\right)}{\left(T_{w}-T_{s}\right)}$ \\
\hline $\begin{array}{l}\text { INNFR WALL TO } \\
\text { SOLIDS } \\
\text { (COVERSD) }\end{array}$ & $40 \frac{\text { B.T. } U_{2}}{\mathrm{hr} \cdot \mathrm{ft}^{2} \cdot \mathrm{F}}$ & $0.25 G^{0.67}$ & $\frac{148 \frac{\text { B.T.U. }}{1}}{\mathrm{hr} \cdot \mathrm{ft}^{2} \cdot \mathrm{F}}$ & note $e^{2}$ & $39.1 \frac{\text { B.T.U. }}{h r . \mathrm{ft}^{20} \mathrm{~F}}$ & $4 \frac{\text { B.T.U }}{\mathrm{hr} \cdot \mathrm{ft}^{2} \mathrm{R}}$ \\
\hline COMEENTS & $\begin{array}{l}G \text {-flow rate of gas } \\
\sigma \text { - Stefan Constant } \\
\varepsilon_{g} \text {-emissivity of gas } \\
\varepsilon_{s} \text {-comprised of emis- } \\
\text { sivity of solids and } \\
\text { wall.. }\end{array}$ & $\begin{array}{l}\varepsilon \text {-emissivity of solid } \\
f \text {-correction factor }\end{array}$ & $\begin{array}{l}K_{g} \text {-thermal conductivity } \\
D_{1} \text {-tnner diameter } \\
v \text {-kinematic viscosity } \\
p \text {-density } \\
c_{p} \text {-specific heat } \\
v_{g} \text {-velocity of gas } \\
D_{e} \text {-equivalent diameter }\end{array}$ & $\begin{array}{l}\lambda_{g} \text { thermal conductivity } \\
D 1 \text { inner diameter } \\
a_{8} \text { absorbtivity of gas } \\
\text { at } T_{8} \\
\alpha_{8}^{*} \text { absorbtivity of gas } \\
\text { at } t_{w}\end{array}$ & $\begin{array}{l}A_{s} \text { area of charge } \\
\text { surface }\end{array}$ & $\begin{array}{l}h=\frac{1+2 h_{0} \sin (p / 2)}{2 \pi-p} \\
2 \pi-p \text { angle subtended } \\
\text { by the solids at the } \\
\text { centre. } \\
h_{0}=0.0758\end{array}$ \\
\hline
\end{tabular}

1. In addition another radiation term is also considered.
2. Lengthy expression from a Russian work. 


\subsubsection{Heat Transfer Coefficients Used in the Present Model}

The following section details the equations utilised in the evaluation of the different heat transfer coefficients in the present model. These heat transfer coefficients are evaluated at each slice along the entire length of the kiln.

\subsubsection{Heat Transfer from Gas to Wall by Radiation}

$$
h_{g w r}=\frac{\sigma\left(\varepsilon_{g} T_{g}^{4}-\alpha_{g}^{\prime} T_{w}^{4}\right)}{\left(T_{g}-T_{w}\right)}
$$

Eq. (37) gives the heat transfer coefficient from gas to wall by radiation, where

$$
\begin{aligned}
& h_{g w r} \text { is the heat transfer coefficient } \\
& \sigma \quad \text { is the stefan-Boltzmann constant } \\
& \varepsilon_{g} \text { is the emissivity of the gas at the } \\
& \text { gas temperature } \\
& \alpha^{\prime} g \quad \text { is the absorptivity of gas at the } \\
& \text { wal temperature }
\end{aligned}
$$

The area term that is used in connection with this heat transfer coefficient is $A_{2}$ as given in Fig. 7(b). Symmetrical molecules like $\mathrm{N}_{2}$ and $\mathrm{O}_{2}$ do not participate in any radiative exchange but asymmetrical molecules such as $\mathrm{CO}_{2}$ and $\mathrm{H}_{2} \mathrm{O}$ do have certain band lengths over which they emit and absorb radiation. McAdams [24] gives a detailed procedure for calculating the 
gas emissivities and absorptivities. The emissivity of any gas species participating in radiative heat exchange depends on the partial pressure of that component, the temperature and the mean beam length. The mean beam length for the gas is a function of the geometry of the system and in this case depends on the diameter of the rotary kiln. Fig. 8 shows the emissivity for $\mathrm{CO}_{2}$ for different values of the product of mean beam length (L) and partial pressure of the gas. Fig. 9 gives the emissivity for $\mathrm{H}_{2} \mathrm{O}$. For the SL/RN model the curves in Figs. 8 and 9 were approximated by polynomial equations and stored in the computer program. The steps involved in calculating the emissivity values in the model are summarised below.

\footnotetext{
(i) Calculation of the partial pressure of the gas concerned.

(i i). Selection of the appropriate line corresponding to that partial pressure.

( $i$ i Reading of the value of emissivity for the particular temperature.

If one is considering a mixture of $\mathrm{H}_{2} \mathrm{O}$ and $\mathrm{CO}_{2}$ as in
} the SL/RN kiln, the total emissivity of the gas is

$$
\varepsilon_{\mathrm{g}}=\varepsilon_{\mathrm{CO}_{2}}+\varepsilon_{\mathrm{H}_{2} \mathrm{O}}-\Delta \varepsilon
$$

where $\varepsilon_{g}$ is the total gas emissivity

${ }^{\varepsilon} \mathrm{CO}_{2}$ is the emissivity contribution from $\mathrm{CO}_{2}$ $\varepsilon_{\mathrm{H}_{2} \mathrm{O}}$ is the emissivity contribution from $\mathrm{H}_{2} \mathrm{O}$ 


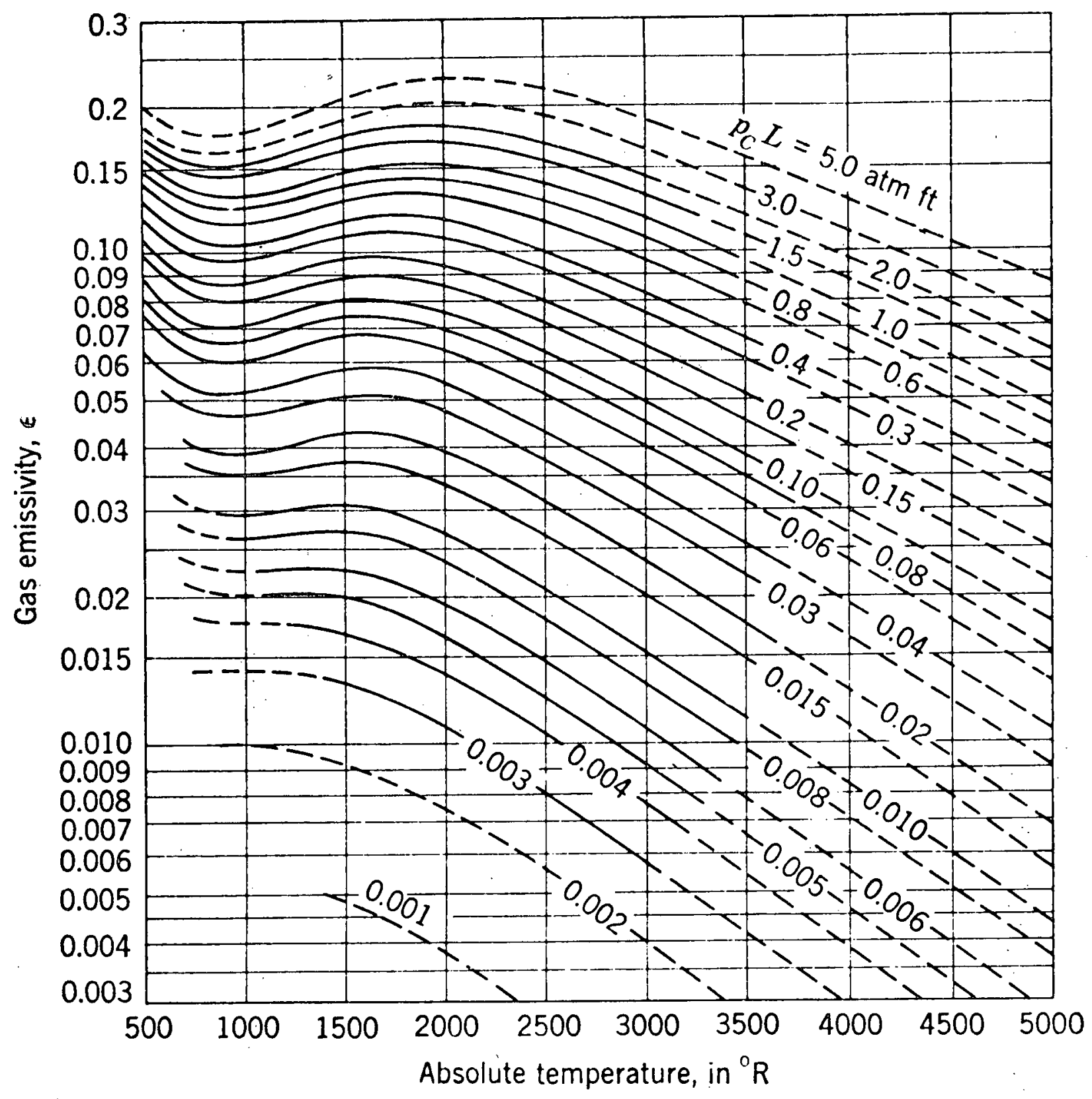

Fig. 8. Gas emmissivity for carbon dioxide (from Perry (30)). 


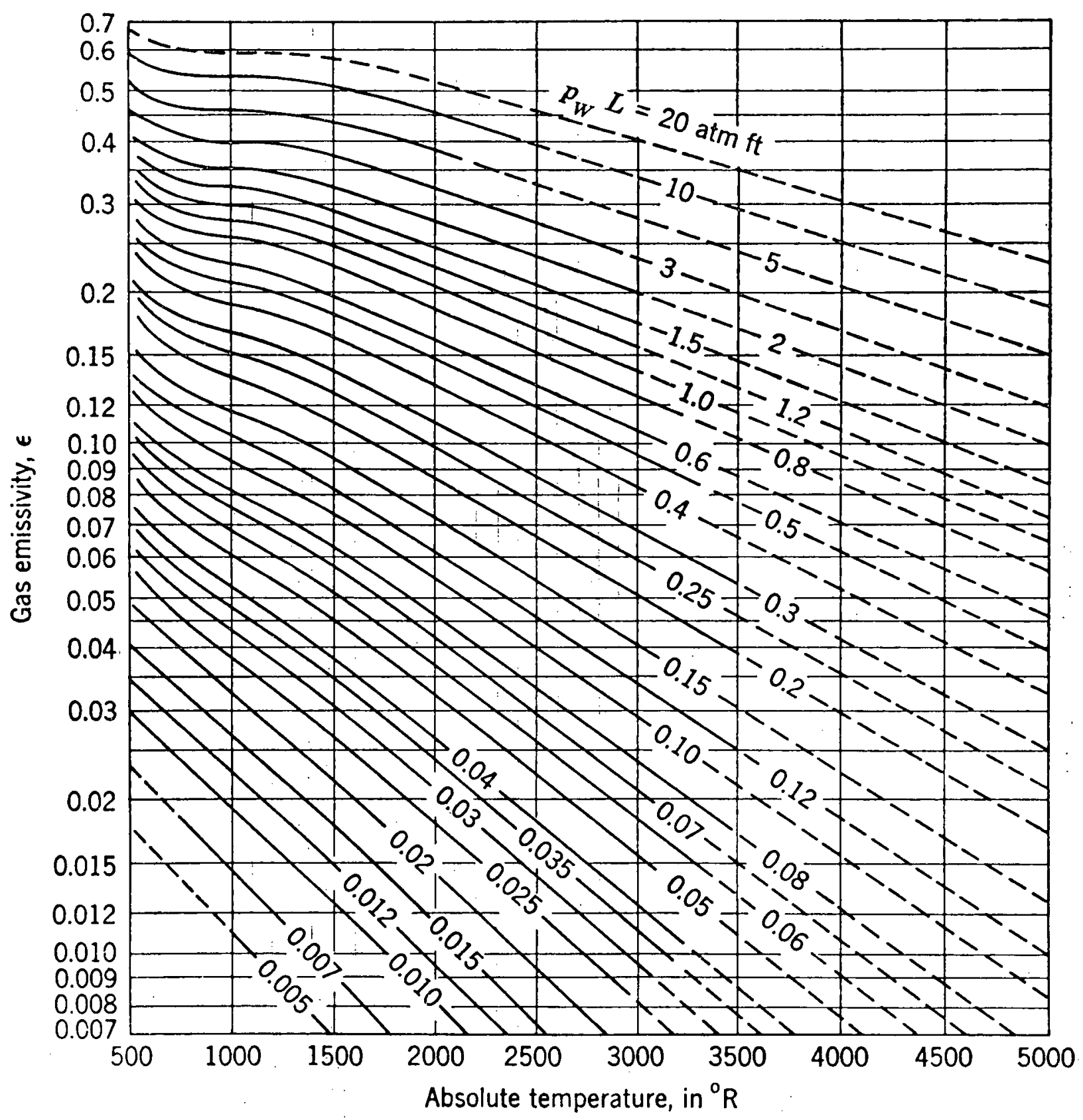

Fig. 9. Gas emissivity for water vapour (from Perry (30)). 
$\Delta \varepsilon$ is the correction factor to account for the overlapping of the two absorption bands

In the model calculations, however, it was found to be unnecessary to apply the correction term as it was relatively negligible.

\subsubsection{Convection from Gas to Wall}

The heat transfer coefficient from gas to wall by convection is given by Eq. (39):

$$
h_{g W C}=0.05 G^{0.67}
$$

where $G$ is the mass flux of the gases.

Since the contribution by convection to the overall heat transfer rate is relatively minor, a change in its magnitude does not affect the overall heat transfer rate to any appreciable extent. This heat transfer coefficient has its maximum value at the charge end where the mass flux of gases is greater. As mentioned earlier, the area term used with this coefficient is $A_{2}$.

\subsubsection{Radiation from Gas to Solids}

The equation describing this heat transfer coefficient is similar to that for gas to wall radiation and is given below

$$
h_{g s r}=\frac{\sigma\left(\varepsilon_{g} \cdot T_{g}^{4}-\alpha^{\prime \prime} g T_{s}^{4}\right)}{\left(T_{g}-T_{s}\right)}
$$


where $\quad h_{g s r}$ is the heat transfer coefficient

$$
\begin{aligned}
& \alpha " g \text { is the absorptivity of the gas at the } \\
& \text { solids temperature }
\end{aligned}
$$

The emissivity and absorptivity calculations are performed in a manner identical to that given in the previous section. The area term used with this heat transfer coefficient is $A_{1}$.

\subsubsection{Convection from Gas to Solids}

The expression employed for this heat transfer coefficient, $h_{g s c}$, is:

$$
h_{g s c}=0.05 G^{0.67}
$$

The area term used here is $A_{1}$.

\subsubsection{Radiation from Exposed Wall to Solids}

This heat transfer mode, together with radiative heat transfer from gas to solids, account for roughly twothirds of the total heat transferred to the solids. The governing equation for radiation from wall to solids is given by

$$
h_{w s r}=f \quad \sigma \quad \varepsilon_{w} \varepsilon_{s}\left(T_{w}^{4}-T_{s}^{4}\right)
$$

where $h_{\text {wsr }}$ is the heat transfer coefficient 


$$
\begin{aligned}
& \varepsilon_{W} \text { is the emissivity of the wall (0.9) } \\
& \varepsilon_{S} \text { is the emissivity of the solids }(1.0)
\end{aligned}
$$

It is not clear from the literature what value of $f$ should be used in the equation. In a $11^{\circ}$ the model calculations presented in this work a value of 1.0 has been used for $f$. The area term here is $A_{1}$.

\subsubsection{Covered Wall to Solids}

The magnitude of this heat transfer coefficient is taken to be five times the magnitude of the convective heat transfer coefficient (Eq. 39). The actual heat transfer mechanism from covered wall to solids will be a mixture of all the three modes of heat transfer. The area term employed in this case is $\mathrm{A}_{3}$.

\subsubsection{Heat Loss to the Surroundings}

Heat loss from the kiln shell depends on the thermal conductivity of the refractory. lining employed and its thickness. Treating the problem as heat transfer through a composite wall and neglecting the thermal resistance of the steel shell the overall heat transfer coefficient can be obtained as follows: 


$$
h_{0}=\frac{1}{2 \pi r_{4}}\left[\frac{1}{\frac{\left(r_{2}-r_{1}\right)}{\pi K_{1}\left(r_{1}+r_{2}\right)}+\frac{\left(r_{3}-r_{2}\right)}{\pi K_{2}\left(r_{3}+r_{2}\right)}+\frac{1}{h_{S A} 2 \cdot \pi r_{4}}}\right]
$$

where $h_{0}$ is the overall heat transfer coefficient $r_{1}, r_{2}, r_{3}, r_{4}$ are radius terms described in Fig. 10

$K_{1}, K_{2}$ are thermal conductivities of the different refractory layers comprising the lining

$\mathrm{h}_{\mathrm{SA}}$ is the heat transfer coefficient from the surface of the kiln to the surroundings by convection and radiation.

The area term used here is $2 \pi r_{4}$.

The convective heat transfer coefficient from the kiln shell to the surroundings is calculated using the equation

$$
\frac{h_{C} D}{K}=0.11\left[\left(0.5 R_{e \omega}{ }^{2}+G_{r}\right) P_{r}\right]^{0.35}
$$

and the radiative coefficient by the standard Stefan-Boltzmann equation.

$$
h_{r}=\varepsilon_{s s} \sigma \frac{\left(T_{s h}^{4}-T_{a}^{4}\right)}{\left(T_{s h}-T_{a}\right)}
$$

where $h_{c}$ is the convective heat transfer coefficient

D is the outside diameter of the kiln

$k$ is the thermal conductivity of air $G_{r}$ is the Grashof number 


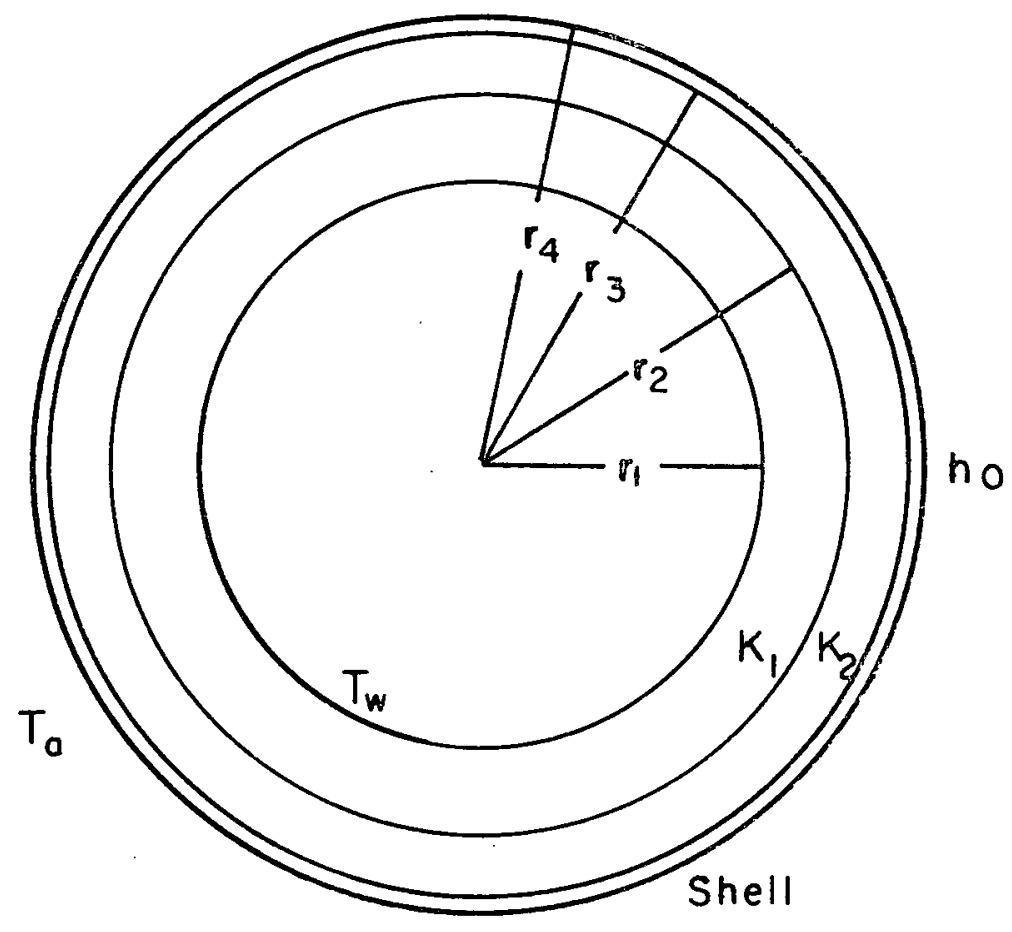

Fia. 10. Cross section of the rotary kiln showing the different radius terms used for calculating heat loss to surroundings. 


$$
\begin{aligned}
& P_{r} \text { is the Prandti number } \\
& \varepsilon_{s s} \text { is the emissivity of the steel shell } \\
& T_{s h} \text { is the temperature of the shell } \\
& T_{a} \text { is the temperature of the ambient medium }
\end{aligned}
$$

Because the shell temperature was found to be virtually independent of axial position, the coefficient $h_{c}$ is evaluated only once for a given run. As noted earlier the shell temperature is not known a priori but is calculated by trial and error as shown in the section concerned with the heat balance on the wall.

\subsubsection{Area Terms for Heat Transfer}

In the model the area terms used in the heat transfer calculations were computed from a knowledge of the angle subtended by the solids. This angle, $\alpha$, was determined from the degree of fill as follows. Referring to Fig. 7(b)

$$
\begin{aligned}
& \text { Area of sector } O A B=\frac{\alpha}{2 \pi} \times \pi r_{1}^{2} \\
& \begin{aligned}
& \text { Area of triangle } O A B=\frac{1}{2} \times r_{1}^{2} \times \sin \alpha \\
& \text { Area of the hatched section }=\pi r_{1}{ }^{2} \frac{\alpha}{2 \pi}-\frac{1}{2} r_{1}^{2} \sin \alpha \\
&=\frac{r_{1}{ }^{2}}{2}[\alpha-\sin \alpha]
\end{aligned}
\end{aligned}
$$


But this is also the degree of fill, F so that $\pi \times r_{1}^{2} \times F=\frac{r_{1}^{2}}{2}[\alpha-\sin \alpha]$

or $\quad \alpha=\sin \alpha+2 \pi F$

where $\quad r_{1}$ is the internal radius of the rotary kiln.

Since this is an implicit relationship in $\alpha$, it is solved by an iterative procedure using the Newton-Raphson method [25]. The important areas for heat flow calculations are arcs $A C B$ and $A D B$, and chord $A B$. Their respective relationships to $\alpha$ are given below.

$$
\begin{aligned}
& \operatorname{arc} A C B=2 \pi r_{1}\left(1-\frac{\alpha}{2 \pi}\right) \\
& \operatorname{arc} A D B=2 \pi r_{1} \frac{\alpha}{2 \pi}=r_{1} \alpha \\
& \text { chord } A B=2 r_{1} \text { sin } \frac{\alpha}{2}
\end{aligned}
$$

\subsection{Numerical Procedure Used in the Model}

Since the solids and gases flow in a counter-current fashion in the SL/RN kiln, the solution of the differential Eqs. (5) to (16), (19) and (22) poses some difficulties. The solids boundary conditions are known at the charge end and that of gases at the discharge end. However, in order to start the computations it is necessary to have the initial conditions 
for both solids and gases at either end. This leads to two routes for solving the mixed boundary problem. Assuming that the end conditions for the gases at the charge end are known the calculations can be started at the charge end. In the model the calculations were begun at the discharge end owing to the complicated nature of the availability of oxygen for combustion in the freeboard gases. In other words it was easier to follow the gases through the kiln rather than the solids. As mentioned before, the wall temperature is not known before hand and hence needs calculation on an iterative basis. The flowsheet for the mathematical model is given in Figs. 11 (a) to (c). The specific numerical method used for solving the first order differential equations (5) to (16), (19) and (22) is the Kutta-Merson method, which is one of the fourth order Runge-Kutta riethods. Briefly stated, the procedure works as follows. If $A, B, C, D$ are four intermediate points in a single integration step, $h$, then the calculations performed are

$$
\begin{gathered}
x_{A}=x_{B}=x_{0}+\frac{h}{3} \\
x_{C}=x_{0}+\frac{h}{2} \\
x_{D}=x_{0}+h=x_{1}
\end{gathered}
$$

Introducing the shorthand notation 


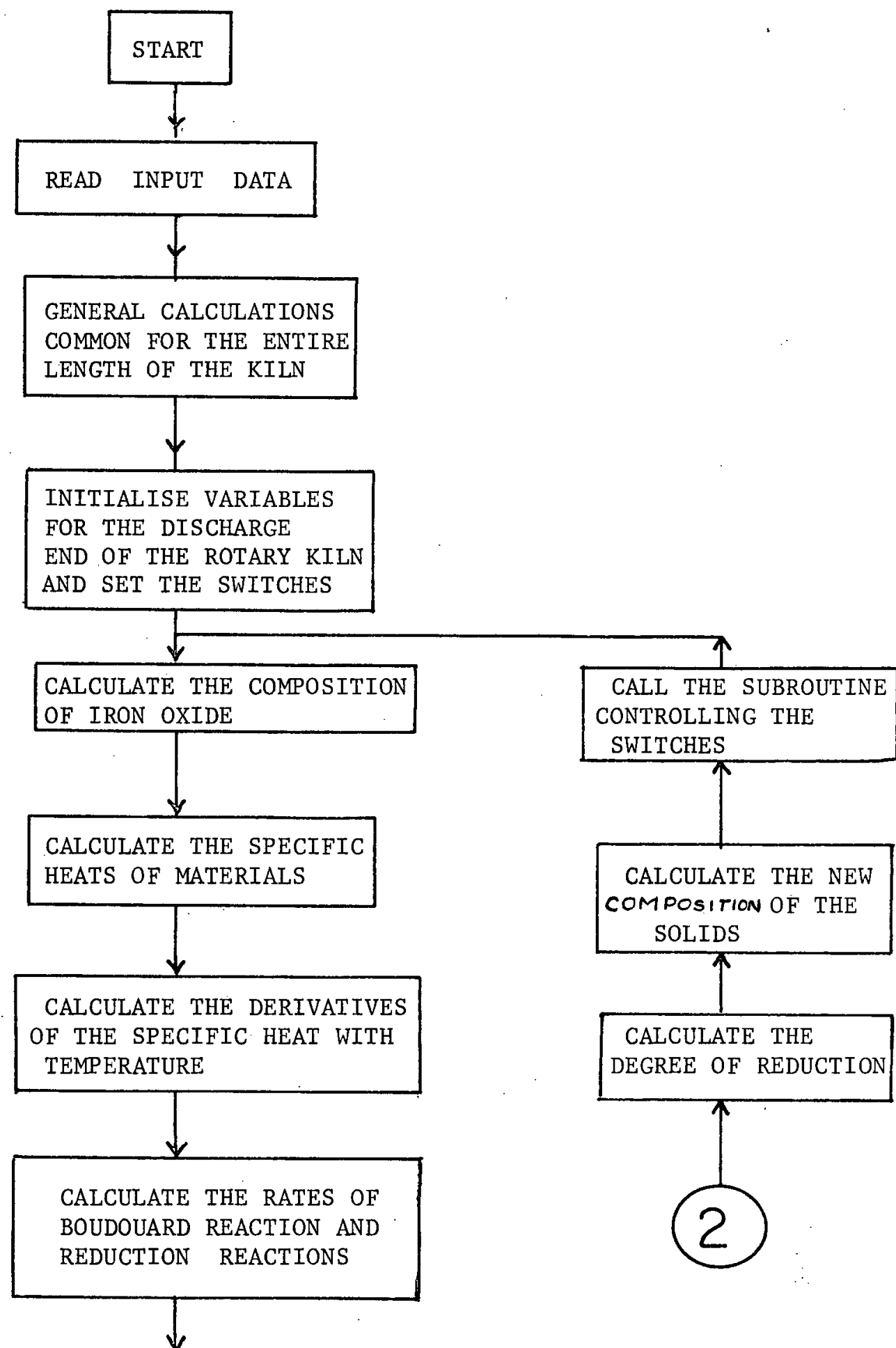

CONTINUED

Fig. 11. Flow sheet of the computer program. 


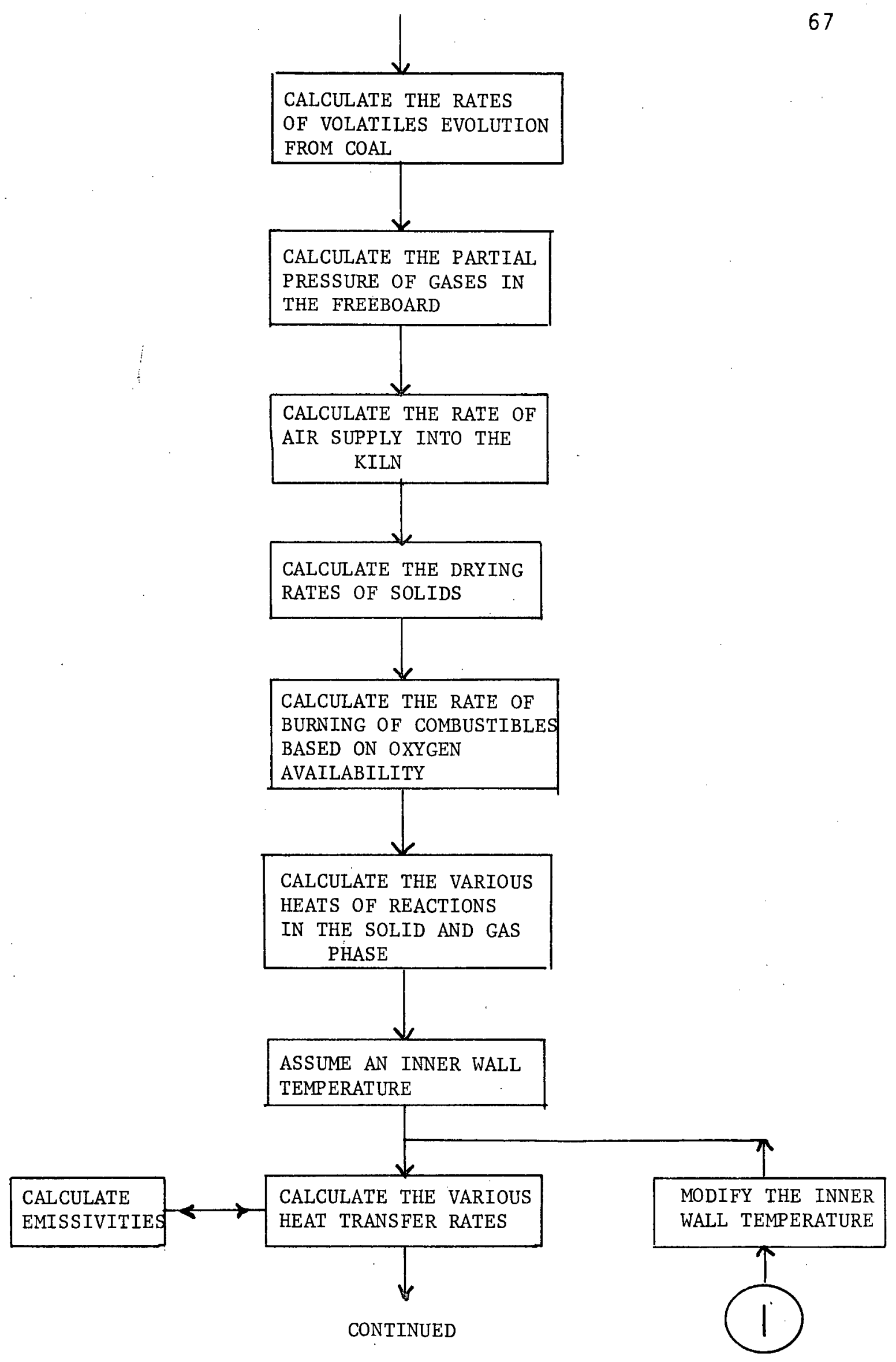




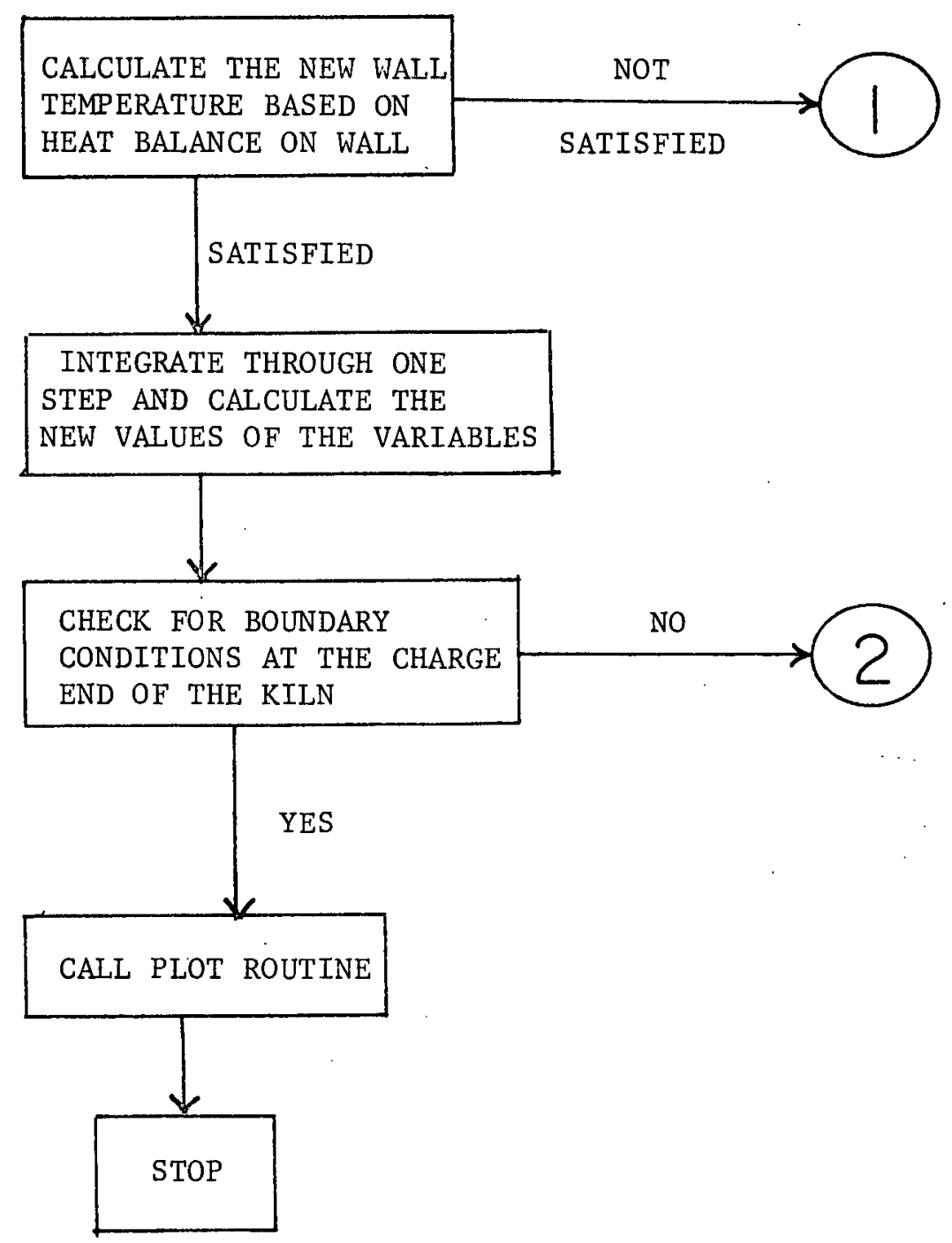




$$
y_{z}^{\prime}=f\left(x_{z}, Y_{z}\right) \quad z=0, A, B, C, D
$$

the method of Merson consists of making the evaluations

$$
\begin{gathered}
Y_{A}=Y_{0}+\frac{h}{3} Y^{\prime} \\
Y_{B}=Y_{0}+\frac{h}{6}\left(Y_{0}^{\prime}+Y_{A}^{\prime}\right) \\
Y_{C}=Y_{0}+\frac{h}{8}\left(Y_{0}^{\prime}+3 Y_{B}^{\prime}\right) \\
Y_{D}=Y_{0}+\frac{h}{2}\left(Y_{0}^{\prime}-3 Y_{B}^{\prime}+4 Y_{C}^{\prime}\right) \\
Y_{I}=Y_{0}+\frac{h}{6}\left(Y_{0}^{\prime}+4 Y_{C}^{\prime}+Y_{D}^{\prime}\right)
\end{gathered}
$$

An estimate of the truncation error is given by

$$
\frac{1}{5}\left[\frac{1}{3} h Y_{0}^{\prime}-\frac{3}{2} h Y_{B}^{\prime}+\frac{4}{3} h Y_{C}^{\prime}-\frac{1}{6} h Y_{D}^{\prime}\right]
$$

which is used to control the step size automatically. The source listing of the computer program is given in Appendix I.

\subsection{Internal Consistency of the Model}

In order to ensure that the calculations performed using the model are internally consistent, a check was made on the overall heat and mass balances. The results of these 
balances are shown below for a typical run with Forestburg coal and Griffith pellets.

\section{Mass Balance}

Mass in

\begin{tabular}{lll}
$\begin{array}{l}\text { ore in } \\
\text { coal in }\end{array}$ & $=$ & $2010.5 \mathrm{~g} / \mathrm{s}$ \\
Nitrogen & $=$ & $1359.9 \mathrm{~g} / \mathrm{s}$ \\
Oxygen & $3287.4 \mathrm{~g} / \mathrm{s}$ \\
Natural gas & $=$ & $998.7 \mathrm{~g} / \mathrm{s}$ \\
$\quad$ TOTAL & & $31.7 \mathrm{~g} / \mathrm{s}$ \\
\hline $688.2 \mathrm{~g} / \mathrm{s}$
\end{tabular}

Mass out

$$
\begin{aligned}
& \text { sponge iron }=1456.0 \mathrm{~g} / \mathrm{s} \\
& \text { non-metallics }=\quad 349.3 \mathrm{~g} / \mathrm{s} \\
& \text { Nitrogen }=3294.9 \mathrm{~g} / \mathrm{s} \\
& \text { oxygen }=59.2 \mathrm{~g} / \mathrm{s} \\
& \text { Carbondioxide }=\quad 1760.4 \mathrm{~g} / \mathrm{s} \\
& \text { water vapour }=\quad 767.4 \mathrm{~g} / \mathrm{s} \\
& \text { TOTAL } \quad 7688.0 \mathrm{~g} / \mathrm{s}
\end{aligned}
$$

Heat Balance

$$
\begin{aligned}
& \text { Reference temperature } 25^{\circ} \mathrm{C} \\
& \text { Solids come in at } 17^{\circ} \mathrm{C} \text { and leave at } 1000^{\circ} \mathrm{C} \\
& \text { Gases come in at } 10^{\circ} \mathrm{C} \text { and leave at } 913^{\circ} \mathrm{C}
\end{aligned}
$$




\section{Heat in}

Burning $\mathrm{CO}=$
Burning volatiles=
in coal
Burning natural gas =
Reduction with
carbon monoxide

$2052 \mathrm{Kcal} / \mathrm{s}$

$1088 \mathrm{Kcal} / \mathrm{s}$

TOTAL

$379 \mathrm{Kcal} / \mathrm{s}$

$67 \mathrm{Kcal} / \mathrm{s}$

$3586 \mathrm{Kcal} / \mathrm{s}$

\section{Heat out}

\begin{tabular}{|c|c|c|c|}
\hline Boudouard Reaction & $=$ & 1252 & $\mathrm{Kcal} / \mathrm{s}$ \\
\hline $\begin{array}{l}\text { Sensible heat in } \\
\text { solids }\end{array}$ & $=$ & 288 & $\mathrm{Kcal} / \mathrm{s}$ \\
\hline $\begin{array}{l}\text { Sensible heat } \\
\text { in gases }\end{array}$ & $=$ & 1561 & $\mathrm{Kcal} / \mathrm{s}$ \\
\hline $\begin{array}{l}\text { Reduction with } \\
\text { hydrogen }\end{array}$ & $=$ & 22 & $\mathrm{Kcal} / \mathrm{s}$ \\
\hline Drying reaction & $=$ & 289 & $\mathrm{Kcal} / \mathrm{s}$ \\
\hline $\begin{array}{l}\text { Heat loss through } \\
\text { kiln wall }\end{array}$ & $=$ & 126 & $\mathrm{Kcal} / \mathrm{s}$ \\
\hline & TOTAL & 3538 & $\mathrm{Kcal} / \mathrm{s}$ \\
\hline
\end{tabular}

As can be seen, the balances close to just over $7 \%$ which clearly demonstrates the internal consistency of the model.

\subsection{Starting and Instability Problems}

It should be pointed out that even though it is possible to obtain a stable run on the computer for a 
hypothetical case, in reality it may be impossible to achieve such a run due to operational problems associated with the process. Thus it is essential that the model is used with extreme caution. One of the most critical aspects in this regard is the choice of starting temperature for the solids at the discharge end of the kiln which are not known a priori. To examine this problem a set of computer runs was undertaken using conditions from the SL/RN pilot kiln, with different solids exit temperatures. Fig. 12 gives the axial solid temperature profiles calculated for three of the runs. As can be seen, use of $900^{\circ} \mathrm{C}$ and $1100^{\circ} \mathrm{C}$ as the initial solids temperature results in wavy profiles that are not found in reality. On the other hand, the starting temperature of $1000^{\circ} \mathrm{C}$ yields a flat profile which is known to obtain in the reduction zone (more details can be found in the following chapter). On the basis of the shape of the solids temperature profile, the solids temperature chosen at the exit would be $1000^{\circ} \mathrm{C}$. Indeed this is the exit temperature measured for these conditions. This indicates that even though the solids exit temperature is not known in advance it can be arrived at by trial-and-error using the shape of the resultant solids temperature profile as a criterion:

Another major problem encountered in running the model was instability. For certain sets of input data the temperature of the solids, for example, would rise exponentially to unrealistic values. It should be pointed out that this 


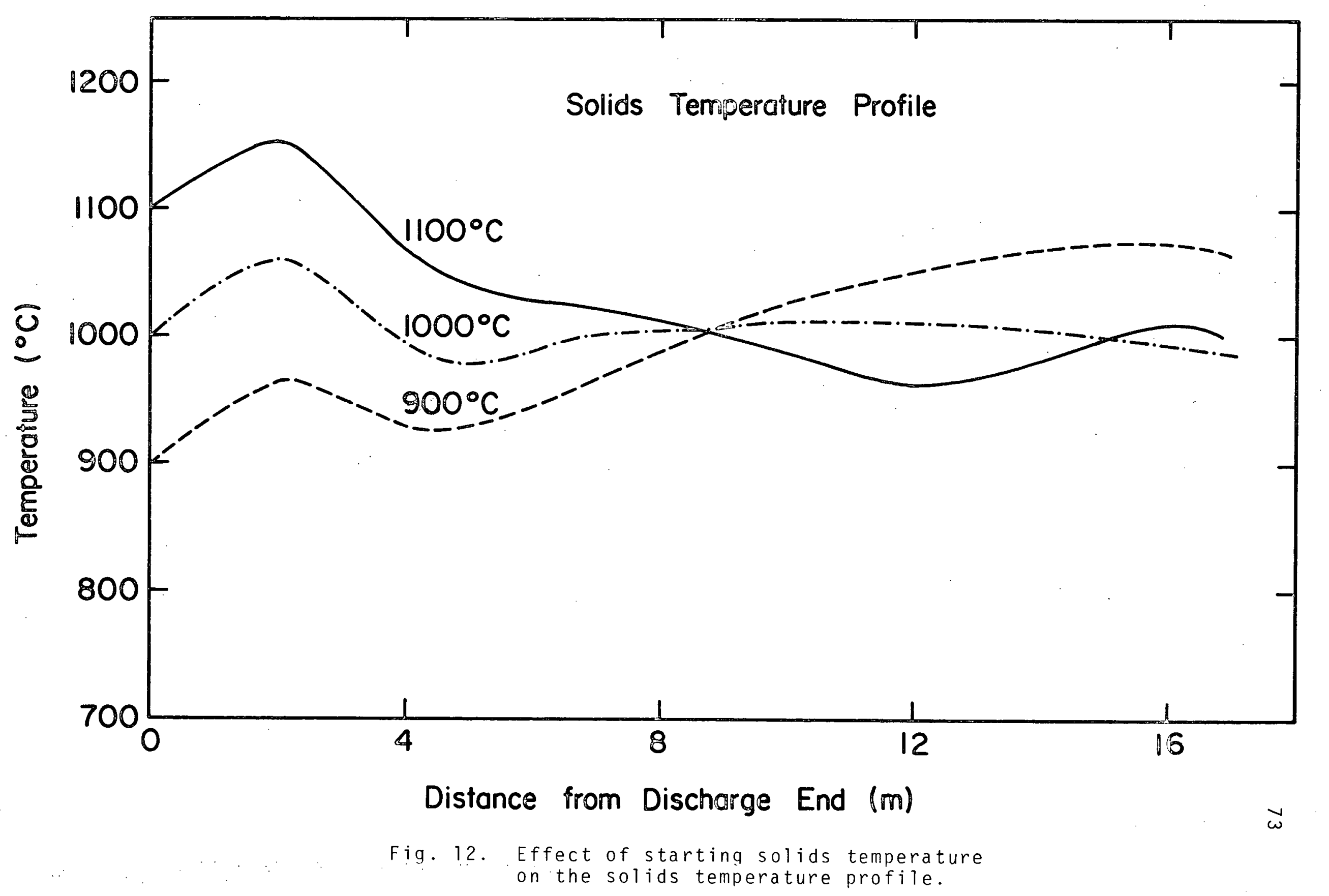


problem did not arise when operating data taken from successful pilot plant trials were used as input. For this reason an instability was taken as an indication that the input parameters for the run in question would result in unsatisfactory kiln performance.

\subsection{Adjustable Parameters in the Model}

One of the most important features of this mathematical model is the relative absence of adjustable parameters. Only one adjustable parameter is employed, near the discharge end to account for the unknown rate of heat transfer to solid particles rolling through the flames at the surface of the bed. This parameter was adjusted so as to yield, from a numerical viewpoint, a stable solution. It is a permanent feature of the model and has not been found to have a significant effect on model reliability. 


\section{Chapter 3}

\section{MODEL CALCULATIONS AND DISCUSSION}

\subsection{Evaluation of the Model}

One of the most important stages in the development of a mathematical model is its evaluation, measured in terms of its ability to make predictions that agree with reality. In the case of the SL/RN process model, considerable time was spent at this stage. Operating data from the large SL/RN pilot kiln ( $35 \mathrm{~m}$ by $2.1 \mathrm{~m}$ id) located at the Stelco Hilton works were procured and used as input to the model. The output from the model, axial temperature and concentration profiles, were then compared to measurements made under the same conditions on the pilot kiln.

Two runs in which the charge consisted of indurated oxide pellets from the Griffith Mine with Forestburg coal (subbituminous) and lignite coal respectively were selected for this purpose. These particular runs were considered most suitable because of the stable operating conditions achieved in the kiln, and also as a result of the potential importance, 
from a Canadian viewpoint of the coals used for reduction - both coals are from Western Canada.

\subsubsection{Evaluation Runs}

\subsubsection{Forestburg Coal and Griffith Pellets}

The input parameters used in this run are given in Table 4. The values which have been taken from Stelco research reports [26] are averages from a campaign lasting three weeks. The air profile used in this run is given in Fig. 13. The air profile was calculated from a knowledge of the burner positions along the kiln and the air rate through individual burners. The area under the curve gives the total air rate blown into the kiln minus the air discharged through the end-burner which is included in the initial conditions.

Using this air profile and solving the set of first order differential equations developed in Chapter 2 , axial concentration and temperature profiles for the various gaseous and solids components were computed. These are presented in Figs. 14 to 19. Fig. 14 gives the solids temperature profile. calculated from the model together with temperatures that have been measured in the solids bed. From Fig. 14 it can be seen that the general agreement between calculated and measured temperatures is quite reasonable. The small difference between the two may arise from one of the many assumptions that have been made in the model such as no radial temperature gradients 
Table 4

Input Data for the Kiln Run Using Griffith Pellets and Forestburg Coal

$\begin{array}{ll}\text { Ore - Griffith Pellets } & 191.8 \text { tons/day } \\ \text { Coal - Forestburg (sub-bituminous) } & 129.9 \text { tons/day } \\ \text { Air (total) } & 52415 \mathrm{ft}^{3} / \text { ton ore } \\ \text { Natural gas } & 676 \mathrm{ft}^{3} / \text { ton ore } \\ \text { Degree of reduction (total) } & 92 \% \\ \text { Hydrogen pre-reduction } & 8 \% \\ \text { Exit solids temperature } & 1000^{\circ} \mathrm{C} \\ \text { Solids degree of fill } & 25 \%\end{array}$




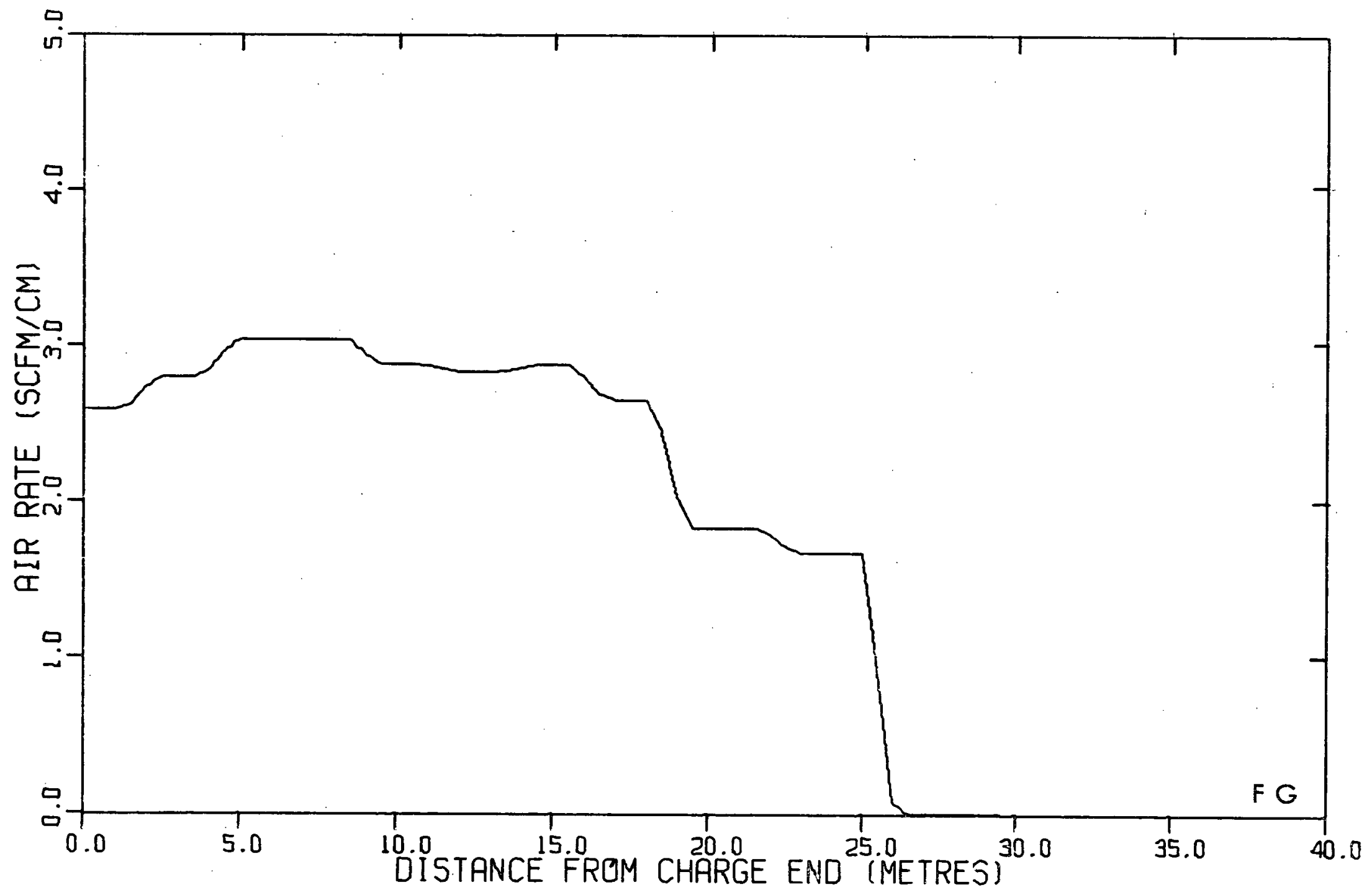

Fig. 13. Air profile for the kiln run using Forestburg coal and Griffith pellets. 


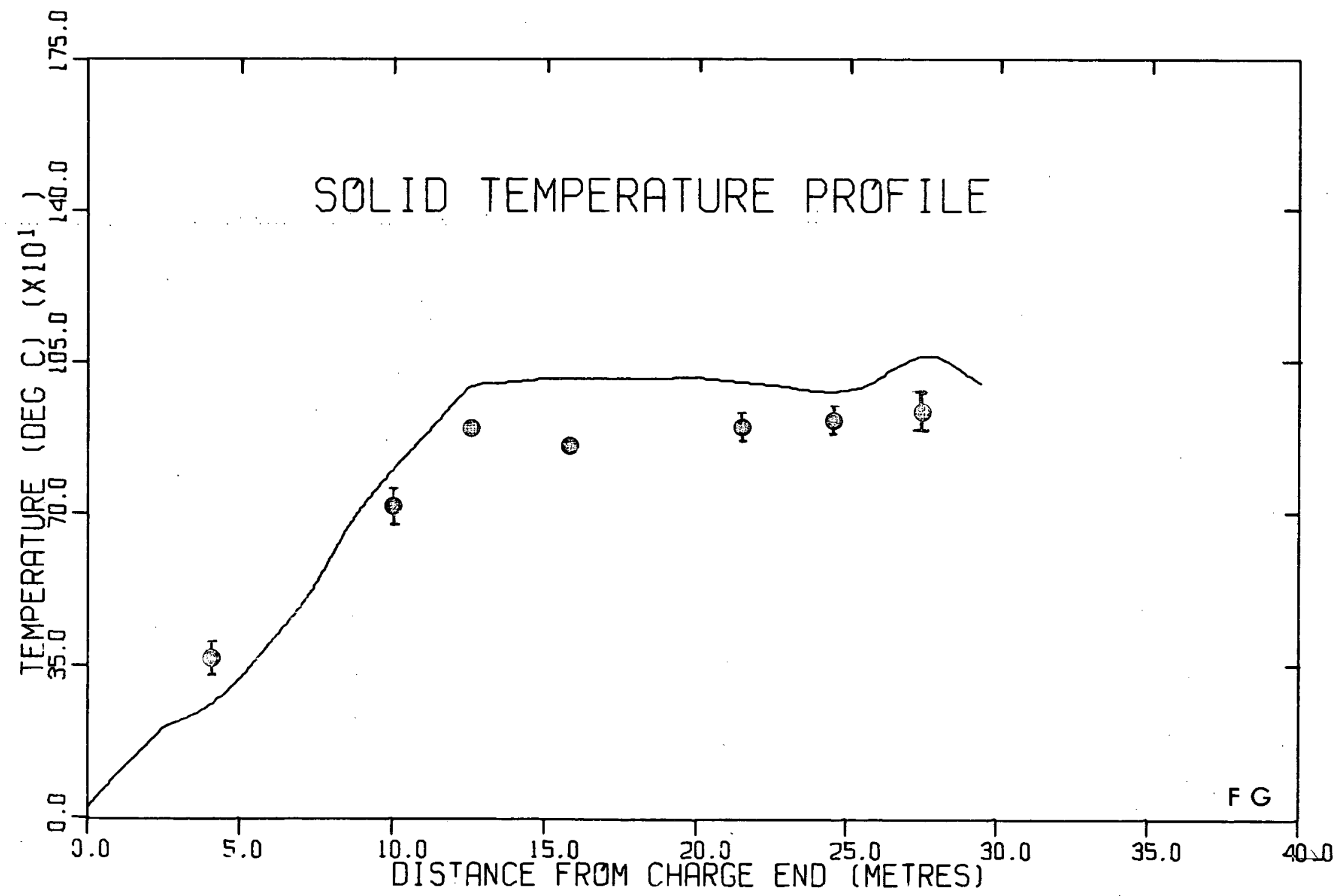

Fig. 14. Solids temperature profile for the kiln run using Forestburg coal and firiffith pellets. 
in the bed. On the other hand, the measurements themselves, made under industrial conditions with heavy duty thermocouples, may be slightly in error. Whatever the source of error, the discrepancy between calculated and measured temperatures is not thought to be serious.

Fig. 14 also gives important information regarding the kiln length. The model calculates a value for the kiln length of $30 \mathrm{~m}$, whereas the actual length is $35 \mathrm{~m}$. If one takes into account dams at either end of the kiln and the position of the charging chute, the discrepancy is only marginally greater than $10 \%$.

The calculated gas temperature profile is plotted in Fig. 15. In this case, comparison with measured temperatures is exceedingly difficult because the measurements were made with sheathed, "rapid response" thermocouples, rather than with suction thermocouples. It is well known that the use of a bare, non-suction thermocouple will result in a gas temperature measurement that is lower than the real value, owing to radiative exchange between the thermocouple and the wall [27]. For the SL/RN kiln this error was calculated to be roughly $150-170^{\circ} \mathrm{C}$. In an attempt to predict the gas temperature profile that would be measured by a non-suction thermocouple, a correction was applied and the lower temperature profile in Fig. 15 was obtained. However, even with this correction the measured gas temperatures. proved to be too erratic to make a meaningful comparison possible. The one point where the gas temperature was accurately 


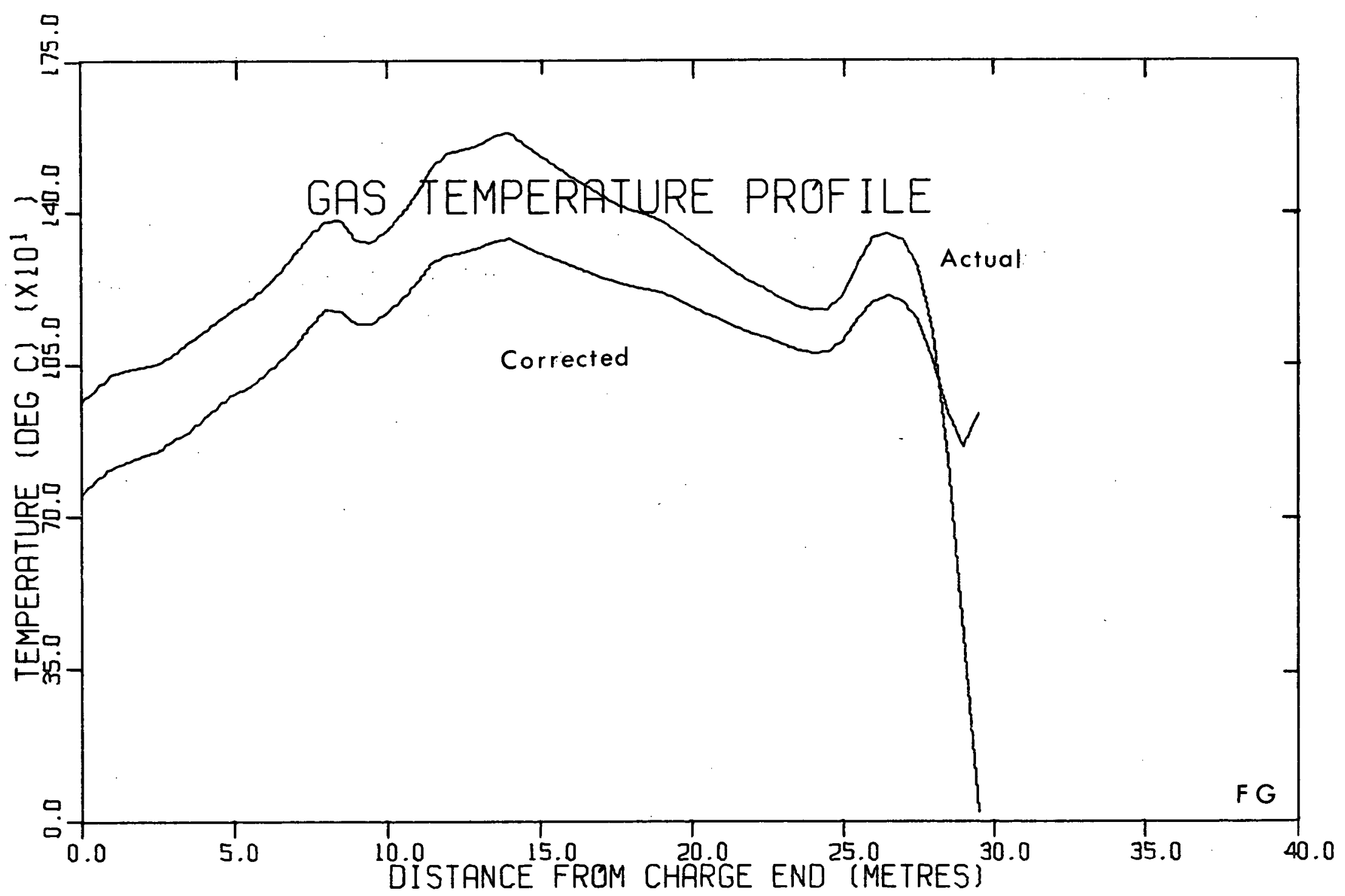

Fig. 15. Gas temperature profile for the run using Forestburq coal and Griffith pellets. 
measured, just beyond the charge end of the kiln, yielded a temperature that agreed well with the calculated value.

Fig. 16 gives the inner wall temperature profile (upper curve) and the outer shell temperature profile (lower curve). The latter profile agrees closely with measurements that have been reported by operators. A direct evaluation of the calculated inside wall temperature is impossible, however, since measurements have not been made. Despite this, there is some indirect evidence that the inside wall temperatures calculated are reasonable. As can be seen from Fig. 16, the inner wall temperature profile reaches a peak over a section of the kiln 12 to $17 \mathrm{~m}$ from the charge end. This also turns out to be the region of the kiln in which the maximum accretion formation is observed. Since, as explained in Chapter 1 , accretions are associated with high inner wall temperatures, this coincidence is expected if the wall temperatures calculated are realistic. This result is important since it also means that the model can be used reasonably to determine the regions of the kiln in which accretions may pose a potential problem. The reduction profile for this run is shown in Fig. 17. The curve is made up of two parts, the first corresponding to hydrogen pre-reduction and the second to reduction by co. Although the transition from one type of reduction to the other is shown to be abrupt, in reality it will be considerably smoother. The general form of the co reduction curve, showing 


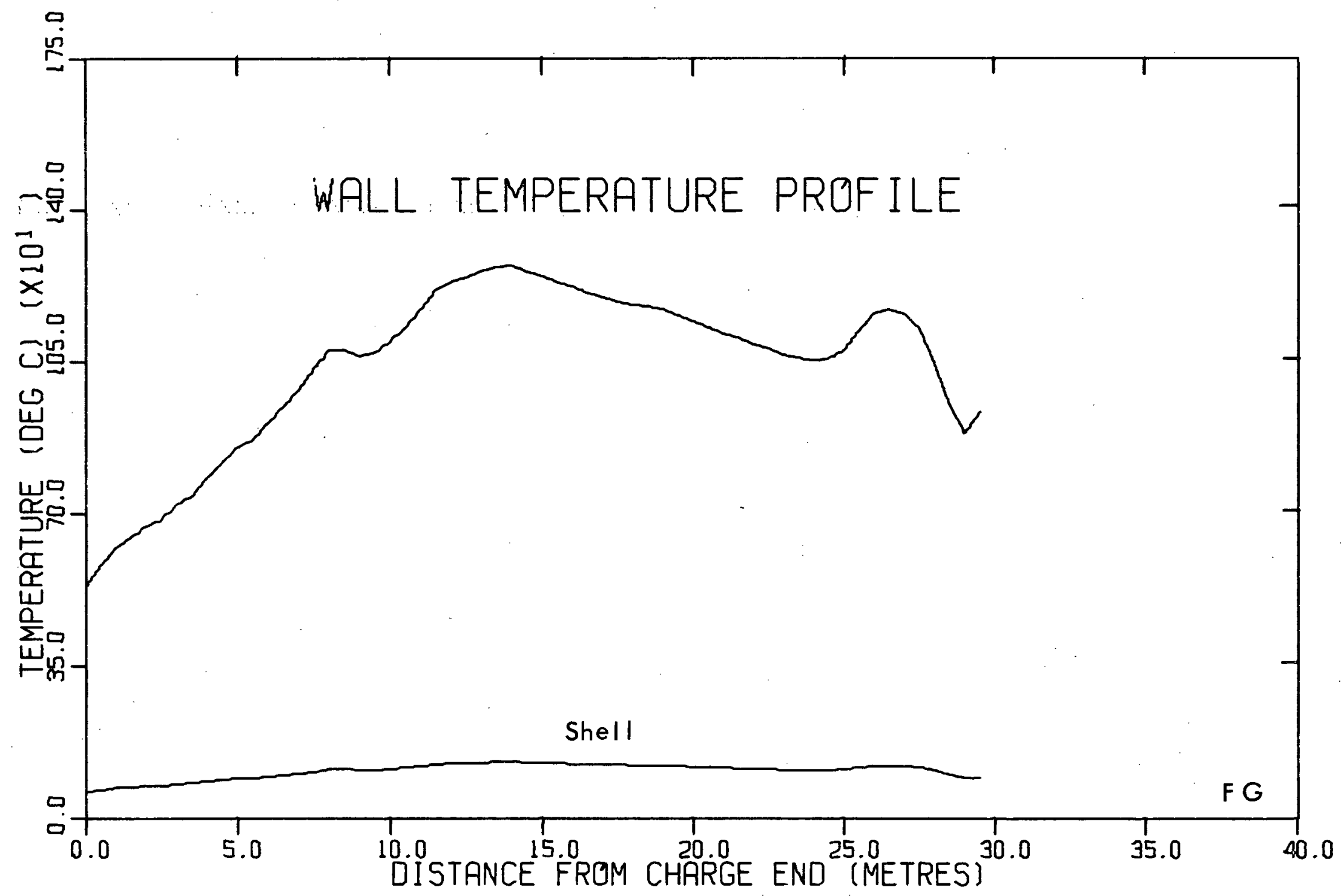

Fig. 16. Inner wall and outer shell temperature for the kiln run using Forestburg coal and Griffith pellets. 


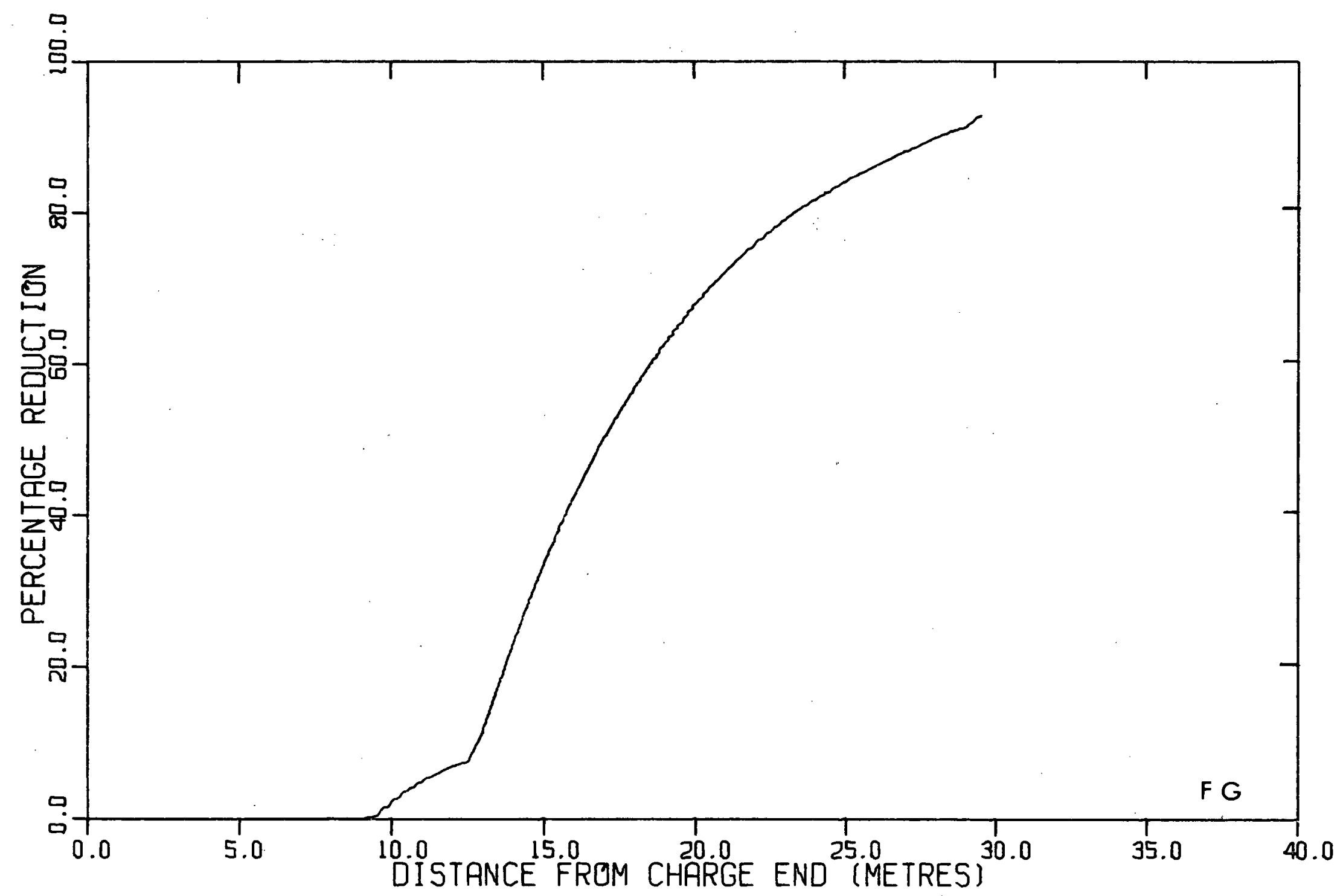

Fig. 17. Reduction profile for the kiln run using Forestburg coal and Griffith pellets. 
a drop in reduction rate toward the discharge end of the kiln is consistent with the governing rate expressions.

Fig. 18 gives the rate of Boudouard reaction as a function of kiln length. This again shows the appreciable drop in the reaction rate with increased degree of reduction. The sudden rise in the Boudouard reaction rate at $13 m$ is an artifact arising from the way the calculations are performed in the mathematical model. In reality, the rise will be less instantaneous, but nevertheless rapid, and should not cause undue error. It is also interesting to note that the peak in the freeboard gas temperature coincides with the region where the Boudouard reaction rate is maximum. This is an expected result since the rate of release of co from the bed and its combustion in the freeboard should also be a maximum at this point.

The axial concentration profiles of the gaseous compounds in the freeboard, expressed as partial pressures, are shown in Fig. 19. The species plotted here include all the major constituents such as $\mathrm{N}_{2}, \mathrm{O}_{2}, \mathrm{CO}_{2}, \mathrm{CO}$ and $\mathrm{H}_{2} \mathrm{O}$. Since in pilot plant runs the gas composition was not analysed at different points along the kiln, the only check that could be made with the calculated results was the waste gas composition. Close agreement between those measured and calculated compositions was obtained.

One of the most interesting points to note in Fig. 19 is the slight excess of oxygen present in the freeboard through most of the reduction zone. The presence of the oxygen is 


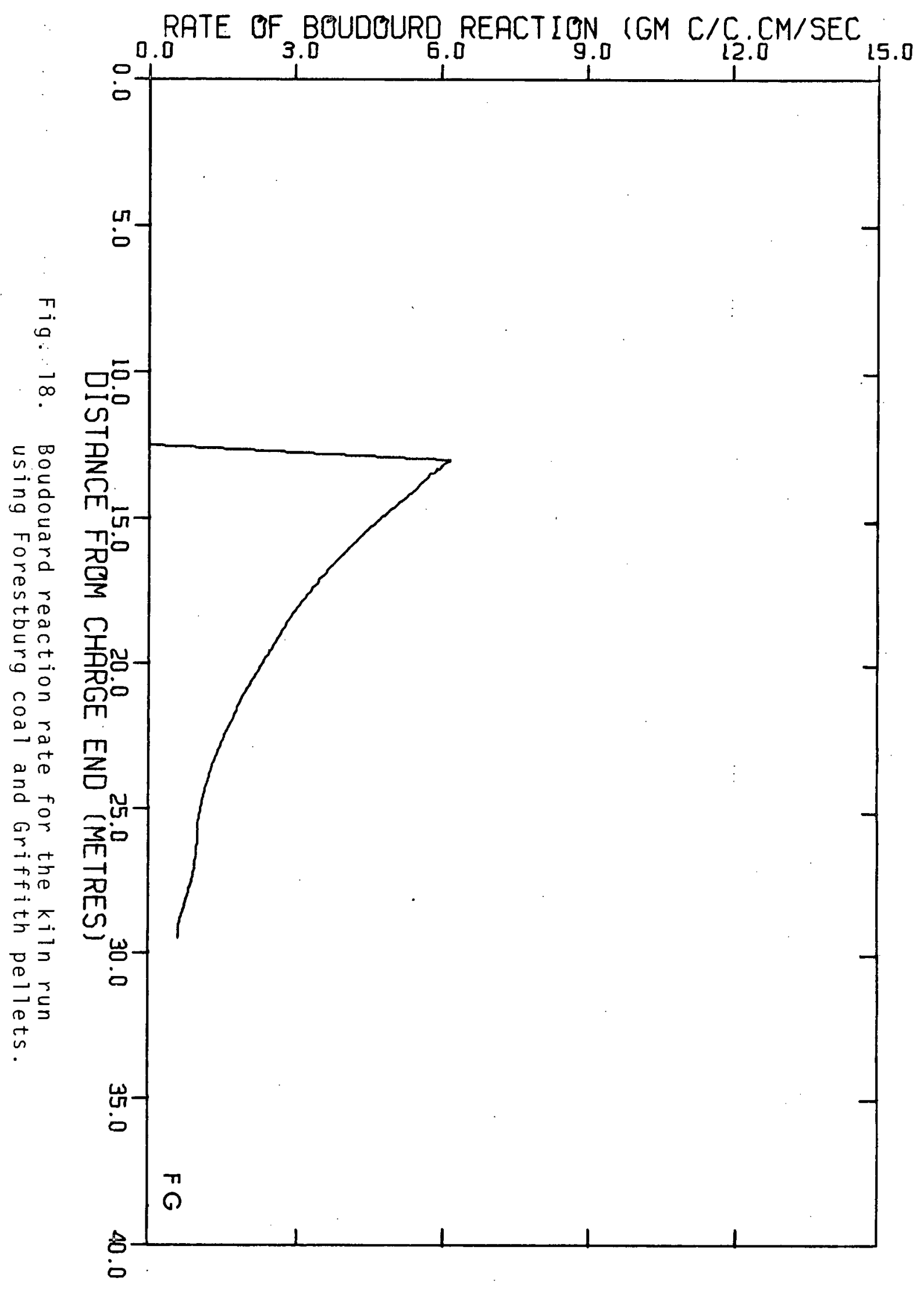




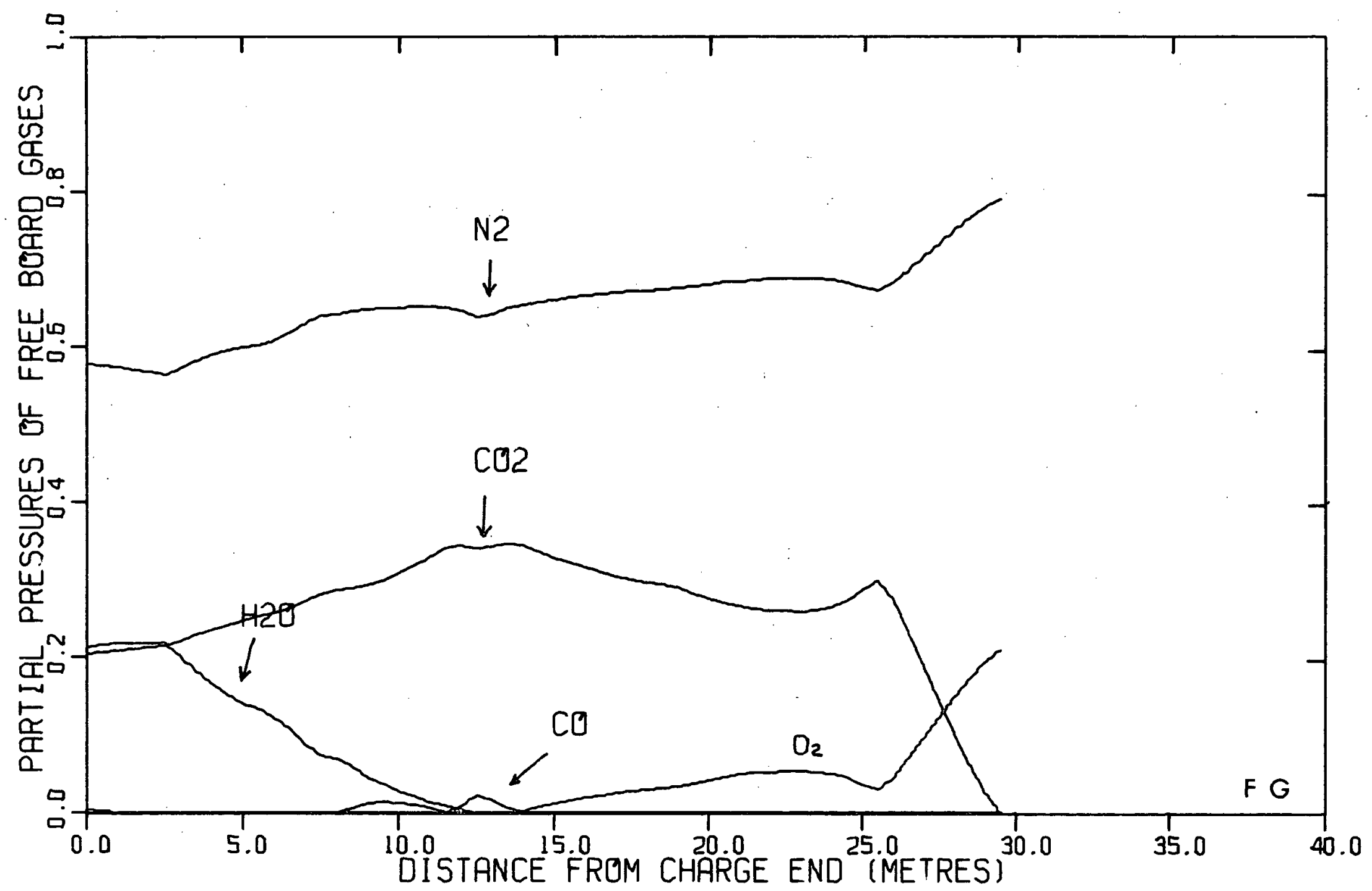

Fig. 19. Freeboard gas composition for the kiln run using Forestburg coal and Griffith pellets. 
believed to be important because it indicates that the co discharging from the bed will be combusted near the surface of the bed rather than at the burner orifice. The flames at the bed surface should enhance heat transfer back to the solids and so assist in maintaining the highly endothermic Boudouard reaction at a satisfactory rate. Without extra heat transfer from the surface flames, it is likely that the bed temperature would drop to a lower level where rates of reduction and carbon gasification would be unacceptably low resulting in poor metallisation. Flames close to the surface of the bed have been observed by kiln operators and can be seen in Fig. 20, which shows a view of the interior of the SL/RN pilot kiln.

Summing up, the mathematical model is able to simulate closely results of the pilot kiln test undertaken with Forestburg coal and Griffith Pellets based on the following comparisons.

1. Solids temperature

2. Shell temperature

3. Length of the kiln

4. Gas composition and gas temperature exiting the kiln

5. Presence of surface flames in the reduction zone

\subsubsection{Lignite Coal and Griffith Pellets}

In order to further test the validity of the model another set of run conditions, conducted on the SL/RN pilot 


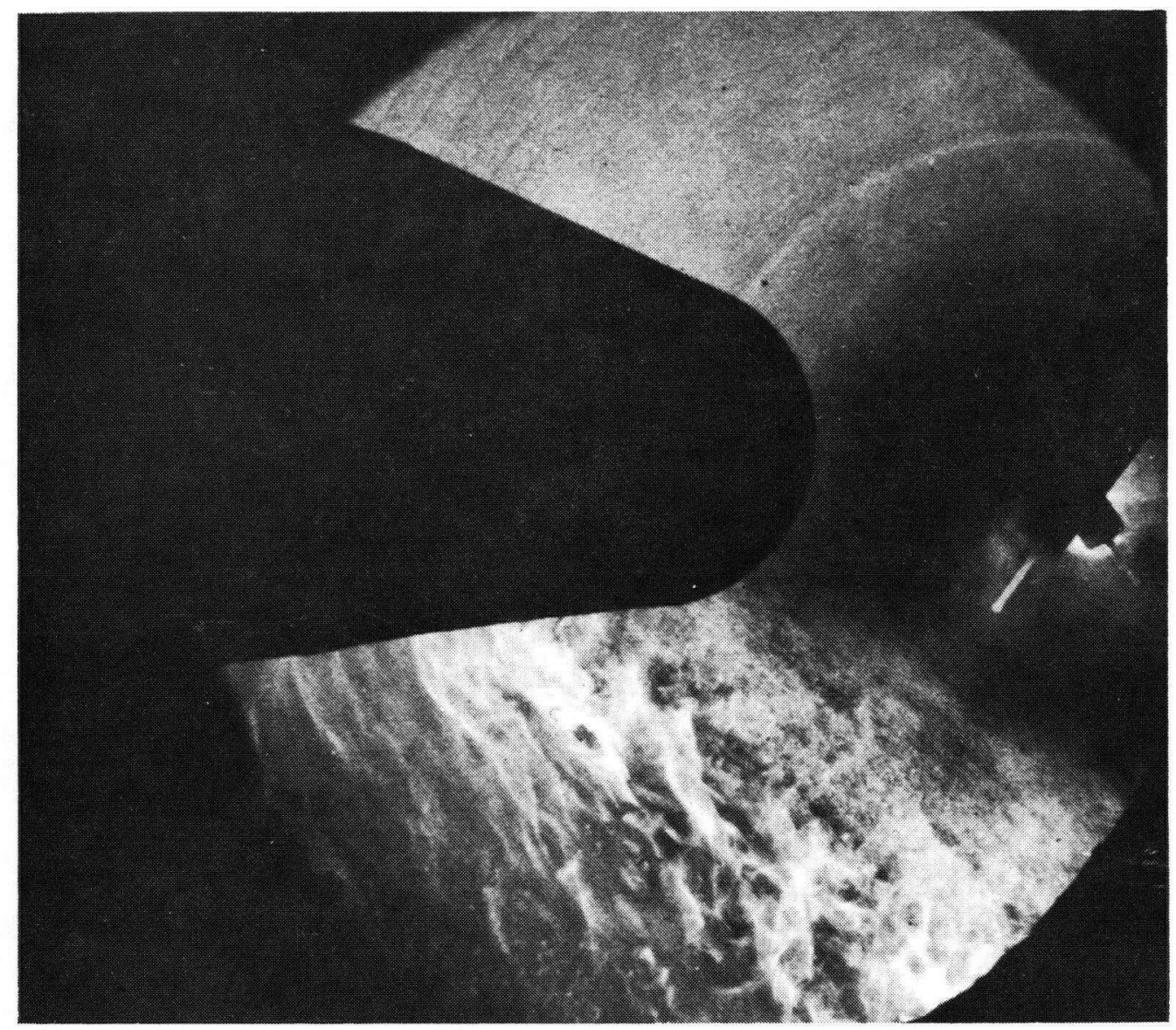

Fig. 20. Interior view of the pilot SL/RN kiln taken from the discharge end. 
kiln [28], was simulated using the model. The coal employed in this campaign was a lignite type from Saskatchewan. The composition of the coal is given in Appendix II. The lignite coal differed slightly from the Forestburg coal in that it contained marginally more water, less fixed carbon and was a little more reactive. The input data for this run are presented in Table 5 .

The air profile for this run is given in Fig. 21. It differs from the profile used in the Forestburg run in that more air is blown into the preheat zone. The extra air in the lignite run was required to combust a higher input of natural gas which was considered necessary to offset the higher water content of the coal. Without the additional supply of natural gas, the larger heat requirement for drying the lignite coal might have extended the length of the preheat zone and thus reduced the maximum achievable solids throughput.

The axial profiles obtained from the model are presented in Figs. 22-26. These results were evaluated in an identical manner to the Forestburg run. Again it was found that the model predictions agreed closely with available experimental measurements. In particular the solids bed temperature profile, shown in Fig. 22, indicated good agreement between measured and calculated values.

The most important difference between the calculated lignite and Forestburg runs was the slightly lower bed temperature determined in the reduction zone for 1 ignite $\left(960^{\circ} \mathrm{C}\right.$ as 
Table 5

Input Data for the Kiln Run Using Lignite Coal and Griffith Pellets

$\begin{array}{ll}\text { Ore - Griffith Pellets } & 179.8 \text { tons/day } \\ \text { Coal - Lignite } & 138.5 \text { tons/day } \\ \text { Dolomite } & 5.5 \mathrm{tons} / \text { day } \\ \text { Air (total) } & 54675 \mathrm{ft}^{3} / \text { ton ore } \\ \text { Natural gas } & 1160 \mathrm{ft}^{3} / \text { ton ore } \\ \text { Degree of reduction (total) } & 92 \% \\ \text { Hydrogen pre-reduction } & 8 \% \\ \text { Exit solids temperature } & 925^{\circ} \mathrm{C} \\ \text { Solids degree of fill } & 25 \%\end{array}$




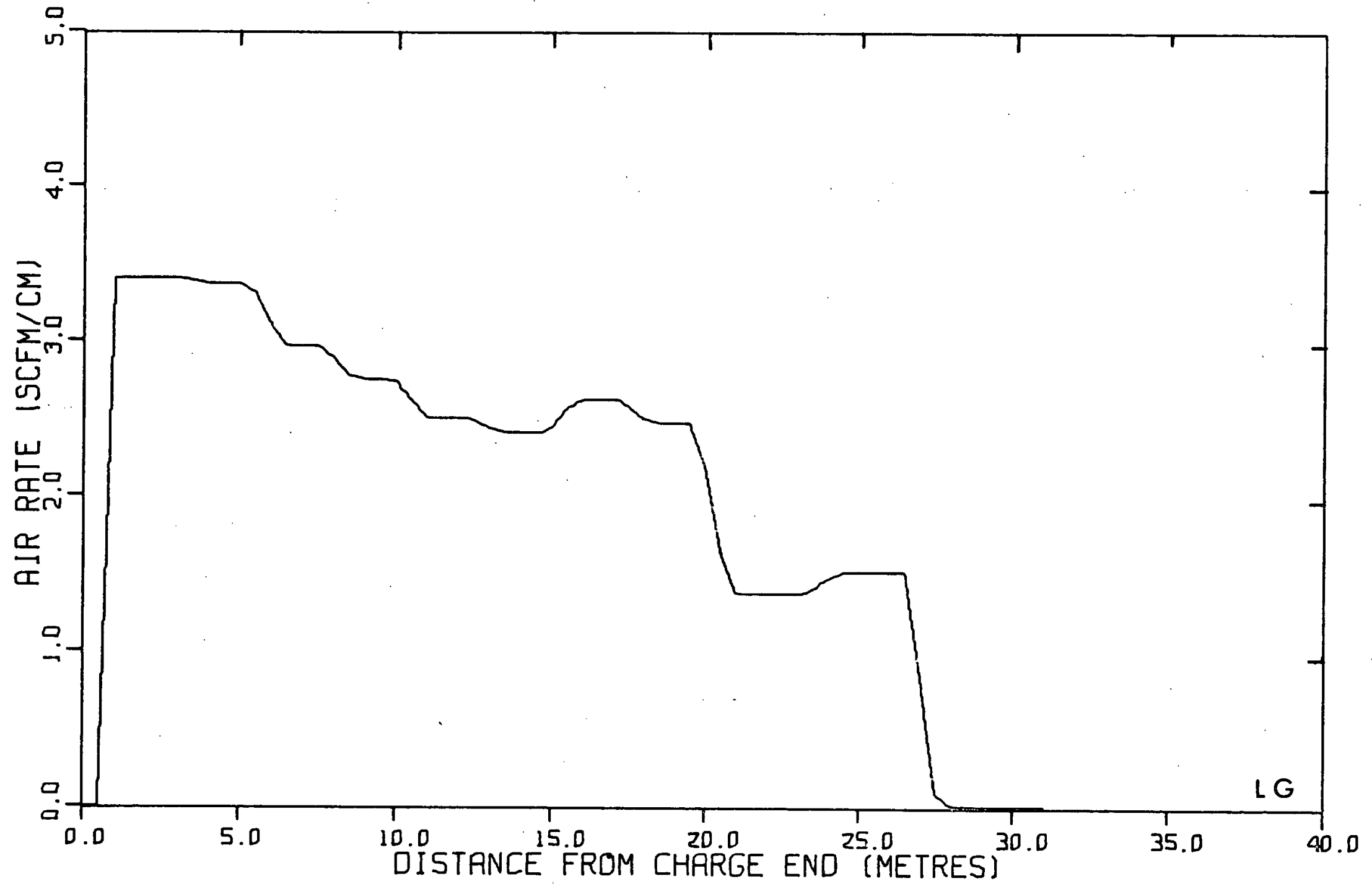

Fig. 21.. Air profile for the kiln run using iignite 


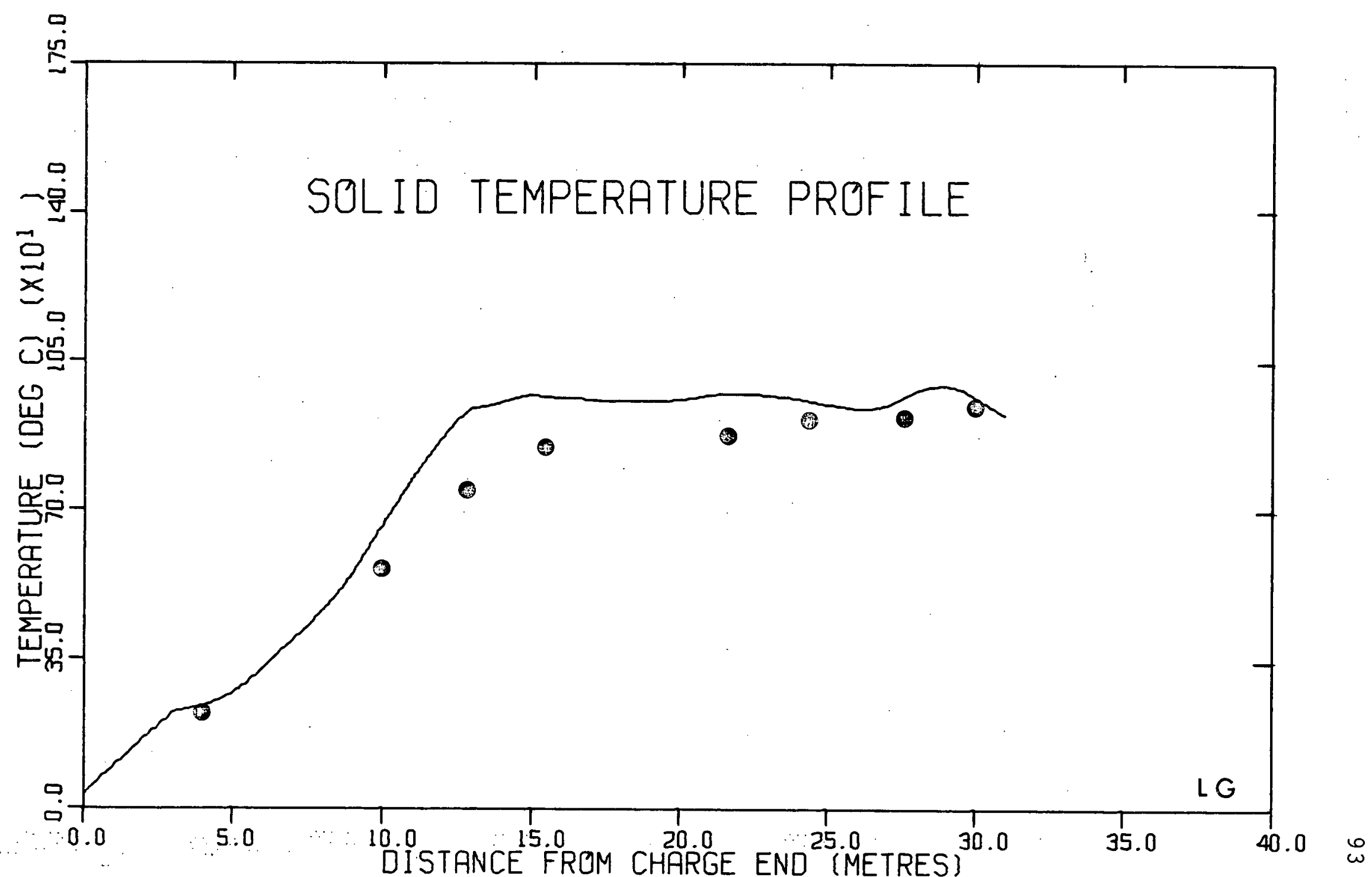

Fig. 22. Solids temperature profile for the kiln run using lianite coal and Griffith 


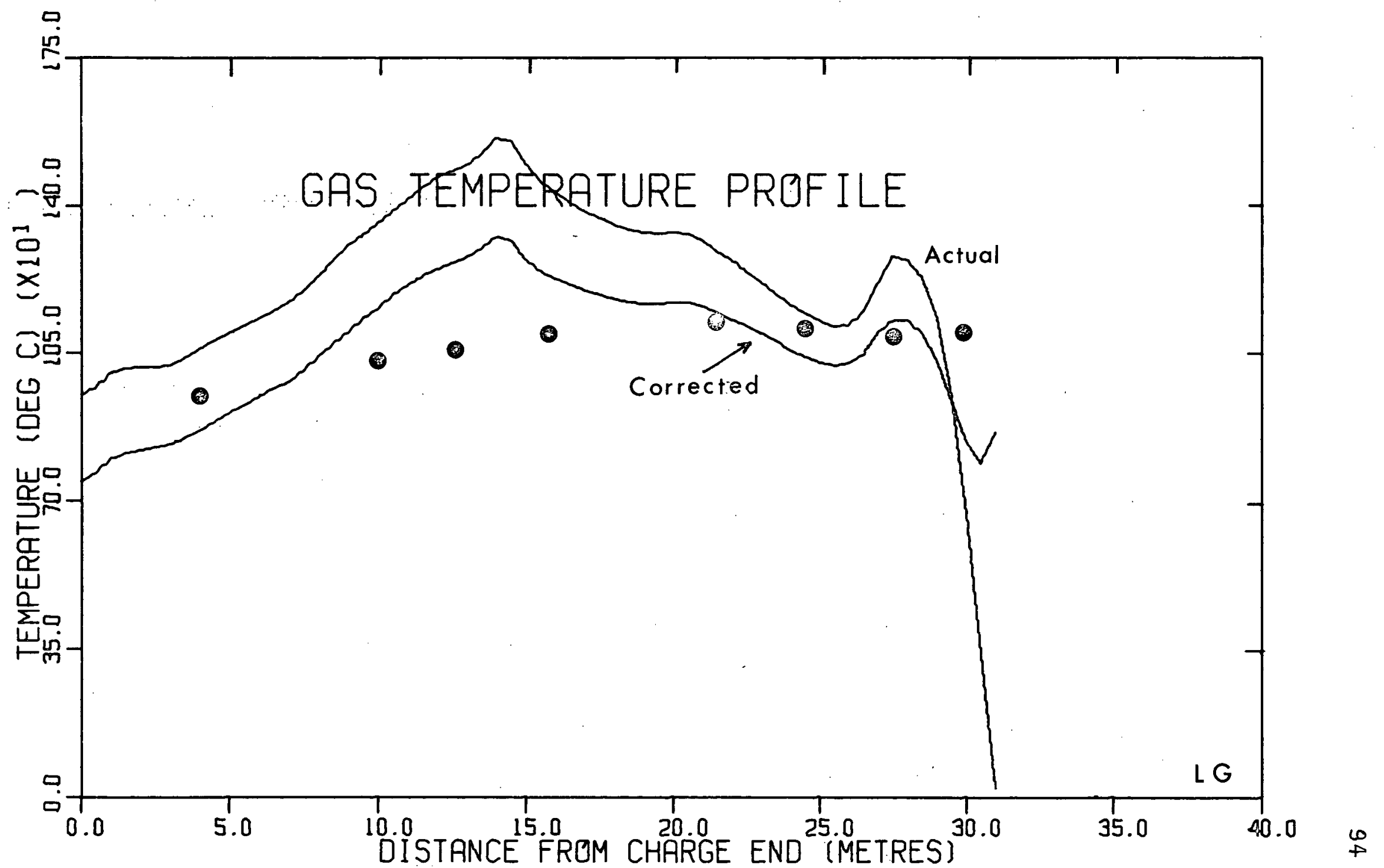

Fig. 23. Gas temperature profile for the kiln run using lignite coal and Griffith pellets. 


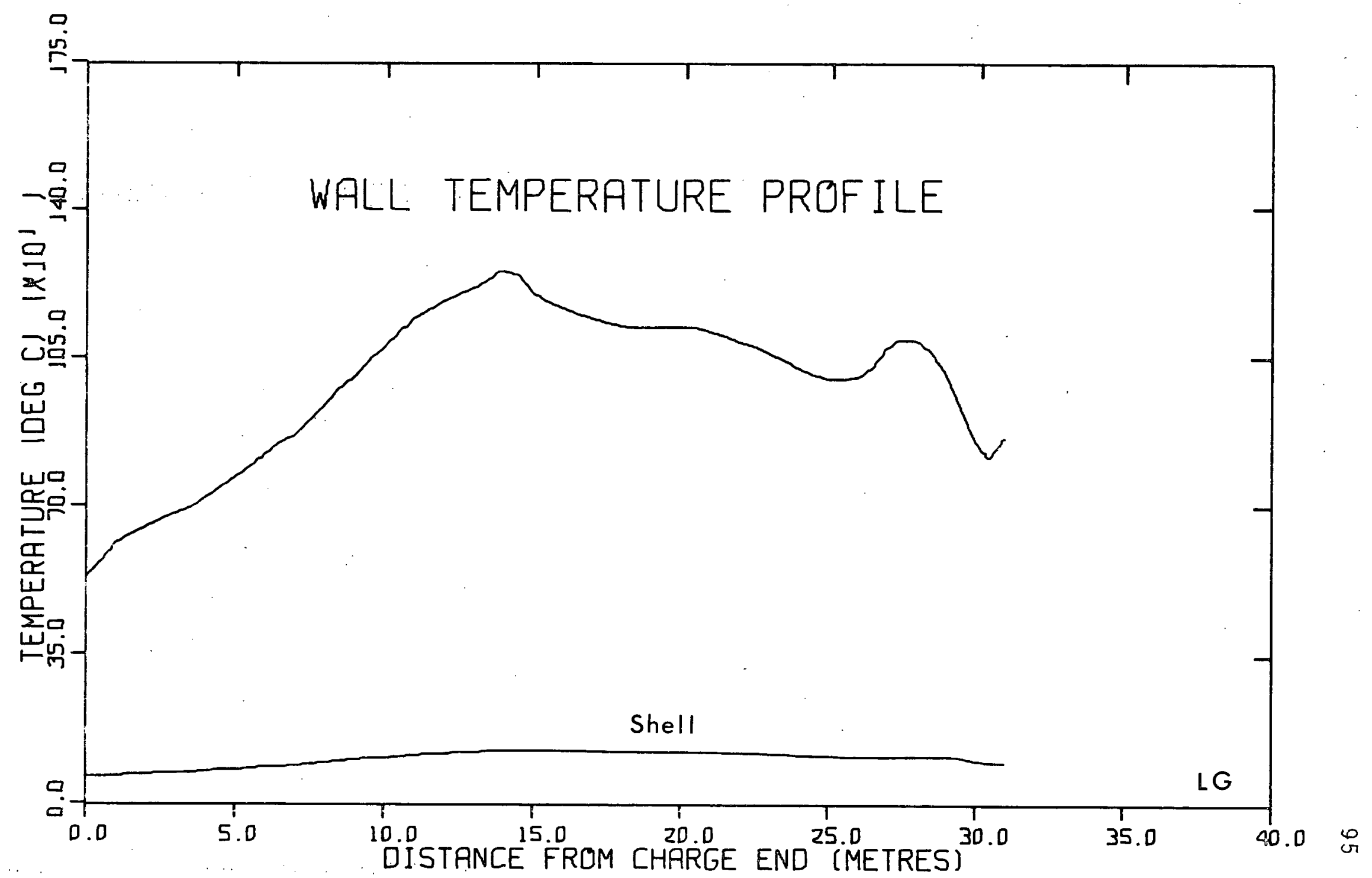

Fig. 24. Inner wall and outer shell temperature profiles for the kiln run usina 1 iqnite coal and Griffith pellets. 


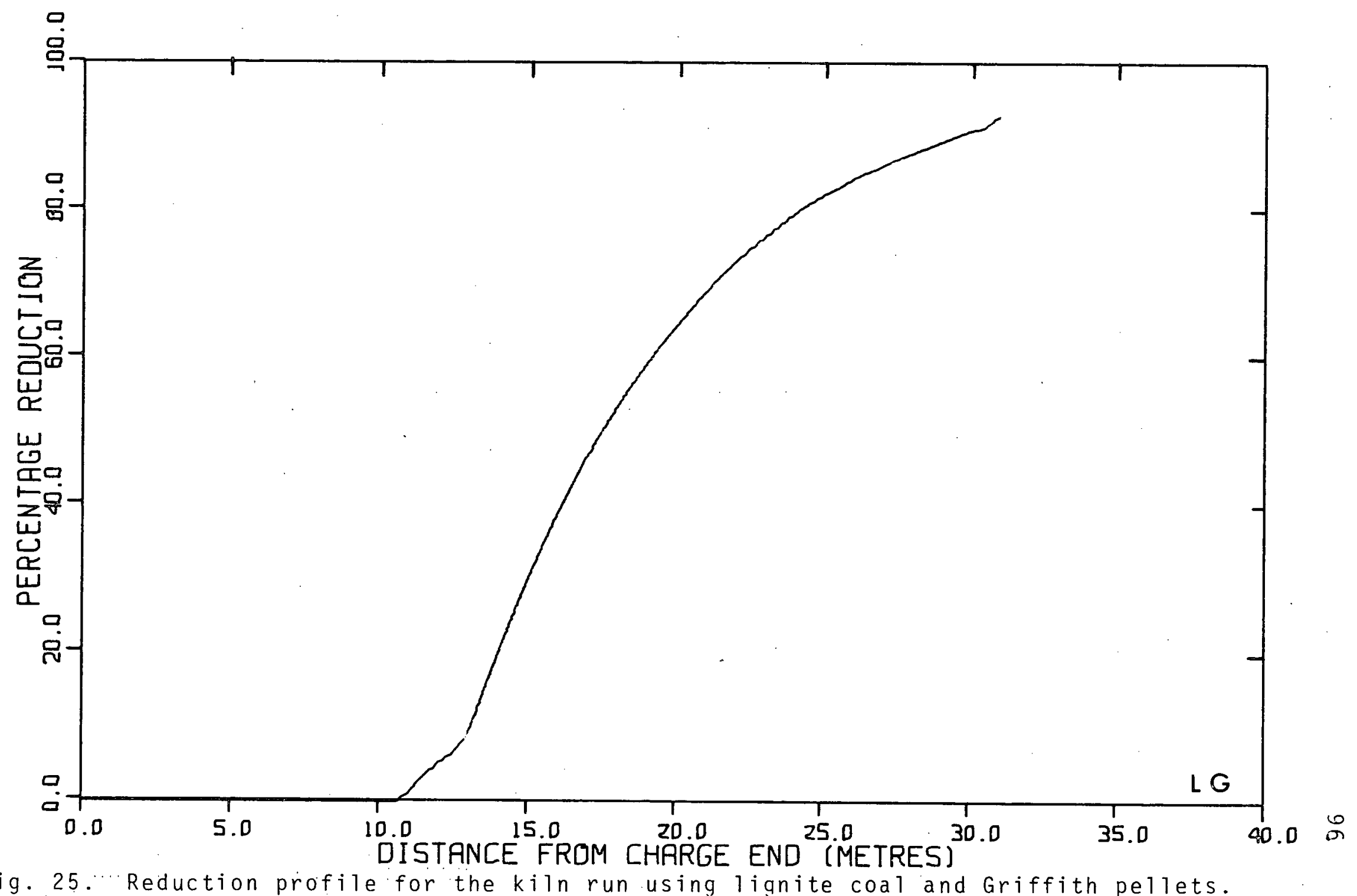

Fig. 25. . Reduction profile for the kiln run using lignite coal and Griffith pellets. 


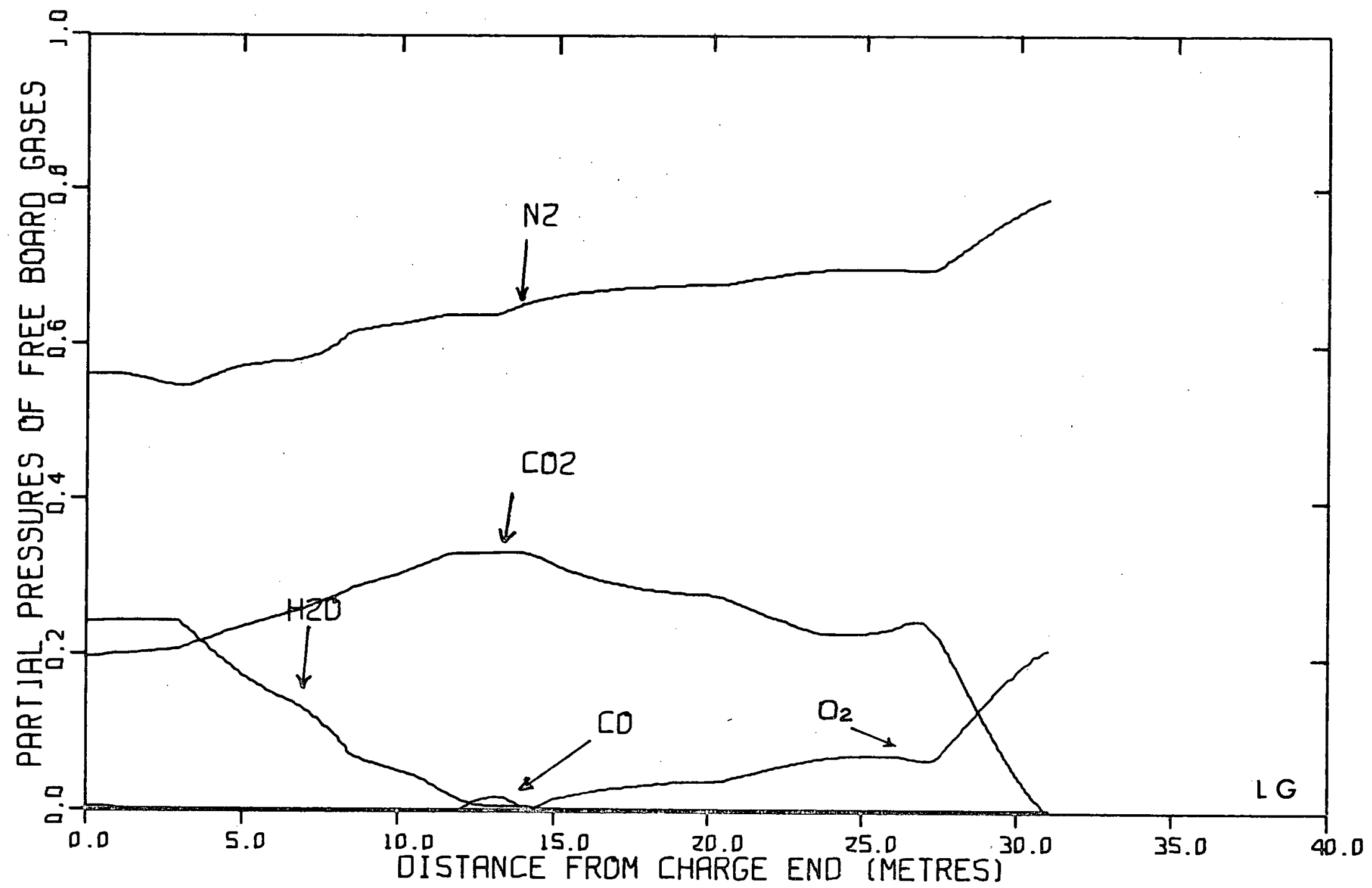

Fig. 26. Freeboard gas composition for the kiln run using lignite coal and friffith pellets. 
compared to $990^{\circ} \mathrm{C}$ ). This result is directly attributable to the higher reactivity of the lignite coal. All other points discussed in the previous section apply equally to this run.

\subsection{Predicted Influence of Operating Variables on Kiln Performance}

Having passed successfully through the evaluation stage, the model was next run in a predictive mode. That is, the model was run under a variety of operating conditions that have not been explored experimentally or fully characterized in order to examine the influence of different variables on the kiln performance. Included in the 1 ist of variables investigated are degree of reduction achieved, throughput, coal reactivity, pellet reducibility, natural gas injection and dust in the freeboard gas (through a change in the gas emissivity). The results of the model predictions are presented in this section.

One of the major difficulties that arose in this stage of the investigation was the isolation of the effect of a single variable on the kiln operation. Because the process involves closely coupled heat and material exchange steps it was found to be virtually impossible to change one variable without seriously upsetting a stable kiln operation. For example, a change of throughput without a corresponding adjustment in the air profile gave rise to inoperable performance, e.g. a very low bed temperature. For this reason in many of 
the cases discussed, one or more variables may have been changed simultaneousiy.

\subsubsection{Effect of Degree of Reduction Achieved}

In order to study the effect of a higher degree of reduction achieved, a run was undertaken with a charge consisting of Forestburg coal and Griffith pellets. The input conditions for this case are given in Table 6 . The conditions are identical to the previous Forestburg run except for the higher degree of reduction effected here, $95 \%$. It should be noted that in order to obtain stable conditions it was necessary to alter the original air profile in that the air rate through the end burner was reduced from 300 to $150 \mathrm{cfm}$. The air profile employed in this run is given in Fig. 27. The results computed from the model are presented in Figs. 28 and 29 . It can be seen that the length of $k i$ in required to achieve a $95 \%$ reduction is $32.5 \mathrm{~m}$, as compared to $30.0 \mathrm{~m}$ for the case of $92 \%$ reduction. If the length of kiln is fixed this means that the throughput must be decreased for a higher degree of reduction. It should be pointed out that it is not economical to go to reductions much higher than $92 \%$ because the rate of reduction drops off exponentially with increasing reduction. In addition reductions beyond $95 \%$ are not practicable because it leads to problems in processing the pellets in the electric arc furnace. 
Table 6

Input Data for the Kiln Run Using Forestburg

Coal and Griffith Pellets with a Degree

of Reduction of $95 \%$

Ore - Griffith Pellets

Coal - Forestburg

Air (total)

Natural gas

Degree of reduction (total)

Hydrogen pre-reduction

Exit solids temperature

Solids degree of fill
191.8 tons/day

129.9 tons/day

$52540 \mathrm{scft} / \mathrm{t}$ of ore

$676 \mathrm{scft} / \mathrm{t}$ of ore

$95 \%$

$8 \%$

$1000^{\circ} \mathrm{C}$

$25 \%$ 


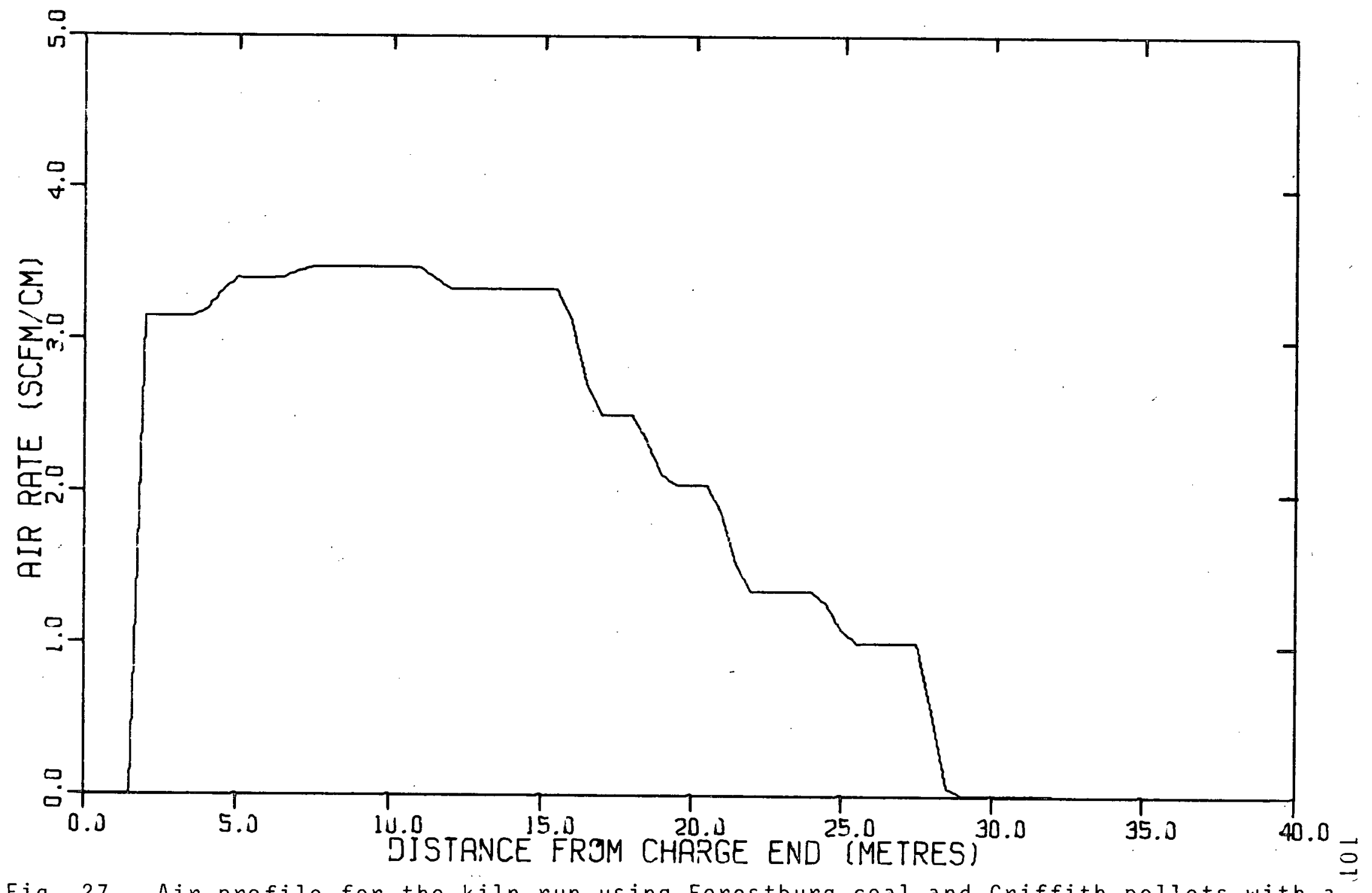

Fig. 27. Air profile for the kiln run using Forestburg coal and Griffith pellets with a degree of reduction of $95 \%$. 


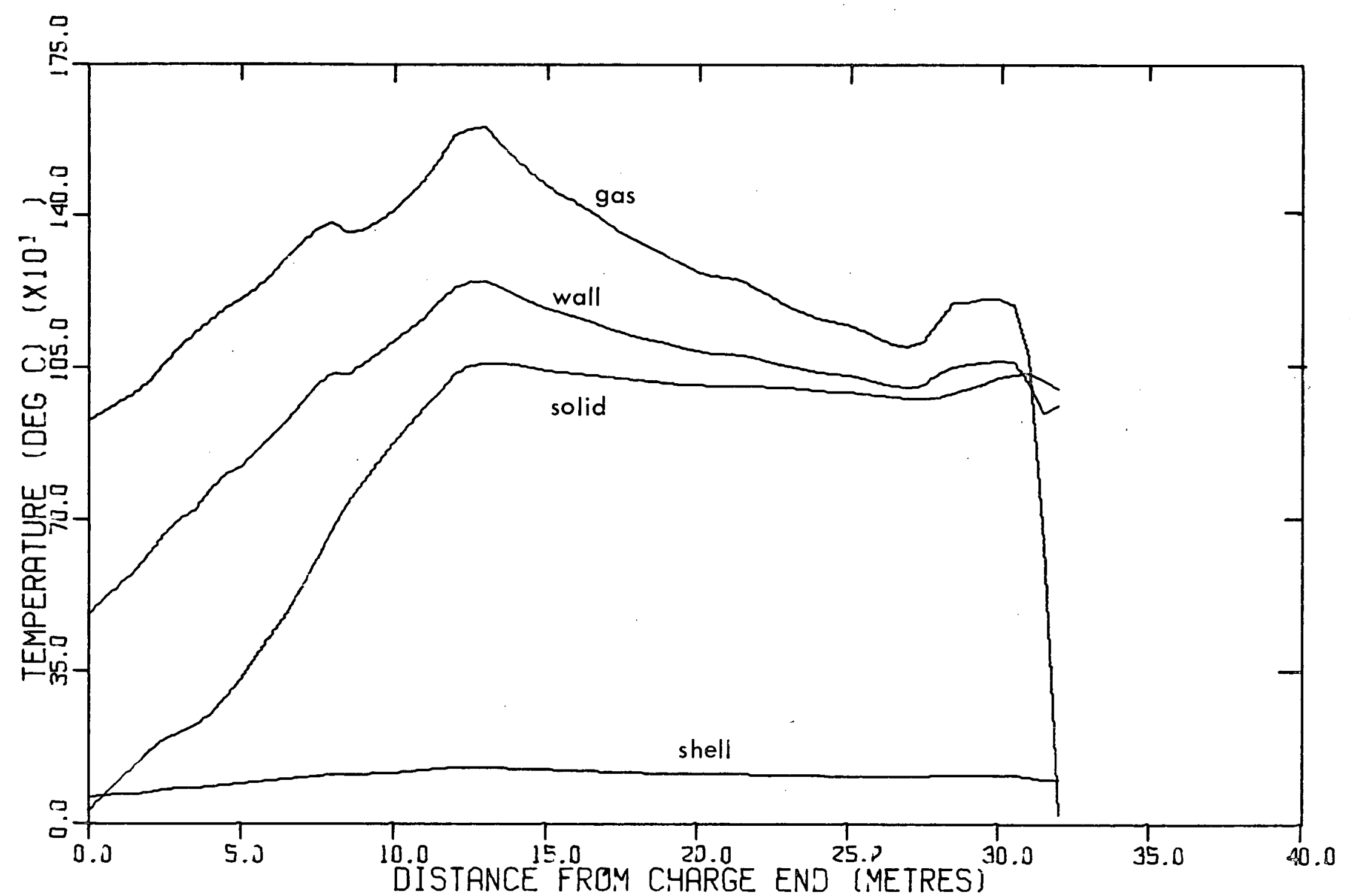

Fig. 28. Solids, gas, inner wall and outer shell temperature profiles for the kiln run using Forestburg coal and Griffith pellets with a degree of reduction of $95 \%$. 
กิ

.

$0.0 \quad 20.0$ PERCENTAGE REDUCTIOS

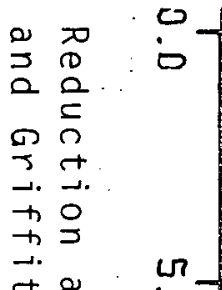

$\stackrel{+}{7} \stackrel{0}{5}: 0$

뭉

$=\frac{D}{2}$

+0
+10
1

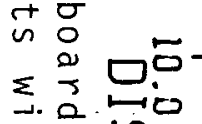

$\stackrel{+}{5} \frac{1}{7}$

o i $D_{2}$

ก。

回

गें

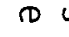

우 $\stackrel{+}{3}$

का

$\overbrace{0}^{\circ} \stackrel{0}{3} \stackrel{\Omega}{I}$

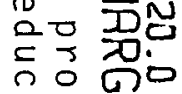

t. $m$

음

in

-

o

아

穴

इ

ᄃ

$\approx \quad 0$

a

$\pi$

त)

$+0$

5

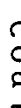

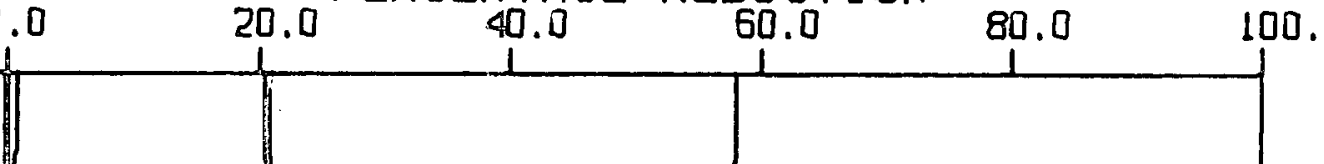

8 


\subsubsection{Effect of Throughput}

Again the original Forestburg run has been used as a base case to evaluate the influence of solids throughput. The data for this run are given in Table 7 . In the present run the ore throughput has been increased by $30 \%$ from 190.8 tons/day to 249.4 tons/day. In this run it has also been necessary to alter the air profile as seen in Fig. 30 , to maintain similar temperature conditions. The results obtained from the mathematical model for these conditions are given in Figs. 31 and 32 . The calculations showed that the increased throughput resulted in an increase of $5 \mathrm{~m}$ in the reduction zone and $1.5 \mathrm{~m}$ in the preheat zone. This is an expected result since the thermal burden in the reduction zone is much higher than in the preheat zone because of the endothermic Boudouard reaction. other features of this run look similar to the original Forestburg run.

\subsubsection{Effect of Lower Coal Reactivity}

A run was undertaken to study kiln behaviour when the coal being charged was of a considerably higher rank, e.g. anthracite coal, which also has a considerably lower reactivity value. Referring back to Table 1 anthracite coal can be seen to have a reactivity that is three orders of magnitude less than that of the Forestburg (sub-bituminous) coal. The input parameters for this run are 1 isted in Table 8 and the air 
Table 7

Input Data for the Kiln Run Using Forestburg Coal and Griffith Pellets with a $30 \%$ Higher Throughput

Ore - Griffith Pellets

Coal - Forestburg

Dolonite

Air $(\operatorname{total})$

Natural gas

Degree of reduction

Hydrogen pre-reduction

Solids degree of fill
249.36 tons/day

168.96 tons/day

0.0

$50100 \mathrm{scft} / \mathrm{ton}$ ore

$578 \mathrm{scft} / \mathrm{ton}$ ore

$92 \%$

$8 \%$

$25 \%$ 


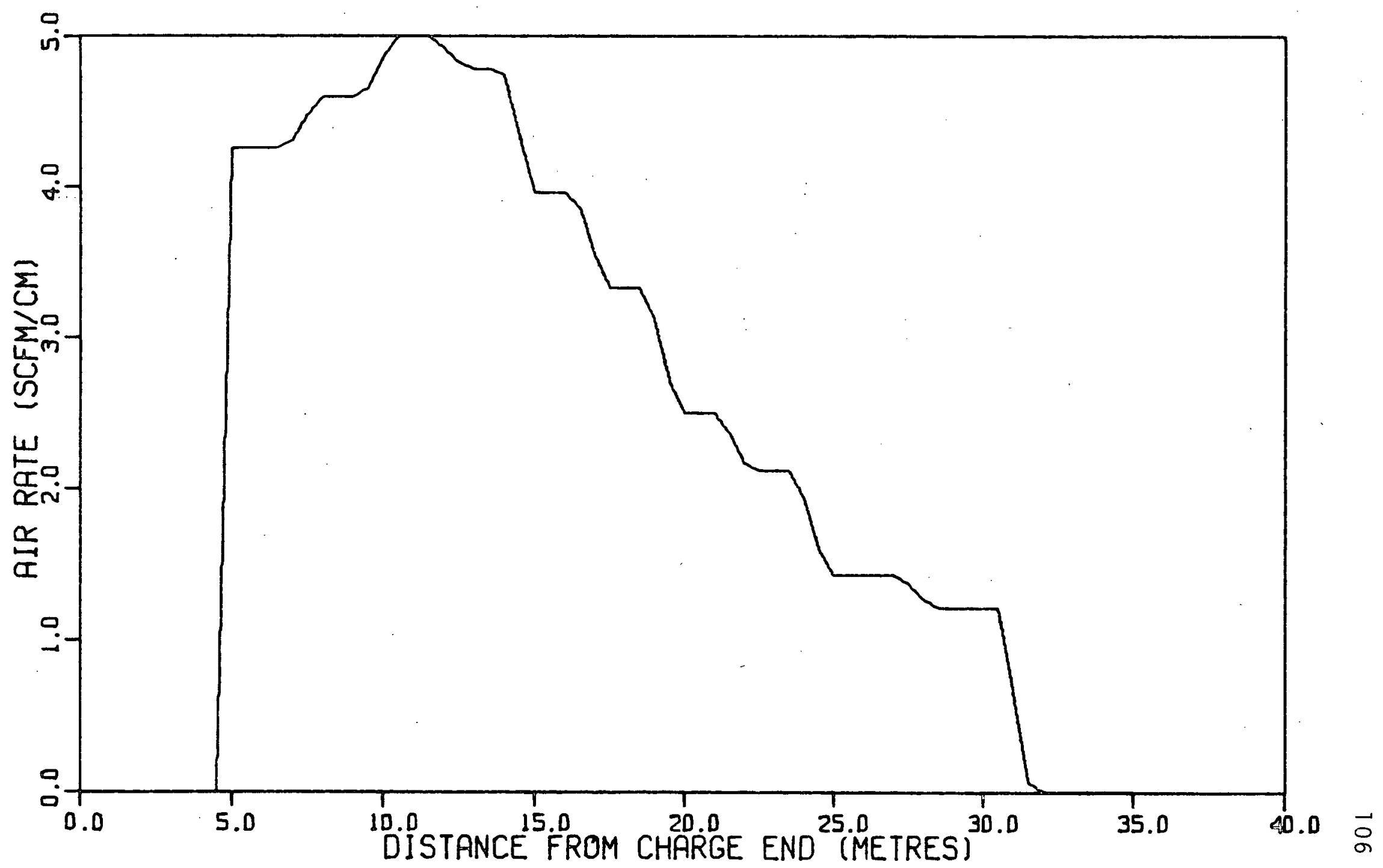

Fig. 30. Air profile for the kiln run using Forestburg coal and Griffith pellets with a $30 \%$ higher throughput. 


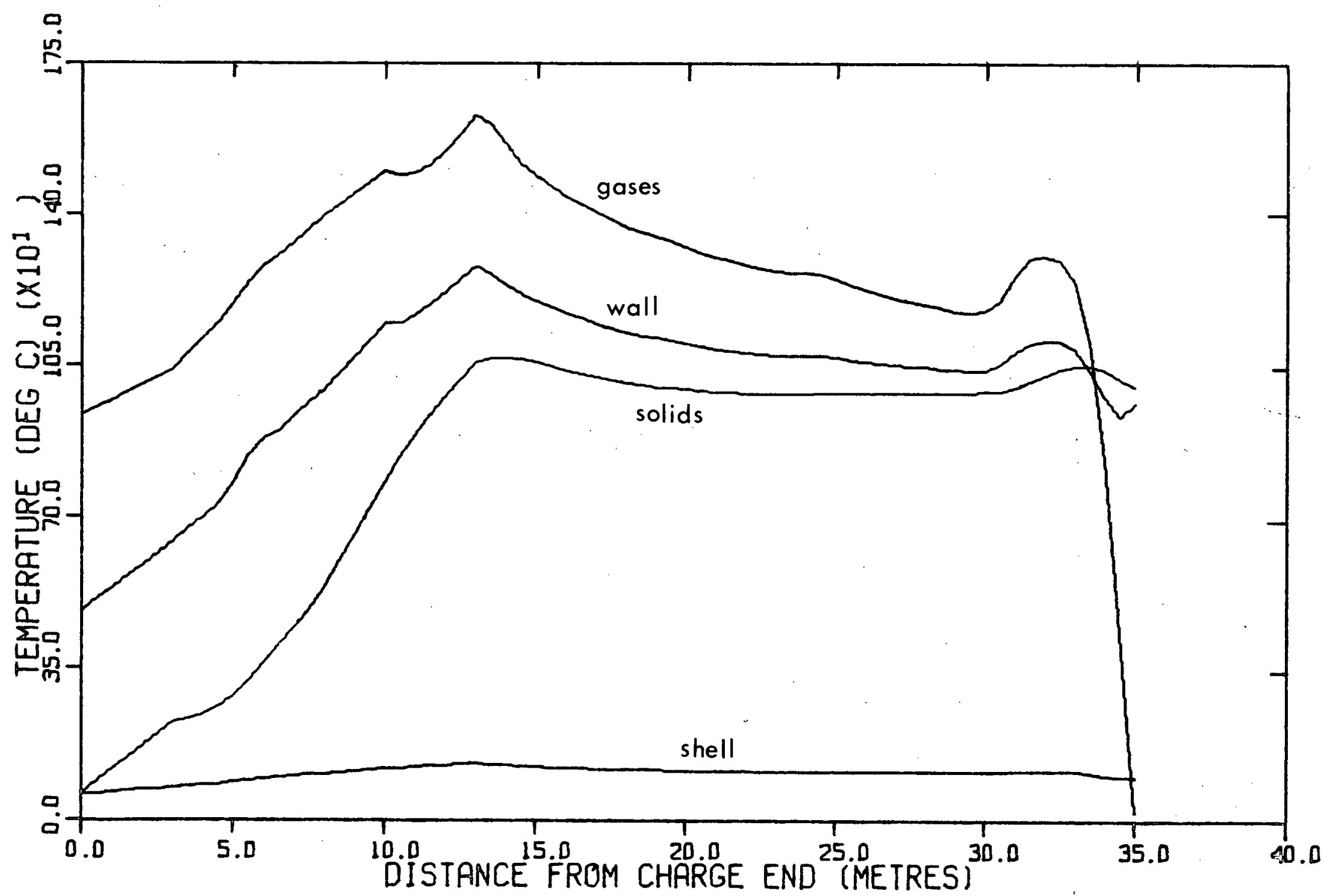

Fig. 31. Solids, gas, inner wall and outer shell temperature profiles for the kiln run using Forestburg coal and Griffith pellets with a $30 \%$ higher throughput. 
profile is given in Fig. 33. The results from the model are presented in Figs. 34 and 35 . The rost striking feature of the model-predictions is the high temperature of the solids bed in the reduction zone $\left(1080^{\circ} \mathrm{C}\right)$ as compared to the original Forestburg run $\left(990^{\circ} \mathrm{C}\right)$. This finding agrees well with observations made during limited pilot kiln trials employing anthracite coal and Griffith pellets. The high solids temperature is a direct consequence of the low coal reactivity, and is required to maintain the Boudouard reaction at a sufficiently high rate to ensure reasonable metallisation. Another important result worth noting is the length of the reduction zone relative to the preheat zone. From Fig. 34 , the reduction zone can be seen to occupy a much longer fraction of the kiln $(21.5 \mathrm{~m})$ as compared to $17 \mathrm{~m}$ in the Forestburg run. That the preheat zone in the anthracite case is shorter is a direct result of a higher feed rate of natural gas. In making these comparisons it should be borne in mind that the maximum achievable throughput found with anthracite coal is considerably lower than in the case of the Forestburg coal. Again this result is confirmed by the pilot kiln trials. It should be noted that since the ash softening temperature [11] of the anthracite $\operatorname{coa} 1\left(1260^{\circ} \mathrm{C}\right)$ is much higher than that of Forestburg coal $\left(1040^{\circ} \mathrm{C}\right)$, operating the kiln at the higher solids bed temperature in this case does not pose any accretion problems. 
Table 8

Input Data for the Kiln Run Using Anthracite Coal and Griffith Pellets

Ore - Griffith Pellets

Coal - Anthracite

Dolomite

Air (total)

Natural gas

Degree of reduction (total)

Hydrogen pre-reduction

Solids degree of fill
128.16 tons/day

69.12 tons/day

4.32 tons/day

$56190 \mathrm{scft} / \mathrm{ton}$ ore

$2135 \mathrm{scft} / \mathrm{ton}$ ore

$92 \%$

$0 \%$

$20 \%$ 


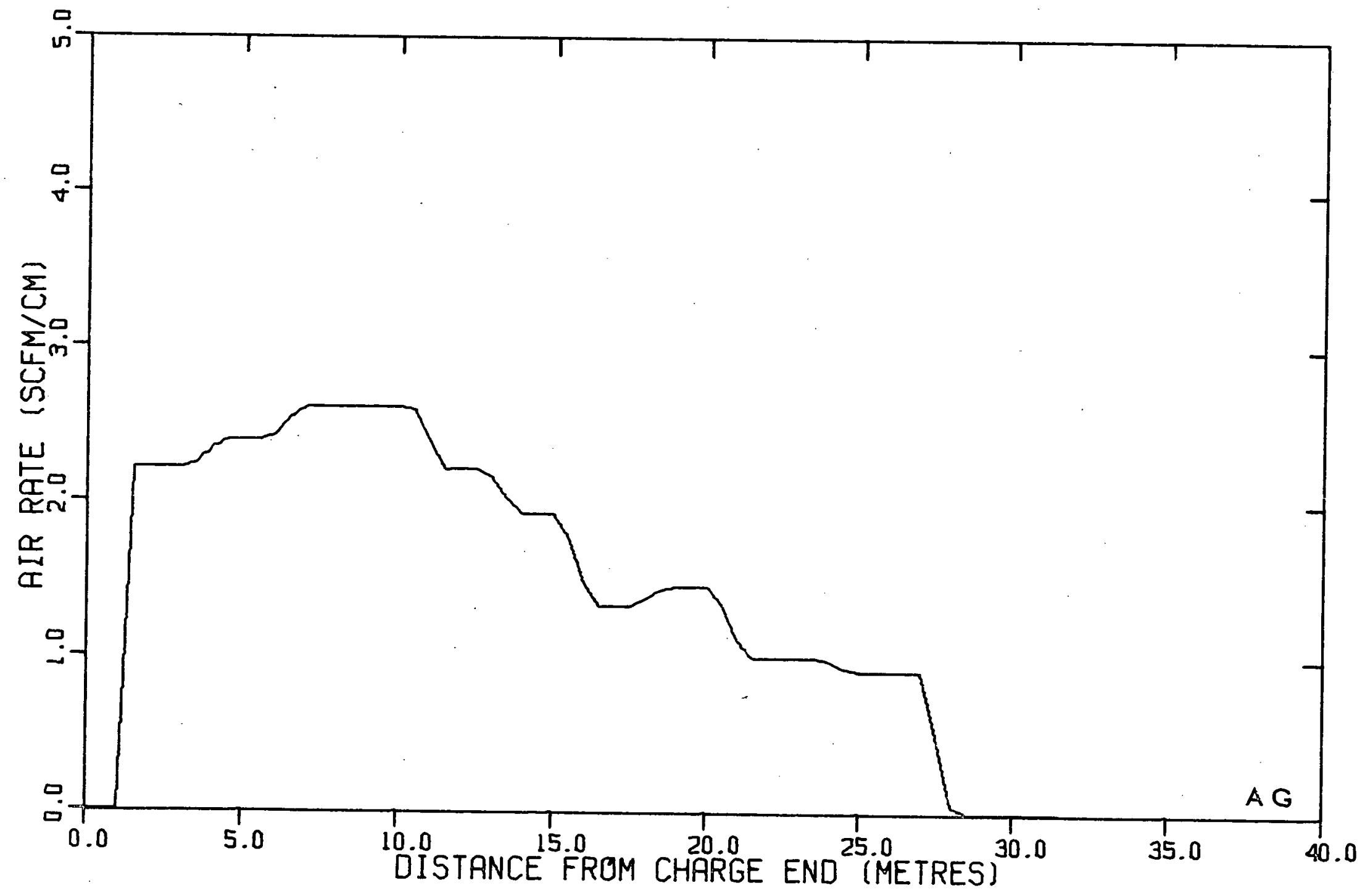

Fig. 33. Air profile for the kiln run using anthracite coal and Griffith pellets. 


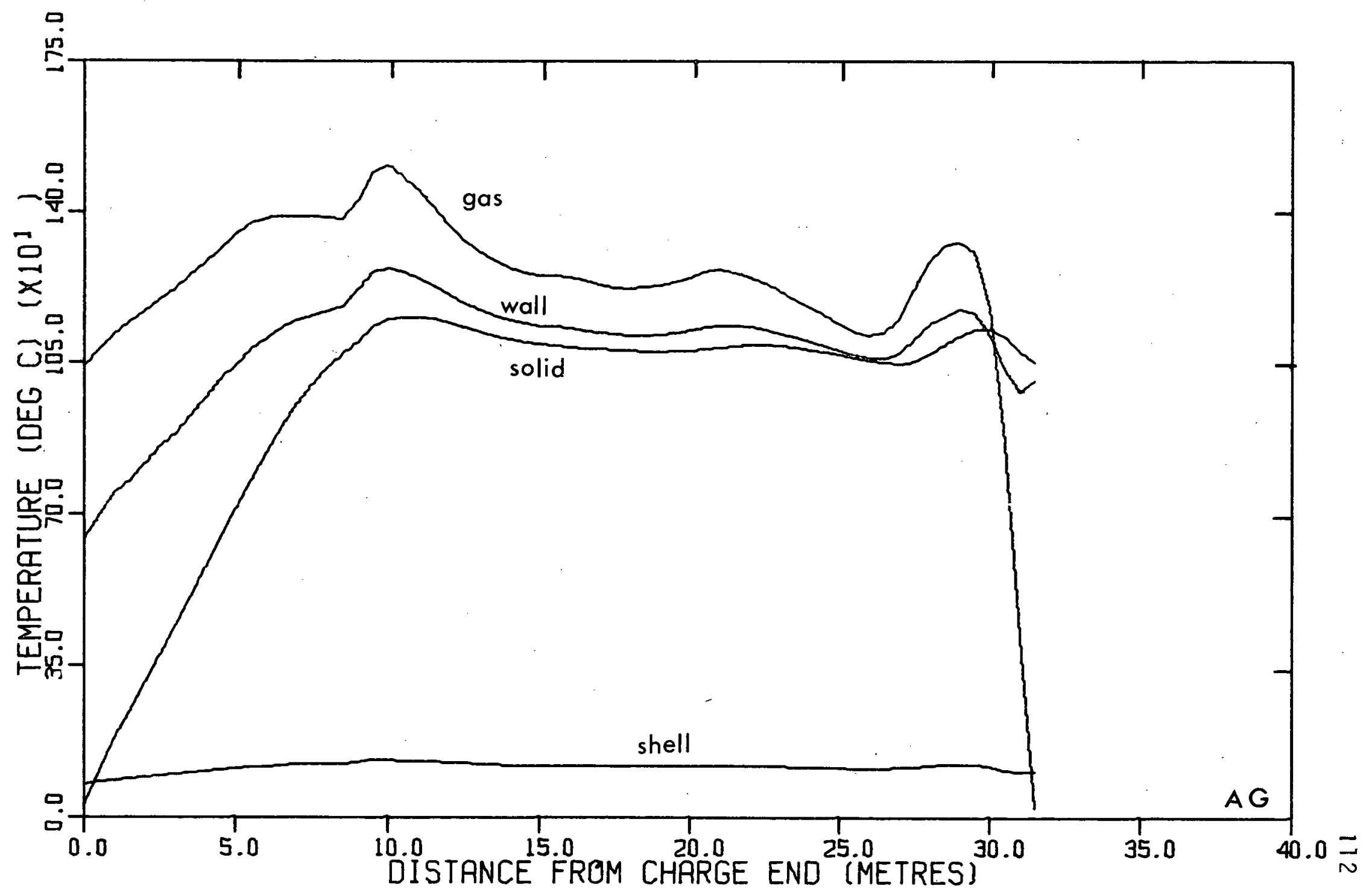

Fig. 34. Solids, gas, inner wall and outer temperature profiles for the kiln run using anthracite coal and Griffith pellets. 


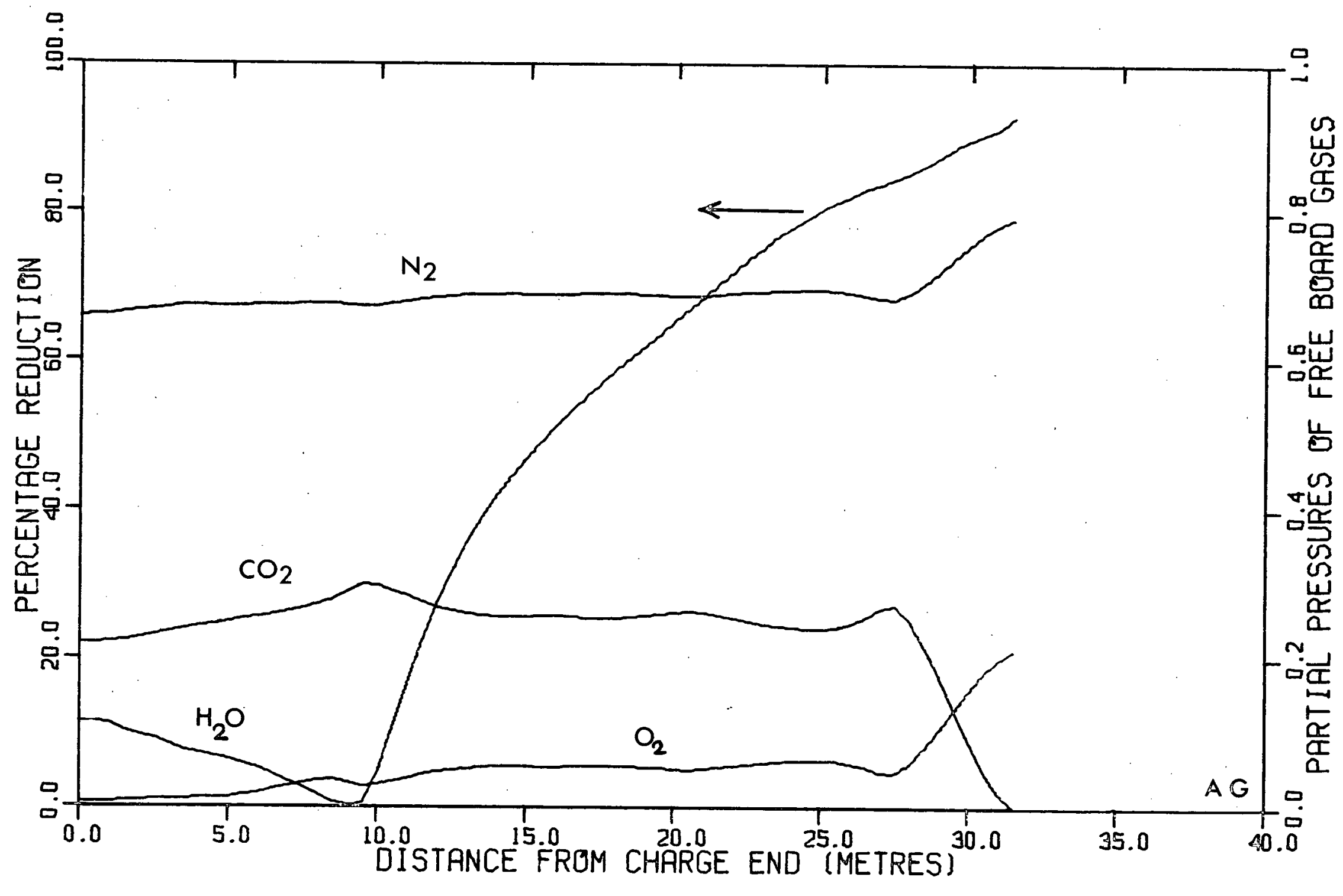

Fig. 35. Reduction and freeboard qas composition profiles for the kiln run using anthractie coal and Griffith pellets. 


\subsubsection{Effect of Pellet Type}

The influence of pellet type on kiln operation can be investigated with the model by adjusting the pellet reducibility factor. In this run, this parameter was changed to correspond to Falconbridge pellets, which are more easily reduced than Griffith pellets. Details regarding ore reducibility are given in Appendix II. The input data for this run are presented in Table 9. The air profile was again adjusted to give a stable operation as seen in Fig. 36 . Figs. 37 and 38 show the model-predicted profiles. The most important feature of this run was the lower temperature of the solids bed (Fig. 37) compared to the Griffith pellets case (Fig. 14). This was accompanied by a lower predicted length of the kiln $(28.5 \mathrm{~m})$. Once again, this means that when operating with this charge it should be possible to increase the throughput in a kiln of fixed length while maintaining a high degree of reduction. Because of the lower wall temperature, this will result in smoother kiln operation with lesser accretion problems.

\subsubsection{Effect of Natural Gas}

Natural gas is injected into the preheat zone of the SL/RN kiln as an auxiliary heat source to enhance heat transfer to the solids. The rate of natural gas injection into the kiln depends on the type of charge employed. It has already been seen that a much higher rate of natural gas was utilized in 
Table 9

Input Data for the Kiln Run Using Forestburg Coal and Falconbridge Pellets

Ore - Falconbridge pellets

Coal - Forestburg

Air (total)

Natural gas

Degree of reduction (total)

Hydrogen per-reduction

Exit solids temperature

Solids degree of fill
191.8 tons/day

129.9 tons/day

$49375 \mathrm{scft} / \mathrm{ton}$ ore

$676 \mathrm{scft} / \mathrm{ton}$ ore

$92 \%$

$8 \%$

$900^{\circ} \mathrm{C}$

$20 \%$ 


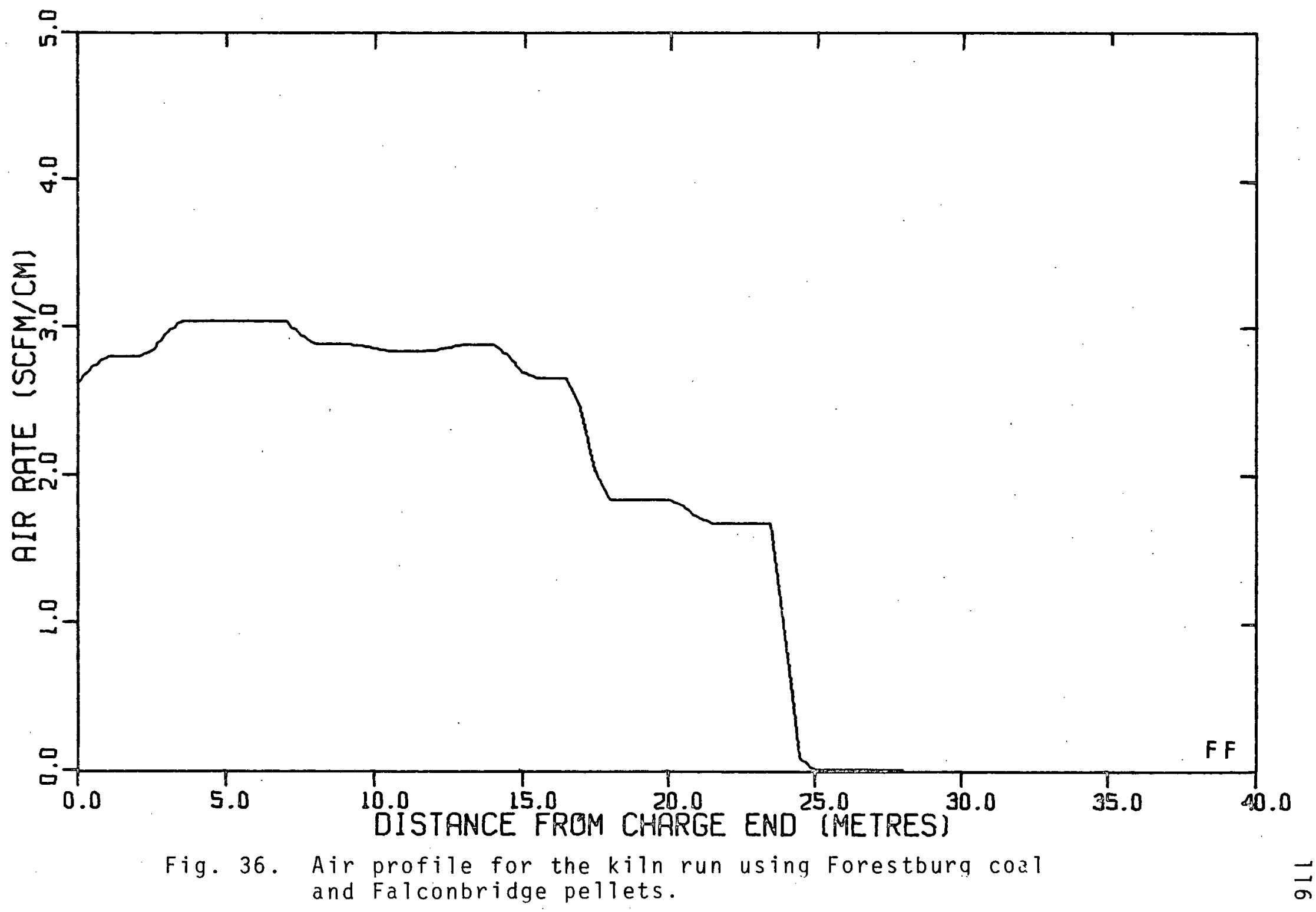




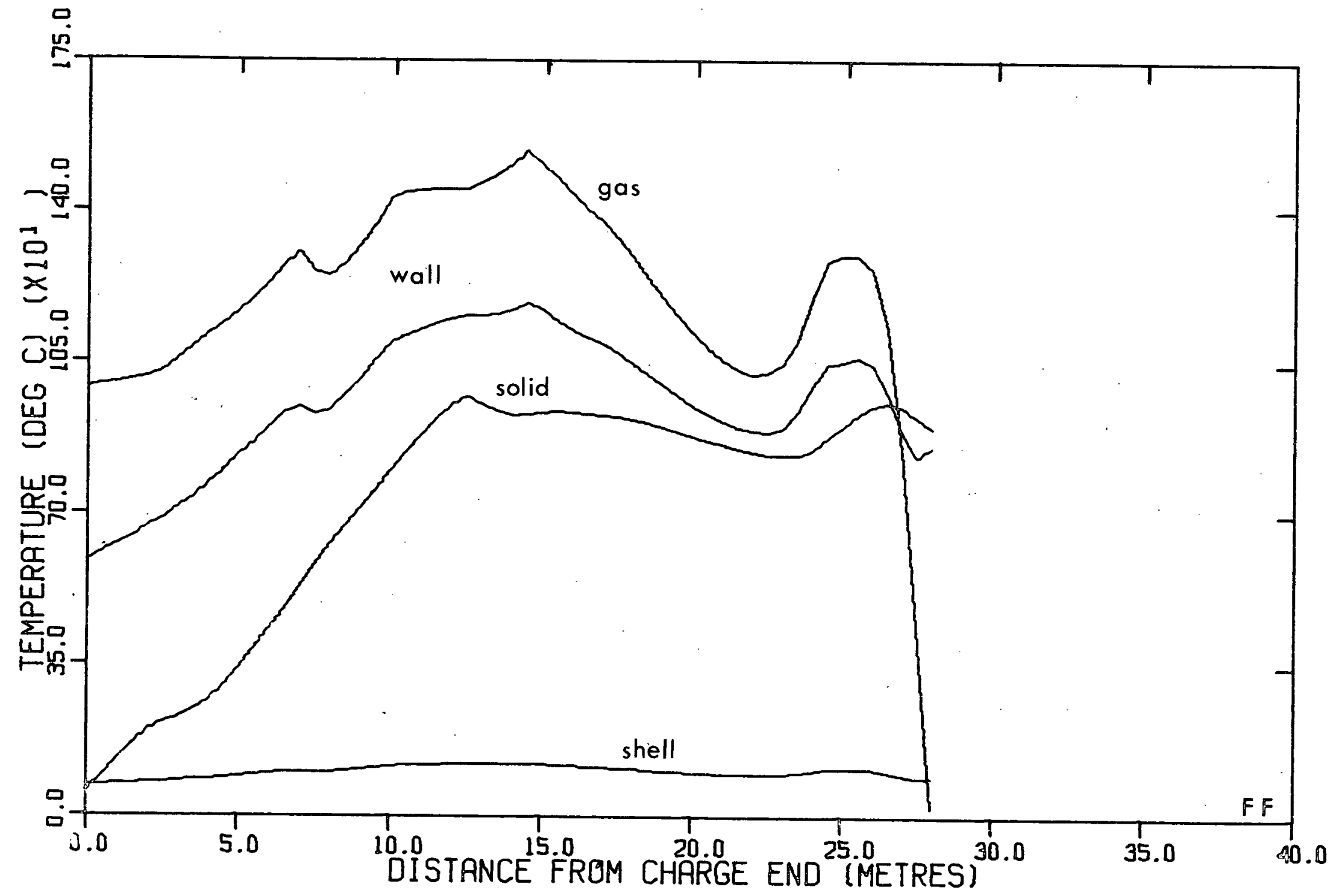

Fig. 37. Solids, gas, inner wall and outer shell temperature for 


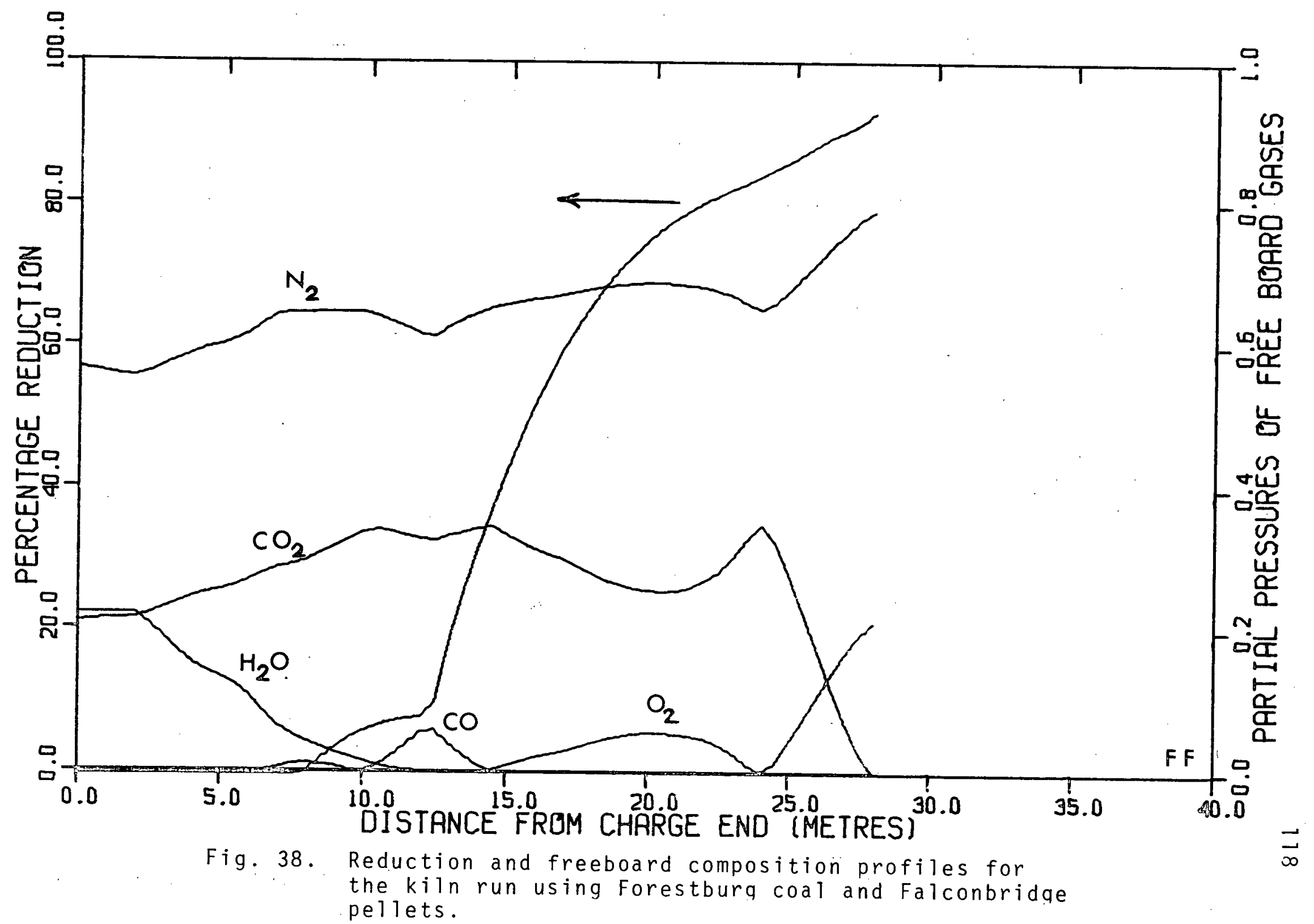


the run with anthracite coal compared to the Forestburg coal, even though the ore throughput was smaller in the former case. To study the effect of natural gas injection in the preheat zone, a run was made without any natural gas, but otherwise under identical conditions to the original Forestburg run in which gas was injected at a rate of $676 \mathrm{cf} / \mathrm{t}$ of ore. The input conditions for this run are presented in Table 10. The air profile is given in Fig. 39. Figs. 40 and 41 show the predicted profiles from the model. By comparison with Fig. 14 the absence of natural gas in this run can be seen to extend the length of the preheat zone by $1.2 \mathrm{~m}$ and also to decrease the waste gas temperature to $745^{\circ} \mathrm{C}$. At the same time it should be noted that the waste gas is richer in oxygen (3\%). If the air input to the preheat zone is reduced so that no oxygen appears in the waste gases, that is to reduce the thermal burden on the gases, a higher waste gas temperature results and the effect of a lack of natural gas combustion diminishes. Thus it is seen that at the low gas rates employed with Forestburg coal the injection of natural gas plays a relatively minor role in the kiln operation. At higher natural gas rates, such as were utilized with the anthracite coal, the presence of this heat has a more significant effect on heat transfer in the preheat zone.

It should be mentioned that the conclusion drawn above is based on the assumption of instantaneous combustion in the freeboard gas. However in the event of incomplete 


\section{Table 10}

Input Data for the Kiln. Run Using Forestburg Coal and Griffith Pellets Without Any Natural Gas

Ore - Griffith pellets

Coal - Forestburg

Air (total)

Natural gas

Degree of reduction (total)

Hydrogen pre-reduction

Exit solids temperature

Solids degree of fill
191.8 tons/day

129.9 tons/day

$52960 \mathrm{scft} /$ ton ore

0

$92 \%$

$8 \%$

$1000^{\circ} \mathrm{C}$

$25 \%$ 


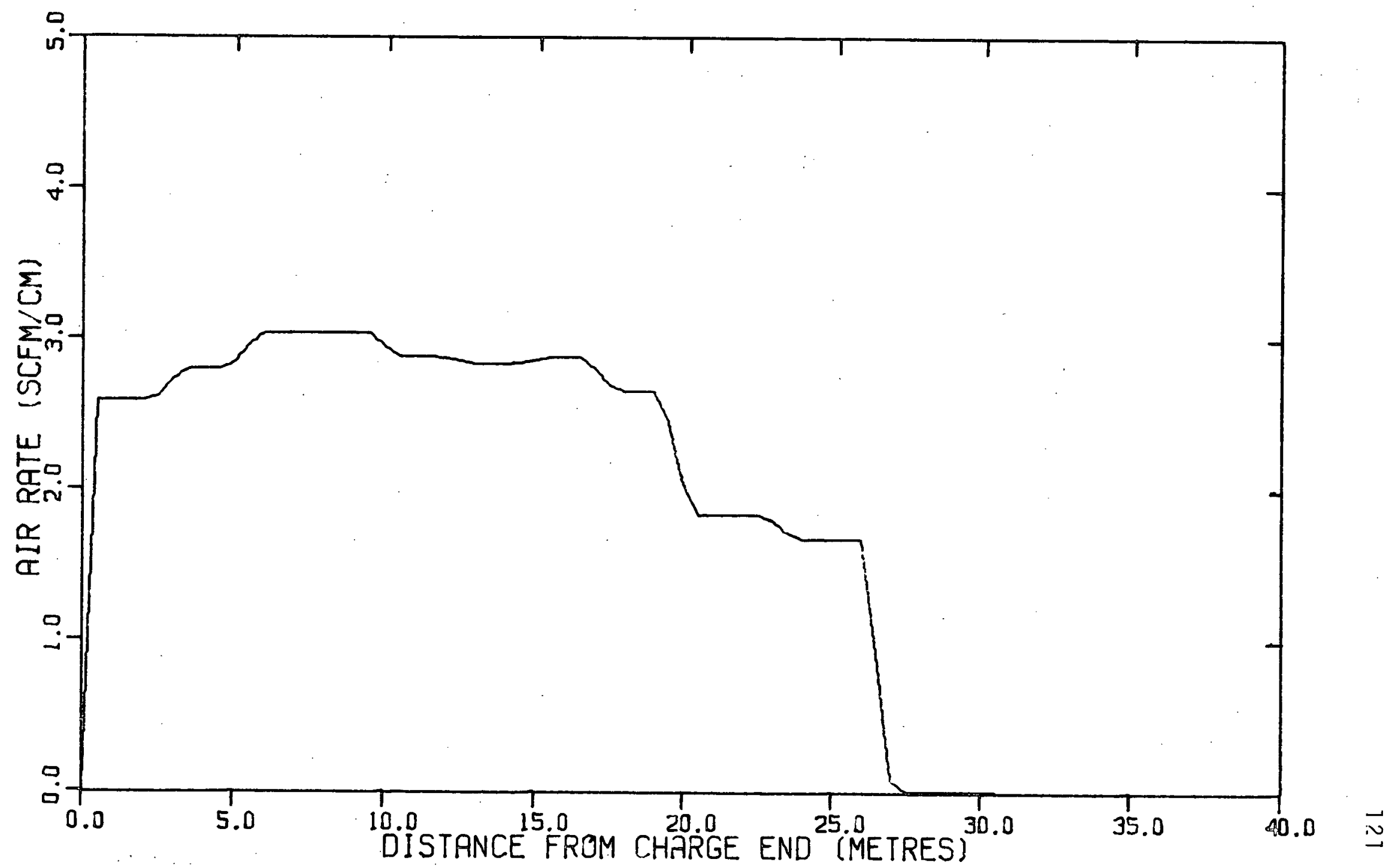

Fig. 39. Air profile for the kiln run using Forestburg coal and Griffith pellets. without any natural gas. 


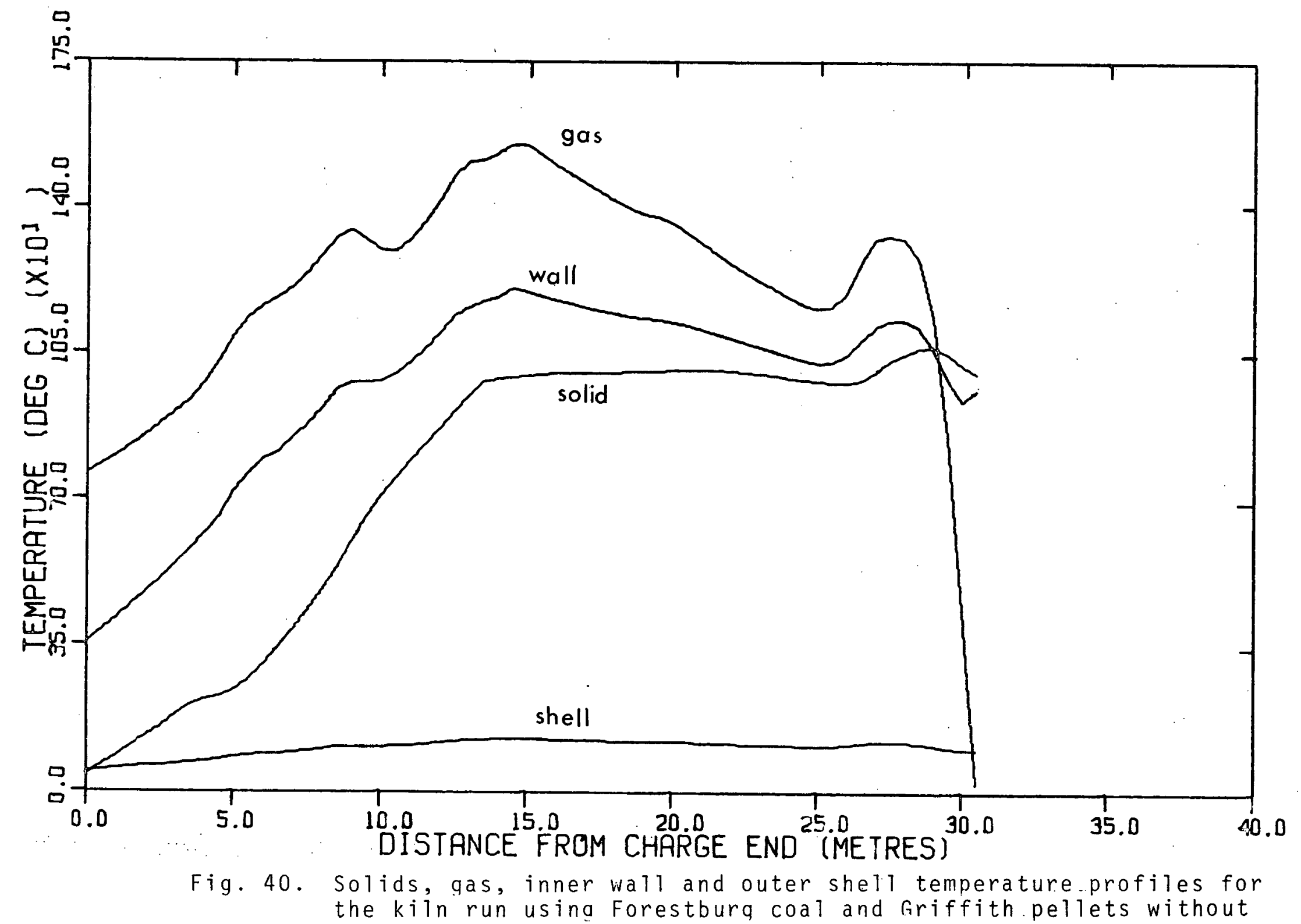




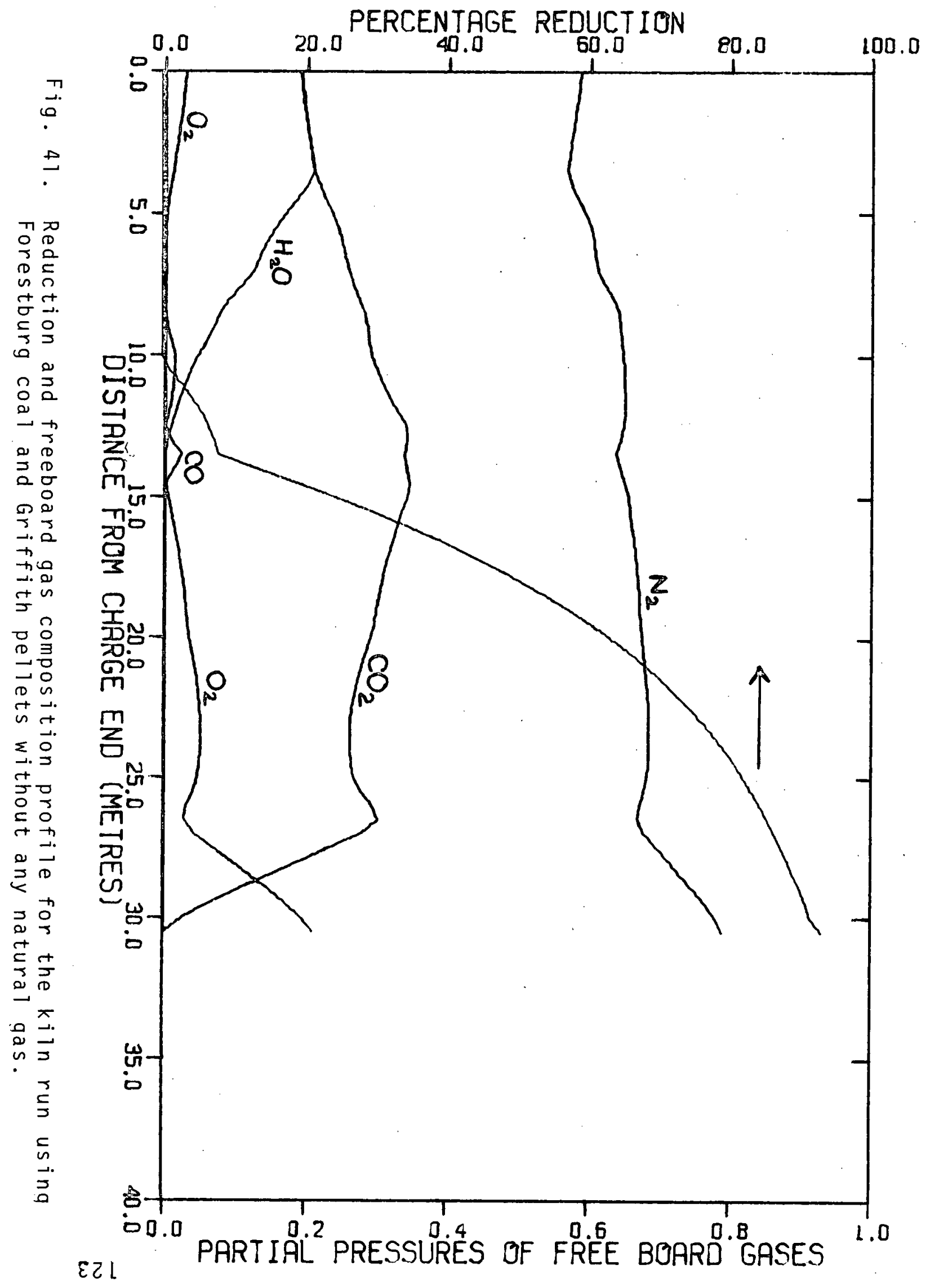


combustion the effect of natural gas may be more pronounced in the preheat zone.

\subsubsection{Effect of Dust in the Freeboard Gas}

One of the problems that generally arises in the operation of rotary kilns, such as the SL/RN kiln, is the generation of dust due to particles abrading against one another in the solids bed. The dust is carried out of the kiln in the freeboard gas, and is important, not only because it represents a loss of material (although usually minor) but also because it can profoundly influence heat transfer from the gas to the kiln wall and bed surface by altering the effective gas emissivity. The extent to which dust is generated in the $\mathrm{SL} / \mathrm{RN}$ kiln is difficult to quantify precisely from pilot plant trials. However, from photographs of the kiln interior, such as shown in Fig. 20, it is believed that the dust loading in the freeboard gas is small, at least in the reduction zone. For this reason, the freeboard gas has been assumed to be "nondusty" in all the model runs reported to this point. Nevertheless, because dust can be a potential problem, it was decided to investigate its influence on kiln behaviour when the charge consisted of Griffith pellets and Forestburg coal.

Hottel [29] has suggested that for engineering purposes the effect of dust on gas emissivity can be taken into account by adding 0.7 to the non-luminous gas emissivity. This adjustment 
was made for the run whose input conditions are given in Table 4. The freeboard gas temperature that resulted from this calculation is presented in Fig. 42 together with the profile originally obtained with the non-dusty gas. It can be seen that, as expected, the dusty gas has a lower temperature, particularly in the reduction zone compared to the non-dusty gas. That the effect of dust is seen more in the reduction zone than in the preheat zone can be attributed to two reasons.

(i) The gas in the reduction zone has a
lower emissivity (in the absence of
dust) than in the preheat zone owing
to a lack of water vapour. Thus the
addition of o. t to ${ }^{\text {a increases the }}$
gas emissivity in the reduction zone
by a proportionately larger amount.
The gas temperature in the reduction
zone is considerably higher than in
the preheat zone with the result that
radiant heat transfer contributes more
to the overall heat flow process in
the reduction zone. Again the effect
of increasing Eg would be greater in
the reduction zone.

This result is important from the standpoint of the model. It means that the effect of dust on heat transfer is greatest in the reduction zone where the freeboard gas has its lowest velocity, and is least likely to pick up dust from the bed surface (Fig. 20). On the other hand in the preheat zone where the freeboard gas velocity is reaching a maximum value so that dust entrainment is enhanced, dust has a relatively minor effect on heat transfer. Thus, the assumption of a non-dusty gas in the model would appear to be quite justifiable. 


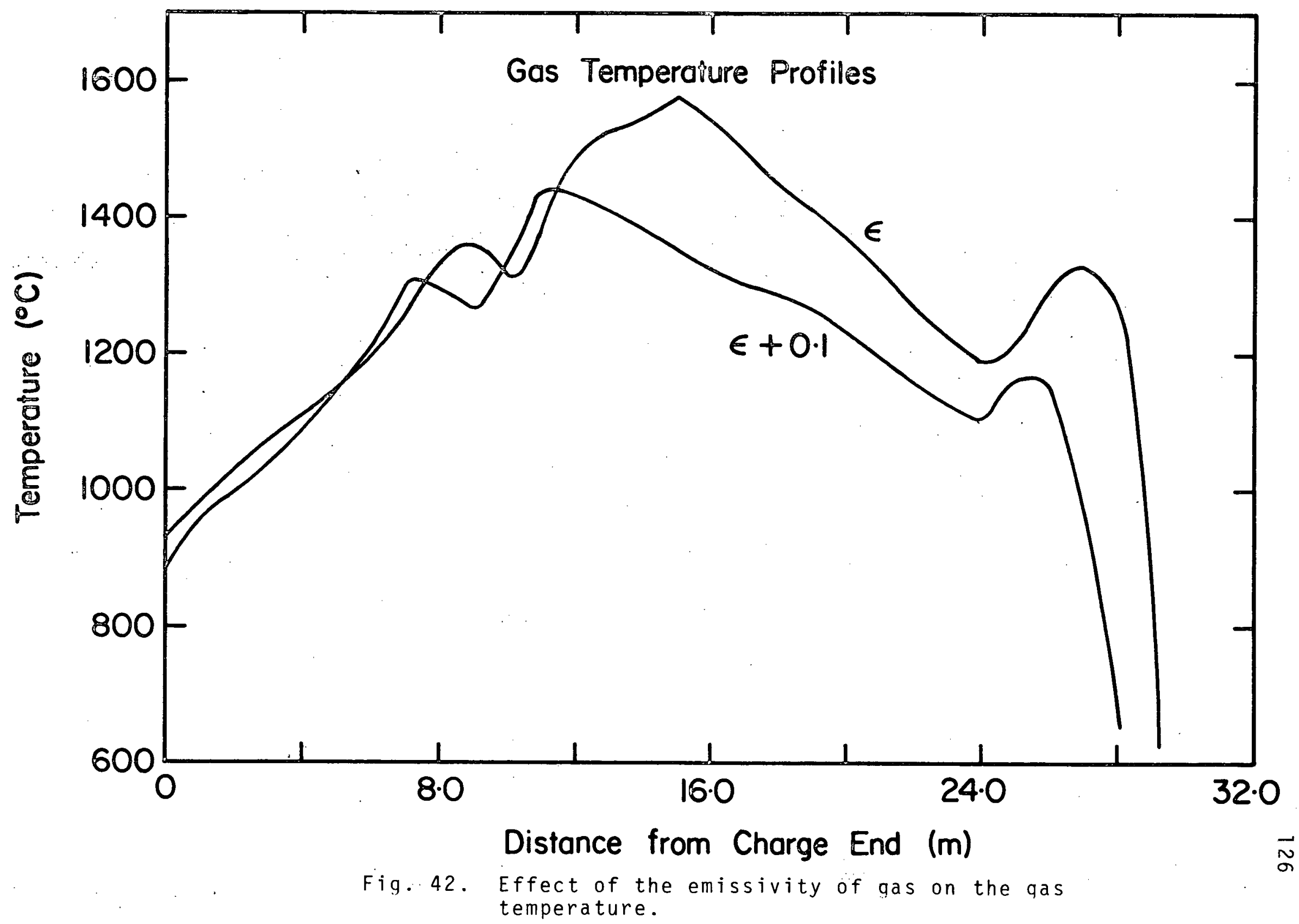


The change in the gas emissivity also resulted in a change in the solids and inner wall temperature. The solids showed an average drop of around $20-30^{\circ} \mathrm{C}$, while the inner wall registered a drop of around $50-70^{\circ} \mathrm{C}$.

\subsubsection{Predictions for the Griffith Kiln}

Perhaps the most important investigation that can be undertaken with the mathematical model, is to study the effect of size on kiln operation - the question of scale-up. In this regard, a unique opportunity presented itself, since at the same time that the model was being developed, Stelco was constructing a large production size kiln, $125 \mathrm{~m}$ long by $6 \mathrm{~m}$ id, at the Griffith Mine, Red Lake, Ontario. The model thus was run to predict the operating behaviour of this large kiln, using as input parameters, the anticipated operating conditions. The results of two model runs where the feed rate of solids was $100 \%$ and $130 \%$ of the designed specification are reported below.

\subsubsection{100\% Design Capacity}

The Griffith kiln is rated to process 72 tons/hr of iron ore pellets taken from the Griffith Mine operations with Forestburg coal being used as the solid reductant. The input variables employed in this run are presented in Table 11. Fig. 43 shows the theoretical air profile selected for this 
Table 11

Input Data for the Griffith Kiln Run Using Forestburg Coal and Griffith Pellets for the Designed Throughput

Ore - Griffith pellets

Coal - Forestburg

Air (total)

Natural Gas

Degree of reduction

Hydrogen pre-reduction

Exit solids temperature

Solids degree of fill
1728 tons/day

1186 tons/day

$47390 \mathrm{ft}^{3} /$ ton ore

$0 \mathrm{ft}^{3} /$ ton ore

$95 \%$

$8 \%$

$850^{\circ} \mathrm{C}$

$20 \%$ 
43

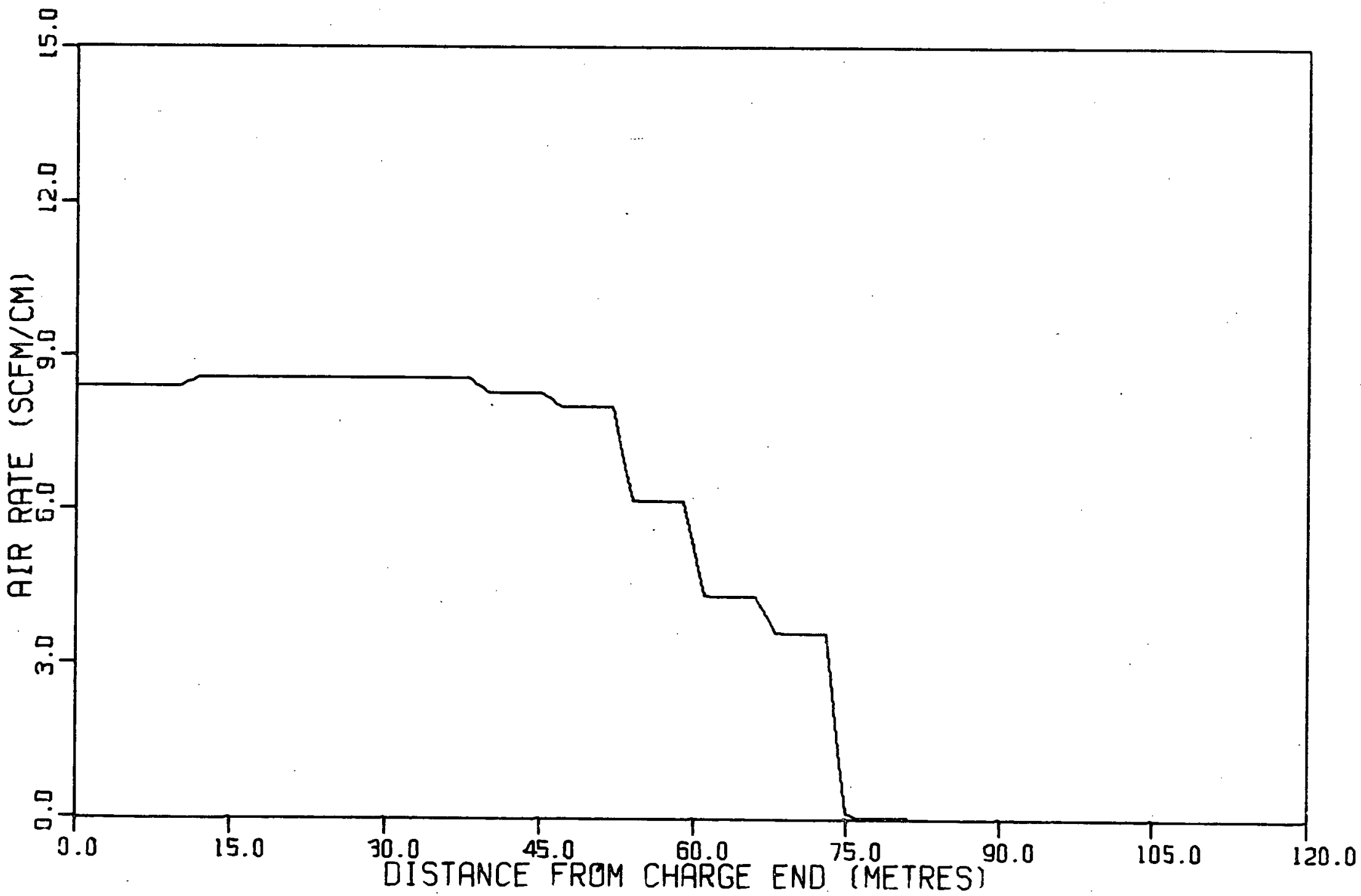

Fig. 43. Air profile for the Griffith kiln run using the Forestbura

$\overrightarrow{\tilde{N}}$ coal and Griffith pellets for the designed throughout. 
set of operating conditions. The results calculated using the model are presented in Figs. 44 to 48 . From Fig. 44, the computed kiln length can be seen to be slightly over $80 \mathrm{~m}$, but considerably shorter than the $125 \mathrm{~m}$ of the actual kiln. Of the calculated length about $30 \mathrm{~m}$ or $37 \%$ is required to preheat the solids. The bed temperature through the reduction zone is around $975^{\circ} \mathrm{C}$. The gas temperature profile is quite similar to the profile in the pilot kiln. The wall temperature is lower than that calculated for the pilot kiln presumably due to an absence of insulating brick in the Griffith kiln. This is also responsible for the higher shell temperature calculated. In common with the pilot kiln there is a need to maintain a slight excess of oxygen in the freeboard through most of the reduction zone.

It should be mentioned that in these calculations instability was a much greater problem than in the pilot kiln runs requiring some external control on the Boudouard reaction rate. Based on experience with the pilot plant runs, this situation may indicate that the anticipated set of operating conditions will result in poor kiln performance.

Further detailed analysis of the characteristics of the pilot and Griffith kilns revealed an interesting fact. For a $25 \%$ degree of fill the ratio of surface area to volume of the solids bed per unit length of the Griffith kiln is roughly one-third the value for the pilot kiln. This means that less heat per unit volume of bed can be transferred to the solids in the Griffith kiln. 


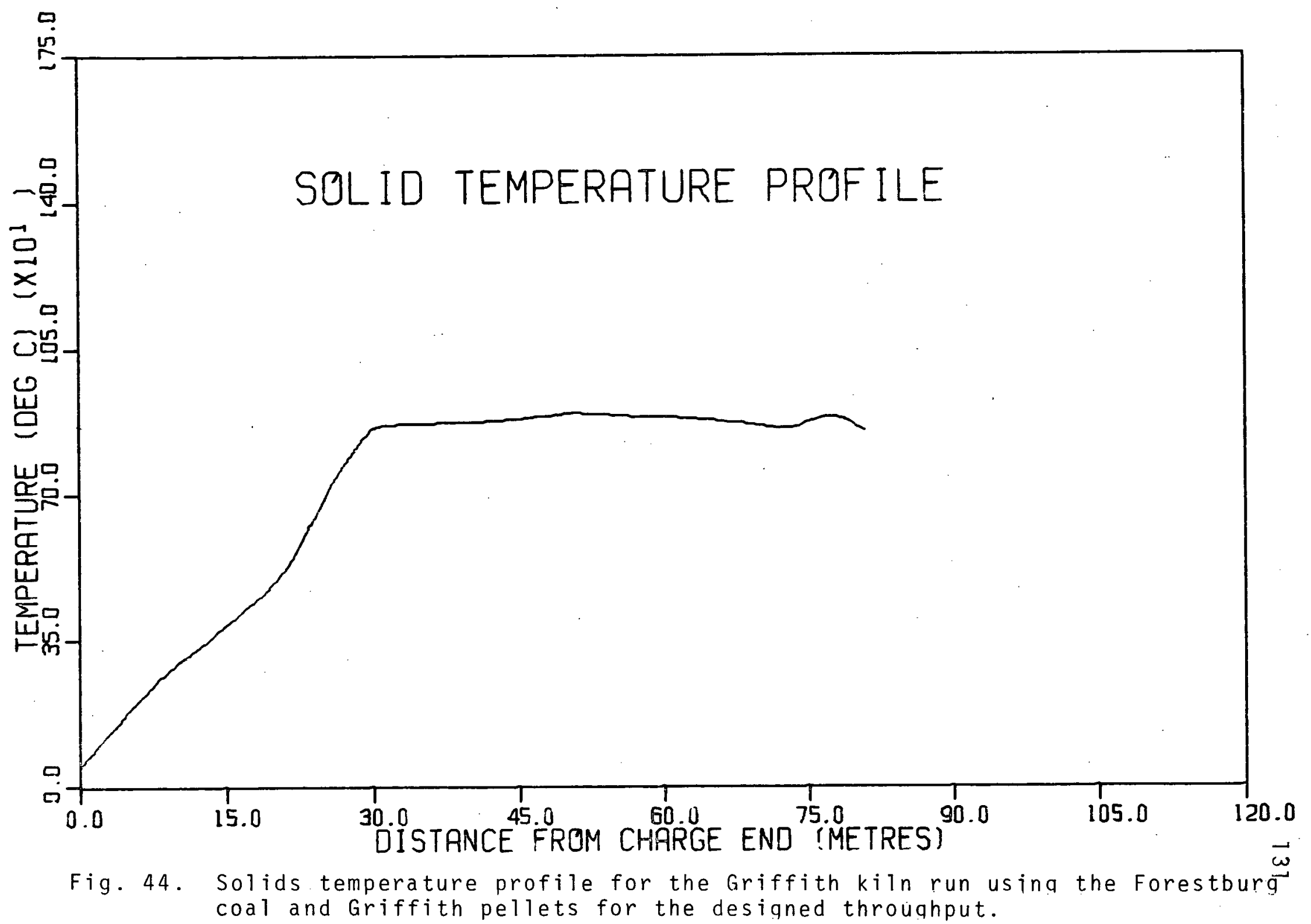




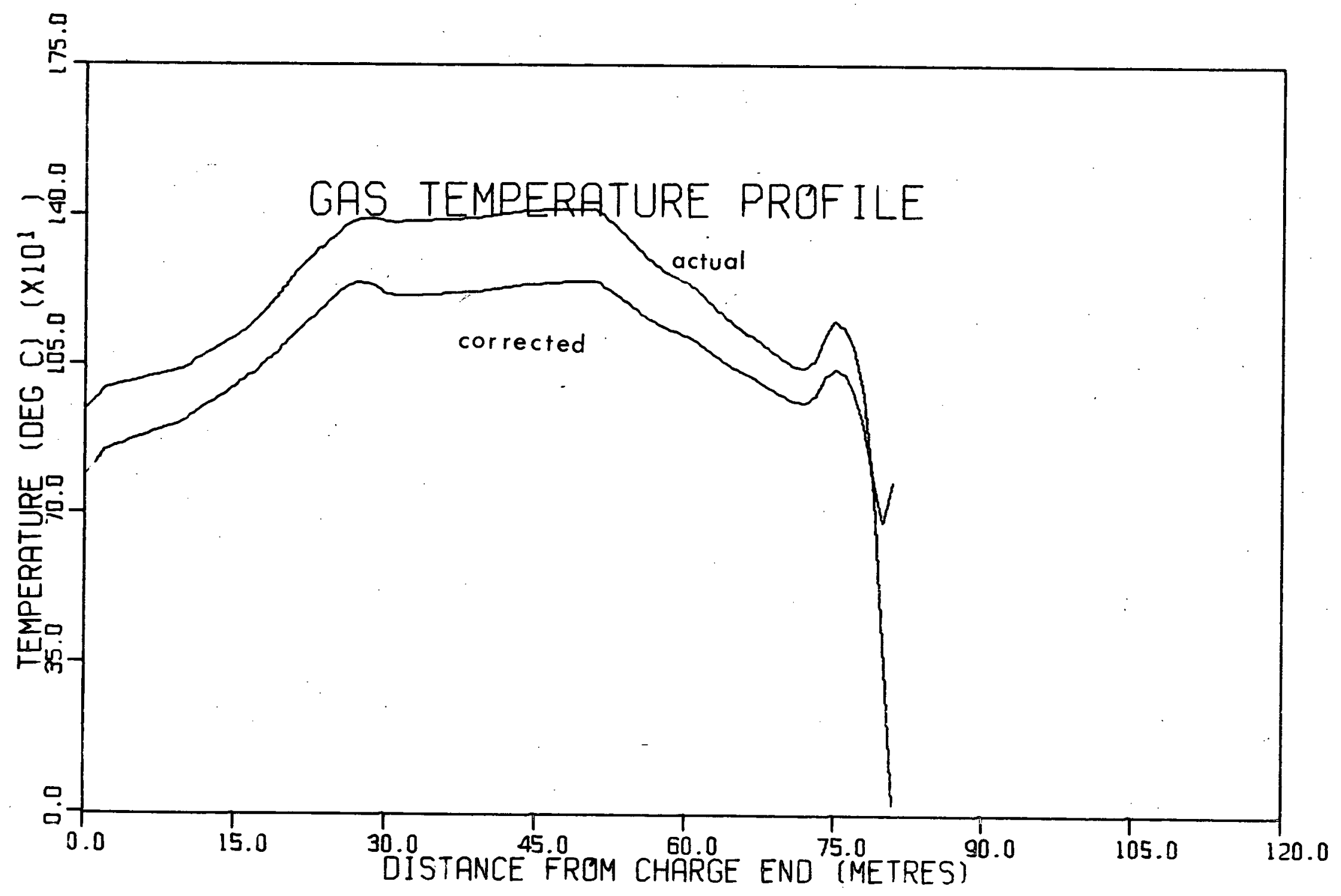

Fig. 45. Gas temperature profile for the Griffith kiln run using the Forestbura
coal and Griffith pellets for designed throughput. 


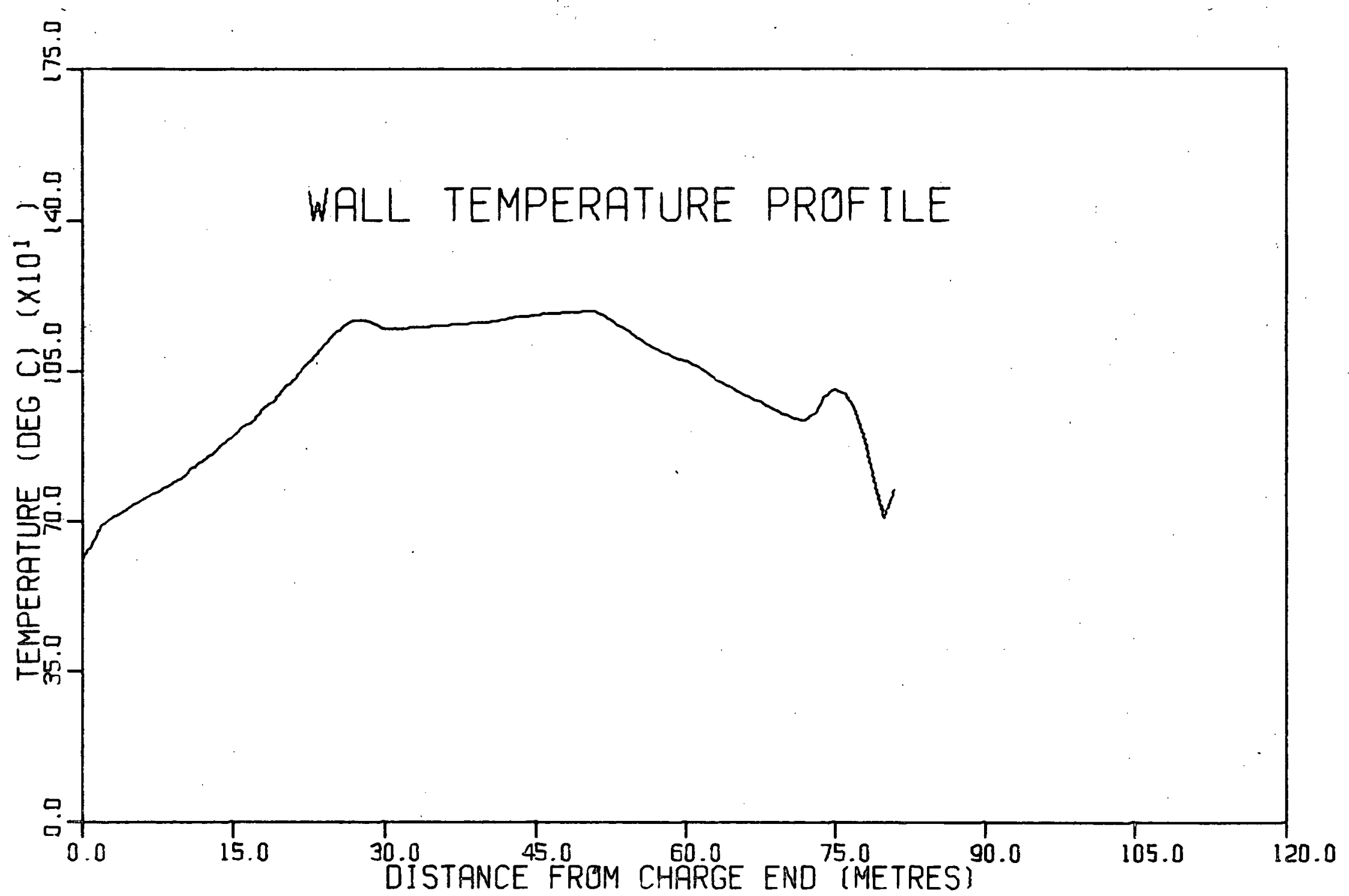

Fig. 46. Inner wall temperature profile for the Griffith kiln run using Forestbura coal and Griffith pellets for designed throughput. 


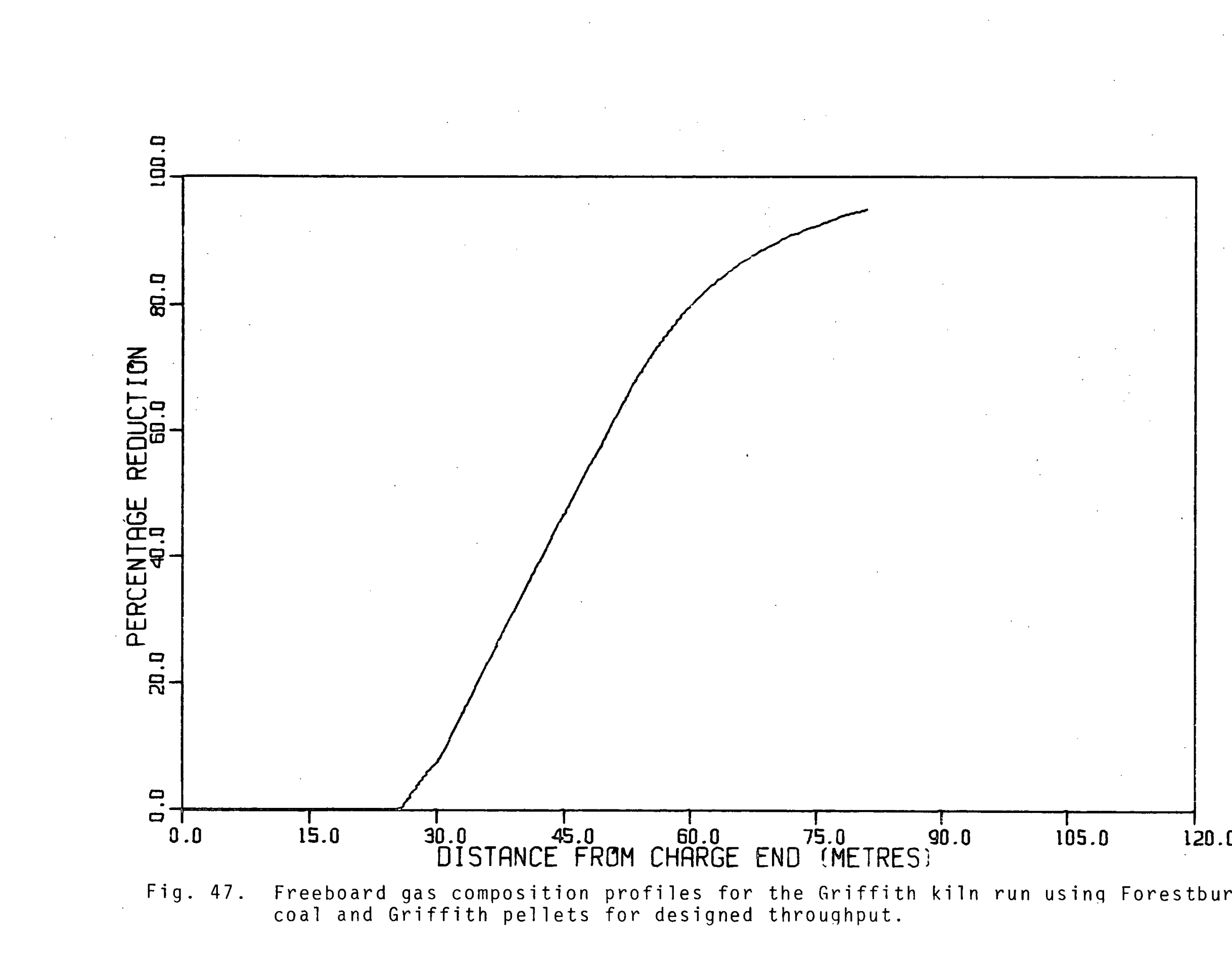




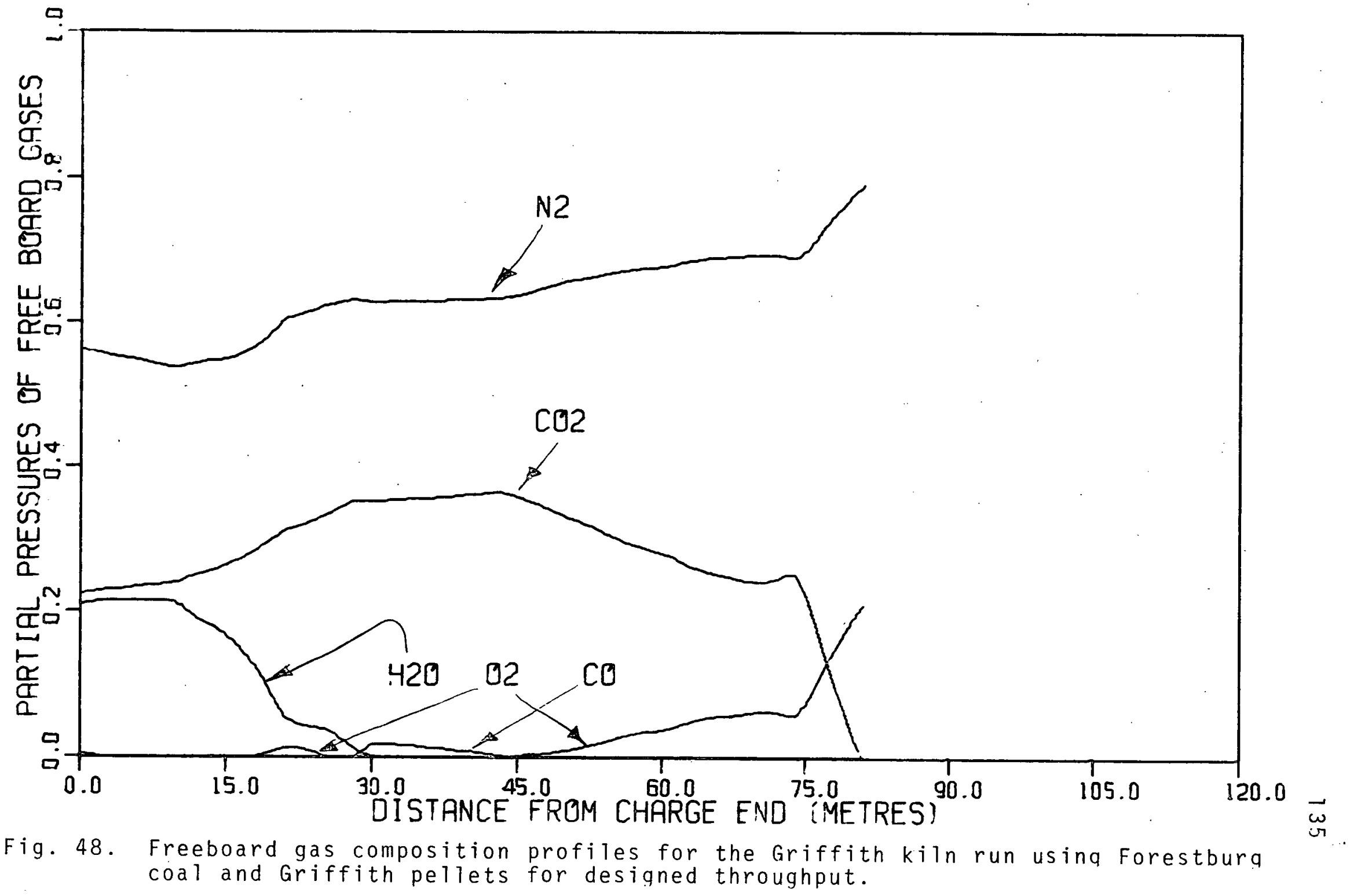




\subsubsection{130\% Design Capacity}

The fact that the actual Griffith kiln is longer than seems required for its designed throughput led to an attempt to predict kiln performance using a throughput which was $130 \%$ of its rated-capacity. The operating conditions assumed were again close to the conditions used in the pilot kiln. The input data for this run is given in Table 12. The theoretical air profile used is shown in Fig. 49 and the results from the model calculations in Figs. 50 to 54. The solids temperature in the reduction zone is very similar to the $100 \%$ run. As discussed in the preceding case, due to instability problems encountered, the Boudouard reaction rate had to be externally controlled. The gas composition profiles again show that an excess of oxygen over most of the reduction zone is in evidence. The length of the kiln calculated from the model for this run is $98 \mathrm{~m}$. Thus from these model calculations it is clear that the Griffith kiln should be able to handle throughputs that are higher than its rated capacity.

\subsection{General Comments on the SL/RN Process}

Having examined the influence of different operating variables on the performance of the SL/RN kiln it is clear that it is a complex operation involving closely coupled heat and mass transport steps. This is contrary to the rather simple picture one might have initially of solid iron oxide pellets 
Table 12

Input Data for the Griffith. Kiln Run Using Forestburg Coal and Griffith Pellets for a $30 \%$ Higher Throughput

$\begin{array}{ll}\text { Ore - Griffith pellets } & 2246 \text { tons/day } \\ \text { Coal - Forestburg } & 1544 \text { tons/day } \\ \text { Air (total) } & 46270 \mathrm{ft}^{3} / \text { ton ore } \\ \text { Natural gas } & 0 \mathrm{ft}^{3} / \text { ton ore } \\ \text { Hydrogen pre-reduction } & 8 \% \\ \text { Exit solids temperature } & 850^{\circ} \mathrm{C} \\ \text { Solids degree of fill } & 20 \%\end{array}$




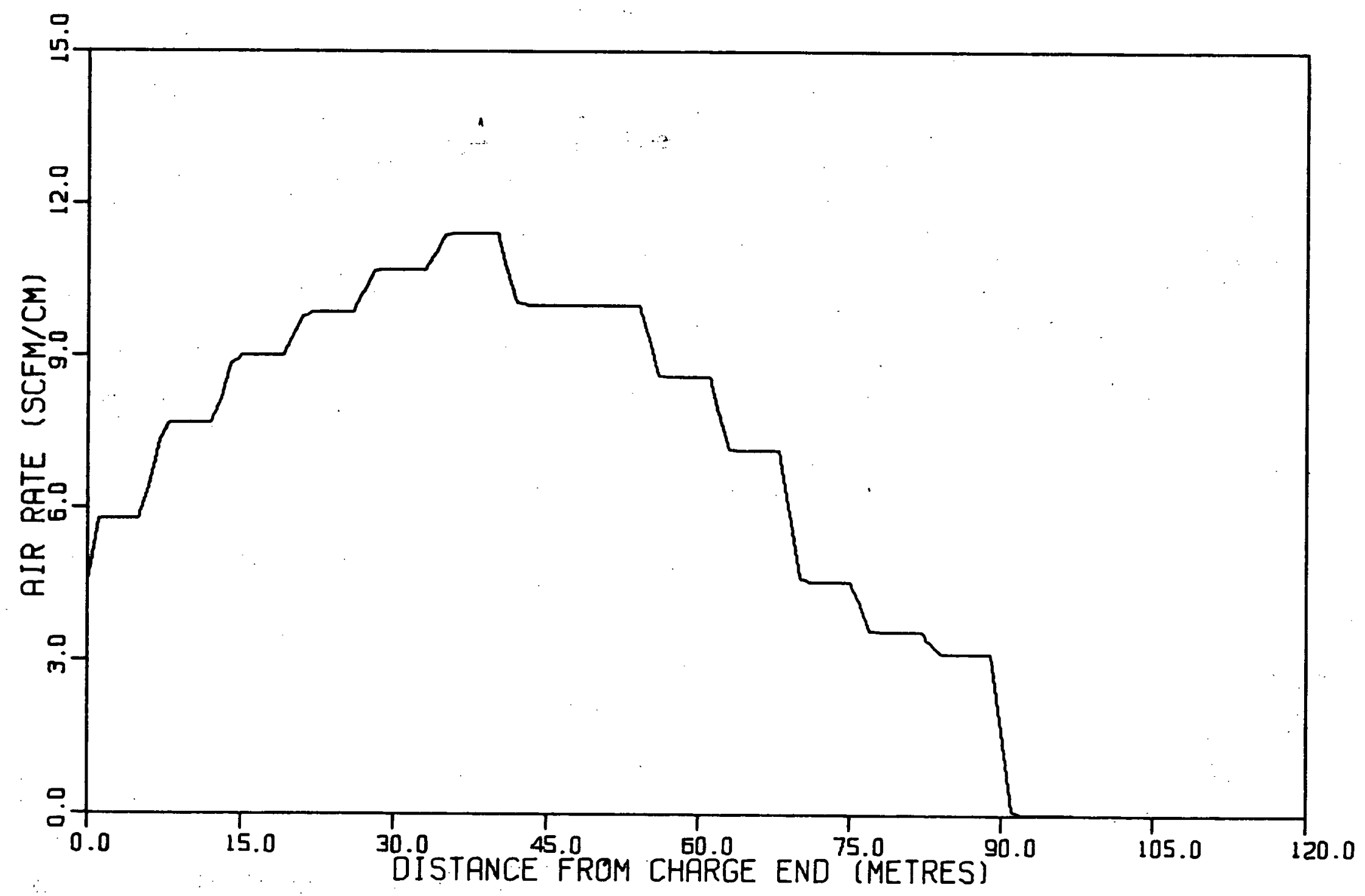

Fig. 49. Air profile for the Griffith kiln run using Forestburg coal and Griffith pellets with a $30 \%$ higher throughput. 


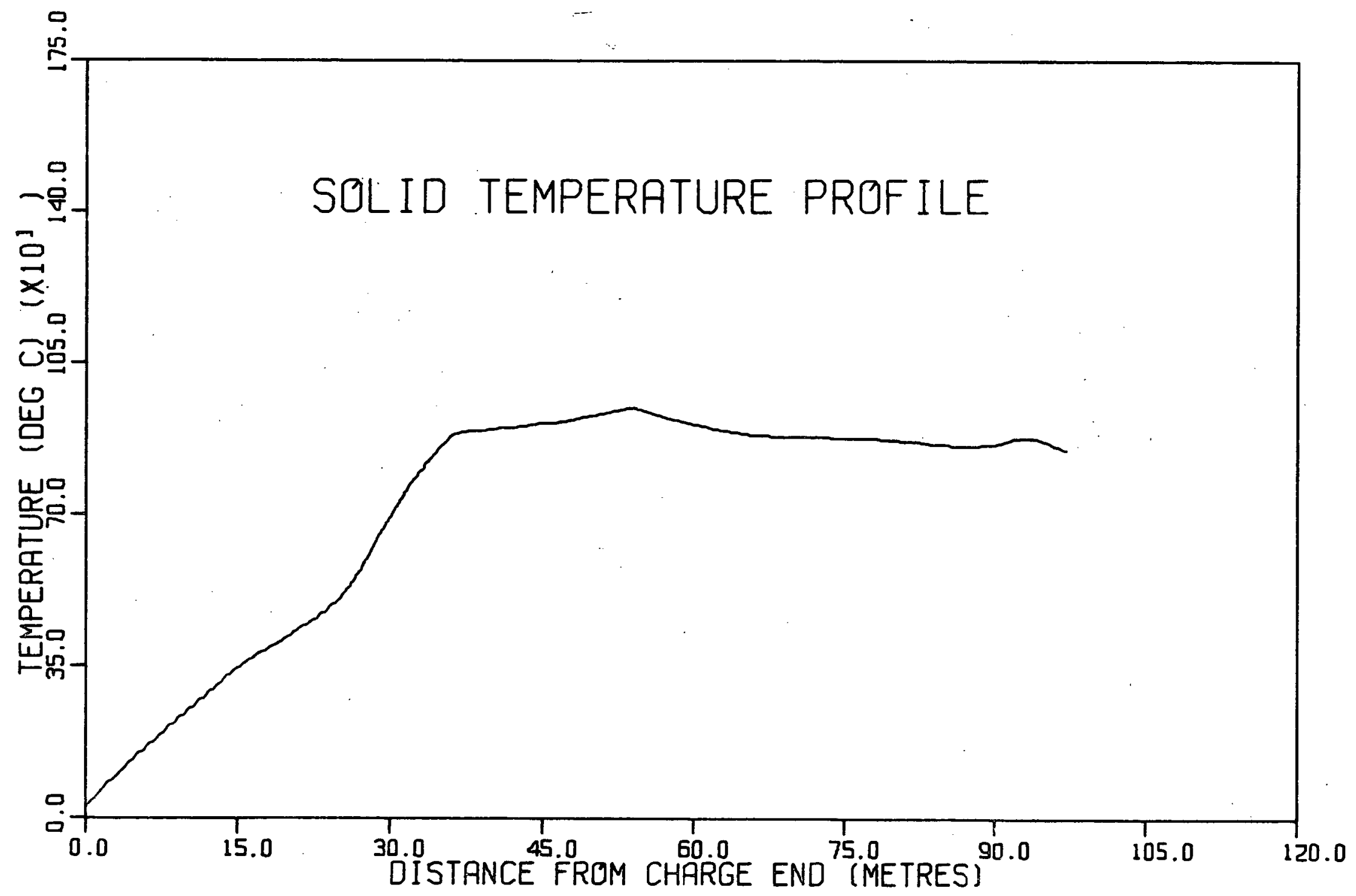
Fig. 50. Solid temperature profile for the Griffith kiln run using Forestbura coal
and Griffith pellets with a $30 \%$ higher throughput. 


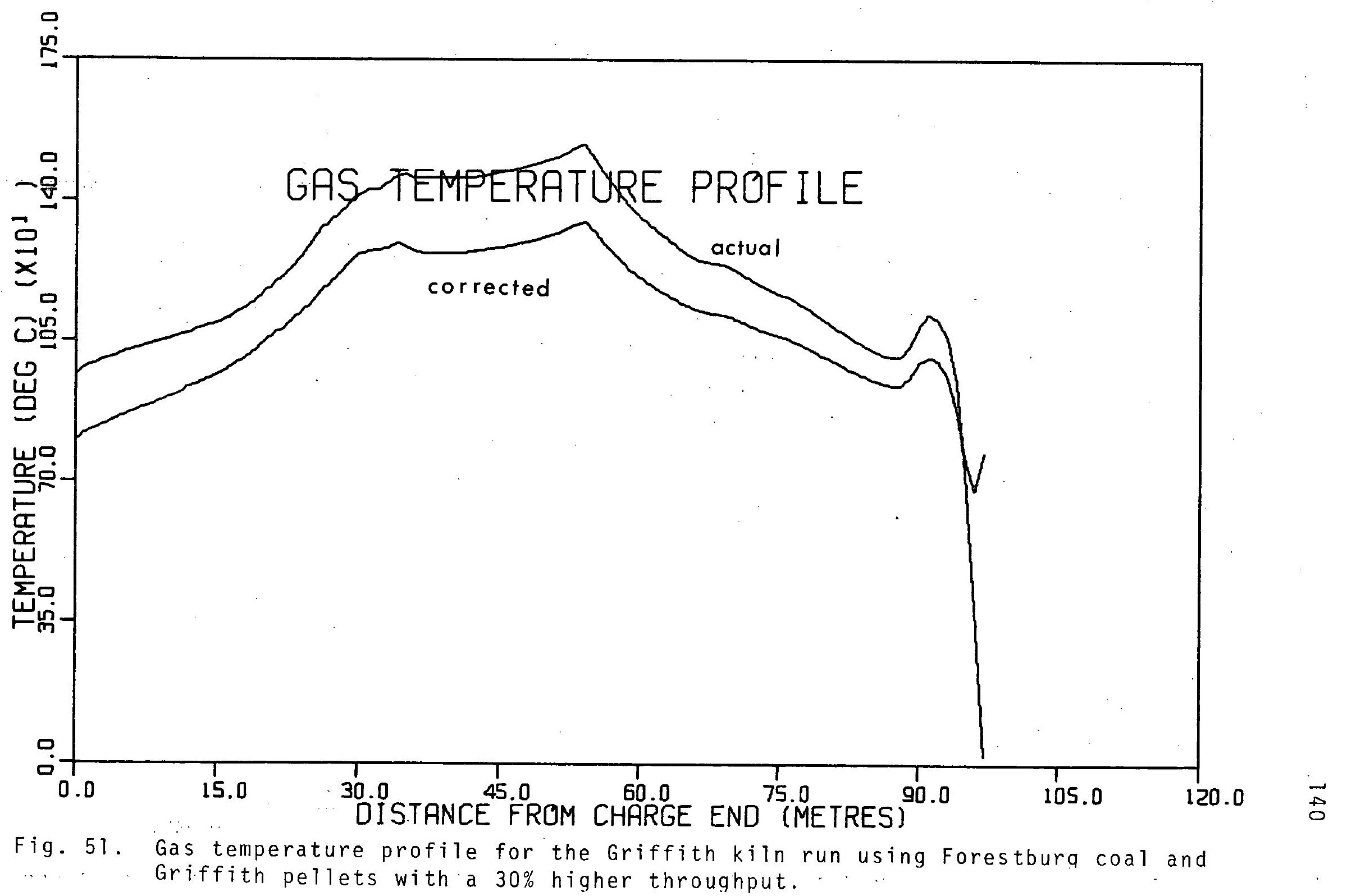




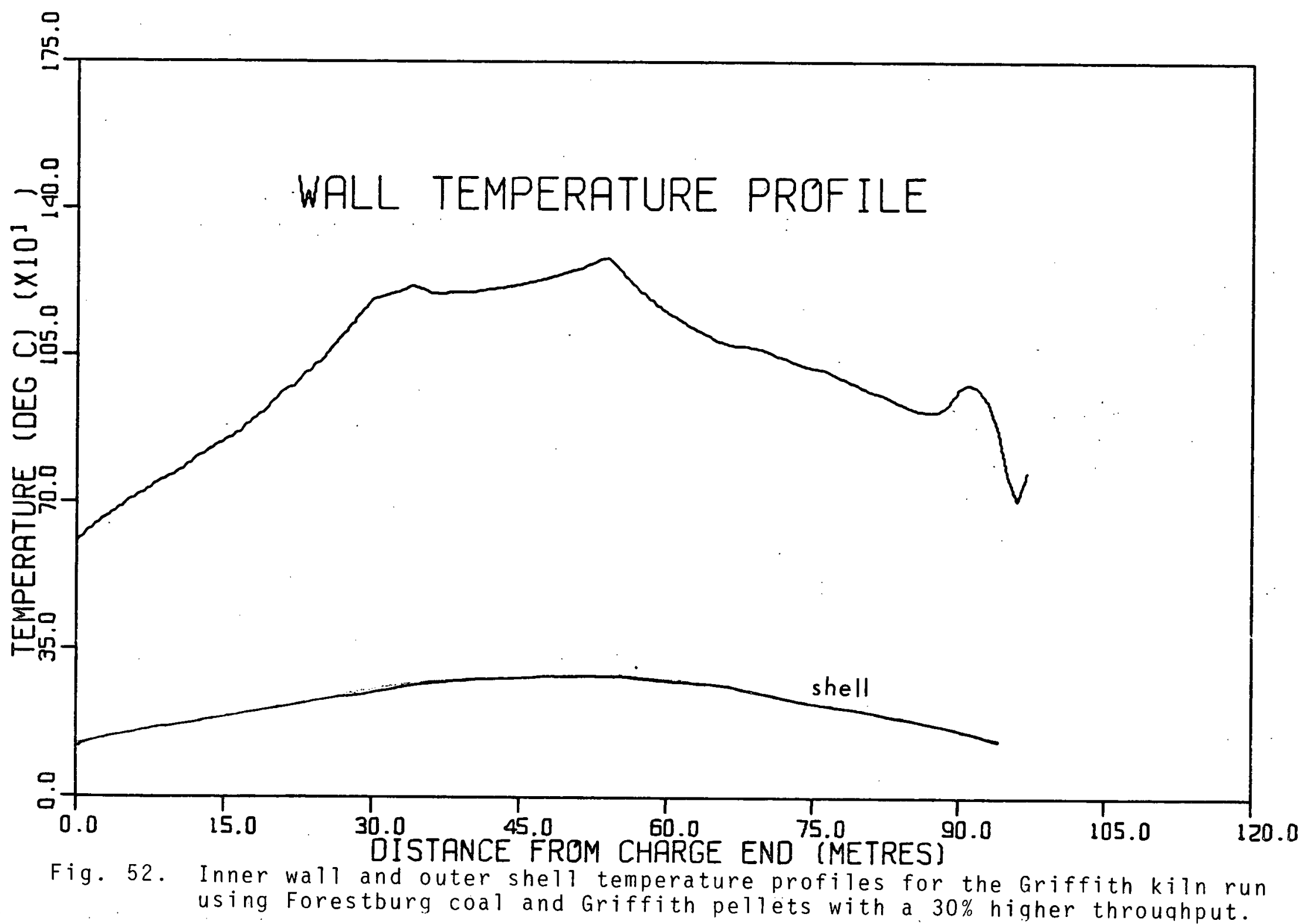




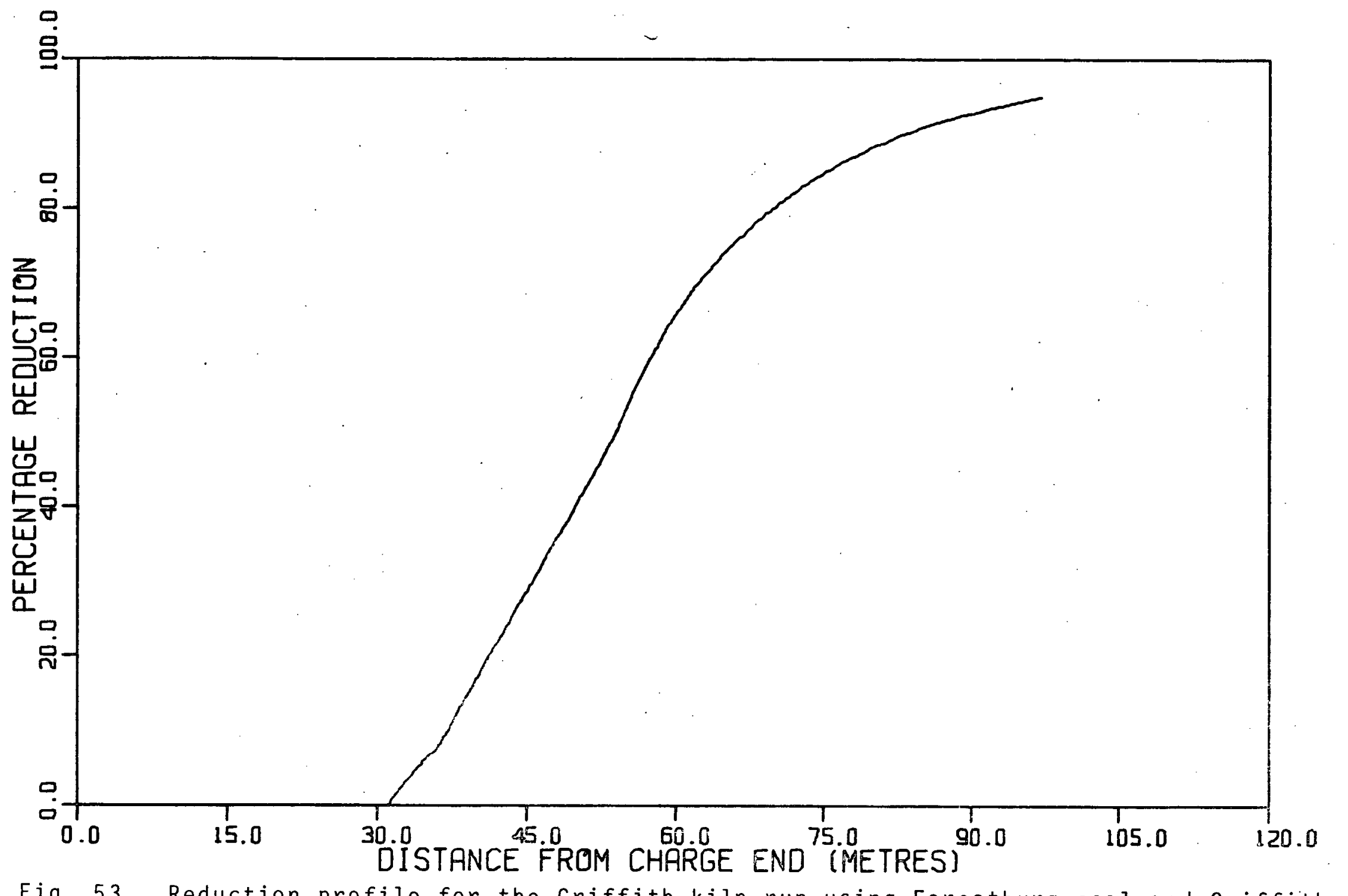

Fig. 53. Reduction profile for the Griffith kiln run using Forestbura coal and Griffith pellets with a $30 \%$ higher throughput. 


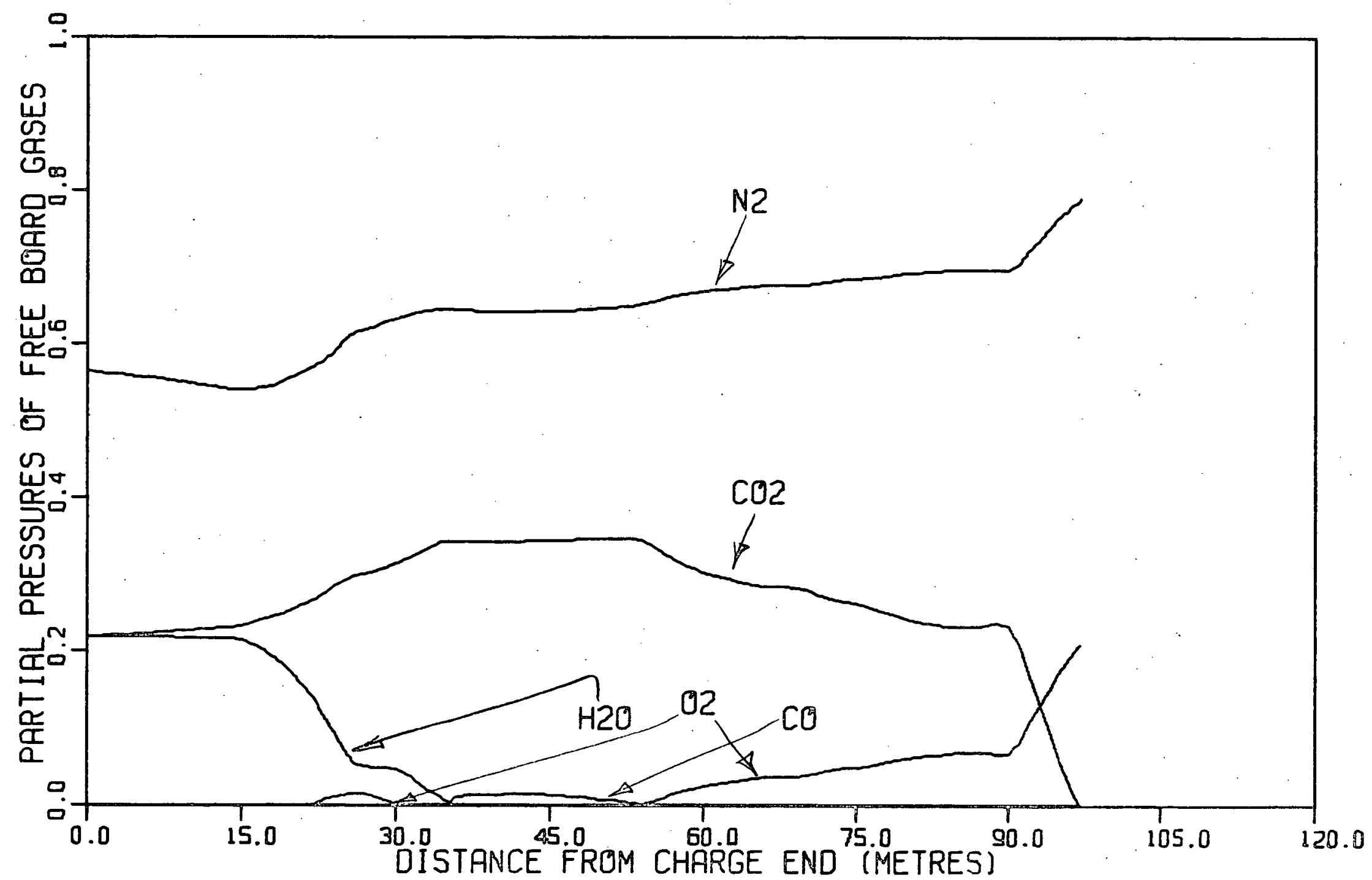

Fig. 54. Freeboard gas composition profiles for the Griffith kiln run using Forestbura coal and Griffith pellets with a $30 \%$ higher throughput. 
passing through a long tube interacting chemically with coal and emerging in a reduced state. In this chapter it has been seen that the behaviour of the SL/RN kiln is strongly influenced by the type of coal and ore pellets comprising the charge, by the air profiles imposed and by the kiln size. It would also seem clear from this work that the prediction of kiln performance without the services of a mathematical model, such as developed here, is virtually out of the question.

At this stage of the study it is possible to delineate some of the more general features of kiln behaviour, particularly as regards the rate limiting steps. The model has shown that the operation of the kiln is extremely sensitive to heat flow conditions. This is reflected in the fact that the air profile is the most important operating variable because it absolutely controls the gas temperature, through combustion; and in addition, the solids bed temperature through heat transfer from the gas. There is strong evidence therefore that the SL/RN process is governed in its operation essentially by heat transfer. This conclusion seems reasonable if the two zones of the kiln are examined separately. In the preheat zone, which has the major function of increasing the sensible heat of the solids, heat transfer is clearly the rate controlling step. In the reduction zone, heat transfer is also extremely important because the Boudouard reaction is so highly endothermic in nature. In order to maintain the bed temperature at a 
higher level and ensure fast reaction rates, heat must be supplied to the bed to meet the demands of the Boudouard reaction.

If heat transfer is the rate controlling step in the SL/RN process it is possible to further state that, for purposes of kiln design and operation, one of the most important variables is the ratio of the surface of the bed to its enclosed volume. The A/V ratio has been calculated as a function of diameter for varying degrees of fill and is shown in fig. 55. Here it can be seen that for a given diameter the A/V ratio increases with decreasing degree of fill. At the same time from the scale-up point of view, if the diameter of the kiln is increased and the $A / V$ ratio is kept constant, the percentage degree of fill must decrease to maintain heat transfer rates. It is not possible, however, to view the $A / V$ ratio in such a simple way. In the first place, an increase in kiln diameter will also result in an increase in the mean beam length and consequently, emissivity of the gas, thereby increasing the radiant heat transfer rate. In the second place the A/V ratio itself affects the residence time of solids in the kiln. This is shown in Fig. 56 for the $6 \mathrm{~m}$ id Griffith kiln where the mean residence time-has been calculated using average solids throughput and bulk density, and assuming plug flow behaviour. It can be seen that an increase in the $A / V$ ratio which is desirable from a heat transfer viewpoint results in a faster decrease in the residence time of solids - an undesirable effect. 


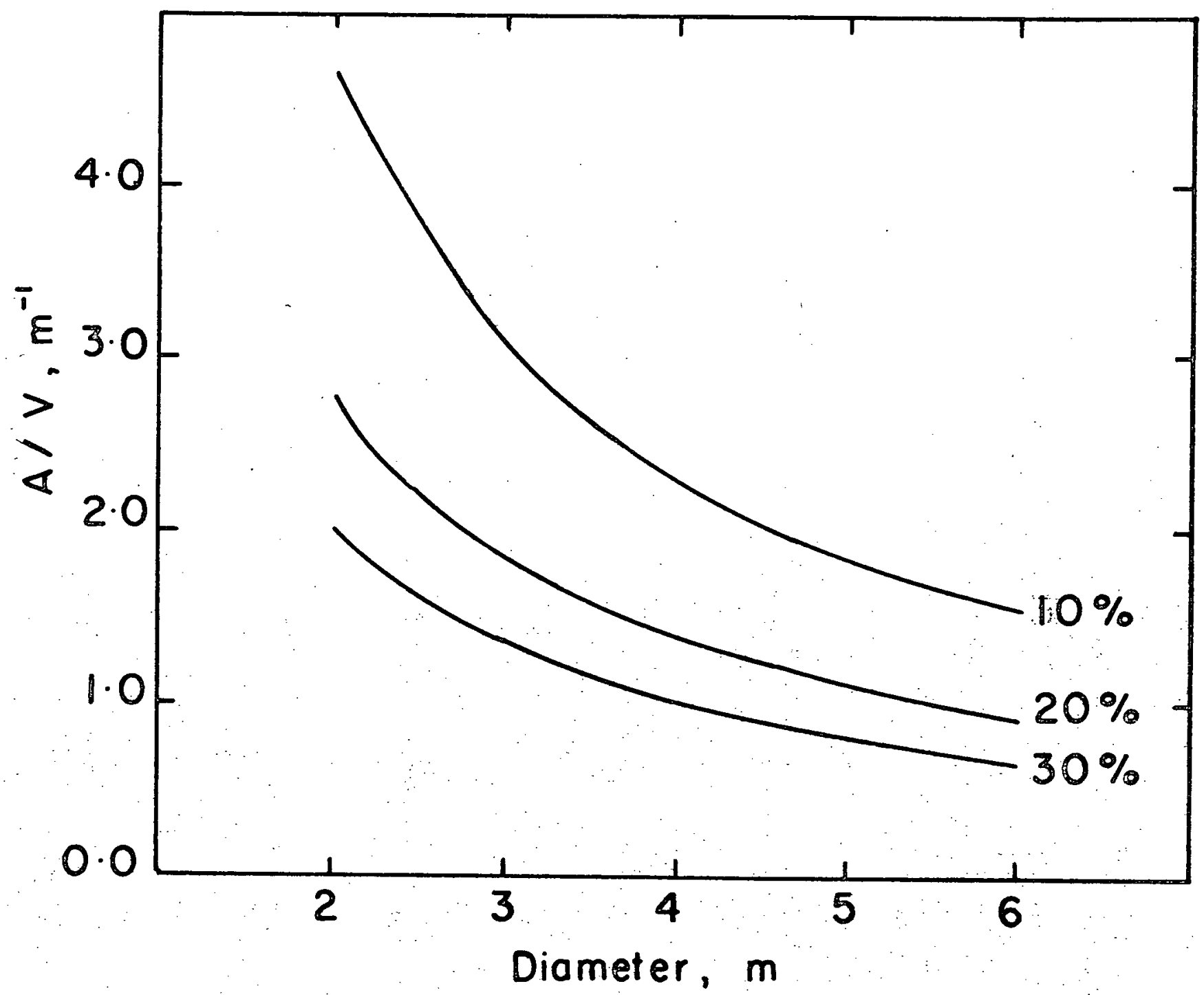

Fig. 55. Effect of kiln diameter on the A/V ratio for different 


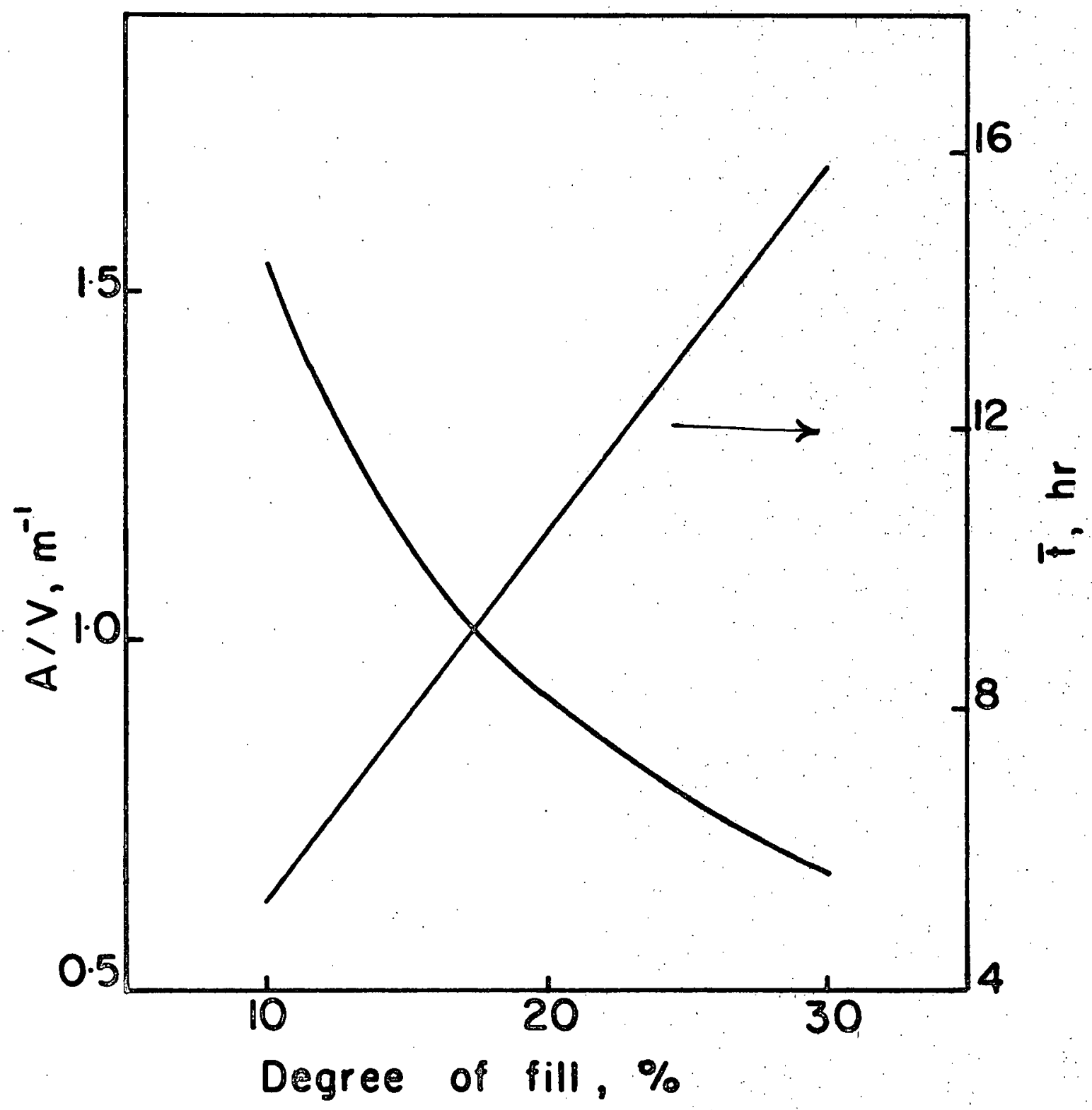

Fig. 56. Effect of the degree of fill on the $A / V$ ratio and mean retention time for a kiln with an id $6 \mathrm{~m}$. 
Clearly a balance must be struck between the $A / V$ and the residence time $\bar{t}$, and for the Griffith kiln this may lead to $15 \%$ degree of fill as being optimum.

Strictly speaking, this analysis, involving $A / V$ ratio and residence time, applies only to the preheat zone of the. kiln. The situation is more complicated in the reduction zone because the $A / V$ ratio can have a catastrophic effect on the rates of the Boudouard and reduction reactions. If the $A / V$ ratio is too small (large degrees of $f i l l$, long residence time) so that the rate of heat transfer per unit volume of bed is low, the bed temperature may seek a low value due to the endothermic Boudouard reaction. In the limit, the bed temperature may be so low that the rate of reduction is effectively halted and the length of the reduction zone required to achieve metallisation increased drastically. In a kiln of fixed length this would mean extremely poor metallisation and unsatisfactory performance. On the basis of the analysis it would appear the kiln should be run with a higher degree of fill in the preheat zone than in the reduction zone. 
Chapter 4

\section{SUMMARY AND CONCLUSIONS}

A mathematical model has been successfully developed for the SL/RN direct reduction kiln. This model, based on fundamental principles of conservation of heat and mass, incorporates mathematical expressions to quantitatively describe the rates of the important chemical and physical processes. Using operating variables as input parameters, the model is able to calculate axial temperature and concentration profiles in both the freeboard gas and the solids bed. The ability of the model to reliably predict the operating performance of an SL/RN kiln has been carefully tested by comparison of model calculations to measurements made on a large pilot kiln at the Hilton Works, Stelco. The mathematical model has then been used to predict the influence of several operating varibles on kiln behaviour on the scale of the large pilot kiln using in most cases Forestburg coal and Griffith pellets. The results of these predictions can be summarised as follows. 
(i) Coal type: In agreement with measurements, the model has shown that the bed temperature is strongly affected by the rank of coal used as solid reductant, being highest for anthracite and lowest for lignite. Further, it has been demonstrated that the use of anthracite coal results in a reduction in the throughput of the SL/RN kiln.

(ii) Pezzet type: The use of a highly reducible pellet as characterised by a reducibility parameter has the effect of reducing the bed temperature and at the same time increasing the throughput of the kiln.

(iii) Reduction achieved: Increases in per cent reduction from 92 to $95 \%$ give rise to an $8 \%$ increase in length of kiln required.

(iv) Throughput: An increase of $30 \%$ in the solids throughput results in a $22 \%$ increase in the kiln length. A major fraction of this increase in length is localised in the reduction zone.

(v) Dust: The presence of dust has a profound effect on the gas temperature profile.

(vi) Natural gas: Using Forestburg coal, the influence of natural gas at a rate of $676 \mathrm{scf} / \mathrm{ton}$ of ore only marginally reduces the preheat zone. With anthracite coal 
the injection of natural gas is seen to play a more important role because of the longer reduction zone required.

Scale-up calculations have also been performed with the mathematical model. Computer runs have been undertaken to predict the performance of the new commercial size SL/RN kiln at the Griffith mine. These have shown that this kiln should be capable of exceeding the designed capacity of 1200 tons of sponge iron per day.

On the basis of model predictions it seems certain that the SL/RN process is controlled by heat transfer in the kiln. This means that one of the important scale-up parameters in designing $S L / R N$ kilns is the $A / V$ ratio of the bed. It also conforms with the finding that the air profile is the most critical control variable. 


\subsection{Suggestions for Future Work}

1. The model should be refined as and when better data is available on the heat transfer aspect of rotary kilns.

2. Based on further comparison with results from the Griffith kiln, the model may be used to study the effects of different variables on commercial scale operation.

3. The use of the model as a basic tool in the optimization and controi of SL/RN kilns may be investigated. 


\section{REFERENCES}

1. Smith, R.P., CEP Symposium Series, Volume 59, Number 43, May, 1963.

2. Sibakin, J.G., Presented at the General Meeting of AISI at New York, May, 1962.

3. Kurt Meyer, Günter Heitmann, and Wolfgang Janke, J. Metals, June, 1966, pp. 748-752.

4. Fraser, M.J. and Grigg, C.R., The Engineering Journal, June, 1965.

5. Proceedings of the Seventh Annual Conference of IISI at Johannesburg, South Africa, 1973.

6. Rollinger, B., I and SM, January, 1975, pp. 10-17.

7. Alternative routes to Steel, Proceedings of the Annual General Meeting of Iron and Steel Institute of London, 1971 .

8. Pearce, F.J., Canadian Mining and Metallurgical Bulletin, April, 1964 .

9. Sibakin, J.G., Hookings, P.H. and Roeder, G.A., Trans. Engineering Institute of Canada, Vol. 11, No. E-1, May, 1968.

10. Greaves, M.J., E/MJ, February, 1975.

11. Meadowcroft, T.R., Johnson, C.W.E. and Wilson, K., Canadian Coal Conference, Victoria, B.C., 1974. 


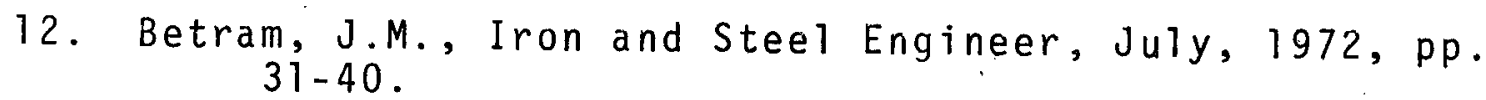

13. Miller, J.R., E/MJ, May 1972, pp. 68-76.

14. McManus, G.J., Iron Age Metal Working International, April, 1971.

15. Imber, M. and Paschkis, V., Int. J. Heat Mass Transfer, Vol. 5, 1962, pp. 623-638.

16. Allan Sass, I and EC Process Design and Development, Vol. 6, No. 4, October, 1967, pp. 532-535.

17. Kaiser, V.A. and Lane, J.W., I and EC Process Design and Development, Vol. 7, 1968, pp. 319-320.

18. Riffaud, J.B., Koehret, B. and Coupal, B., Brit. Chem. Eng. and Proc. Tech., Ko1. 17, No. 5, May, 1972.

19. Sprang, III, H.A., Automatica, Vol. 8, 1972, pp. 309-323.

20. Andrzej Manitius, Ewa Kurcyusz, and Wieslaw Kawecki, Ind. Eng. Chem. Process Des. Develop., Vol. 13, No. 2, 1974, pp. 132-142.

21. Wingfield, S.L., Prothero, A. and Auld, J.B., J. Inst. Fuel, March, 1974, pp. 64-72.

22. Stelco Reports 720061.

23. von Bogdandy, L. and Enge11, H.J., The Reduction of Iron Ores, Springer-Verlag, Berlin, Heidelberg, New York, 1971 .

24. McAdams, W.H., Heat Transmission, 3rd Ed., McGraw-Hill, New York, N.Y., 1954.

25. Dorn, W.S. and McCracken, D.D., Numerical Methods with Fortran IV Case Studies, John Wiley \& Sons, Inc., New York, 1972.

26. Stelco reports 740041,730085 . 
27. Kreich, F., Principles of Heat Transfer, 2nd Ed., Int. Text Book Company, 1969.

28. Stelco Reports 720161.

29. Hotte1, H.C. and Sarofim, A.F., Radiative Transfer, McGraw-Hill Book Co:, 1967.

30. Perry, R.H. and Chilton, C.H., Chemical Engineers Handbook, Fifth Edition, McGraw Hill Book Company, 1973 .

31. Lyons, J.W., Min. H.S., Parisot, P.E. and Paul, J.F., I \& EC Process Design and Development, Voi. 1 , No. 1 , January 1962 . 
APPENDIX I

SOURCE LISTING OF THE COMPUTER PROGRAM 


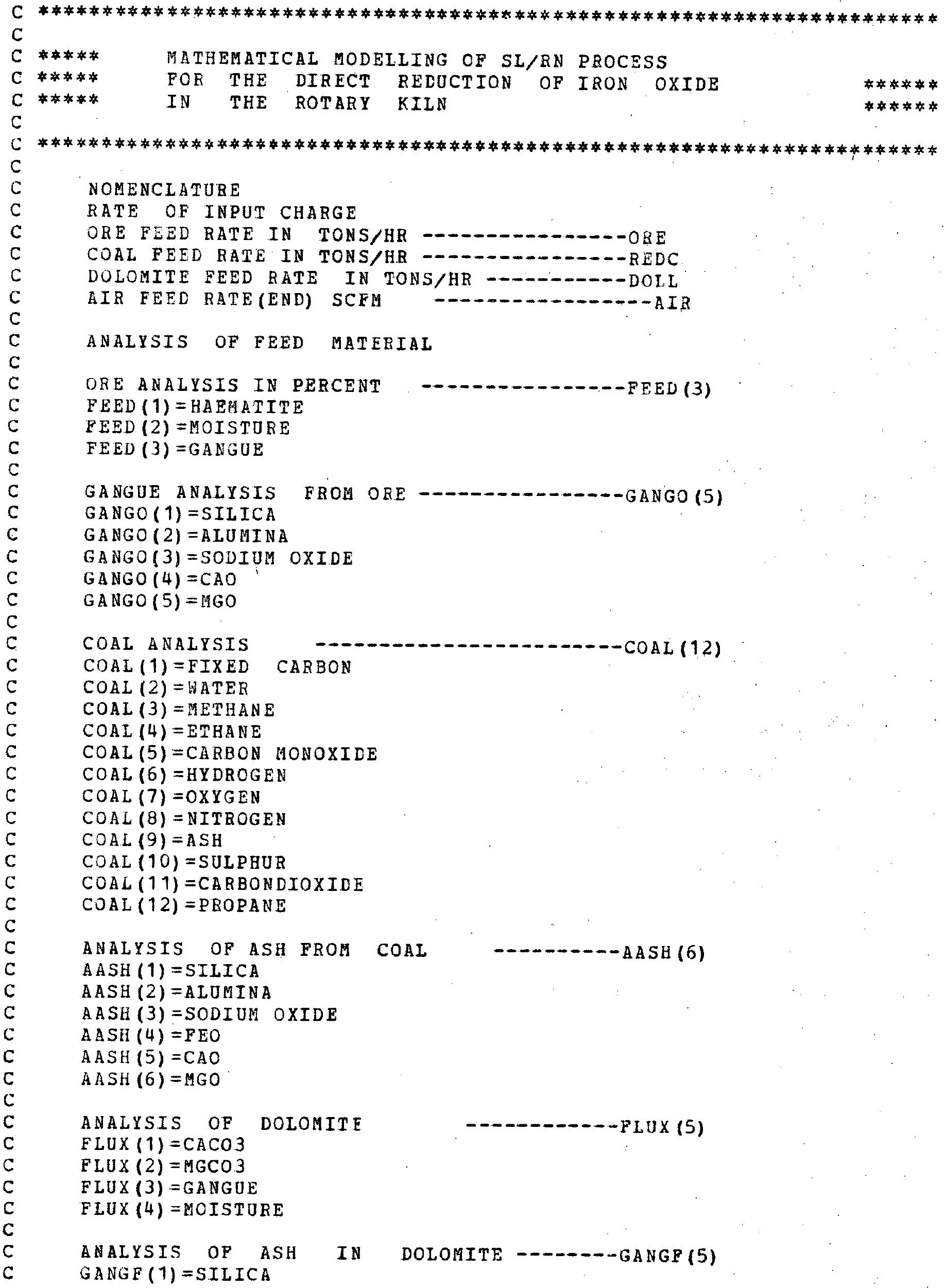


GANGF $(4)=$ FEO

ANALYSIS OF AIR

MOIST-LBS OF GATER PER $100 \mathrm{SCF}$---RMOIS

VOLUME OF NATURAL GAS IN SCFM -

GAS $(1)=$ METHANE

GAS (2) = ETHANE

GAS (3) = PROPANE

CHARACTERISTICS OP THE KILN -

LENGTH OF THE KILN IN CMS

DIAMETEE OP THE KILN CMS

DEGREE OF FILL FRACTION - - - FILL

TEMPERATURE OF AIR -

PERCENT DEGREE OF METALIISATION

RETENTION TIME OF SOLIDS -

THE EMISSIVITY VALUES FOR GASES ARE DESCRIBED THROUGH

POLYNOMIAL EQUATIONS

RATES OF VOLATILES REMOVAL FRCM COAL ALSO DESCRIBED

WITH THE HELP OF POLYNOMIAL EQUATIONS

TEMPERATURE OF NATURAL GAS -

INSULATION FOR THE KILN

$R X(I)=$ THICKNESS OF INSULATION

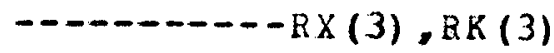

RK (I) = THERAAL CONDUCTIVITI OF THE MATERIAL

THE CHARACTERISTICS OF COAL AND ORE ARE INCORPORATED

IN THE SUBROUTINE BOUD

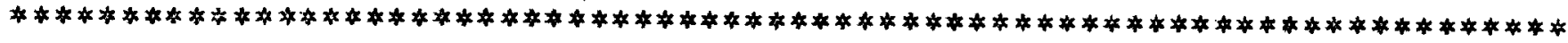

IMPLICIT REAL*B $(\mathrm{A}-\mathrm{H}, \mathrm{C}-\mathrm{Z})$

EXTERNAL FUNC

DIMENSION Y (15), F(15), T (15), S (15), G (15), DUSTC (4)

DIMENSION AX (30), AY (30),AZ (30), AM (30)

DIMENSION RD (100), RBD (100), RVHD (100), RVCOD $(100), R V D(100)$

DIMENSION ATTD $(100), C O 2 D(100)$, RND (100),ROD $(100), S H D(100)$

DIMENSICN COD $(100), H D(100), R A T D(100), B P(11)$

DIMENSION RS (12)

DIMENSION TSD (100), TUD (100), TGD (100), DIST (100), AIRD (100), TCD (100)

LOGICAL SHCHB, SHCHV,SHCHA, SHCHR,SWCC,PIN, PAN

$\mathrm{COMMON} / \mathrm{SH} / \mathrm{SHCH}$

LOGICAL SHCH, SH2

COMMON/ANDY/XG (30), YG (30), ZG (30)

COMMON/DISTAN/BP

COMHON/PARAM/TSD,TWD,TGD,TCD, DIST, AIRD

COMMON/CL/CLPX, OTME

COMMON/PARAM 1/RD, RBD, RVHD, RVCOD, RVMD, SHD

COMHON/EARAM2/WATD,CO2D,RND, ROD,COD, HD, RATD

COMUON/COAD/FEED (3), GANGO (5)

COMMON/CFAD/FLUX (4), GANGF (5)

COMMON/CCAD/COAL (12), AASH (6)

COMMON/ADJDST/PAR1,PAR2, REDP, BURN, TLEN

COMMON/COMH/RLEN,D(14),ALEN,OXY

COMMON/DCPS/DCPORE, DCFCOA,DCPDOL

COHMON/RNEH/TOTNI, TOTCO, TOTCD, TOTET, TOTPR, TOTHY

COHMON/CPS/CPOBE, CPCOAL,CPDOI

COMMON/BANG/CVGS,RAGS,CVGH, RAGH,CDWS, RAWS

COMMON/PRESS/PPR (9) 
COMMON/POLY/P $(11,25), 0(11,32)$

COMMON/SPECT/FEO,FE2O3,EE3O4,FE

COMMON/DUSTS/ODUST,CDUST, ADUST,DL1, DL 2

COMMON/EDUSTS/RODT, RCDT, RADT

COMYON/EMISS/EMIS, AESS, ABSH

COMMON/ARC/CHORD, ARCA, ARCB, ARCC

COMHON/RPAR/EL,DIAM

COMMON/SWITCH/PIN,PAN

COMMON/AREAS/AW, AS, AG

COMMON/GASHTR/GCVS,GES, GCVH,GR月, GSWT,RHVH

COMMON /HTCOEF/HCVGSC, HRGSC, HRWSC, HCWSC, HCVGWC, HRGWC, HCV HAC

COMMON/HTRFER/HCVS, HRGS,HRHS, HCWS, HRST

COMMON/TEMP/TWAL, THALN

COMMON/THICK/RX (3), RK (3),AIDIA

COMMON/COMBR/RBCO, RBH, REM, RBE, BBP, RBO

COMMON/DRYR/ORED, DOLOD, DOLOC

COMMON/FROD/RPCO2, BPH 20

COMMON/CFLUX/FLUXO, FLUXD

COMMON/TWITCH/SWCHB,SWCHV,SWCHM, SWCHR, SHCC

COMMCN/BCRE/RHBO,RHVOL,RHDO, RHDRY,RHRED, RHBG, RFSB

COMMON/FILE/GH $(11,9)$

COMMON/HYC/CETH, CPRO

COMMON/IAST/AIR, RMOIS,VGAS,GAS (3), N1, N2

COMMON/EEACT/HFORM (30)

COMMON/CPST/AX,AY,AZ

COMHON/BUD/RC, RO,RCO2, RCO, RCB

COMMON/DEGR/RMAS,RMETH, RCOUNT, REATER, RCHECK

COMHON/VCLT/RVH,RVCO,RVCO2,RVM, RVE, RVP,RVN,RVT, RHO, RCM

COMMON/DELT/RINT

COMMON/CAMG/PACT

COMMON /MISSED/ROXYT,ROXYN, TOTFE

COMMON/RATES/RNIT, RMOI,RME, RET,RPR, ROX, RHGAS

COMHON/AMBI/TAIR,TNAT

COMMON/MISSIN/ARED, AOLCD, AOLOC

NAMELIST/LISTA/ORE, REDC, DOLL, AIR

NAMELIST/LISTE/FEED,GANGO

NAMELIST/LISTC/COAL, AASH

NAMELIST/LISTD/FLUX,G ANG F

NAMELIST/LISTE/RHOIS, TAIR, TNAT, VGAS, AMET, RTME, N1, N2

NAMELIST/LISTF/RX, RK

NAMELIST/LISTG/RLEN, DIAM, FILL

NAMELIST/LISTH/PAR1,PAR2,BURN,TLEN, REDP

NAMELIST/LISTI/DUST,DI1,DL2, DUSTC

READING INPOT DATA FOR THE PROGRAM

READ $(5,10)$ ORE, REDC, DOLI, AIR

$\operatorname{READ}(5,10)(\operatorname{REZD}(I), I=1,3)$

$\operatorname{BEAD}(5,10)$ (GANGO (I), $I=1,5)$

$\operatorname{READ}(5,10)(\operatorname{COAL}(I), I=1,12)$

$\operatorname{READ}(5,10)(\operatorname{AASH}(I), I=1,6)$

$\operatorname{READ}(5,10)$ (FLUX (I), $I=1,4)$

$\operatorname{READ}(5,10)$ (GANGF (I), $I=1,4)$

READ $(5,10)$ RMOIS

$\operatorname{READ}(5,10)(\operatorname{GAS}(I), I=1,3)$

READ $(5,10)$ BDOR, BDCL, BCDI

$\operatorname{KEAD}(5,10)(R X(I), I=1,3)$

$\operatorname{KEAD}(5,10)(\mathrm{RK}(\mathrm{I}), I=1,3)$

READ $(5,10)$ TAIR, TNAT

10 FORMAT (8610.4)

READ $(5,10)$ VGAS,N $1, N 2$

$\operatorname{READ}(5,10)$ AMET 
$\operatorname{BEAD}(5,10) \operatorname{RTME}$

READ $(5,10)$ RLEN, DIAH, FILL

CALL FREAD (5, 'REAL...' PAR1, PAR2, EURN, TLEN,REDP)

$\operatorname{READ}(5,10) \operatorname{AMAXL}$

$R E A D(5,10)$ DUST, DL 1, DL 2, (UUSTC (I), I=1,3)

$\operatorname{READ}(5,10)$ TSIN

C READ COEFFIENTS OF SPECIFIC HEAT

DO $15 I=1,25$

$\operatorname{READ}(5,10) \operatorname{AX}(\mathrm{I}), A Y(I), A Z(I), A M(I)$

$X G(I)=A Y(I) / A M(I)$

$X G(I)=A Y(I) / A M(I)$

$Z G(I)=A Z(I) / A M(I)$

15 CONTINUE

C READ STANDARD HEATS OF FORMATIONS

DO $25 \quad I=1,25$

$\operatorname{READ}(5,31)$ HFORM (I)

31 FORMAT (F10.4)

25 CONTINUE

$\operatorname{READ}(5,33)$ NUМB

33 FORMAT (I 1)

C POLYNOMIAL COEFFICIENTS FOR DESCRIBING EMISSIVITY OF CO2 DO $50 \quad J=1.25$

50 CONPINUE

C POLYNOMIAL COEFFICIENTS FOR DESCRIBING EMISSIVITY OF H2O DO $56 \quad J=1,32$

$\operatorname{KEAD}(4)(Q(I, J), I=1,11)$

56 CONTINUE

C COEFFIENTS OF THE POLYNOMIAL FOF THE RENOVAL OF VOLATILES

C FROM COAL

DO $30 \mathrm{~K}=1,7$

30 CONTINUE

WRITE $(6$, LISTA)

WRITE $(6, \operatorname{LISTB})$

WRITE (6.IISTC)

WITE $(6$, LISTD)

WRITE (6.LISTE)

WRITE $(6$, LISTF)

WRITE (6, LISTG)

WRITE (6, LISTH)

HRITE (6,LISTI)

C CALCULATION OF AREAS OCCUPIED BY GAS AND SOLIDS

$A S=(3.1416 * D I A B$ DIAM/4.) *FILL

$A G=(3.1416 * D I A M * D I A M / 4) *.(1 .-P I L L)$

CALL ANGIE (FILL, ALPHA)

C CALCULATION OF DIFFERENT ARC LENGTHS

$C H O R D=D I A M * D S I N(A L P H A / 2$.

$A R C A=3.1416 * D I A M *(1 .-(A I P B A /(2 . * 3.1416)))$

$A R C B=3.1416 * D I A-A R C A$

C CALCULATION OF THE EFFECTIVE BEAMLENGTH FOR RADIATION $\mathrm{RAD}=\mathrm{DIAM} / 2$.

$E L=0.9 *(R A D+R A D * D C O S(A L E H A / 2)$.

$A W=A S+A G$

$A R C C=A R C A+A R C B$

$P I N=$. TRUE.

PAN $=$. TRUE.

TERM $=454 . /(A S * 3600$.

ODUST=DUST*DUSTC (1) *TERA

CDUST $=$ DUST *DUSTC $(2) * T E R M$ 
ADUST=DUST*DUSTC (3) *TERA

RMAS $=O R E * 2000 . * 454 . /(3600 . * A S)$

$O C O A L=R E D C * 2000 . * 454 . /(3600 . * A S)$

$O D O L=D C L L * 2000 . * 454 . /(3600$.*AS)

$A L E N=10.0$

H

RMETH $=0.0$

EW ATER $=0.0$

KCOUNT $=O C O A L * C O A L(3)$

TOTNI $=O C O A L$ COAL $(8)$

TOTCO = CCOAL *COAL (5)

TOTCD $=O C C A L * C O A L(11)$

TOTET $=$ CCCAL *COAL (4)

TOTPR =OCOAL * COAL (12)

TOTHY =CCOAL *COAL (6)

ROXYT $=$ RNAS*0.3*FEED (1)

ROXYN $=$ ROXYT $($ ROXYT*AMET)

TOTFE = FHAS*FEED (1) *0.7

FLUXD $=$ ODCL

FLUXO=RMAS

$A R E D=F I U X O * F E E D(2) /(R I E N * 0.5)$

$A O L O D=F L U X D * F L U X(4) /($ RLEN $* 0.5)$

$A O L O=F L U X D * F L U X(1) * 44 . / 100.08+F L O X D * F L U X(2) * 44 . / 84.32$

$A O L O C=A O L O /(R L E N * 0.333)$

$S$ HCHV $=$. FALSE.

$S W C H R=$.FALSE.

SUCHH= .FALSE.

$\mathrm{SHCH}=$. TRUE.

$S$ WC $=$. THUE.

$S W 2=$. TRUE.

FLOXO=RMAS

$C L F X=O C O A L$

FLUXD $=O D O L$

$C E T H=C L F X * C O A L(4) /(R L E N * 0.333)$

$C P R O=C L F X * C O A L(12) /(R L E N * 0.333)$

$F A C ?=F L U X(1) / F L U X(2)$

CALL AIRE $(10$, ASK)

$\mathrm{GLEN}=\mathrm{BP}(\mathrm{N} 1)-\mathrm{BP}(\mathrm{N} 2)$

$V G A S=V G A S * 0.472 /(G L E N * A G)$

C INITIALISING VALUES OF THE DEPENDENT VARIABIES

C ATTHE DISCHARGE END OF THE KILN

$Y(1)=$ KMAS- (FEED (2) *RMAS+AMET*RMAS*FEED (1)*0.3)-ODUST

CCCN $=$ RMAS *FEED $(1) * 0.3 * A H E T * R E D P * 12 . / 16$.

$\mathrm{CCON}=\mathrm{CCCN}+\mathrm{CCON} * \mathrm{BURN}$

$Y(2)=O C O A L-(O C O A L(C O A L(2)+\operatorname{COAL}(3)+\operatorname{COAL}(4)+\operatorname{COAL}(5)+\operatorname{COAL}(6)+\operatorname{COAL}(7)$

$1+\operatorname{CCAL}(8)+\operatorname{COAL}(11)+\operatorname{COAL}(12)))-\operatorname{CCON}-A \mathrm{DUST}-\mathrm{CDUST}$

$Y(3)=O D C L-1 O D O L * F L U X(4)$ +ODOL*FLUX(1)*(44./100.) +ODOL*FLUX (2)*(44./

$184.321)$

$\mathrm{N}=14$

DO $60 \quad I=4,12$

$Y(I)=0.0$

60 CONTINUE

$Y(4)=A I R * 0.472 * 0.79 * 28 . /(A G * 22.4)$

$Y(5)=A I F * 0.472 * 0.21 * 32 . /(A G * 22.4)$

$Y(13)=$ TSIN

$Y(14)=20$.

DO $70 \quad I=1,14$

$D(I)=Y(I)$

70 CONTINUE

RCHECK $=$ CCOAL $*$ COAL (2) 
UTME $=R T M E / R L E N$

$S$ HCHB $=$. TRUE.

C

ANALYSIS OF THE SULIDS AT THE DISCHARGE END

SORZ=3MAS*FEED (1)-RMAS*AMET*FEED (1)*0.3-ODUS1

$S O G=R M A S * F E E D(3)$

$\operatorname{PRED}(2)=0.0$

$\operatorname{FEED}(1)=S O R E /(S O R E+S O G)$

EEED $(3)=S C G /(S O B E+S O G)$

$S F C=O C C A L * C O A L(1)-C C O N-C D U S T$

CSAS $=O C C A L * C O A L(9)-A D U S T$

CSUL $=O C O A L O O A L(10)$

CSTO $=S F C+C S A S+C S U L$

$\operatorname{COAL}(1)=\mathrm{SFC} / \mathrm{CSTO}$

DO $220 \quad I=2,8$

$\operatorname{COAL}(I)=0.0$

220 CONTINUE

$\operatorname{COAL}(9)=\operatorname{CSAS} / \operatorname{cs} \mathrm{CO}$

COAL $(10)=$ CSUL $/$ CSTO

$\operatorname{COAL}(11)=0.0$

$\operatorname{COAL}(12)=0.0$

$S C A C=E I \Pi X(1) * O D O I *(1 .-(44 . / 100)$.

SMGO=ELUX (2) *ODOL* $(1 .-(44.184 .32))$

IF (ODOL. $\$ 0.0 .0) G O$ TO 230

$S D G=F L U X(3) * O D O L$

$S G T=S C A C+S M G C+S E G$

$\mathrm{FLUX}(1)=5 C A O / S G T$

PLUX (2) $=5 M G O / S G T$

FLUX (3) $=S D G / S G T$

PLUX $(4)=0.0$

230 CONIINUE

$D I F F L=D I 2-D L 1$

ODUST $=$ CDUST $/ D I F E L$

$\because D U S T=C D U S T / D I F F I$

$A D U S T=A D U S T / D I F F L$

$A I R C=A I R$

TS $=200$.

$\mathrm{RABOA}=0.0$

RHVOLA $=0.0$

RHDOA $=0.0$

IA $A R E D A=0.0$

HRSTA $=0.0$

$\operatorname{RFSBA}=0.0$

तi $H B G A=0.0$

$G S \mathrm{TA}=0.0$

RHGASA $=0.0$

RHVMA $=0.0$

RHDRYA $=0.0$

$A: D I A=D I A M$

$T$ TAL $=885$.

CALL PQRESS

TWALN=TKAL

CALL HTRATE

CAIL WAIL (WICSS,TS)

TWAL $=$ TWAIN

$\operatorname{DIST}(1)=0.0$

$\mathrm{RD}(1)=\mathrm{AMET} * 100$.

WATD $(1)=0.0$

$\operatorname{Co} 2 D(1)=0.0$

$\operatorname{RND}(1)=0.79$

$\operatorname{KOD}(1)=0.21$ 
$\operatorname{con}(1)=0.0$

HD $(1)=0.0$

$\operatorname{Tsi}(1)=Y(13)$

$\mathrm{Z} \mathrm{G} D(1)=Y(14)$

IB $D(1)=$ THALN

$\operatorname{ICD}(1)=$ TWALN

$\operatorname{AIN} \mathcal{L}(1)=0.0$

i] $=1$

$E=.001$

$H=10.0$

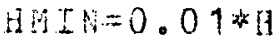

$D Y Y=1 .-A M E T$

औरT $\mathrm{K} E(6,240)$

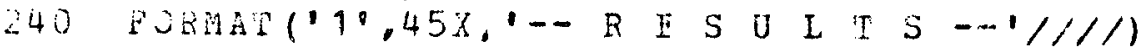

$A L E N=0.0$

$O I N I=Y(1) * A S$

C.INI $=Y(2) * A S$

DINI $=Y(3) * A S$

CALL HEATS

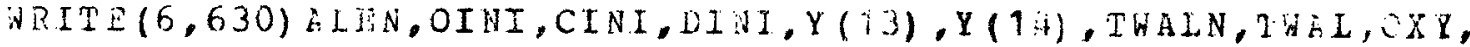
IHWLOS

$x=0.0$

$500 \quad$ CONTINUE

$M=M+1$

DO $750 \quad I=1.5$

$Z=X+H$

$\Lambda L E N=Z$

$\mathrm{BINT}=Z-X$

CALL OXIDE

CGIL HEATS

CALL DERIV

CALL BCUD

CALL RATE

CALL PPRESS

CALL AIRR (RAIR)

CAIL DRYING

CELL BUENT

CALL RAPE

CALL HEURN

200 CONTINUE

CALI， ATRATE

EALI WALL (WLOSS,TS)

IF (DABS (TWALN- MAL) . LE. 2.0) GO TO 1400

TAAL $=$ TWLN

GO TO 200

1400 CONTIAUE

CALI DRKC $(N, X, Z, Y, P, H, B G I N, Z, F U N C, G, S, T)$

HWLOSS $=$ H LOSS + WLCSS $*$ RINT

$A I \mathrm{I} C=A I B C+\mathrm{BIN} \mathrm{P}^{*} \mathrm{RAIR}$

RHBOA $=$ RHEOA+ RHBO RINT*AS

RHVOLA = PHVOLA+RHVOL RINT*AS

BHDOA = FHICA + HHDO*RINT*AS

KIIIEEDA = RHEEDA+RHRED*RINT *AS

HRSTA $=$ HRSTA+HRST *RINT AS

K $\overrightarrow{2} \triangle B A=$ ITFSBA+RFSB*RINT*AS

AHEGA $=\pi H B G A+R H B G * R I N T * A G$

GSWTA $=G S W T A+G S W T$ RINT*AG

RHGESA $=$ RHGASA+RHGAS*RINT*AG

EHVHA $=9 H V M A+R H V M * R I N T * A G$

RHDRYA=RHEFYA+EADRY*RINT*AS 
$\operatorname{IF}(X \cdot G E \cdot A \cap A X L) \operatorname{Si} 2=$. FALS: .

$I F(Y(13) \circ G E .1200) S W 2=$.. ALSE.

IF (Y (13) . LE. 20.) SW 2=.FAISE.

CALI ANGIYS

CALI, DEGBEE

CAIL CCNTCL

Do $610 \quad K=1,14$

$j(K)=Y(K)$

510 CONTINOE

750 CONTENUF

$Y G K=X(1+)+27.3$.

$C P N=C D(14, Y G K)$

$C P C J=C S(19, Y G K)$

$C E 0 O 2=C P(12, Y G K)$

$\angle P O=C P(13, Y(B K)$

RQIIE $(6,770)$ CPN, CPCO, CECO2,CPO

770 PUEAR $(4 X, 4(\mathrm{~F} 5.4,2 \mathrm{X}))$

IF (RUAB.NE. 1) GO TO 666

CALL WRCEE

666 CONIINBE

SALL CCRECT $(Y(14)$, TWAIN, TC)

D) $620 \mathrm{~J}=1,3$

$\operatorname{BS}(\mathrm{J})=\mathrm{Y}(\mathrm{J}) * \mathrm{AS}$

520 CONIINUE

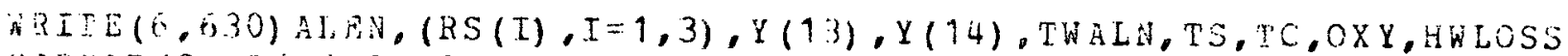

$630 \mathrm{~F}) \mathrm{RMAT}(2 \mathrm{X}, \mathrm{FG}, 1,2 \mathrm{X}, 3(\mathrm{~F} 8.1,4 \mathrm{X}), 5(\mathrm{FG}, 1,3 \mathrm{X}), 1 \mathrm{X}, \mathrm{F} 6,4,4 \mathrm{X}, \mathrm{FB}, 1 /)$

i) $650 \mathrm{~J}=4,12$

$\mathrm{SiS}(\mathrm{J})=\mathrm{Y}(\mathrm{J}) * \mathrm{AG}$

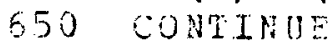

WPTTE $(\dot{0}, 535)(R S(J), J=4,12), A I R C$

O35 EORMAT $(2 X, 10(F 8.1,4 X))$

ATITE $(5,640)$ (PPR (I), I=1,9)

640 EOHAT $(8 X .9(55.2 .4 X) / 1 / 1)$

c STORING VALUES FOR THE PLOTS

$\operatorname{DIST}(M)=\operatorname{MIEN}$

$\mathscr{E D D}(M)=\mathrm{TC}$

$\operatorname{TSD}(M)=Y(13)$

TGD $(M)=Y(14)$

IND $(M)=T$ T

$\operatorname{sid}(x)=\operatorname{TS}$

$A I D D(M)=\operatorname{RAIS}$

ISD $(\mathrm{HI})=(1 .-O X Y) * 100$.

IS $3 D(M)=R C * 10 * *(5)$

RVID (IS) $=$ RVH

$R V C O D\left(N_{j}\right)=R V C O$

IIVMD $(M)=$ EVM

$\operatorname{ASD}(M)=\operatorname{PES}(6)$

$\operatorname{CO} 2 D(M)=\operatorname{EER}(3)$

$3 \mathrm{AD}(M)=\mathrm{PFR}(1)$

SOD $(M)=P P R(2)$

$\therefore 2 D(M)=$ PFR (4)

(AD $(M)=\operatorname{PEF}(9)$

b6C OONENUE

IF (.NOT.SW2) GO LO 555

Gis 500

555 CONTINU

WEITE $(6,570)$ RHBOA, RHVCLA, RHDOA, EHREDA, HRST, REDEYA

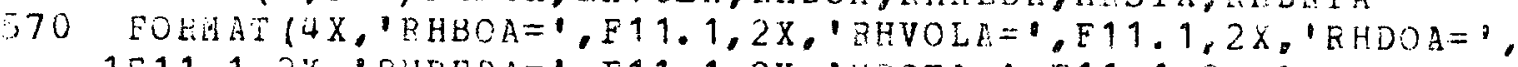

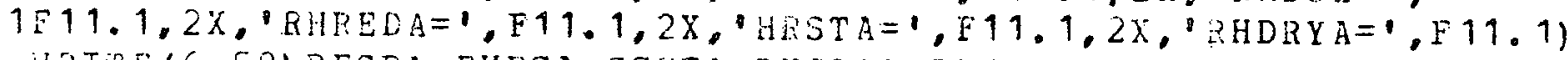

WRITE $(6,58)$ RESEA, RHEGA, GSWTA, RHGASA, RHVMA 


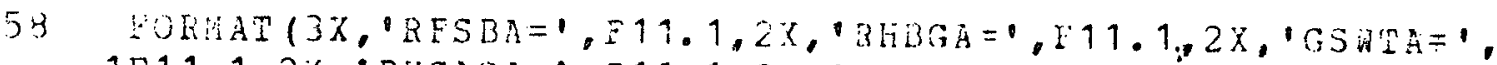

$1 F 11.1,2 X, ' R H G A S A=1, F 11,1,2 \%, \cdot$ KHVMA $=1, F 11.1)$

CALL $\because A N O(M)$

CALL BLCTND

d

STOP

END

C

$\mathrm{C}$

$c$

$\mathrm{C}$

C

$\begin{array}{lllll}\text { THIS } & \text { SDBEOUIINE CAICUIATES THE AVERAGE } & \text { VALUE CF } \\ \text { DCP/DS FOR ORE, CCAL AND COLOMITE } & \end{array}$

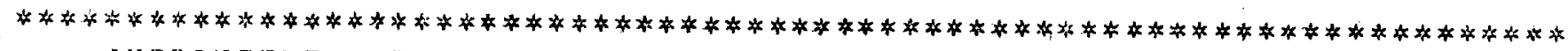

SUBRCUTINE DERIV

IMPLICIT REAL*8 $(A-\mathrm{H}, \mathrm{C}-2)$

COMMON/ANDY/XG(30), YG(30), ZS (30)

COMHON /DCES/DCPOEB, DCECOA, DCPDOL

COMUCN/CCMM/RLEN,D(14), ALEN,OXY

COMMON/CCAD/FEED (3), GANGO (5)

COUMON/CFAD/FI.UX (4), GANGF (5)

COMHON/COAD/COAL (12), AASH (6)

COMMON/CFLUYY ELUXO, ELUXD

COMUCN/SEECY/FFO,FE2O3, EE 304, EE

$C$ AVERAGE DCP OF ORE

$D T=D(13)+273$.

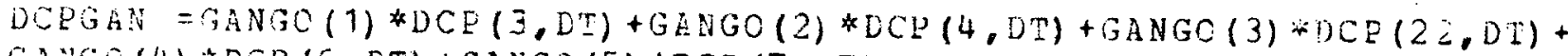
$1 G A N G C(4) * D C P(6, C T)+G A N G O(5) * D C P(7, D T)$

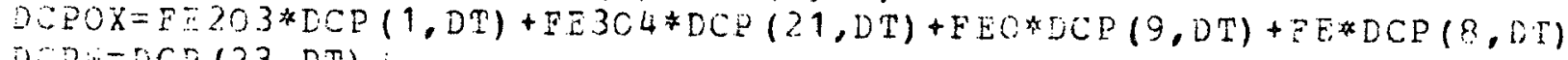

i) $C D=D C E(23, D T)$

DCPORE= CCDOX FEEC (1) + LCEN*FEED(2) +DCEGAN*FEED(3)

c

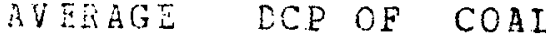

DCPASH $=$ A SSH (1) *DCP $(3, D T)+A A S H(2) * D C P(4, D T)+A R S H(3) * D Q P(22, D T)+A A S H$ $1(4) * \operatorname{DCP}(9, D T)+\operatorname{AASH}(5) * \operatorname{DCP}(6, D T)+\operatorname{AASH}(6) * D C P(7, D T)$

$D C P C C A=C C A L(1) * D C P(2, D T)+C O A L(2) * D C P(23, D T)+C C A I(3) * D C P(17 . D T)+C O A$

$1 L(4) * D C P(16, D T)+C C A L(5) * D C P(11, C T)+C O E L(6) * D C P(15, D T)+C O A L(7) * D C P($ $213, D T)+\operatorname{CCAL}(8) * D C P(14, D T)+\operatorname{COAL}(9) * D C P A S H+\operatorname{COAL}(10) * D C P(5, D T)+\operatorname{COAI}(1$ 31) $* \mathrm{D})(12, \mathrm{DT})$

IE (FLUXD.EQ.0.0) GO TO 99

$I=10$

$\mathrm{J}=20$

$I P(D(13) .62 .650) I=$.

I: (D) (13) . ST T .500.) $\mathrm{I}=7$

$D C P D G=G A H G F(1) * D C P(3, E T)+G A N G F(2) * D C P(4, D T)+G A N G E(3) * D C D(22, D T)+G A$

$1 \mathrm{NGI}(4) * D C P(9, D \mathrm{~T})$

$D C P D O L=F L U X(1) * D C P(I, I T)+E L U X(2) * D C P(J, D I)+F I U X(3) * D C E D(j+E T, U X(4) * D$

$1 C P(23, D I)$

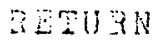

99 DCFLCL $=0.0$

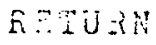

END

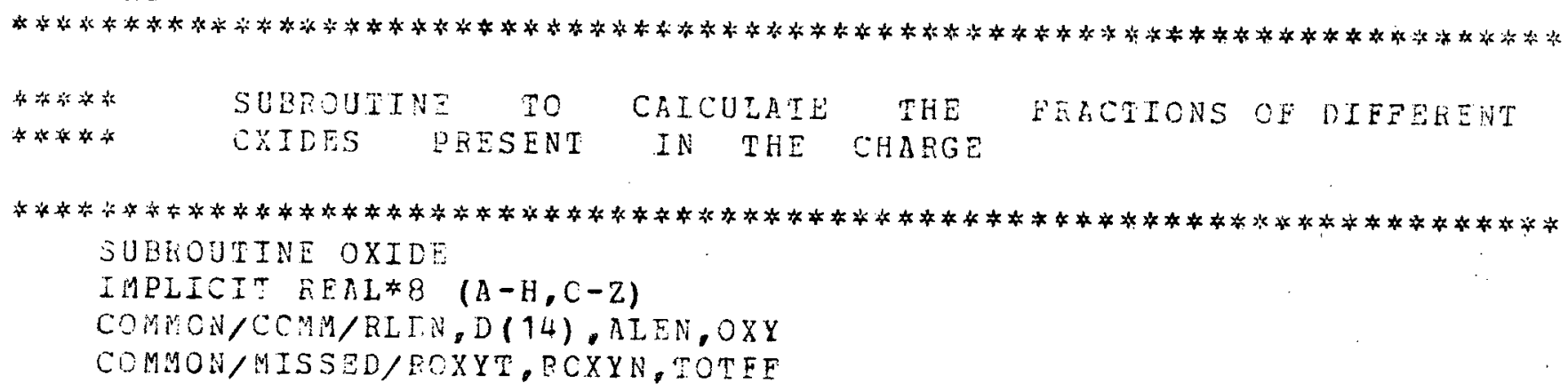


IP (OXY.LT.0.652) GO TC 40

IF (OXY.GT.0.662.AND.OXY.LE..883) GO TO 50

C

THE SEECIES PRESENT ARE FE2O3,FE304

$F E O=0.0$

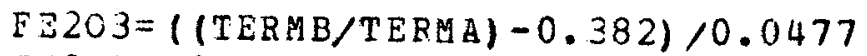

FE $304=(1 .-F E 203)$

$\mathrm{F} E=0.0$

GO TO 100

$\begin{array}{lllll}C & \text { THE SPECIES ERESENT ARE FE3O4 AND FEC } \\ 50 & \text { FE2O3 } & 0.0\end{array}$

EE $304=($ (TERMB $/$ TERMA) -0.2865$) / 0.0955$

$F E C=1 .-E E 304$

$\mathrm{FE}=0.0$

GO TO 100

C SPECIES FRESENT ARE FEO AND FE

$40 \quad F E 203=0.0$

$F E 304=0.0$

EEO $=($ (TERMB $/ T E R M A) / 0.2865)$

$F E=1 .-F E C$

100 CONTINUE

RETURN

iND

C

C

$\mathrm{C}$

$\mathrm{C}$

$\mathrm{C}$

C

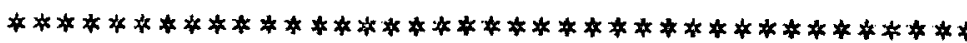

THIS SUBRODTINE CAICULATES, THE AVERAGE SPECIFIC

HEATS CF ORE, COAL AND DCLOMITE

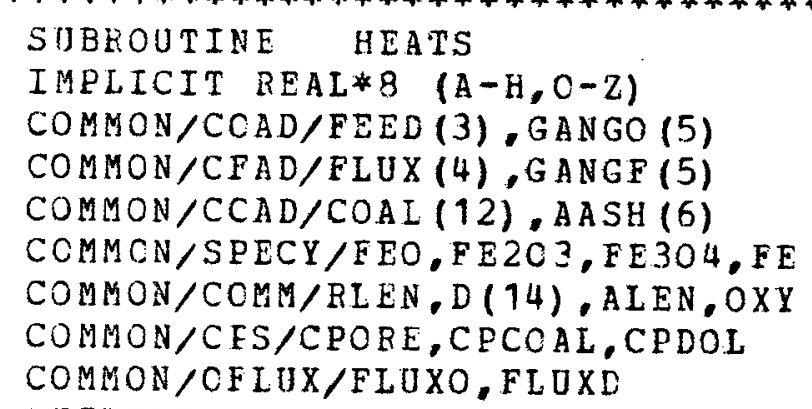

C AVERAGE CP OF ORE

$\mathrm{TO}=\mathrm{D}(13)+273$.

$C P G A N G=G A N G O(1) * C P(3, T O)+G A N G O(2) * C P(4, T O)+G A N G O(3) * C P(22, T O)+G A N G$

$10(4) * C P(6, T O)+G A N G O(5) * C P(7, T C)$

$C P C X=F E 2 O 3 * C P(1, T O)+F E 304 * C P(21, T O)+F E O * C P(9, T O)+F E * C P(8, T O)$

$C P W=C P(23, T O)$

$C P O R E=C P C X * F E E D(1)+C P * F E E D(2)+C P G A N G * F E E D(3)$

C SPECIEIC HEAT OF COAL

$T C=D(13)+273$.

CPASH=AASH $(1) * C P(3, T C)+\operatorname{AASH}(2) * C P(4, T C)+\operatorname{AASH}(3) * C P(22, T C)+\operatorname{ASH}(4) *$

$1 C P(1, T C)+A A S H(5) * C P(6, T C)+A A S H(6) * C P(7, T C)$

$C P C O A L=C O A L(1) * C P(2, T C)+\operatorname{COAL}(2) * C P(23, T C)+\operatorname{COAL}(3) * C P(17, T C)+\operatorname{COAL}(4$

1) *CP $(16, T C)+\operatorname{COAL}(5) * \operatorname{CP}(11, \mathrm{TC})+\operatorname{COAL}(6) * \mathrm{CP}(15, \mathrm{TC})+\operatorname{COAL}(7) * \mathrm{CP}(13, \mathrm{TC})+$

$2 \operatorname{COAL}(8) * \operatorname{CP}(14, \mathrm{TC})+\operatorname{COAL}(9) * \operatorname{CPASH}+\operatorname{COAL}(10) * \operatorname{CP}(5, \mathrm{TO})+\operatorname{COAL}(11) * \operatorname{CP}(12,1$ 3 )

C AVERAE SPECIFIC HEAT OF DOLOMITE

IF (FLUXD.EQ.0.0) GO TO 99

$\mathrm{TD}=\mathrm{D}(13)+273$.

$I=19$

$\mathrm{J}=20$ 
$I F(D(13) \cdot G T \cdot 650) I=$.

IF (D (13) . GT.500.) J=7

$C P D G=G A N G F(1) * C P(3, T D)+\operatorname{GANGF}(2) * C P(4, T D)+G A N G F(3) * C P(22, T D)+G A N G F($ 14) $* C P(9, T D)$

$C P D O L=F L U X(1) * C P(I, T D)+F L U X(2) * C P(J, T D)+F L D X(3) * C P D G+F L U X(4) * C P(23$ $1, T D)$

RETURN

$99 \quad$ CPDOL $=0.0$

RETURN

END

C

$\mathrm{C}$

$\mathrm{C}$

* * Calculaticn of hall temperature

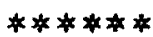

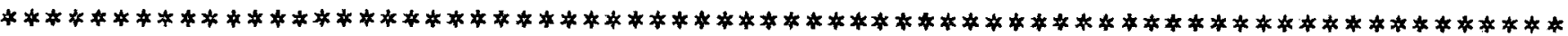

SUBRUUTINE WALI (WLCSS, TSUR)

INPLICIT REAL * $8 \quad(\mathrm{~A}-\mathrm{H}, \mathrm{C}-\mathrm{Z})$

LOGICAL EIN, PAN

COMMON/ARC/CHORD, ARCA, ARCE, ARCC

COMAON/AREAS/AW, AS, AG

COMMCN/CCMM/RLEN,D(14), ALEN, OXY

COMMON/TFMP/THAL,TRALN

COMMON/HTCOEF/HCVGSC, HRGSC, HRGSC, HCWSC, HCVGWC, HRGWC, HCVWAC

COMMON/THICK/RX (3), RK (3), AIDIA

COMMON/SWITCH/PIN,PAN

IF (.NOT.PAN) GO TO 10

TOUTC $=15$.

TAMBIC $=$ TSUR

TDIFF $=($ TAMBIC-TOUTC $) * 1.8$

$\mathrm{HTCON}=0.000135 * 1.69$

STEFAN $=1.355 \mathrm{D}-12$

TOUTK $=$ TOOTC +273

$T A M B K=T A M B I C+273$.

HTRAD $=0.9 * S T E F A N *$ (TOUTK**4-TAMBK* 4 )/(TOUTK-TAMBK)

if TSA $=$ HTRAD +HTCON

$R O=A I D I A / 2$.

$\mathrm{R} 1=\mathrm{R} 0+\mathrm{RX}(1)$

R $2=R 1+R \times(2)$

R. $3=R 2+R \times(3)$

$R E S A=(B 1-R 0) /(3.1416 * R K(1) *(R 1+R 0))$

$R E S B=((R 2-R .1) /(3.1416 * R K(2) *(R 2+R 1)))$

$\operatorname{RESC}=1 . /(\operatorname{HTSA} * 2 . * 3.1416 * \mathrm{R} 3)$

$H W A O C=1 . /(R E S A+R E S B+R E S C)$

PAN $=$. FAISE.

CALCULATION OF HEAT LOSS FROM OUTSIDE TO AMBIFNT CONDITION

CALCULATICN OF HALI TEMPERATURE

HGWOC=HCVGWC +HBGWC

$\mathrm{HWSOC}=\mathrm{HBWSC}+\mathrm{HCWSC}$

$T$ TLN $=(H G W C C * A R C A * D(14)+H R W S C * C H O R D * D(13)+H W A O C * T O U T C+$

$1 \mathrm{HCWSC} * A R C B * D(13)) /(H G W O C * A R C A+H R W S C * C H O R D+H W A O C+H C W S C * A R C B)$

WLOSS $=$ HWAOC* (TWAL-TOOTC)

TSUR =HWACC* (TWAL-TOUTC) *RESC+TOUTC

RETURN

END

† 
$* * * * * * * * * * * * * * * * * *$
SUBROUTINE BAPR

IMPLICIT REAL*8 $(\mathrm{A}-\mathrm{H}, \mathrm{C}-\mathrm{Z})$

COMMCN / RRCD/RPCO2, RPH 20

COMMON/CCMBR/RBCO, RBH, REM, RBE, RBP, RBO

$R P C O 2=R B C O * 44 . / 28 .+R B M * 44 . / 16 .+R B E * 88 . / 30 .+R B P * 132 . / 44$

$\mathrm{RPH} \angle \mathrm{O}=\mathrm{RBH} * 18 . / 2 .+\mathrm{RBM} * 36 . / 16 .+\mathrm{RBE} * 54 . / 30 .+\mathrm{RBP} * 72 . / 44$.

RETUEN

END

$C$
$C$
$C$
$C$
$C$
$C$
$C$
$C$

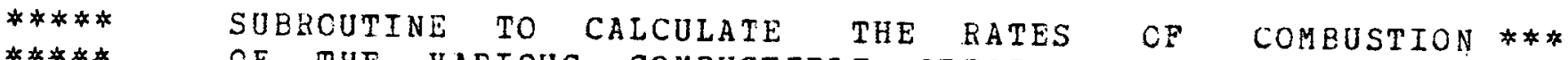

$* * * *$

OF THE VARICUS COMBUSTIBIE SPECIES

$* * *$

$\mathrm{C}$

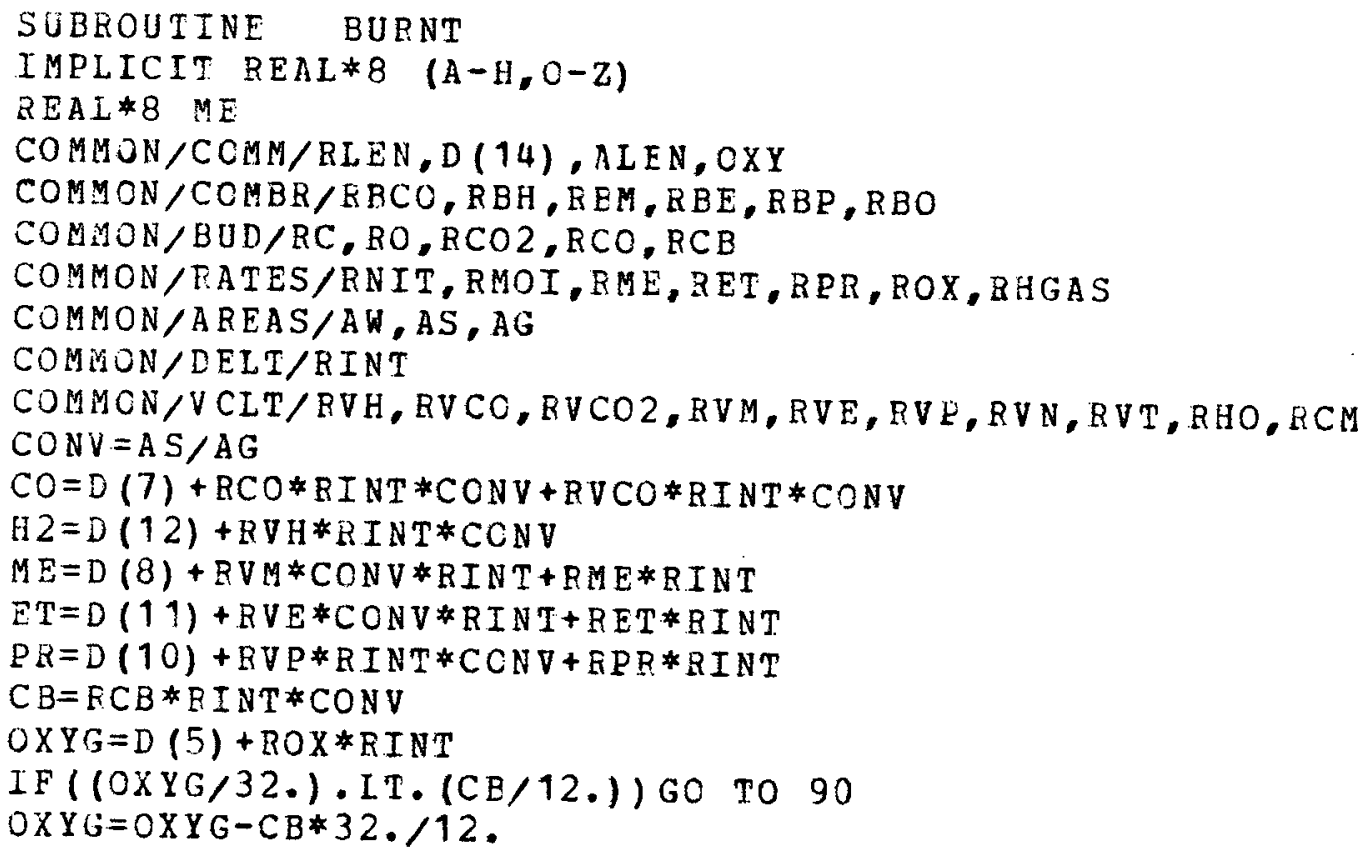

CHECK TO SEE WHETHER OXYGEN PRESENT IS SUFFICIENT

TO BURN CARBCN MONCXIDE

IF $((O X Y G / 16.) \cdot I T \cdot(C O / 28)$.$) GO TO 100$

$\mathrm{BBCO}=\mathrm{CO}$

$O X Y G=O X Y G-R B C O * 16, / 28$.

IF $((O X Y G / 16.) \cdot L T \cdot(H 2 / 2)$.$) GO TO 110$

$\mathrm{RBH}=\mathrm{H}_{2}$

$O X Y G=O X Y G-R B H * 16 . / 2$.

$\operatorname{IF}((O X Y G / 64.) \cdot L T \cdot(M E / 16)$.$) GO TO 120$

$R B M=M E$

$O X Y G=O X Y G-R B M * 64 . / 16$.

$\operatorname{IF}((O X Y G / 112.) \cdot \operatorname{TT} \cdot(\mathrm{ET} / 30)$.$) GO TO 130$

$R B E=E T$

$O X Y G=O X Y G-R B E * 112 . / 130$.

$I F((O X Y G / 160.) \cdot L T \cdot(P R / 44)$.$) GO TO 140$

$\mathrm{HBP}=\mathrm{PR}$

GO TO 999

$90 \quad \mathrm{KCB}=0 \times Y G * 12$ * $A G /(\mathrm{RINT} * 32 . * A S)$

$\mathrm{RBCO}=0.0$

$\mathrm{RBH}=0.0$

$R B M=0.0$

$R B E=0.0$

$\mathrm{RBP}=0.0$ 
Go To 939

100

$R B C O=(C X Y G / 16) *$.28 .

$\mathrm{RBH}=0.0$

$R B Y=0.0$

$R B E=0.0$

$\mathrm{BBP}=0.0$

GO TO 999

$110 \quad \mathrm{BBH}=(\mathrm{OXYG} / 16) *$.2 .

E B $=0.0$

$R B E=0.0$

$K B P=0.0$

GO TO 999

$120 \quad R B M=O X Y G * 16 . / 64$.

R. $B E=0.0$

$\mathrm{KBP}=0.0$

GO TO 999

$130 \quad \mathrm{RBE}=\mathrm{OXYG} * 30 . / 112$

$\mathrm{RBP}=0.0$

GO TO 999

$140 \quad R B P=O X Y G * 44 . / 160$.

999 CONTINUE

$\mathrm{RBO}=\mathrm{RBCC} * 16 . / 28 .+\mathrm{RBH} * 16 . / 2 .+\mathrm{RB} * 64 \cdot / 16 \bullet+\mathrm{RBE} * 112 \cdot / 30 .+\mathrm{RBP} * 160 . / 44$. $\mathrm{RBCO}=\mathrm{RECO} / \mathrm{RINT}$

$\mathrm{RBH}=\mathrm{RBH} / \mathrm{RINT}$

$\mathrm{RBM}=\mathrm{RBM} / \mathrm{RINT}$

$\mathrm{RBE}=\mathrm{RBE} / \mathrm{RINT}$

$\mathrm{BBP}=\mathrm{RBP} / \mathrm{RINT}$

$R B O=R B O / R I N T$

RETURN

END

c

C

$C * * * *$

$* * * * * *$

SUBROUTINE

TO CALCULATE THE EMISSIVITY CF THE GAS

$* * * *$

EMISSIVITY

VALUES ARE CALCULATED

EQUATIONS

CALCULATED

BEFOREHAND

USING THE PCLYNOMIAL

$\mathrm{C}$

$\mathrm{C}$

$\mathrm{C}$

c

C

SUBEOUTINE EMIT (TG,EM)

IMPLICIT REAL * $8 \quad(\mathrm{~A}-\mathrm{H}, \mathrm{O}-\mathrm{Z})$

COMMON/CCMM/RLEN,D (14), ALEN, OXY

COMMON/KBAR/EL, DIAM

COMMON / POLY/P $(11,25), Q(11,32)$

COMMON/PRESS/PPR (9)

C CALCULATION OF EMISSIVITY FOR CARBONDIOXIDE

DIMENSICN A(25), B(32)

DATA $A / 5 ., 3 ., 2 \ldots 1.5,1,0.8,0.6,0.4,0.3,0.2,0.15,0.1,0.08,0.06,0.04$ $1,0.03,0.02,0.015,0.010,0.008,0.006,0.005,0.004,0.003,0.0021$

DATA $B / 20,10,5,3 ., 2, .1 .5,1.2,1.0,0.8,0.6,0.5,0.4,0,3,0.25,0.20$,

$10.15,0.12,0.10,0.08,0.07,0.06,0.05,0.04,0.035,0.03,0.025,0.02 .0 .01$ $25,0.012,0.01,0.007,0.005 /$

$F E L=E L / 30.54$

$T G R=T G$

$E X=(T G R / 4500) *$.

$\mathrm{PCL}=\mathrm{FEI} * \mathrm{EPR}(3)$

IF (TGR. LT.525.) GO TO 70

IF (PCL.GT.5.) GO TO 50

IF (PCL.LT.0.002) GO TC 70 
DO $55 \mathrm{~J}=1.25$

$\mathrm{JK}=\mathrm{J}+1$

IF (PCL.IE. A(J).AND.PCL.GT.A(JK)) GO TO 40

55 CONTINUE

50 WRITE $(6,60)$

60 FORHAT( $1 \mathrm{X}$, 'THE VALUE OF PCL EXCEEDS 5 FEET-ATMOSPHERES')

CALL EXIT

$70 \quad \mathrm{EMCO}=0.0$

GO TO 101

$40 \quad Y=P(1, J)+E X *(P(2, J)+E X *(P(3, J)+E X *(P(4, J)+E X *(P(5, J)+E X *(P(6, J)+E X$

$1 *(P(7, J)+E X *(P(8, J)+E X *(P(9, J)+E X *(P(10, J)+E X *(P(11, J))))))))))$

$E M C O=D E X P(2.303 *((Y / 4.894)-2.5229))$

C EMISSIVITY FOR HATER VAROUB

$101 \quad \mathrm{PCLW}=\mathrm{PPR}(6) * \mathrm{FEL}$

IF (PCLW.GT.20.) GO TO 90

IF (TGR.IT.525.) GO TO 100

IF (PCLW.LT.0.005) GO TO 100

DO $110 \quad I=1.32$

$I J=I+1$

IF (PCLW.IE.B(I) A AND.PCLW.GT.B (IJ)) GO TO 120

110 CONTINUE

90 HEITE $(6,130)$

130 FORMAT ( $1 X$, THE VALUE OF PCL EXCEEDS 20 FEET ATMOSPHERES')

CAIL EXIT

$100 \quad E M W=0.0$

GO TO 140

$120 \quad Y W=Q(1, I)+E X *(Q(2, I)+E X *(Q(3, I)+E X *(Q(4, I)+E X *(Q(5, I)+E X *(Q(6, I)+E$

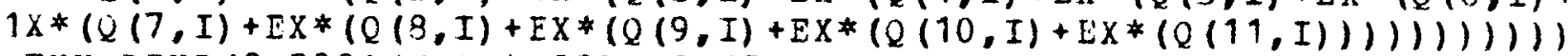

$140 \quad E M=E M C C+E M$ W

RETURN

END

C

c

C

C

C****FUNCTION

C***HEATS

SUBROUTINE

TO CALCULATE

THE

\section{INDIVIDUAL COMPONENT}

SPECIFIC $* * *$

c

C *

C

C

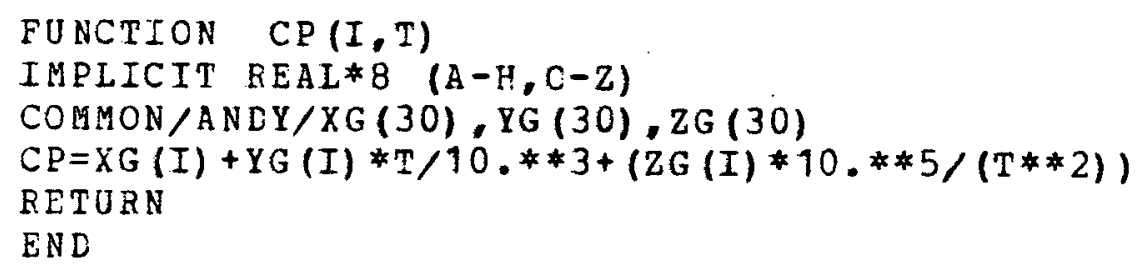

FUNCTION $C P(I, T)$

IMPLICIT REAL* 8 (A-H,C-Z)

COMMON/ANDY/XG (30), YG (30), ZG (30)

$C P=X G(I)+Y G(I) * T / 10 * * 3+(Z G(I) * 10 * * 5 /(T * 2))$

RETURN

END

C

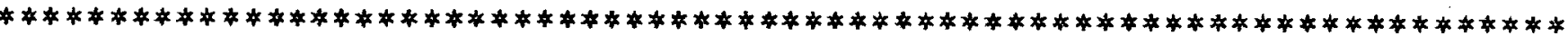

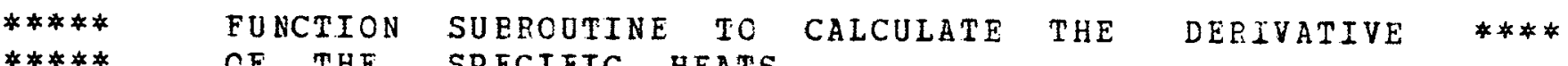
CF THE SPECIEIC HEATS

†

FUNCTION DCP $(I, T)$

IMPLICIT REAL $* 8 \quad(\mathrm{~A}-\mathrm{H}, \mathrm{O}-\mathrm{Z})$

COMMON/ANDY/XG (30), YG (30), ZG (30)

$D C P=Y G(I) * 10 . *(-3)-2 G(I) * 2 . * 10 . * 5 /(T * 3)$ 
$E N D$

C

C

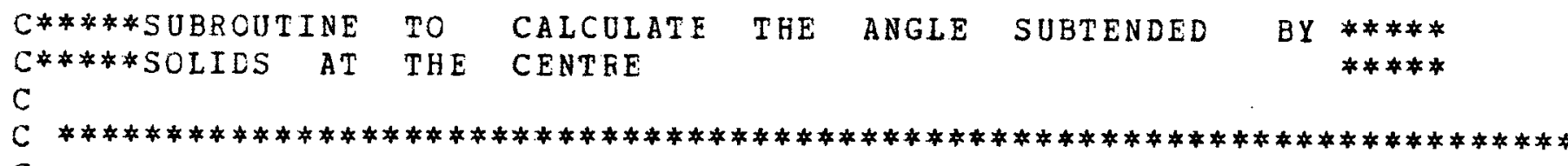

C

C

C

C

HERE NEWTON RAPHSON ITERATIVE TECHNIQUE IS USED IN THE CALCULATIONS

SUBROUTINE ANGLE (F, ALPHA)

IMPLICIT REAL*8 (A-H,C-Z)

$\mathrm{PI}=3.1416$

NOIT $=6$

NIT $=1$

$\mathrm{ANGO}=\mathrm{PI} / 2$.

TOL $=1 . E-03$

$10 \quad A L P H A=A N G O-((D S I N(A N G O)+2 . * P I * F-A N G O) /(D C O S(A N G O)-1)$.

IF (DABS (AIPHA-ANGO). LE. TOL) GO TO 20

$A N G O=A L P H A$

$N I T=N I T+1$

IF (NIT.IE.NOIT) GO TO 10

30 WRITE $(6,30)$

30 FORMAT ( $1 \mathrm{X}$, 'THE NUMBR OF ITERATIONS EXCEEDS 61$)$

CALL EXIT

20 CONIINUE

RETURN

END

C

C

$\mathrm{C}$

C

**** SUBROUTINE TC CALCUIATE THE RATE OF BOUDOURD ANE RATE CF BEDUCTION REACTION

$\mathrm{C}$

C

† SUBROUTINE BOUD

IMPLICIT REAL 8 (A-H, $\mathrm{C}-\mathrm{Z})$

LOGICAL SWCHB, SWCHV, SHCHM, SWCHR, SWCC

COMMCN/CCMM/RLEN, D (14), ALEN, OXY

COMMON/BOD/RC, RO, BCO2, $\mathrm{BCO}, \mathrm{RCB}$

COMMON/TWITCH/SWCHB, SWCHV, SWCHM, SWCHR, SWCC

COMMCN/AREAS/AW, AS, AG

COMMON/ADJUST/EAR1, PAR2,REDP, BURN, TLEN

$\mathrm{TSK}=\mathrm{D}(13)+273$.

IF (. NOT.SWCHB) GO TO 40

$\mathrm{R}=1 .-\mathrm{OXY}$

$A M C=0.253$

$\mathrm{A}$ i $\mathrm{FE}=0.763$

$\mathrm{HC}=0.519 \mathrm{D} 18$

$\mathrm{AP}=3.14 \mathrm{D}-3$

TERMA $=(-20360 . / T S K)+20.97$

$A K B=D E X P(T E R M A)$

$T E R M B=(2105 . / T S K)-2.525$

$A K R=D E X P(T E R M B)$

$\mathrm{PCO} 20=((2 .+\mathrm{AKB})-\mathrm{DSQRT}(4 . * A K B+A K B * 2)) / 2$.

$P C O 2 F=A K R /(A K R+1$.

TERMC $=H C * A M C * D E X P(-86000 . /(1.987 * T S K)) /(82 . *$ TSK $)$

TERMD $=0.0448 * A M F E * A P *(1 .-R) * D E X P(-7250 . /(1.987 * T S K))$

$T E R M E=F C C 2 F *(T E R M D+T E F M C * P C O 2 O)$ 


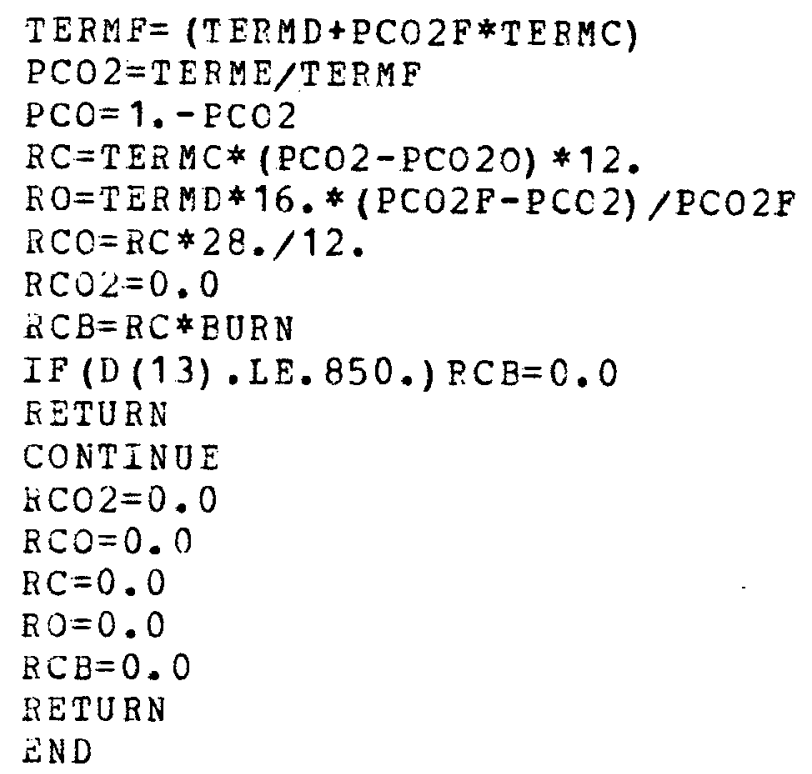


COMMON/AREAS/AB, AS, AG

COMMON/HTCOEF/HCVGSC, HRGSC, HRHSC, HCWSC, HCVGWC, HRGWC, HCVWAC

COMMON/HTRFER/HCVGS, HRGS, HRTS, HCHS, HRST

COMMON/TEMP/TWAL, TWALN

COMMON/BANG/CVGS, RAGS, CVGW, RAGW, CDWS, RATS

COMMON/EMISS/EMIS, AESS, ABSW

IIEAT TRANSFER BY CONVECTICN FROM GAS TO SOLIUS

$G S F L U X=(D(4)+D(5)+D(6)+D(7)+D(8)+D(9)+D(10)+D(11)+D(12)) *(A G / A W)$

TKELS $=D(13)+273$

TKELG $=\mathrm{D}(14)+273$.

TKELW $=T$ TAL +273 .

HCVGSC $=0.000135 * 0.05 *($ (GSELOX/0.0001352)**0.67)

HCVGS $=$ HCVGSC* $(C H O R D / A S) *(D(14)-D(13))$

C

HEAT TRANSFER BY RADIATION FROM GAS TO SOLIDS

$S I G M A=1.355 D-12$

TRANS $=\mathrm{D}(13) * 1.8+492$.

$T R A N G=D(14) * 1.8+492$.

TRANW=TWAL*1.8+492.

CALI EMIT (TRANG, EMIS)

CALL EMIT (TRANS, AESS)

$E M I S=E M I S+0.0$

$A B S S=A B S S+.0$

HRGSC=SIGMA * (EMIS*TKELG**4-ABSS*TKELS**4)/(TKELG-TKELS)

HRGS $=H K G S C(C H O R D / A S) *(C(14)-E(13))$

HEAT

$F U=0.9$

HRWSC=SIGMA *FO* (TKELW* *4-TKELS* 4)/(TKELW-TKELS)

HRAS = HRESC* (CHORD/AS) * (TWAL-D (13))

HEAT TRANSFER
HCWSC $=5$. *HCVGSC

BY

CONEUCTION

FROM

WALI TO

SOLIDS

HCWS $=$ HCWSC $(C H O R D / A S) *(T W A L-D(13))$

C

HEAT TRANSFER

HCVGWC = HCVGSC

C

HEAT TRANSFER BY RADIATION GAS TO WALL

CALL EMIT (TRANW, ABSH)

$A B S W=A B S W+0.0$

HRGWC=SIGMA* (EMIS*TKEIG**4-ABSW*TKELW*4)/(TKELG-TRELW) $\begin{array}{lll}\text { HEAT } & \text { TRANSFERRED FROM GAS TO SOLIDS BY CONVECTION } \\ \text { AND } & \text { RADIATION } & \end{array}$

$G C V S=H C V G S *(C H O R D / A G) *(D(14)-D(13))$

$G R S=H R G S *(C H O R D / A G) *(D(14)-D(13))$

$c$

HEAT TRANSFERRED FROM GAS TO

AND FADIATION

$G C V W=H C V G W C(A R C A / A G) *(D(14)-T W A L)$

$G R W=H R G C *(A R C A / A G) *(D(14)-T H A L)$

$G S W T=G C V S+G R S+G C V W+G R W$

$C V G S=H C V G S * A S$

RAGS $=$ HRGS*AS

$C V G W=G C V W * A G$

$K A G W=G R W * A G$

$C D$ W $=H C W S * A S$

RAWS $=$ HE 且 $S$ * AS

RETURN

$E N D$

$\mathrm{C}$

C 
C

C

C

SUBROUTINE DRYING

IMPLICIT REAL $* 8 \quad(A-H, O-Z)$

LOGICAI SWCHB, SWCHV, SWCHM, SWCHR, SHCC

COMMCN/COMM/RLEN, D (14), ALEN, OXY

COMMON/TWTTCH/SHCHB, SWCHV, SWCHM, SWCHR, SWCC

COMMON/DUSTS/ODUST, CDUST, ADUST,DL 1, DL 2

COMMON/RDUSTS/RODT, RCLT, RADT

COMMCN/DFYR/ORED, DOLOL, DOLOC

COMMON/MISSIN/ARED, AOLOD, AOLOC

IF (SWCHB) GO TO 50

$O R E D=A R E D$

$D O L O D=A O L O D$

DOLOC $=$ AOLOC

50

GO TO 999

$O R E D=0.0$

$D O L O D=0.0$

DOLOC $=0.0$

999 CONTINUE

IF (ALEN.GE. DL1. AND. ALEN.IT.DL2) GO TO 500

RODT $=0.0$

$\mathrm{RCDT}=0.0$

$\mathrm{RADT}=0.0$

RETORN

500 CONTINUE

DELTAL $=\mathrm{DI} 2-\mathrm{DL} 1$

RODT $=O D U S T * 2 . *(A L E N-D I 1) / D E L T A L$

RCDT $=$ CDUST 2 * * (AIEN-DI 1)/DELTAL

RADT $=A D U S T * 2 *(A L E N-D I 1) / D E L T A L$

RETORN

END

$c$

$\mathrm{C}$

C *\#\# * SUBROUTINE TO CALCULATE THE VOLUMETRIC RATE

$C * * *$ OOF AIR AND NATURAL GAS SUPPLY

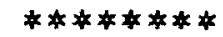

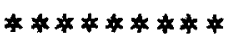

C

C

C

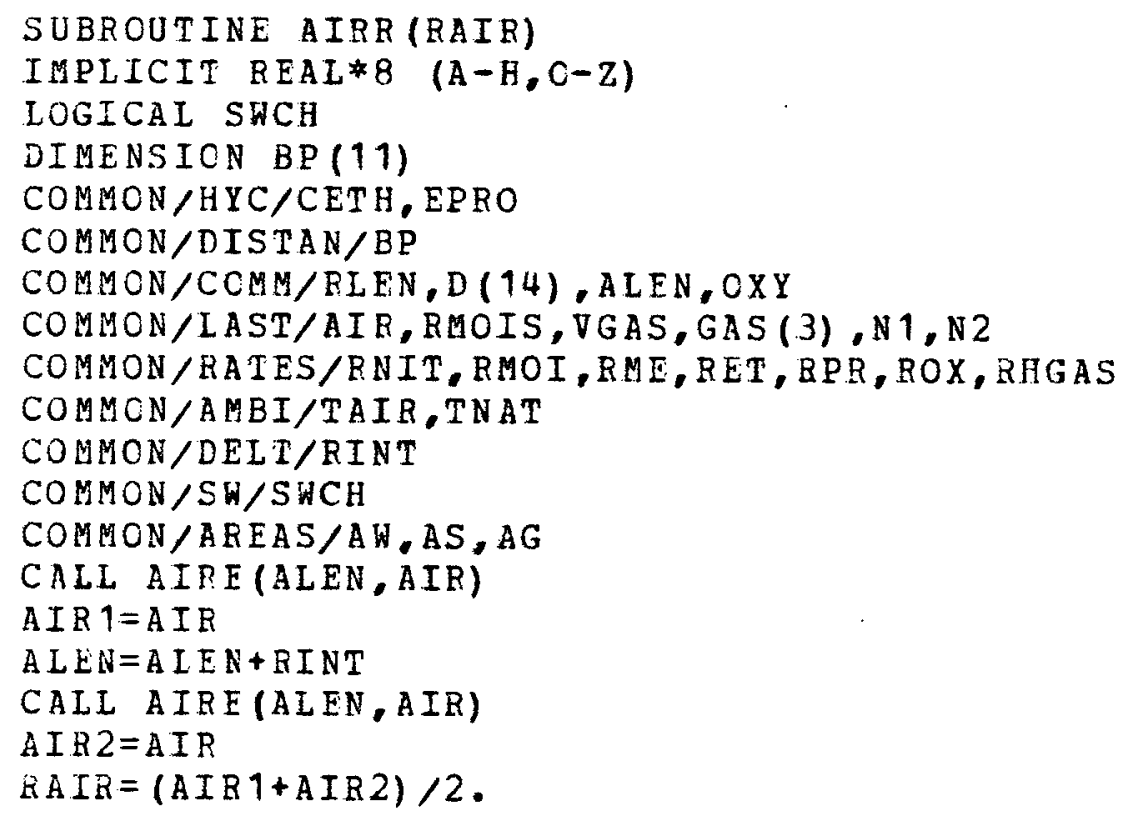


$A L E N=A L E N-R I N T$

$A I B=R A I R$

$A I R=(A I R * 0.472) / A G$

$R N I T=A I R * 28 * 0.79 / 22.4$

$F O X=A I R * 32 . * 0.21 / 22.4$

IF (ALEN.LT.BP (N2) . OR, ALEN,GE,BE (N 1)) GO TO 50

RME $=$ VGAS*16.*GAS (1) $/ 22.4$

$E Z T=\operatorname{VGAS}$ GAS $(2) * 30.122 .4$

$R P R=\nabla G A S * G A S(3) * 44.122 .4$

GO TO 99

50 RME $=0.0$

$\mathrm{RET}=0.0$

$R P R=0.0$

GO TO 99

99 RMOI $=0.0$

HIGHT $=273$.

$T A I=T A I R+273$.

$T N A=T N A T+273$.

KHGAS=RNIT*ENT (HIGHT, TAI, 16) +ROX*ENT (HIGHT, TAI, 13) + RME*ENT (HIGHT, T

1NA, 17) + EET*ENT (HIGHT, TNA, 16) +RPR*ENT (HIGHT, TNA, 18)

RETURN

END

C

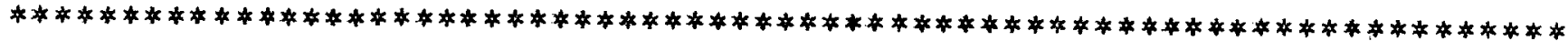

$\mathrm{C}$

$C$

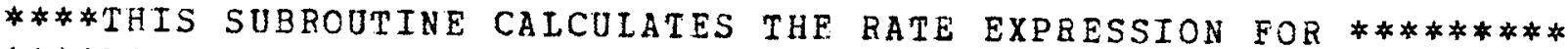

*** *OLATILES AND MOISTURE FROM COAL

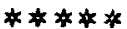

$\mathrm{C}$

$\mathrm{C}$

$\mathrm{C}$

SUBROUTINE RATE

IMPLICIT REAL $* 8 \quad(\mathrm{~A}-\mathrm{H}, \mathrm{O}-\mathrm{Z})$

DIUENSION Z(7)

LOGICAI SHCHB, SWCHV, SWCHM, SWCHR, SWCC

COMMCN/VCIT/BVH, RVCO,RVCO2,RVM, RVE,RVP,RVN,RVT, RHO, RCM

COMMCN/COMM/RLEN, D (14), ALEN, OXY

COMMON/TWITCH/SHCHB, SWCHV, SWCHM, SWCHR, SWCC

COMMON $/ C L / C L F X, U T M E$

COMMON /HYC/CETH, CPRO

COMMON/RNEH/TOTNI, TOTCO, TOTCD, TOTET, TOTPR, TOTHY

COMMON/FILE/GH $(11,9)$

COMHON/DELT/RTNT

COMMCN/DEGR/RMAS, RMETH, RCOUNT, RWATER, RCHECK

IF (.NOT.SWCC) GO TO 190

$A C N=0.0$

$A C O=0.0$

$A C D=0.0$

$\mathrm{AET}=0.0$

$A P R=0.0$

$A H Y=0.0$

$S W C C=$. FALSE.

190 CONTINUE

$A=((3500 .-A L E N) * .091428)-25$.

$A B=A / 20$.

$A M=D(13) /(9 . * 10$.

IF (. NOT.SWCHV) GO TO 50

IF (D (13) .LT.250.) GO TO 50

DO $10 \quad I=1,5$

$Z(I)=G H(1, I)+A B *(G H(2, I)+A B *(G H(3, I)+A B *(G H(4, I)+A B *(G H(5, I)+A B *(G$ $1 H(6, I)+A B *(G H(7, I)+A B *(G H(8, I)+A B *(G H(9, I)+A B *(G H(10, I)+A E *(G H(11$, (2I)) ) ) ) ) ) 
$\operatorname{IF}(D(13) \cdot \operatorname{LE} \cdot 250.) \mathrm{Z}(1)=0.0$

$I F(D(13) \cdot I E .250) Z.(2)=0.0$

IF (D (13) . IE. 310.) Z (3) $=0.0$

IF (D (13) . IE. 360.) Z (4) $=0.0$

$I F(D(13) \cdot I E .450) Z.(5)=0.0$

15

WRITE $(6,15)$ ALEN, D (13), CLFX,UTME, ( $(I), I=1,5)$

FORMAT $(1 X, 9(E 12.5,2 X))$

$R V H=D E X P(2.303 *(Z(4) / 2)) * 1 . D-.6 * C L F X * U T M E$

$R V C O=D E X P(2.303 *(Z(2) / 2)) * 1 . D-.6 * \operatorname{CLFX} * 0 \mathrm{TME}$

RVCO2 $=\operatorname{DEXP}(2.303 *(2(1) / 2)) * 1 . D-.6 * \operatorname{CLFX} * \mathrm{UTME}$

$R V M=D E X P(2.303 *(Z(3) / 2.1) * 1 . D-6 * C L F X * U T M E$

$R V N=D E X P(2.303 *(2(5) / 2)) * 1 . D-.6 * C L F X * U T H E$

$R H O=R V H *(16 . / 2$.

$\mathrm{R} \vee \mathrm{E}=\mathrm{CETH}$

$\mathrm{RVP}=\mathrm{CP} \mathrm{P}_{\mathrm{B}} \mathrm{RO}$

IF (. NOT.SWCHR) GO TO 20

$\mathrm{R} V \mathrm{H}=0.0$

GO T:O 60

20

CONTINUE

$\mathrm{RHO}=0.0$

GO TO 60

$50 \mathrm{RVH}=0.0$

$\mathrm{R} V \mathrm{CO}=0.0$

$\mathrm{RHO}=0.0$

$\operatorname{RVCO} 2=0.0$

$R \vee M=0.0$

$\mathrm{RVE}=0.0$

$\mathrm{R} \vee \mathrm{P}=0.0$

$\mathrm{EVN}=0.0$

$\mathrm{RVT}=0.0$

60 IF (. NOT.SWCHM) GO TO 80

IF (AM. IT.1.75) GO TO 80

DO $70 \quad M=6,7$

$Z(M)=G H(1, M)+A M *(G H(2, M)+A M *(G H(3, M)+A M *(G H(4, M)+A M *(G H(5, M)+A M *(G$

$1 H(6, M)+A M *(G H(7, M)+A M *(G H(8, M)+A M *(G H(9, M)+A M *(G H(10, M)+A M *(G H(11$,

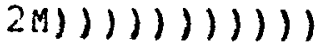

70 CONTINUE

$M=6$

IF (D (13) - GE. 360..AND. C (13) . LT.525.) M=7

IF (D (13) . LT. 150..OR.D(13) . GE.525.) GO TO 80

$R C M=Z(M) * 0.210 D-2 * C L F X * O T M E$

GO TO 99

$80 \quad \mathrm{BC} M=0.0$

99 CONTINUE

IF (ACN.GE.TOTNI) RVN $=0.0$

IF (ACO.GE.TOTCO) RVCO $=0.0$

IF (ACD.GE. TOTCD) RVCO $2=0.0$

IF (AET. GE. TOTET) RVE $=0.0$

$I F(A P R, G E$. TOTPR) RVP $=0.0$

IP (AHY. GE. TOTHY) RVH $=0.0$

$A C N=A C N+F V N * R I N T$

$A C O=A C O+R V C O * R I N T$

$A C D=A C D+R V C O 2 * R I N T$

$A E T=A E T+R V E * R I N T$

$A P R=A P F+R V P * R I N T$

$A H Y=A H Y+R V H * R I N T$

$R V T=R V H+R V C O+R V C O 2+R V M+R V E+R V E+R V N$

KETURN

END 
SUBROUTINE CONTCL

IMPLICIT REAL*8 $(\mathrm{A}-\mathrm{H}, \mathrm{C}-\mathrm{Z})$

COMMON/ADJDST/PAR1,PAR2, REDP,BURN, TLEN

COMMCN/COMH/RLEN,D(14), ALEN, OXY

COMMON/THITCH/SWCHB, SWCHV,SHCHM,SHCHR, SWCC

LOGICAL SHCHB, SWCHV, SWCHM, SWCHR, SWCC

COMNON/DELT/RINT

COMMON/VCLT/RVH, RVCO, RVCO2, RVM, RVE, RVP, RVN, RVT, RHO, RCM

COMMON/DECR/RMAS, RMETH, RCOUNT, RAATER, RCHECK

RMETH=RMETH+RVM RINT

RWATEK = RHATER+RCM RINT

IF (OXY.GE.REDP) GO TO 10

SWCHB $=$.TRUE.

SWCHV =. FALSE.

SWCHR=.FALSE.

$S W C H M=$. FALSE.

RETURN

10 SHCHB =.FALSE.

SWCH $=$. TROE.

IE (OXY.GE.1.) SWCHR= . FALSE.

IF (RMETH. GE. RCOUNT) GO TO 20

SWCHV $=$.TRUE.

GO TO 30

20 SWCHV=.FALSE.

30 IF (RWATER.GE.RCHECK) GC TO 40

SWCHM = . TEUE.

RETURN

40 S WCHM =. FALSE.

FETURN

END

\section{* * * SUBROUTIE TO CALCULATE THE OXYGEN RENAINING}

***IN THE CEE $=--O X Y$

$* * * * * * *$

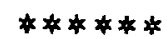

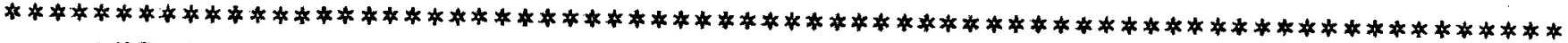
SUBRCUTINE DEGREE

IMPLICIT REAL*8 $(\mathrm{A}-\mathrm{H}, \mathrm{O}-\mathrm{Z})$

COMMCN/VCLT/RVH, RVCO,RVCO2,RVM, RVE, RVP, RVN, RVT, RHO, RCM

COMMON/COMM/RLEN,D (14), ALEN,OXY

COMMON/MISSED/ROXYT, RCXYN, TOTFE

COMMON/DELT/RINT

$\mathrm{COMMON} / \mathrm{BUD} / \mathrm{RC}, \mathrm{RO}, \mathrm{RCO} 2, \mathrm{RCO}, \mathrm{RCB}$

ROXYN $=R O X Y N+R I N T$ RO+RHO*RINT

$O X Y=R O X Y N / B O X Y T$

RETURN

END 
FUNCTION ENT (TI, TF, I)

IHPLICIT REAL $* 8 \quad(\mathrm{~A}-\mathrm{H}, \mathrm{O}-\mathrm{Z})$

COMMON/ANDY/XG (30), YG (30), ZG (30)

$\mathrm{INT}=\mathrm{XG}(\mathrm{I}) *(\mathrm{TF}-\mathrm{TI})+\mathrm{YG}(\mathrm{I}) * .5 *(\mathrm{TF} * 2-\mathrm{TI} * 2) * 10 . *(-3)+\mathrm{ZG}(\mathrm{I}) *((1 . / \mathrm{TI})$

$1-(1 . / T F)) * 1 . D 5$

RETURN

END

$C$

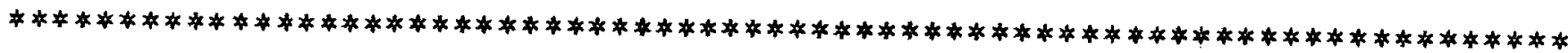

*** SUbEOUTINE to CALCULATE NET HEAT GENERATED IN THE

***BED AND THE FREE EOARI THROUGH DIFFERENT REACTIONS

$\# * * * * * *$

C

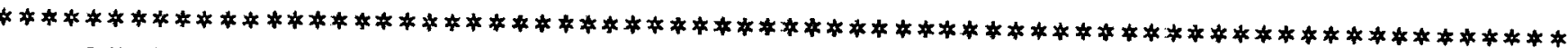

SUEROUTINE HBURN

IMPIICIT REAL*8 (A-H,O-Z)

DIMENSION AX (30), AY (30), AZ (30)

COMMON/COMBR/RBCO,REH, REM, RBE, RBP, RBO

COMMCN/CPST/AX,AY,AZ

COMMON/CAMG/FACT

COMHON/REACT/HFORM (30)

COMMON/DRYR/ORED, DOLCD, DOLOC

COMMON/BUD/RC, RO, RCO2, RCO, RCB

COMHON/BOEE/RHBO, REVOL, RHDO, RHDRY, RHRED, RHBG, RESB

COMMCN/VCLT/RVH, RVCO,RVCO2, RVM, RVE, RVP, RVN, RVT,RHO, RCM

COMMON/ALJUST/PAR1, RAE2,REDP, BURN, TLEN

COMMON/COMM/RLEN, D (14), ALEN, OXY

COMMON/AREAS/AH, AS, AG

$\mathrm{T}=\mathrm{D}(13)$

FAC2 $=1.0$

IF (ALEN.GE.TLEN) GO TO 20

$F A C=P A R 1-(($ PAE $1-P A R 2) * A L E N / T L E N)$

20

GO TO 30

CONTINUE

$F A C=0.0$

30 CONTINUE

$\operatorname{REAC} 10=540$.

REAC $11=0.0$

$R E A C 12=-11333$.

REAC 13=-11060.

CALL HFUNCT $(1,2,1,12,2,11,0,25, T, \operatorname{REAC} 1)$

CALL HFUNCT $(1,9,1,11,1,8,1 \ldots 12, \mathrm{~T}, \operatorname{REAC} 2)$

CALL HFONCT $(1, .19,0 ., 25,1,6,1 \ldots, 12, \mathrm{~T}, \operatorname{REAC} 3)$

CALL HFUNCT $(1,20,0,25,1,7,1, \ldots 12, T, \operatorname{REAC} 4)$

CALL HFUNCT $(1,11,0.5,13,1,12,0,25, \mathrm{~T}, \mathrm{BEAC} 5)$

CALL HEUNCT $(1, \ldots 2,1,13,1,12,0,25$, T, REAC6)

CALL HFUNCT $(1,, 17,2,13,1,12,2,24$, T, REAC7)

CAIL HEUNCT $(1,, 1,3,, 15,2,, 8,3,24, T, \operatorname{REAC} 8)$

CALL HFONCT $(1,15,0.5,13,1, .24,0 ., 25, T, R E A C 14)$

$R E A C 9=F A C T * R E A C 3+(1,-F A C T) * R E A C 4$

$\mathrm{RHBO}=(\mathrm{REAC} 1 / 12), * \mathrm{RC}$

RHRED $=(R E A C 2 / 16) * R O+.B H O *(R E A C 8 / 48$.

Rid DO = (REAC $9 / 44) * D O L O$.

$\angle H D R Y=R E A C 10 *(O R E D+C O L O D+R C M)$

RHVOL $=$ REAC11*RVT

$R H C O B B=R B C O *(R E A C 5 / 28) *.(1 .-F A C)+R C B *(R E A C 6 / 12) *$.

11. $-F A C 2) * A S / A G$

$\mathrm{RHBG}=\mathrm{RHCCBB}+\mathrm{RBH} *(\mathrm{REAC} 14 / 2)+.\mathrm{RBM} *(\mathrm{REAC} 7 / 16)+.\mathrm{RBE} * \mathrm{REAC}$

$112+R B P * R E A C 13$ 
$R F S B=R B C C *(R E A C 5 / 28) * F A C * A. G / A S+R C B *(R E A C 6 / 12$.) *FA

1C2

RETURN

END

C

$\mathrm{C}$

$C$ *** THIS SUBROUTINE CONTAINS THE DIFFERENTIAL EQUATIONS

C*** THIS IS AN EXTERNAL FUNCTION FOR RKC

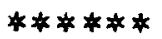

$* * * * *$

SUBROUTINE FUNC $(X, Y, F)$

IMPLICIT REAL* $8(\mathrm{~A}-\mathrm{H}, \mathrm{O}-\mathrm{Z})$

DIMENSION $Y(1), F(1)$

COMMON/FDUSTS/RODT,RCET,RADT

$\mathrm{COMMCN} / \mathrm{BUC} / \mathrm{RC}, \mathrm{RO}, \mathrm{RCO} 2, \mathrm{RCO}, \mathrm{RCB}$

COMMON/DRYR/ORED, DOLOL, DCLOC

COMMON/VCLT/RVH, RVCC, RVCO2,RVM, RVE, RVP, RVN, RVT,RHO, RCM

COMMON/BCRE/RHBO, RHVOL, RHDO, RHDRY, RHRED, RHBG, RESB

COMMON/RATES/RNIT,RMOI,RME,RET,RPR, ROX,RHGAS

$\mathrm{COMMON} / \mathrm{COMBR} / \mathrm{RBCO}, \mathrm{RBH}, \mathrm{BEM}, \mathrm{BBE}, \mathrm{BBP}, \mathrm{RBO}$

COMMON/COMM/RIEN,D (14),OXY, ALEN

COMMON/HTRERR/HCVGS, HRGS, HRWS, HCWS, HRST

$\mathrm{COMMON} / \mathrm{PRCD} / \mathrm{RPCO} 2, \mathrm{RPH} 20$

COMMON/AREAS/AG, AS, AG

COMMON/COAD/FEED (3), GANGO (5)

COMMON/CFAD/FLUX (4), GANGF (5)

COMMON/CCAD/COAL (12), AASH (6)

COMMON/CES/CPORE, CPCOAL, CPDOL

COMMON/DCES/DCPORE, DCECOA, DCPDOL

COMMON/GASHTR/GCVS, GRS, GCVH, GRW, GSWT, BHVM

$\mathrm{CONV}=\mathrm{AS} / \mathrm{AG}$

HRST = HCVGS + HRGS + HRWS + HCWS

EQUATIONS DESCRIBING THE MASS BALANCE

$\mathrm{T} 2=\mathrm{D}(13)+273$.

$\mathrm{T} 1=273$.

RHVM=RVN*CONV*ENT $(T 1, T 2,14)+(R V C O 2+D O L O C) * C O N V *$

$1 \mathrm{ENT}(\mathrm{T} 1, \mathrm{~T} 2,12)+(\mathrm{RCO}+\mathrm{EVCC})$ *CONV ENT $(\mathrm{T} 1, \mathrm{~T} 2,11)+(\mathrm{ORED}+$

$2 D O L O D+R C M) * C O N V$ ENT $(T 1, T 2,24)+R V H * C O N V * E N T(T 1, T 2,15)$

$3+R V M * C O N V * E N T(T 1, T 2,17)+R C B * C O N V * E N T(T 1, T 2,12) * 44, / 12$.

$4+\mathrm{RHO} * \mathrm{ENT}(\mathrm{T} 1, \mathrm{~T} 2,24) *(18 . / 16$.

$F(1)=O R E D+R O+R H O+R O D T$

$F(2)=R C+R C M+R V T+R C B+R C D T+R A D T+R H O * 2 . / 16$.

$F(3)=D C L C D+D O L O C$

$F(4)=R N I T+R V N * C O N V$

$F(5)=R O X-R B O-R C B * 32 * * C O N V / 12$.

$F(6)=R \nabla C C 2 * C C N V+F P C O 2+D C L O C * C O N V+R C B * C O N V * 44 . / 12$.

$E(7)=R C O * C C N V+B V C O * C O N V-R B C O$

$F(8)=R V M * C O N V+R M E-R B M$

$F(9)=R P H 2 O+B M O I+(O R E D+D O L O D+R C M) * C O N V+R H O * C O N V * 18,116$ CONV $=A S / A G$

$F(10)=R P R+R V P * C O N V-R E P$

$\mathrm{F}(12)=\mathrm{BVH} * \mathrm{CONV}-\mathrm{RBH}$

CALL HEATS

$F(11)=R V E * C O N V-R B E+R E T$

CALL DERIV

C

EQUATIONS DESCRIBING THE HEAT BALANCES

$\operatorname{TOLD}=\mathrm{D}(14)+273$ 
$F(13)=(1 R H B O+R H V O L+R H C O+R H D R Y+R H R E D-H R S T+R F S B)-(X(13) *(F(1) * C P O R E$

$1+\mathrm{F}(2) * \mathrm{CFCOAL}+\mathrm{F}(3) * \mathrm{CPDOL}))) /((\mathrm{Y}(1) * \mathrm{DCPORE}+\mathrm{Y}(2) * \mathrm{DCPCOA}+\mathrm{Y}(3) * D C P D O L)$

$2 * Y(13)+(C P O R E * Y(1)+C P C O A * Y(2)+C P D O I * Y(3)))$

$E R G D C P=Y(4) * D C P(14, T O L D)+Y(5) * D C P(13, T O L D)+Y(6) * D C P(12, T O L D)+Y(7) *$

$5 D C P(11, T O L D)+Y(8) * D C P(17, T O L D)+Y(9) * D C P(24$, TOLD $)+Y(10) * D C P(18$, TOLD

2) $+Y(11) * \operatorname{DCP}(16$, TOLD $)+Y(12) * D C P(15$, TOLD $)$

$P R C P D G=C E(14, T O L D) * F(4)+C P(13, T O L D) * F(5)+C P(12, T O L D) * F(6)+C P(11, T C$

$1 L D) * P(7)+C P(17$, TOLD $) * F(8)+C P(24$, TOLD $) * P(9)+C P(18$, TOLD $) * F(10)+C P(16$

$2, T O L D) * F(11)+C P(15, T O I D) * F(12)$

$P R C P G=Y(4) * C P(14$, TOLD $)+Y(5) * C P(13$, TOLD $)+Y(6) * C P(12$, TOLD $)+Y(7) * C P(1$

11, TOLD $)+Y(8) * C P(17, T O L D)+Y(9) * C P(24, T O L D)+Y(10) * C P(18, T O L D)+C P(16$,

2 TOLD $* Y(11)+Y(12) * C P(15, T O L D)$

$R D H G=R O D T *(D(14)-D(13)) * C P O R E+(R C D T+R A D T) * C P C O A L *$

$1(D(14)-D(13))$

$F(14)=((-R H B G-G S H T+R H G A S+R H V M-R D H G)-Y(14) * P R C P D G) /(P R C P G+P R G D C P *$

$1 Y(14))$

RETURN

$E N D$

c

SUBRODTINE ANALYS

IMPLICIT REAL*8 (A-H, C-Z)

COMMCN/CCAD/FEED (3), GANGO (5)

COMMON/CEAD/FLUX (4) , GANGF (5)

COMHON/REUSTS/RODT, RCDT, RADT

COMMON/CCAD/COAL (12). AASH (6)

COMMON/VCLT/RVH, RVCO,RVCO2, RVM, RVE, RVP, RVN, RVT, RHO, RCM

COMMON/DEYR/ORED, DOICD, DOIOC

COMMON/BUD/RC, RO, RCO2, RCO, RCB

COMMON/COMM/RLEN, D (14), ALEN,OXY

COMMON/CAMG/FACT

COMMON/DELT/RINT

CALCULATION OF THE NEW ORE COMPOSITION

$H A E M=F E E D(1) * D(1)+R O * R I N T+R O D T * R I N T+R H O * R I N T$

$O R E M=F E E D(2) * D(1)+O R E D * R I N T$

$O R E G=F E E D(3) * D(1)$

$O R E T=H A E M+O R E M+O R E G$

FEED (1) = HAEM/ORET

FEED (2) =OREM/ORET

FEED (3) $=$ CREG $/ O R E T$

C

C

$\mathrm{C}$

C

\footnotetext{
CALCULATICN OF THE NEW COLOMITE COMPOSITION

$C A C=F I U X(1) * D(3)+D O L C C * F A C T * R I N T$.

MGC $=$ FLUX $(2) * D(3)+D O L O C *(1 .-F A C T) * R I N T$

$F G=F \operatorname{LUX}(3) * D(3)$

$F M=F L U X(4) * D(3)+D O L O D * R I N T$

$F T=C A C+M G C+F G+F M$

FLUX (1) $=C A C / F T$

$F \operatorname{LUX}(2)=\mathrm{MGC} / \mathrm{FT}$

$\operatorname{ELUX}(3)=F G / F T$

FLUX $(4)=F M / F T$

CALCULATION OF THE NEW COAL COMPOSITION

$C \vec{F} C=C O A L(1) * D(2)+R C * R I N T+R C D T * R I N T+R C B * R I N T$

$C F M=C O A I(2) * D(2)+R C M * R I N T$

$C M E=\operatorname{COAL}(3) * D(2)+R V M * R I N T$
} 
$C E T=C O A I(4) * D(2)+R V E * R I N T$

$C C O=C O A L(5) * D(2)+R V C O * R I N T$

$C N=C O A L(8) * D(2)+R V N * R I N T$

$\mathrm{CH} Y=\operatorname{CCAL}(6) * \mathrm{D}(2)+\mathrm{RVH} * \mathrm{EINT}+\mathrm{RHO} * \mathrm{RINT}+2 \cdot / 16$.

$\mathrm{CO}=\operatorname{COAL}(7) * \mathrm{D}(2)$

$\mathrm{CASH}=\mathrm{COAL}(9) * \mathrm{D}(2)+\mathrm{RADI} * \mathrm{RINT}$

$C S=C O A I(10) * D(2)$

$\operatorname{CCO} 2=\operatorname{COAL}(11) * \mathrm{D}(2)+\mathrm{EVCO} 2 * \mathrm{RINT}$

$C P R=C O A I(12) * D(2)+R V P * R I N T$

$\mathrm{CT}=\mathrm{CFC}+\mathrm{CFM}+\mathrm{CME}+\mathrm{CET}+\mathrm{CCO}+\mathrm{CHY}+\mathrm{CO}+\mathrm{CN}+\mathrm{CASH}+\mathrm{CS}+\mathrm{CCO} 2+\mathrm{CPR}$

$\operatorname{COAL}(1)=\mathrm{CHC} / \mathrm{CT}$

$\operatorname{COAL}(2)=C F M / C T$

$\operatorname{COAL}(3)=\mathrm{CME} / \mathrm{CT}$

$\operatorname{COAL}(4)=\mathrm{CET} / \mathrm{CT}$

$\operatorname{COAL}(5)=\mathrm{CCO} / \mathrm{CT}$

$\operatorname{COAL}(6)=\mathrm{CHY} / \mathrm{CT}$

$\operatorname{COAL}(7)=\mathrm{CO} / \mathrm{CT}$

$\operatorname{COAL}(8)=\mathrm{CN} / \mathrm{CT}$

$\operatorname{COAL}(9)=\mathrm{CASH} / \mathrm{CT}$

$\operatorname{COAL}(10)=\mathrm{CS} / \mathrm{CT}$

$\operatorname{COAL}(11)=\mathrm{CCO} 2 / \mathrm{CT}$

$\operatorname{COAL}(12)=\mathrm{CPR} / \mathrm{CT}$

RETURN

END

C

C*

$c *$

C *

C

SUBROUTINE FOR RRINTING SEVERAL OSEPUL VALUES

SUBROUTINE WROTE

IMPLICII REAL *8 (A-H,C-Z)

$\mathrm{COMMON} / \mathrm{BUD} / \mathrm{RC}, \mathrm{RO}, \mathrm{RCO} 2, \mathrm{RCO}, \mathrm{RCB}$

COMMON/EANG/CVGS,RAGS, CVGW,RAGH, CDHS, RAWS

COMHON/DRYR/ORED, DOLCE, DOLOC

COMMCN/VCIT/RVH, RVCO, RVCO2, RVM, RVE, RVP, RVN, RVT, RHO, RCM

COMMCN/BCRE/RHBO, RHVOL,RHDO, RHDRY, RHAED, RHBG, RFSB

COMMON/RATES/RNIT, RMOI, RME, RET, RPR, ROX, RHGAS

COMMCN/CCMBR/RBCO,REH, REH, RBE, RBP, RBO

COMMON/CCMM/RLEN,D(14), ALEN,OXY

COMMON/HTCOEF/HCVGSC, HRGSC, HRHSC, HCWSC, HCVGWC, HRGWC, HCVWAC

COMMON/CCAD/FEED (3) , GANGO (5)

COMMON/CFAD/FLUX (4), GANGF (5)

COMMON/CCAD/COAL (12). AASH (6)

COMMCN/CES/CPORE, CPCOAL, CPDOL

COMMON/DCPS/DCPORE, DCFCOA, DCPDOL

COMMCN/SPECY/FEC,FE203,FE304,FE

COMNON/EMISS/EMIS, ABSS, ABSW

$\mathrm{J}=6$

WRITE $(J, 5)$ ALEN

5 FORMAT $(4 \mathrm{X}$, 'ALEN=1,F6,1, 'CMS')

WEITE $(J, 10) R C, E O, R C B$

FORMAT $\left(4 X,{ }^{\prime} R C=\prime, E 12,5,2 X,{ }^{\prime} R O=\prime, E 12,5,2 X,{ }^{\prime} R C B=\prime, E 12,5\right)$

WRITE $(\mathrm{J}, 20)$ ORED, DOLOD, DOLOC

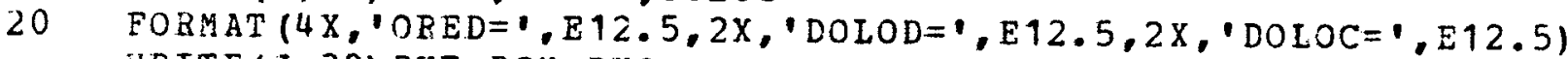
WRITE $(J, 30)$ RVT, RCM, RHC

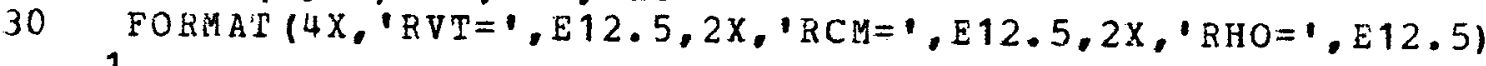
1

WRITE $(J, 40)$ RHBO, RHVOL, RHDO, RHDEY, RHRED, RHEG, RFSB

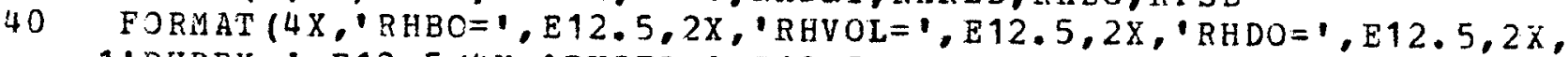

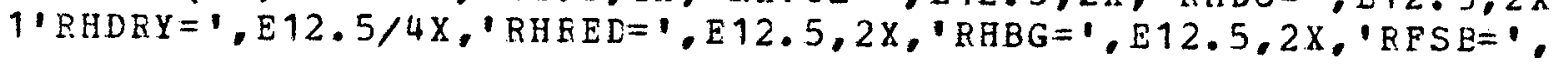


$2 E 12.5)$

WRITE $(J, 50)$ RNIT, RMOI, RME, RET, RPR, BOX, RHGAS

FORMAT $14 X, X^{\prime}$ RNIT $=1, E 12.5,2 X, '$ RMOI $=1, E 12.5,2 X, ' R M E=1, E 12.5,2 X$,

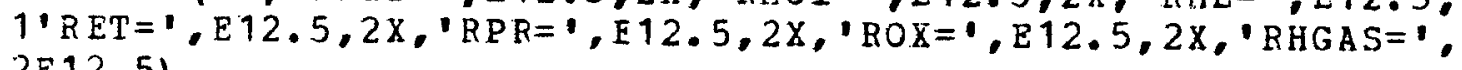

2E12.5)

WRTTE $(J, 60) R B C O, R B H, R E M, R B E, R B P, R B O$

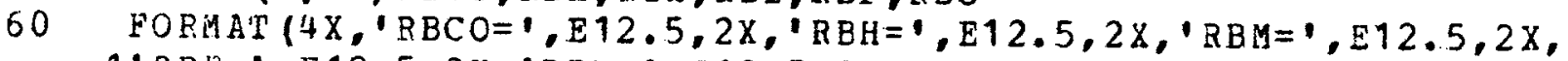
$1 ' R B E=1, E 12.5,2 x, \cdot R B P=', E 12.5,2 x, P R B==, E 12.5)$

WRITE $(\mathrm{J}, 70)$ HCV GSC, HRGSC, HRWSC, HCWSC, HCVGWC, HRGWC

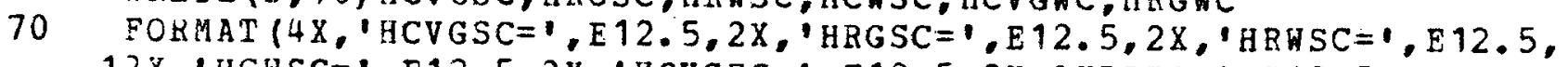
$12 X,{ }^{\prime} H C W S C=1, E 12.5,2 X,{ }^{\prime}$ HCVG XC $=1, E 12.5,2 X, 1$ HRG WC $=1, E 12.5$ )

WRITE $(J, 75)$ CVGS, RAGS, CVGW, RAGW, CDGS, RAWS

75 FORMAT $(1 X, 6 \pm 12.5)$

WRITE $(J, 80)$ (FEED (I), I $=1,3)$

80 FCRMAT $(4 X, 1$ ORE $, 4 X, 3(F 5.3,2 X))$

WRITE $(J, 90)(\operatorname{COAL}(I), I=1,12)$

90 FORMAT $\left(4 X, C^{\prime}\right.$ COAL $\left., 4 X, 12(F 5,3,2 X)\right)$

$\operatorname{URITE}(J, 100)(\operatorname{FLUX}(I), I=1,4)$

100 FORMAT $(4 X,+$ DOLOMITE , $4 X, 4(F 5,3,2 X))$

WRITE $(J, 110)$ CPORE, CPCCAL, CPDOL

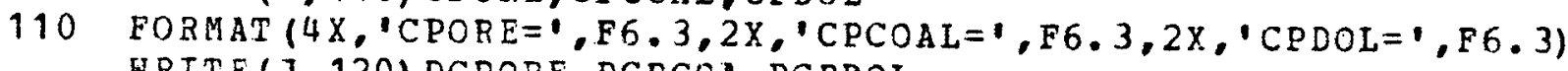

WRITE $(J, 120)$ DCPORE, DCPCCA, DCPDOL

120 FORMAT $(4 X, \cdot D C P O R E=,, F 6,3,2 X, \cdot D C P C O A L=1, F 6,3,2 X, \cdot D C P D O L=1, F 6.3 / 1)$ WRITE $(J, 130) \mathrm{FE} 203, \mathrm{FE} 3 \mathrm{C} 4, \mathrm{FEO}, \mathrm{FE}$

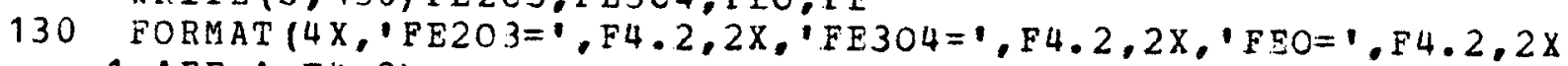
$1, ' F E=1, F 4.2)$

WRITE $(J, 140)$ EMIS, ABSS, ABS H

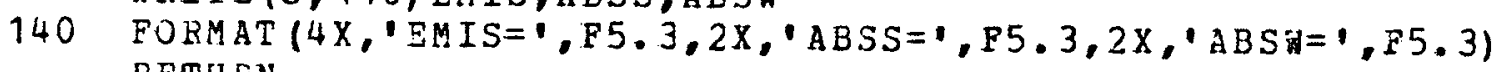

RETURN

END

C

C

C*

$\mathrm{C} *$

C

SUBROUTINE TO CALCULATE THE AIR RATE

SUBROUTINE AIRE (ALENS, AIRS)

I 4 PLICIT REAL 8 (A-H, O-Z)

DIMENSION BD (11), BP(11), BA (11), AA (11)

COMMON/SW/SWCH

COMMCN/DISTAN/BP

NA MELIST/TNP/BD, BA

LOGICAL SWCH

IF (.NOT. SWCH) GO TO 750

$\operatorname{READ}(5,710)(B D(I), I=1,11)$

710 FORMAT (8F10.1)

$A=50$.

SUM $=0.0$

DO $720 \quad I=1,11$

$S U M=S U M+B D(I)$

720 CONTINUE

$B P(1)=S U M$

DO $730 \quad I=2,11$

$B P(I)=B P(I-1)-B D(I-1)$

730 CONTINUE

DO $740 \quad I=1,11$

$A A(I)=B A(I) / B D(I)$

740 CONTINUE

$\operatorname{WRITE}(6,60)(B P(I), I=1,11),(B D(I), I=1,11),(A A(I), I=1,11)$

60 FORMAT $(1 X, 11$ F $8.2 /)$ 
WRITE $(6, T N P)$

750 CONTINUE

IF (ALENS.GT.BP (1)) GO TO 900

755 CONTINUE

D) $760 \mathrm{~J}=2,10$

IE (ALLNS.LT. (BP (J) +A). AND.ALENS.GE. (BP (J)-A)) GO TO 780

760 CONTINUE

IF (ALENS.LT. (BP (11) +A) . AND.ALENS.GT. (BP(11)-A)) GO TO 800

IF (ALENS.LT. (BP (11)-A)) GO TO 900

780 AIRS $=A A(J-1)-(A A(J-1)-A A(J)) *(B P(J)+A-A L E N S) /(2 . * A)$

RETURN

$790 \quad A \perp E S=A A(J)$

KEETURN

800 AIRS $=A A(10)-(A A(10)-A A(11)) *(B P(11)+A-A L E N S) /(2 . * A)$

RETURN

999 AIES $=$ A A ( 1)

RETURN

900 AIRS $=0.0$

RETURN

END

C

C*

$C *$

$C *$

PLOTTING SUBROUTINE

C

SUBROUTINE PLATO (M)

IMPLICIT REAL*8 $(\mathrm{A}-\mathrm{H}, \mathrm{C}-\mathrm{Z})$

DIMENSION TSD (100), THC (100), TGD (100),DIST (100), AIRD (100), TCD (100)

DIMENSION RD (100), RBD (100), RVHD (100), RVCOD $(100), \operatorname{RVMD}(100)$

DIMENSION WATD $(100), C O 2 D(100)$, RND $(100), \operatorname{ROD}(100), \operatorname{SHD}(100)$

DIMENSICN COD (100), HD (100), RATD (100)

COMMON/PARAM 1/RD, RBD, RVHD, RVCOD, RVMD, SHD

COMMCN/PAPAM2/WATD, CC2E,RND,RCD,COD, HD, RATD

COMMON/PAKAM/TSD, TWD, TGL, TCD, DIST, A IRD

$M=M-1$

$\operatorname{EBD}(1)=\operatorname{RBD}(2)$

$\operatorname{SIID}(1)=\operatorname{SHD}(2)$

$X M I N=0.0$

$Y M I N=0.0$

$D X=5.0$

$D Y=350$.

DO $10 \mathrm{~J}=1 . M$

$\operatorname{DIST}(J)=((D I S T(M)-D I S T(J)) /(D X * 100))+$.

$\operatorname{TSD}(J)=(\operatorname{TSD}(J)-Y M I N) / D Y)+2.0$

$\operatorname{TGD}(J)=((T G D(J)-Y M I N) / D Y)+2$.

$\operatorname{TWD}(J)=(\operatorname{THD}(J)-Y M T N) / D Y)+2.0$

$\operatorname{SHD}(J)=((\operatorname{SHD}(J)-Y M I N) / D Y)+2.0$

$\operatorname{ICD}(J)=((\operatorname{TCD}(J)-Y M I N) / C Y)+2: 0$

$R D(J)=((R D(J)-0.0) / 20)+$.

$\operatorname{RBD}(J)=((\operatorname{RBD}(J)-0) / 3)+$.

$W \operatorname{ATD}(J)=((\operatorname{WTD}(J)-0.0) / 0.2)+2.0$

$\operatorname{Co2} D(J)=((\operatorname{Co} 2 D(J)-0.0) / 0.2)+2.0$

$\operatorname{END}(J)=((\operatorname{RND}(J)-0.0) / 0.2)+2.0$

$\operatorname{ROD}(J)=((\operatorname{ROD}(\mathrm{J})-0.0) / 0.2)+2.0$

$\operatorname{CON}(J)=((\operatorname{COD}(J)-0.0) / 0.2)+2.0$

$\mathrm{HD}(\mathrm{J})=((\mathrm{HL}(\mathrm{J})-0.0) / 0.2)+2.0$

$\operatorname{AIRD}(\mathrm{J})=\operatorname{AIRD}(\mathrm{J})+2.0$ 
CALI AXIS $(1,5,2.0$, TEMPERATURE (DEG C)', 19,5,.90, YMIN,DY)

CALI SYMBCL $(3, .6 \ldots 0.21$, SOLID TEMPERATURE PROFILE, $0 ., 25)$

CALL SING (DIST, TSD, M, 1)

CALL PIOT $(12,0 .,-3)$

CAIL XAXIS

CALE AXTS $(1.5,2.0$, TEMPERATURE (DEG C) $1,19,5, .90$. . Y UIN, DY)

CALI SYMBOL $\left(3,, 6,0.21,{ }^{\circ}\right.$ GAS IEMPEBATURE PROFILE',0.,23)

CALL SING (DIST,TGD,, 1$)$

CALI SING(DIST, TCD,M, 1)

CALL PLCT $(12,0.0,-3)$

CALL XAXIS

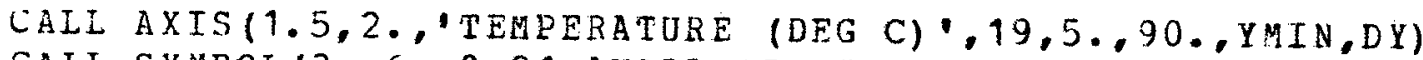

CALL SYMBOL $(3, .6,0.21$, WALL TEMPERATURE PROFIL, $0 ., 24)$

CALL SING(DIST, TWD, M, 1)

CALL SING (DIST, SHD, M, 1)

CAIL PICT $(12, \ldots, 0,-3)$

CALL XAXIS

CALL AXIS $(1.5,2, \ldots \operatorname{AIR} \operatorname{RATE}(\operatorname{SCFM} / \mathrm{CM}), 18,5,90,0,0,1.0)$

CALL SING (DIST, AIRD, M, 1)

CALL PLCT $(12,0,0,-3)$

CALL XAXIS

CALL AXIS $(1.5,2, \ldots$ 'PERCENTAGE REDUCTION',20,5.,90,0.,20.)

CAIZ SING (DIST, BD, M, 1)

CALL PLCT $(12, .0 .,-3)$

CALL XAXIS

CALL AXIS $(1.5,2 .$, RATE OF BOUDOURD REACTION (GM C/C.CM/SEC

1) $\quad, 40,5,90,0,0.1$

CALI SING (DIST, RBD, M, 1)

CAIL PICT $(12,0, \ldots-3)$

CAIL XAXIS

CALL AXIS $(1.5,2$, PARTIAI PRESSURES OF FREE BOARD GASES , $1,37,5,90, .0,0.2)$

CALI, SING(DIST, FND, M, 1)

CALL SING (DIST, CO2D, M, 1)

CALL SING (DIST, COD, M, 1)

CALL SING (DIST, WATD, M, 1)

CALL SING(DIST, FCD, M, 1)

CALL SING (DISI, HD, M, 1)

CALL SYMBOL (DIST $(50),($ WATD $\left.(50)+0.5), 0.14,1 \mathrm{H} 20^{\prime}, 0,0,3\right)$

EALL SYMBCL (DIST (35), (CO2D $(35)+0.5), 0.14,1 \mathrm{CO} 2,0 ., 3)$

CALL SYMBOL (DIST (35), (RND (35) +0.5),0.14,N21,0.,2i)

CALL SYMBCI (DIST $(40),(\operatorname{ROD}(40)+0.5), 0.14,02,0 ., 2)$

CALL SYMBOL (DIST $(30),(\operatorname{COD}(30)+0.5), 0.14, \operatorname{CO}, 0 ., 2)$

CAZL SYMBCL (DIST (55), (HD (55) +0.5), 0.14, H2, $0 ., 2)$

ลETU กิ

END

C * SUBROUTINE FOR PLOTTING AXIS

SUEROUTINE XAXIS

IMPLICIT REAL $* 8 \quad(\mathrm{~A}-\mathrm{H}, \mathrm{O}-\mathrm{Z})$

$X M I N=0.0$

$D X=5.0$

CAIL AXIS $(1.5,2.0$, DISTANCE FROH CHAHGE END (METRES)', -3.3,8, , 10. .XMIN, $\mathrm{XX)}$

CALL PLCT $(1.5,7.0,3)$

CAIL PLCT $(9.5,7.0,2)$

CALI PIOT $(9.5,2.0,2)$

CALI PLCT $(1,5,2.0,3)$

EETURN 
END

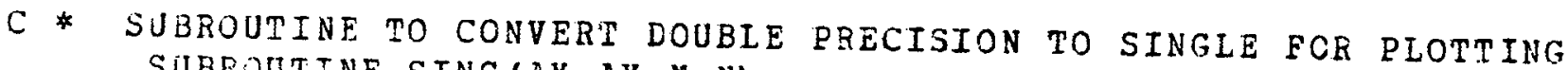

SUBROUTINE SING $(A X, A Y, M, N)$

KEAL*B AX (M), AY (M)

DIMENSION SX(100), SY(100)

DO $10 \quad J=1, M$

$S X(J)=S N G L(A Y(J))$

$\operatorname{SY}(J)=\operatorname{SNGL}(A Y(J))$

10 CONTINUE

CALL IINE $(S X, S Y, M, N)$

RETURN

END

$\ulcorner$ SUBROUTINE TO CALCULATE HEAT OE REACTION AS A FUNCTION OF TEMP SUEROUTINE HEUNCT (A,IJ,E,JK,C,KL, D, LM, T, REAC)

IMPLICIT REAL $8 \quad(\mathrm{~A}-\mathrm{H}, \mathrm{O}-\mathrm{Z})$

DIMENSTON AX (30), AY $(30), A Z(30)$

COMMON/REACT/HEORM (30)

COMMCN/CPST/AX, AY, AZ

$\mathrm{T} 2=\mathrm{T}+273$.

T1 $7=298$.

$\operatorname{TLEM} 1=(D * A X(L M)+C * A X(K L)-A * A X(I J)-B * A X(J K))$

$\mathrm{TERA} 2=(\mathrm{D} * \mathrm{AY}(\mathrm{LM})+C * A Y(K L)-A * A Y(I J)-B * A Y(J K))$

$\operatorname{TERM} 3=(D * A Z(I M)+C * A Z(K I)-A * A Z(I J)-B * A Z(J K))$

$\mathrm{HO}=(\mathrm{D} * \mathrm{HEOFM}(\mathrm{IM})+\mathrm{C} * \mathrm{HFORM}(\mathrm{KL})-\mathrm{A} * \mathrm{HFORM}(\mathrm{IJ})-\mathrm{B} * \mathrm{HFORM}(\mathrm{JK}))$

$\mathrm{REAC}=(\mathrm{T} 2-\mathrm{T} 1) *(\mathrm{TERM} 1+(\mathrm{TERM} 2 *(\mathrm{~T} 2+\mathrm{T} 1) / 2) *.(10 * * * 3))+$

$1(\mathrm{TERM} /(\mathrm{T} 2 * \mathrm{~T} 1)) *(10 \ldots(5)))+\mathrm{HO}$

RETURN

END

C

$* * * * * *$

C

$c$

C

CONVERTING GAS TEMPERATURES TC BARE THERMCCOURLE VALUE

SUBEOUTINE CORECT (TG, TH, TCN)

IMPLICIT REAL*8 $(\mathrm{A}-\mathrm{H}, \mathrm{C}-\mathrm{Z})$

CUMMON/HTCOEF/HCVGSC, HRGSC, HRWSC, HCWSC, HCVGWC, HRGWC, HCVWAC

COMMON/EMISS/EMIS, AESS, ABSW

$\mathrm{ET}=0.8$

SIGM $A=0.1355 n-11$

$T G K=T G+273$.

$T W K=T W+273$.

$T C O=T G K-20$.

NOIT $=10$

$N=1$

15 CONTINUE

TCOR $=1.8 * \mathrm{TCO}$

CALL EMIT (TCOR, EMT)

$F X=((S I G M A *((1 .+E T) / 2) *.(E M I S * T G K * * 4-E M T * T C O * 4))-(S I G M A * E T *$

$1(\mathrm{TCO} * 4-\mathrm{T} W * 4))) *(1 . / \mathrm{HCVGSC})+\mathrm{TGK}-\mathrm{TCO}$

$\mathrm{FDX}=((\operatorname{SIGMA} *((1 .+\mathrm{ET}) / 2) *.(-4$. $\mathrm{EMT} * \mathrm{TCO} * 3))-(\operatorname{SIGMA} * \operatorname{ET} *(4 . * \operatorname{TCO} * 3)$

1) )*(1./HCVGSC -1 .

$\mathrm{TCN}=\mathrm{TCC}-\mathrm{EX} / \mathrm{FDX}$

IF (DABS (TCN-TCO) . LE. 5.) GO TO 99

$T C O=T C N$

IF (N.GE.NCIT) GO TO 200

$\mathrm{N}=\mathrm{N}+1$

GO TO 15

CUNTINUE

$T C N=T C N-273$.

BTTURN 
110 PORMAI (1X,'NO OE ITERATIONS EXCEEDS', 2X,I2) SETURN END 


\section{IMPORTANT DATA USED IN THE MODEL}

Composition of Forestburg coal

Fixed Carbon
Moisture
Methane
Ethane
Carbon monoxide
Hydrogen
Nitrogen
Ash
Sulphur
Carbon dioxide
Propane

$42 \%$

$31 \%$

$4 \%$

$0.6 \%$

$6 \%$

$1 \%$

$0.6 \%$

$10 \%$

$0.3 \%$

$4.0 \%$

$0.5 \%$

Composition of Anthracite coal

Fixed carbon

Water

Methane

Carbon monoxide

Hydrogen

Nitrogen

Ash

Sulphur

Carbon dioxide
$74.6 \%$

$7.4 \%$

$1.3 \%$

$2 \%$

$0.3 \%$

$0.25 \%$

$12.4 \%$

$0.45 \%$

1. $3 \%$ 
Composition of Lignite coal

Fixed carbon
Moisture
Methane
Ethane
Carbon monoxide
Hydrogen
Nitrogen
Ash
Sulphur
Carbondioxide
Propane

Fixed carbon

Moisture

Me thane

Carbon monoxide

Hydrogen

Ash

Carbondioxide

Propane

$37 \%$
$36 \%$
$3 \%$
$0.3 \%$
$5 \%$
$1 \%$
$0.6 \%$
$10 \%$
$0.3 \%$
$6.6 \%$
$0.2 \%$

$37 \%$

$36 \%$

$0.3 \%$

$5 \%$

$1 \%$

$0.6 \%$

$10 \%$

$0.3 \%$

$0.2 \%$

\section{Composition of Griffith pellets}

$\begin{array}{ll}\text { Hematite } & 95.5 \% \\ \text { Mositure } & 1.4 \% \\ \text { Gangue } & 3.1 \%\end{array}$

The same composition has been used for Falconbridge pellets.

Reducibility parameter for the oxide pellets

$$
\begin{array}{ll}
A_{p} \text { for Griffith pellets } & =3.143\left(10^{-3}\right) \\
A_{p} \text { for Falconbridge pellets } & =6.20\left(10^{-3}\right)
\end{array}
$$

The activation energy $E_{R}$ for both pellets $7250 \mathrm{cal} / \mathrm{mol}$

Carbon concentration in the bed $M_{c}=0.253$

Iron concentration in the bed $\mathrm{M}_{\mathrm{Fe}}=0.763$

\section{Composition of Natural Gas}

Methane

Ethane

Propane
$96.3 \%$

$3.2 \%$

$0.5 \%$ 
Pilot kiln dimensions

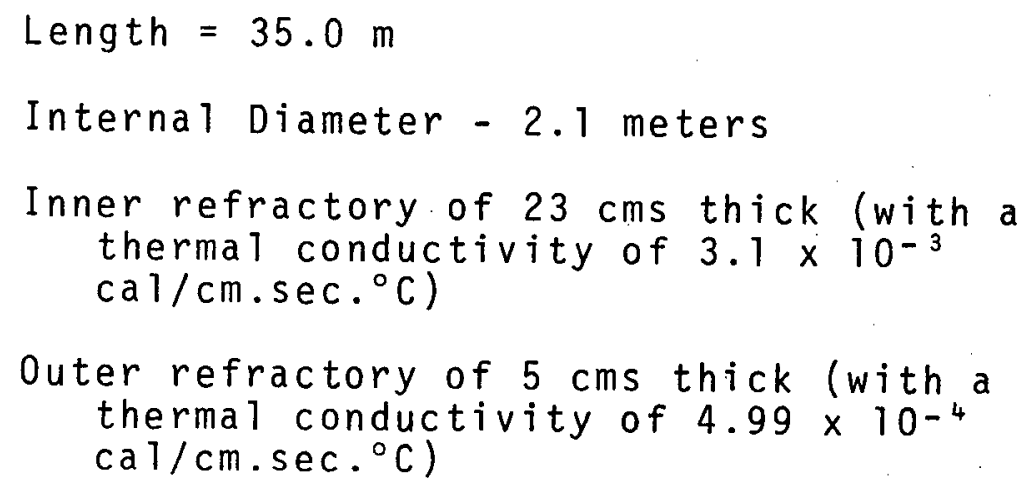

Griffith kiln dimensions

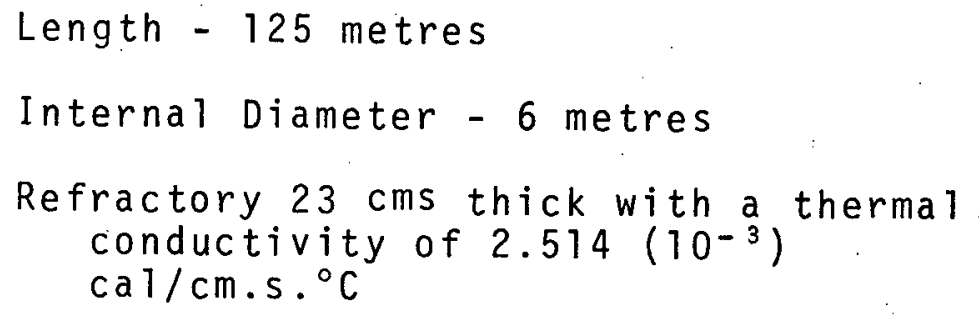


Specific Heat Data

$$
C_{p}=x+y T\left(10^{-3}\right)+z\left(10^{+5}\right) T^{-2}
$$

where $C_{p}$ is specific heat in $c a l / m o l, T$, temperature in ${ }^{\circ} K$ and $x, y, z$ are coefficients

\begin{tabular}{|c|c|c|c|}
\hline Substance & $x$ & $y$ & $z$ \\
\hline $\mathrm{Fe}_{2} \mathrm{O}_{3}$ & 23.49 & 18.6 & -3.55 \\
\hline Carbon (gr) & 4.10 & 1.02 & -2.10 \\
\hline Silica & 13.38 & 3.68 & -3.45 \\
\hline $\mathrm{Al}_{2} \mathrm{O}_{3}$ & 27.38 & 3.08 & -8.20 \\
\hline Sulphur & 3.58 & 6.24 & 0.0 \\
\hline $\mathrm{CaO}$ & 11.86 & 1.08 & -1.66 \\
\hline $\mathrm{MgO}$ & 10.18 & 1.74 & -1.48 \\
\hline $\mathrm{Fe}(r)$ & 1.84 & 4.66 & 0.0 \\
\hline $\mathrm{Fe} 0$ & 12.38 & 1.62 & -0.38 \\
\hline $\mathrm{CO}$ & 6.79 & 0.98 & -0.11 \\
\hline $\mathrm{CO}_{2}$ & 10.55 & 2.16 & -2.04 \\
\hline $\mathrm{O}_{2}$ & 7.16 & 1.00 & -0.4 \\
\hline $\mathrm{N}_{2}$ & 6.66 & 1.02 & 0.0 \\
\hline $\mathrm{H}_{2}$ & 6.52 & 0.78 & 0.12 \\
\hline $\mathrm{CH}_{4}$ & 5.65 & 11.44 & -0.46 \\
\hline $\mathrm{CaCO}_{3}$ & 24.98 & 5.24 & -6.20 \\
\hline $\mathrm{MgCO}_{3}$ & 18.62 & 13.80 & -4.16 \\
\hline $\mathrm{Fe}_{3} \mathrm{O}_{4}$ & 21.88 & 48.2 & 0.0 \\
\hline $\mathrm{H}_{2} \mathrm{O}$ & 15.70 & 5.40 & 0.0 \\
\hline $\mathrm{H}_{2} \mathrm{O}(1)$ & 18.03 & 0.0 & 0.0 \\
\hline $\mathrm{H}_{2} \mathrm{O}(\mathrm{g})$ & 7.17 & 2.56 & 0.08 \\
\hline
\end{tabular}

1 - From Metallurgical Thermochemistry by Kubaschewski et al., 4th Edition. 